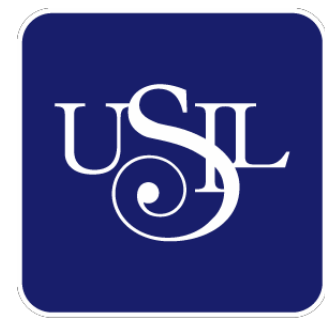

UNIVERSIDAD

SAN IGNACIO

DE LOYOLA

ESCUELA DE POSTGRADO

Maestría en Ciencias Empresariales

\title{
PLAN ESTRATÉGICO PARA EL CENTRO VACACIONAL HUAMPANI
}

Tesis para optar el grado de Maestro en Ciencias Empresariales

\author{
CASTRO LENGUA DIANA \\ MENDOZA BEDOYA ERIKA
}

\author{
Asesor: \\ Edmundo Casavilca Maldonado \\ Lima - Perú \\ 2018
}




\section{PLAN ESTRATÉGICO}

\section{CENTRO VACACIONAL HUAMPANI - CVH}




\section{Resumen Ejecutivo}

El siguiente trabajo se basa en el plan estratégico para el Centro Vacacional Huampani - CVH, en adelante "CVH", con el propósito de implementarlo y llegar a ser uno de los más importantes en la industria de los Centros de Convenciones, basándose en un proyectado al año 2021. Este Plan estratégico se dirige al segmento nacional por mantener demanda creciente; y en los últimos años ha habido un crecimiento del mercado interno por lo cual debe ser atendido.

Este plan estratégico se desarrolla con la finalidad para que el CVH obtenga mayor rentabilidad y ayude a mejorar a la empresa tanto financieramente como su imagen debido a los altos estándares y costos de la industria.

Con este plan se espera que el directorio del CVH oriente sus objetivos en mejorar los servicios y racionalizar el uso de los recursos con la finalidad de incrementar su rentabilidad y su cuota de mercado.

Con el desarrollo de este plan estratégico va a permitir aplicar los conocimientos aprendidos para incrementar la cuota de mercado en la industria de convenciones y hotelera.

En un mercado con tanta competencia, nuestra prioridad es enfocarnos en la calidad del servicio en el rubro de Centro de Convenciones por eso se ha planteado estrategias para mejorar su crecimiento a través de la diferenciación de servicio.

La visión que proponemos para el CVH es llegar a ser uno de los centros de convenciones líderes en el mercado, enfocada en diferentes tipos de eventos logrando ambientes y servicios de calidad al terminar el año 2021. Esto se logrará gracias a la estrategia elegida que es la diferenciación del servicio.

Finalmente, en cuanto a la inversión del plan estratégico, ascendería a S/140,900.00 y mediante la medición de ratios que alcanzarían una TIR de 56\%. 


\section{Índice}

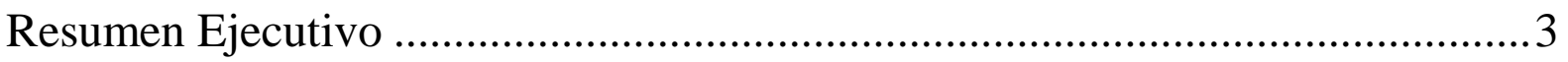

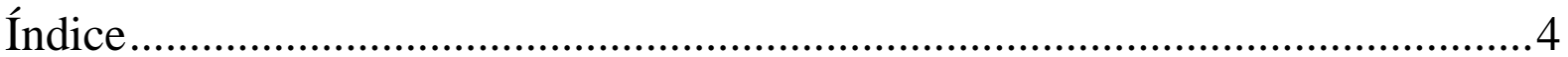

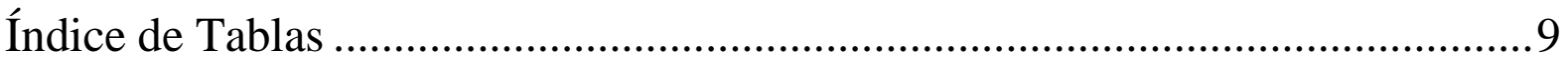

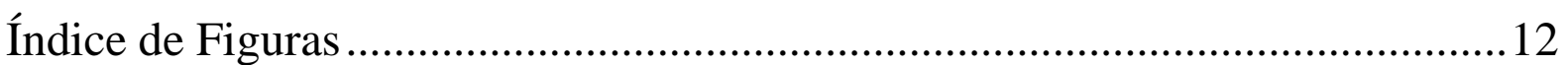

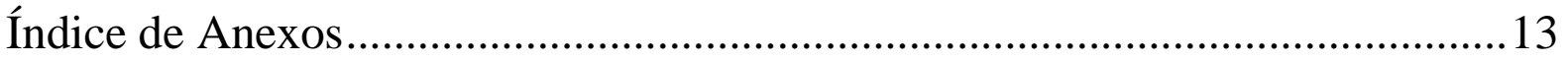

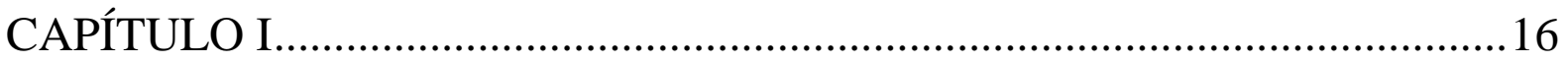

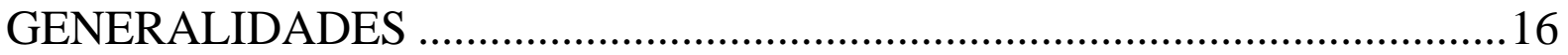

1.1 Antecedentes de la investigación.............................................................. 16

1.2 Determinación del problema u oportunidad ........................................... 17

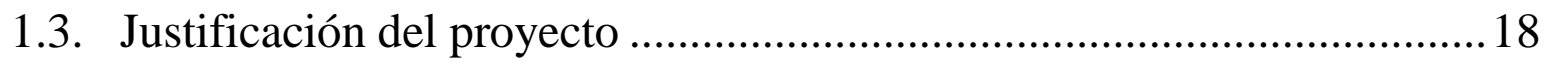

1.4. Objetivos generales y específicos …….................................................. 18

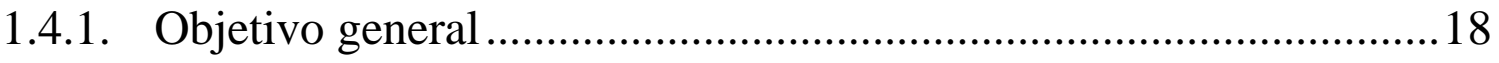

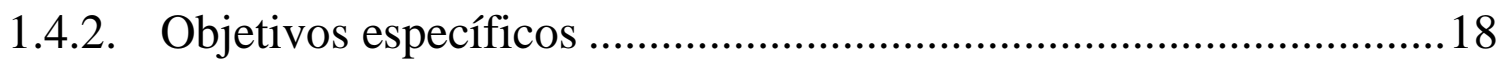

1.5. Alcances y limitaciones de la investigación .............................................19

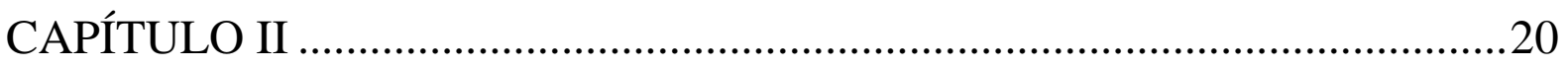

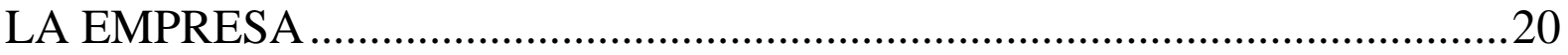

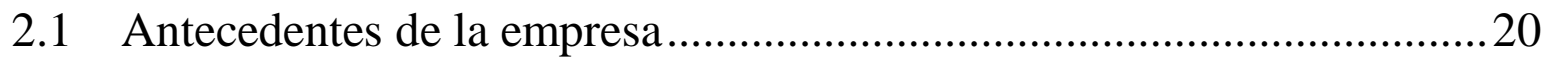

2.2. Descripción del negocio ....................................................................21

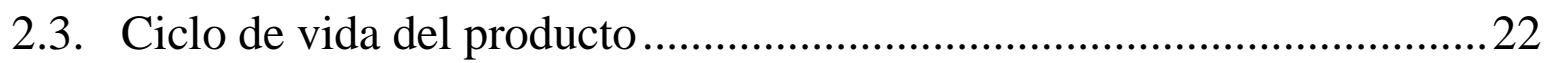

2.4. Estructura organizacional actual de la empresa.....................................24

2.5. Situación de mercado y financiero de la industria...................................24

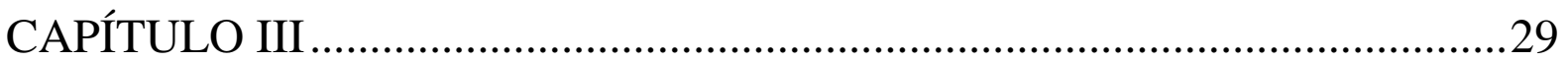

FORMULACIÓN DE VISIÓN, MISIÓN Y VALORES DE LA EMPRESA ..29

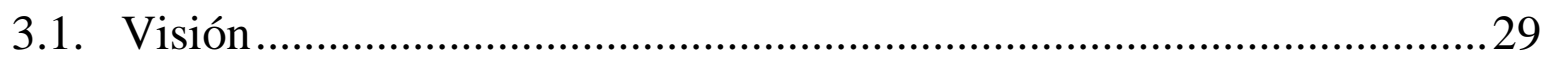

3.1.1. Visión actual de la empresa ...........................................................29

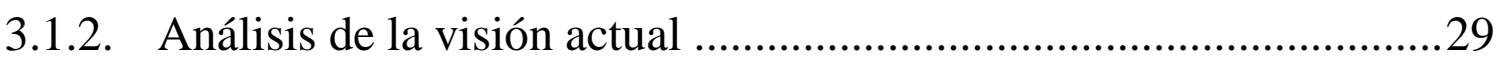

3.1.3. Matriz de la visión propuesta para la empresa................................29

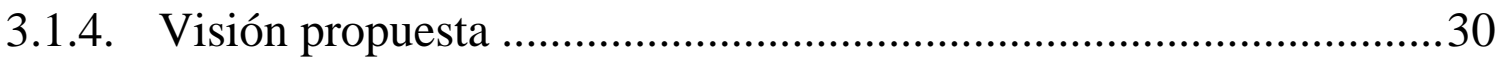




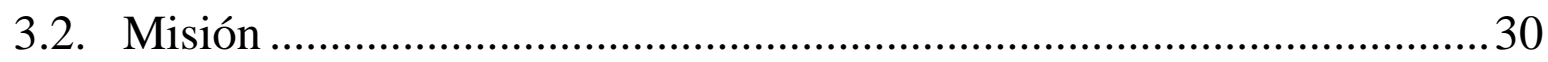

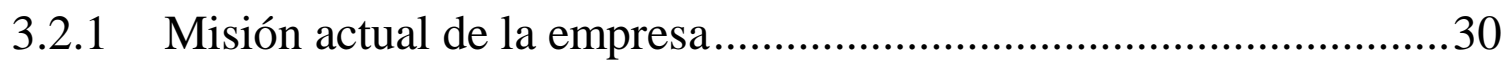

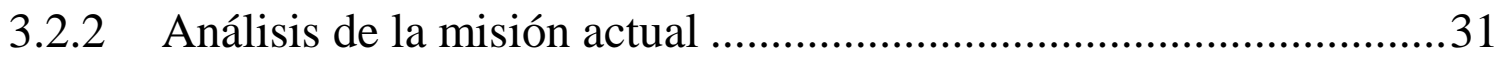

3.2.3. Elementos de la misión propuesta para la empresa ..........................31

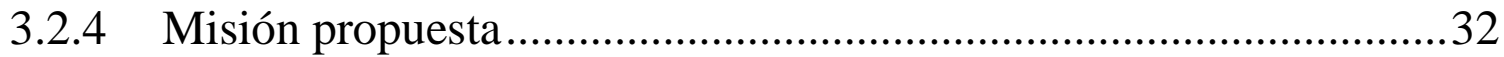

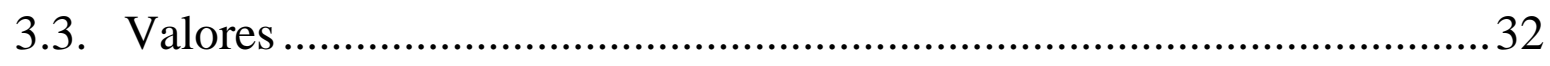

3.3.1 Valores actuales de la empresa …...................................................

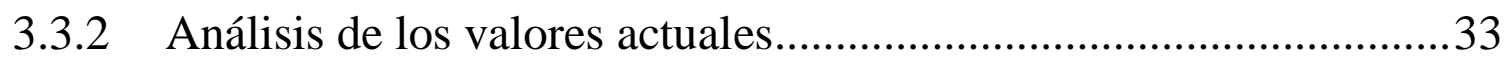

3.3.3 Elementos de los valores propuestos para la empresa ......................33

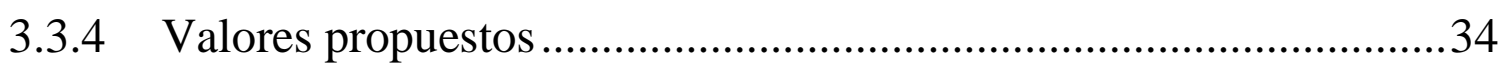

3.4. Alineamiento estratégico de la Visión, Misión, y valores de la empresa 34

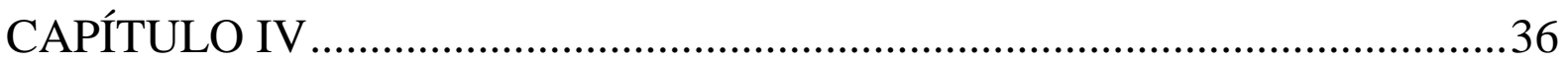

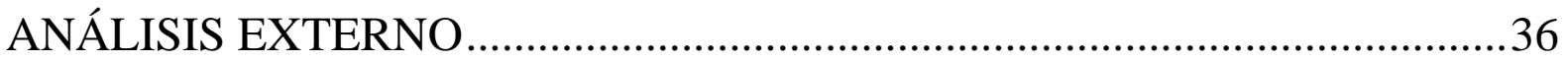

4.1 Tendencias de las variables del entorno ...................................................36

4.1.1 Análisis Político - Gubernamental ..................................................36

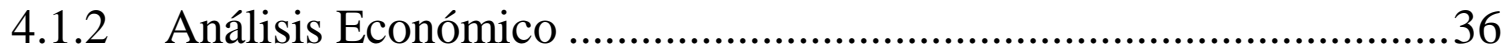

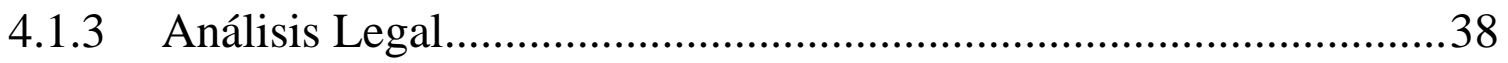

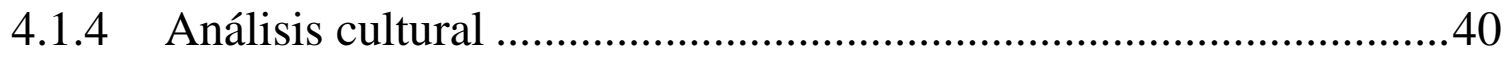

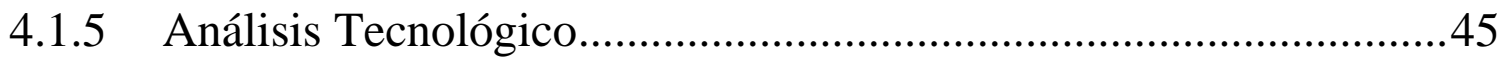

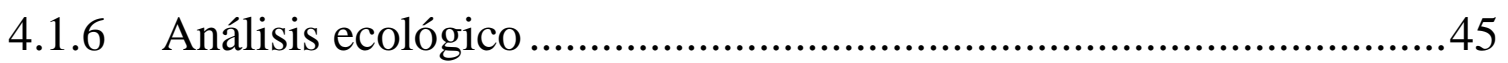

4.2. Impacto en clientes/ proveedores de cada una de las variables del

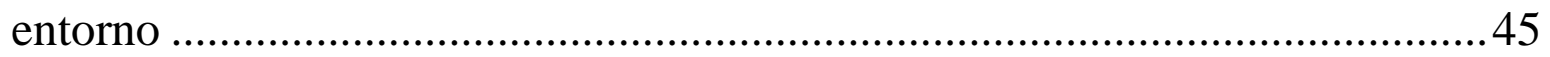

4.3 Efecto en la empresa de cada una de las variables del entorno ...............48

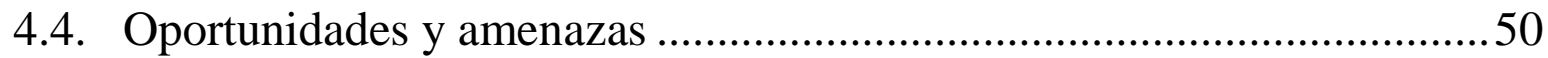

4.5. Matriz de Evaluación de Factores Externos (EFE) .................................51

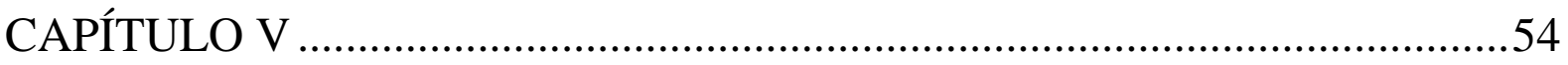

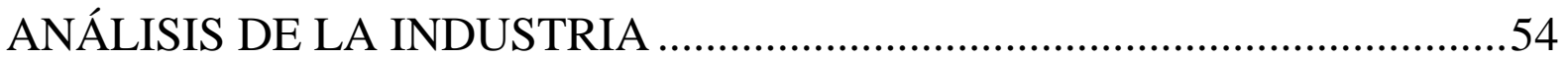

5.1. Descripción del Mercado (demanda) e Industria (Oferta).......................54

5.2. Descripción de las cinco fuerzas competitivas de la industria ................55 


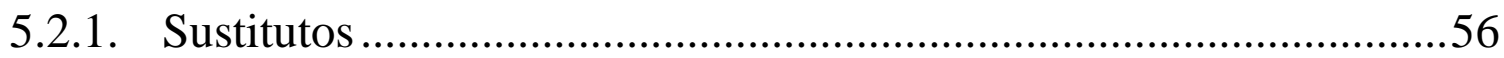

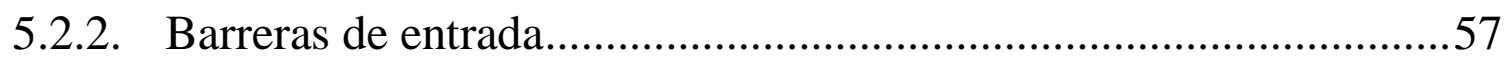

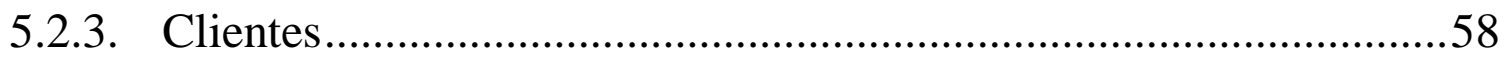

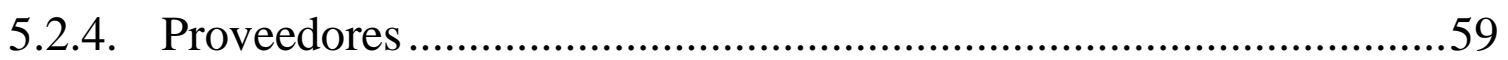

5.2.5. Competencias en el mismo sector ...............................................60

5.3. Matriz de atractividad de cada una de las cinco fuerzas .........................61

5.4. Análisis del Grado de atractividad de la industria..................................61

5.5. Matriz de Perfil Competitivo MPC .........................................................61

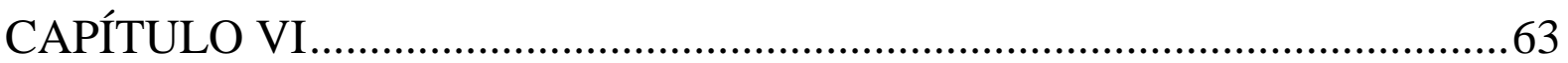

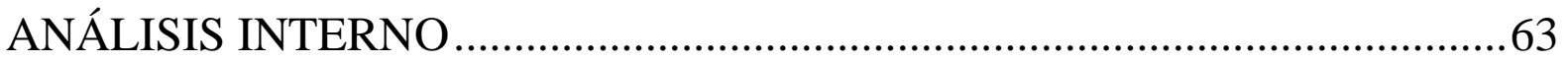

6.1 Descripción de las actividades de la cadena de valor de la empresa......63

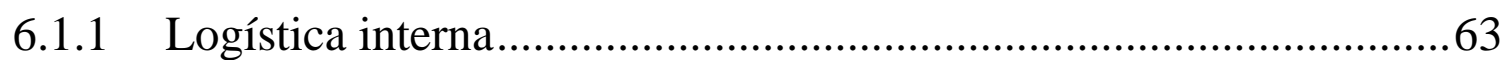

6.1.2 Análisis de las actividades de apoyo.................................................64

6.2 Indicadores de cada una de las actividades de la cadena de valor .........67

6.3. Benchmarking y comparación con los líderes de la industria de cada una de las actividades de la cadena de valor ....................................................67

6.4. Determinar las competencias de la empresa ........................................69

6.5. Identificación y determinación de las ventajas competitivas de la

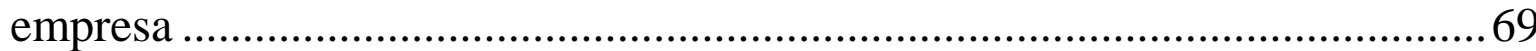

6.6 Matriz de Evaluación de Factores Internos EFI .....................................69

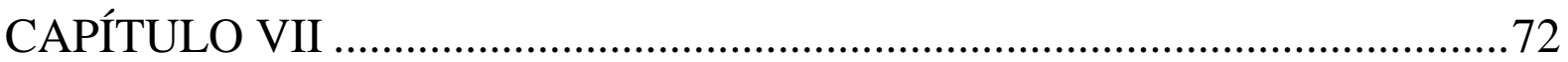

FORMULACIÓN DE LOS OBJETIVOS Y DISEÑO DE LAS ESTRATEGIAS .72

7.1. Alcance y planteamiento de los objetivos estratégicos ..........................72

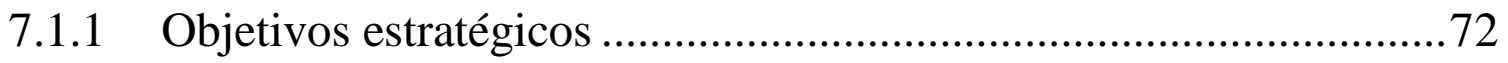

7.1.2 Análisis de los objetivos estratégicos .............................................74

7.2. Diseño y formulación de estrategias ........................................................78

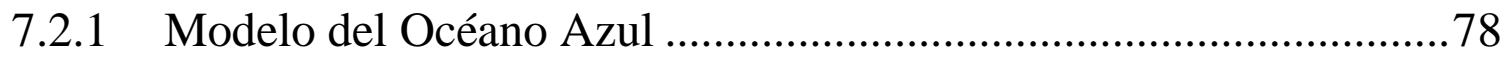

7.2.1.1 Lienzo de la estrategia actual de la empresa .................................78

7.2.1.2 Matriz (eliminar, reducir, incrementar, crear).............................79 
7.2.1.3 Lienzo de la nueva estrategia considerada ...................................79

7.2.2 Matrices de la formulación de estrategias......................................... 80

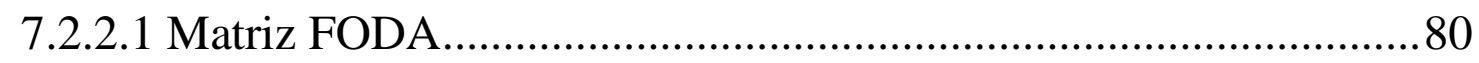

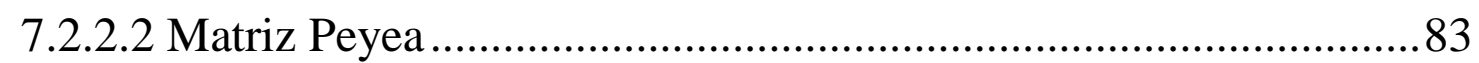

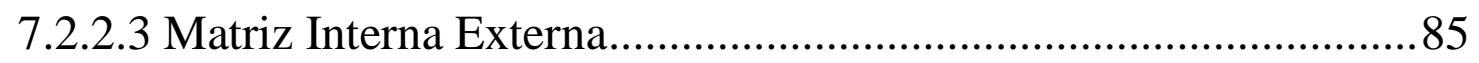

7.2.2.4 Matriz Boston Consulting Group ……………..............................86

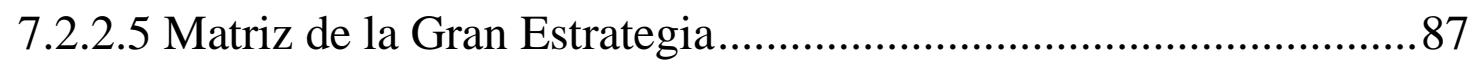

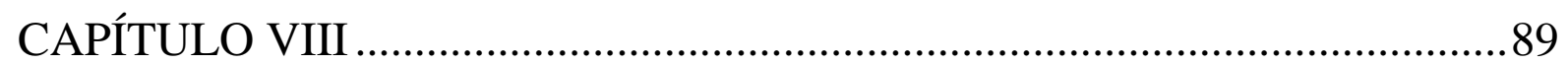

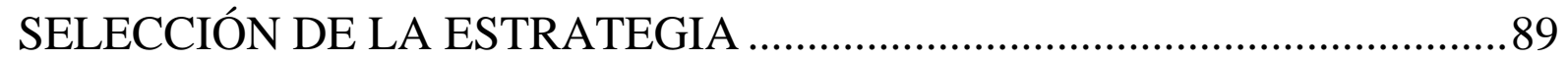

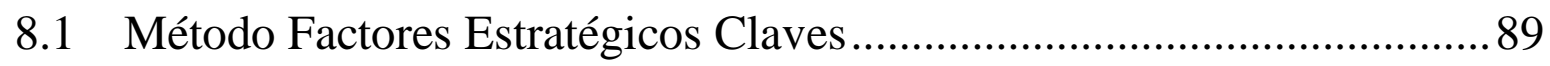

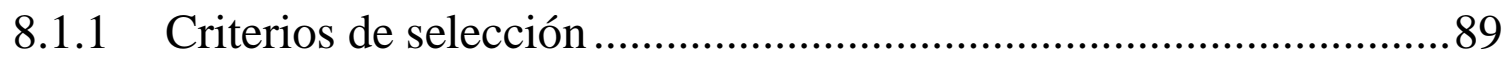

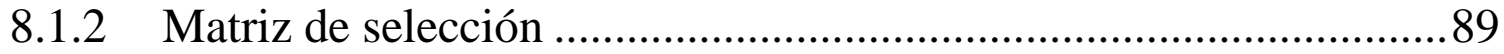

8.2. Matriz de Planeación Estratégica Cuantitativa MPEC .............................90

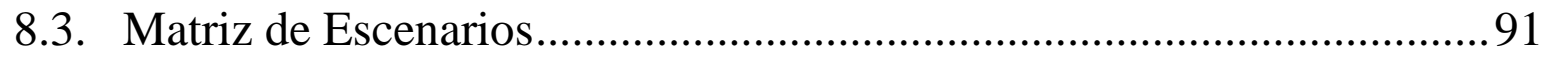

8.3.1 Descripcion de Escenarios Considerados .......................................91

8.3.2 Comparacion de estrategias con escenarios .....................................92

8.4 Descripción de estrategia seleccionada ................................................94

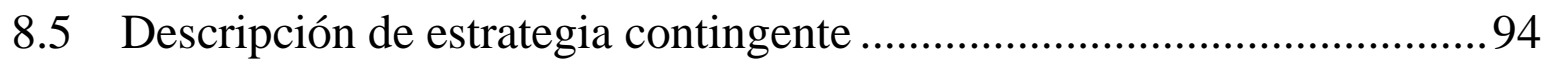

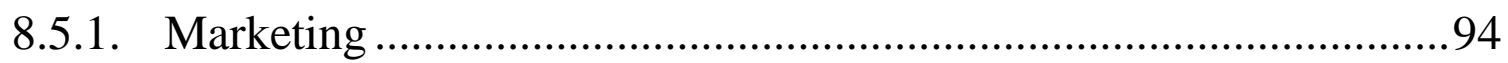

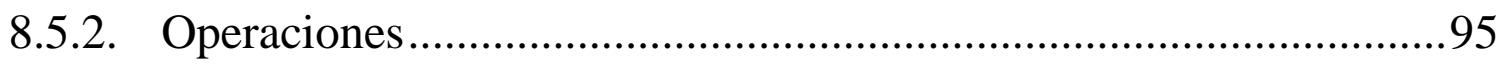

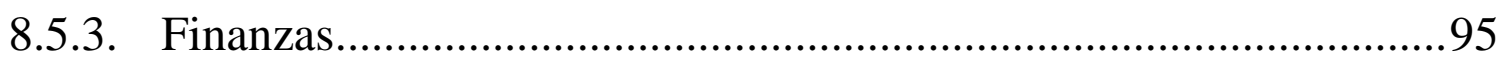

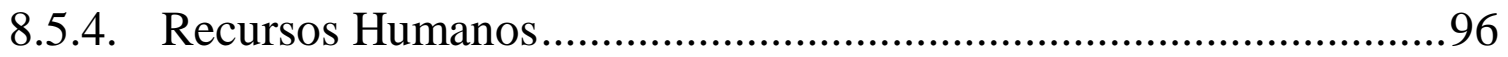

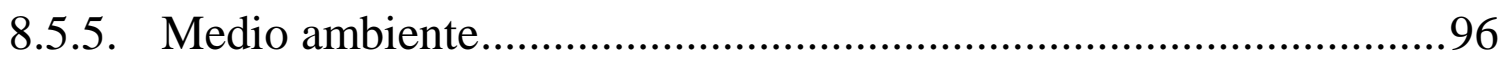

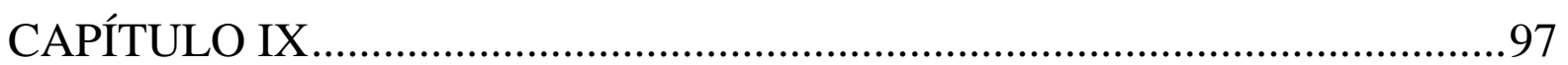

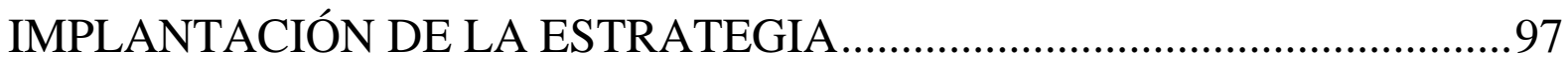

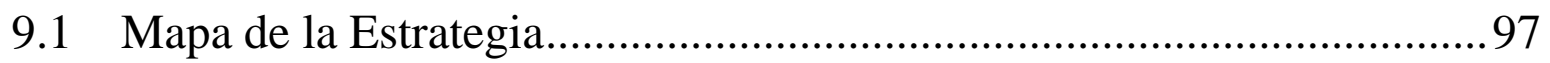

9.2 Objetivos específicos según el mapa de la estrategia............................99

9.3 Indicadores para cada uno de los objetivos específicos ........................100

9.4 Metas para cada uno de los objetivos específicos ................................101

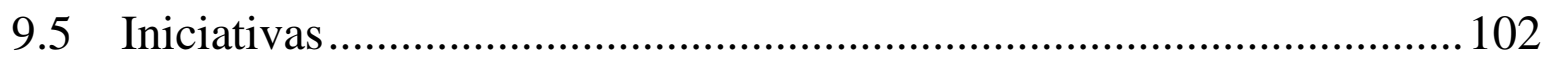


9.6 Responsable de cada una de las iniciativas .......................................... 104

9.7 Presupuesto de cada una de las iniciativas .............................................. 106

9.8 Cronograma de cada una de las iniciativas..........................................111

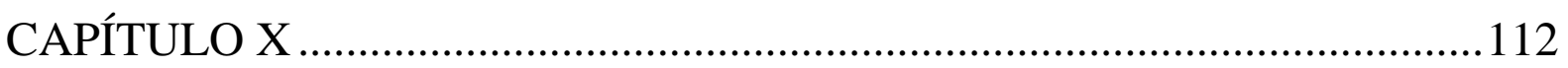

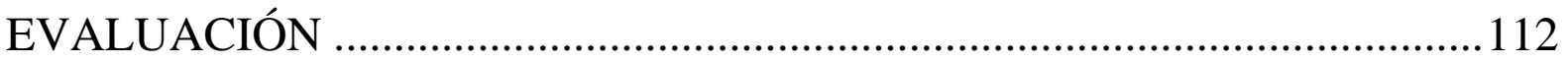

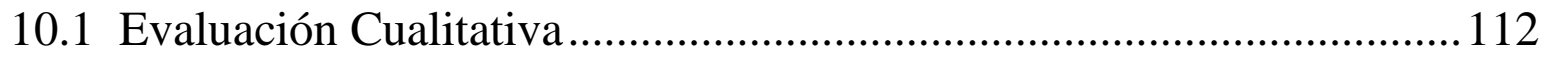

10.1.1 Criterios de Evaluación ..................................................................112

10.1.2 Comparación de la estrategia con los criterios ................................112

10.2 Evaluación Financiera de la Estrategia................................................113

10.2.1 Proyección de estados financieros (situación actual y con la nueva

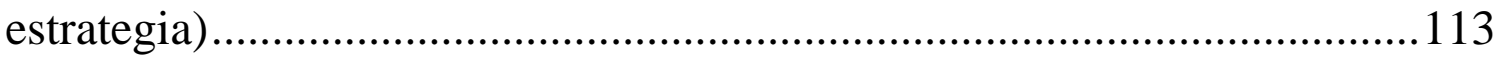

10.2.2 Estados de resultados (situación actual y con la nueva estrategia) 114

10.2.3 Balance general (situación actual y con la nueva estrategia) ..........118

10.2.4 Flujo de efectivo (situación actual y con la nueva estrategia)........121

10.2.5 Evaluación financiera (VAN, TIR y ratios financieros)...................124

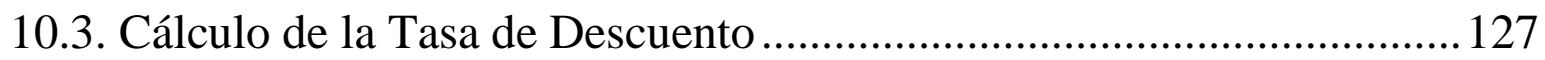

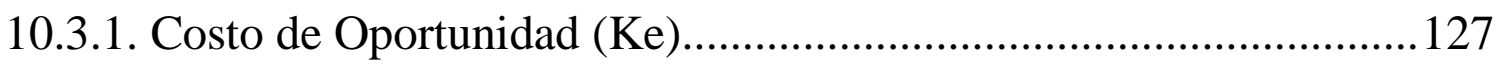

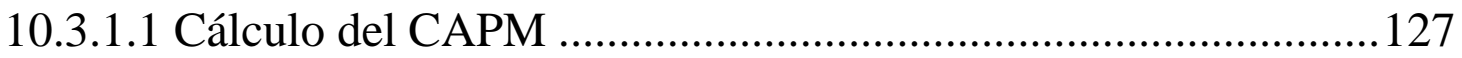

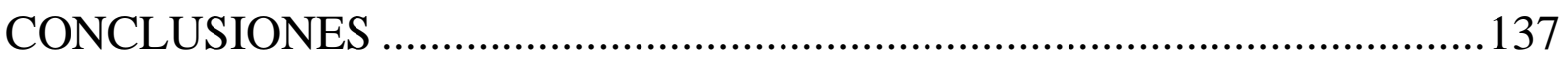

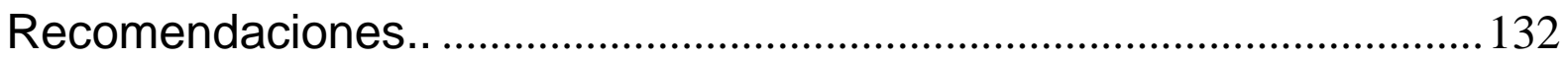

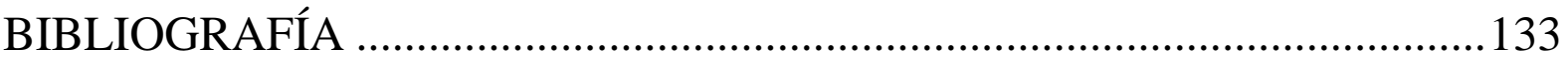

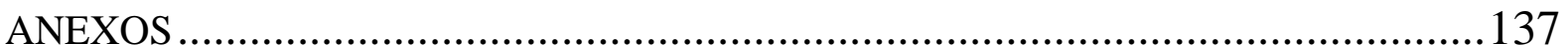




\section{Índice de Tablas}

Tabla 1 Competencia directa de centro de convenciones y recreación en Lima .25

Tabla 2 Matriz para evaluar la visión actual

Tabla 3 Matriz de evaluación de la visión de la propuesta .................................................. 30

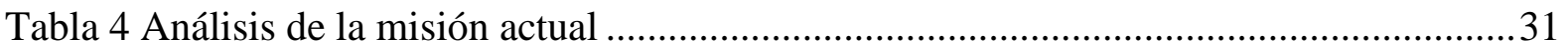

Tabla 5 Análisis de la misión de la propuesta........................................................................ 31

Tabla 6 Alineamiento estratégico de la Visión, Misión, y valores de la empresa ....................35

Tabla 7 Análisis político - gubernamental/ impacto cliente - proveedores ............................46

Tabla 8 Análisis económico/ Impacto cliente - proveedores .............................................46

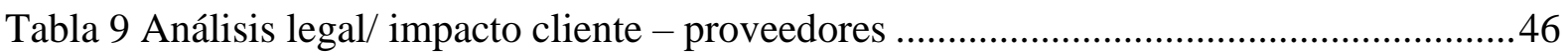

Tabla 10 Análisis cultural/ Impacto cliente - proveedores................................................47

Tabla 11 Análisis tecnológico/ Impacto cliente - proveedores ............................................ 47

Tabla 12 Análisis ecológico/ Impacto cliente - proveedores .............................................. 47

Tabla 13 Análisis Político - Gubernamental/ Impacto cliente - proveedores........................ 48

Tabla 14 Análisis económico/ Impacto cliente - proveedores ................................................48

Tabla 15 Análisis legal/ Impacto cliente - proveedores .....................................................49

Tabla 16 Análisis Cultural/ Impacto cliente - proveedores ............................................... 49

Tabla 17 Análisis tecnológico/ Impacto cliente - proveedores .............................................50

Tabla 18 Análisis ecológico/ Impacto cliente - proveedores ..............................................50

Tabla 19 Matriz Evaluación de Factores Externos para el CVH ..........................................52

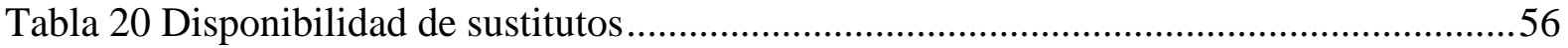

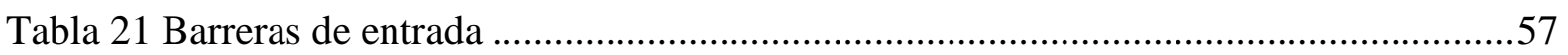

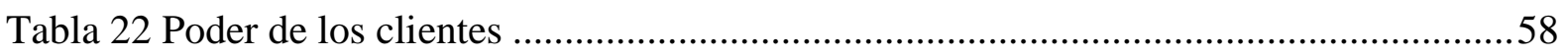

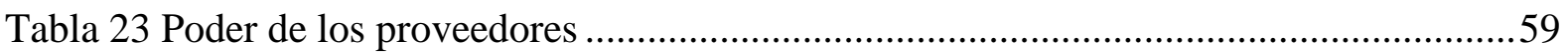

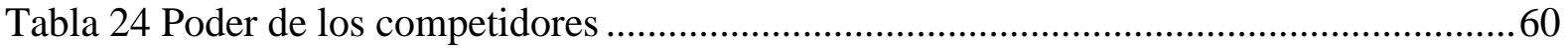


Tabla 25 Matriz de atractividad .61

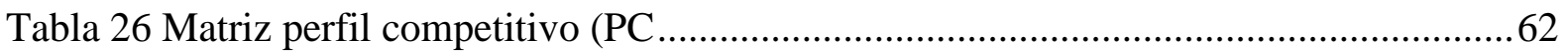

Tabla 27 Análisis de la Cadena de Valor del CVH ...........................................................66

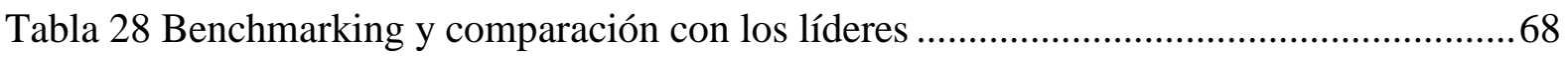

Tabla 29 Matriz evaluación de factores internos para el CVH ............................................. 70

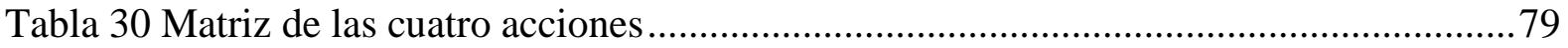

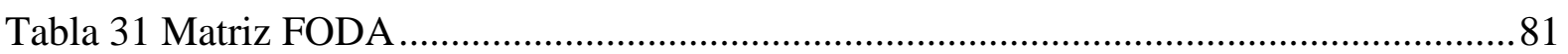

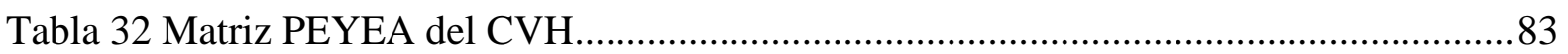

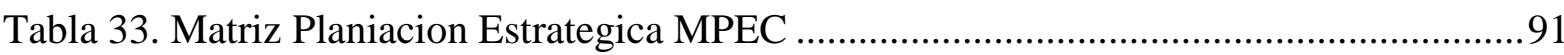

Tabla 34. Selección de la Estrategia con Escenarios ............................................................92

Tabla 35. Matriz de Estrategias vs. Objetivos a Largo Plazo ...............................................93

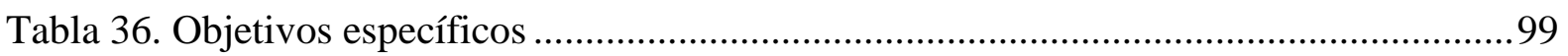

Tabla 37. Indicadores para cada uno de los objetivos específicos ..................................... 100

Tabla 38. Metas para cada uno de los objetivos específicos............................................ 101

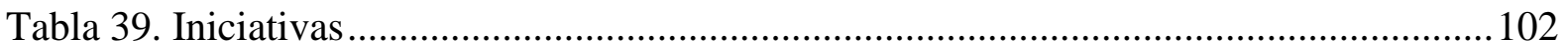

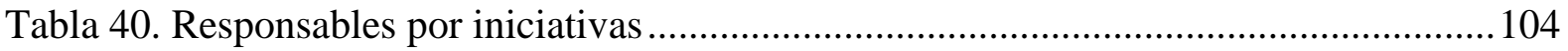

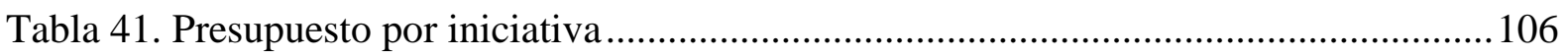

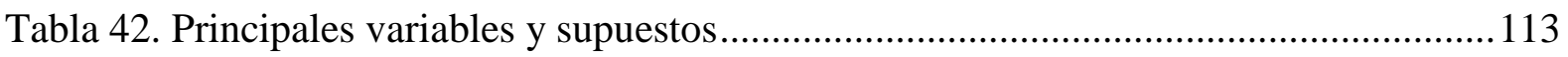

Tabla 43. Estado de Resultados, Situación Actual ................................................................. 115

Tabla 44. Estado de Resultados, Situación Nueva Estrategia................................................117

Tabla 45. Balance General / Situación Actual .................................................................... 119

Tabla 46. Balance General / Situación con Estrategia ........................................................ 119

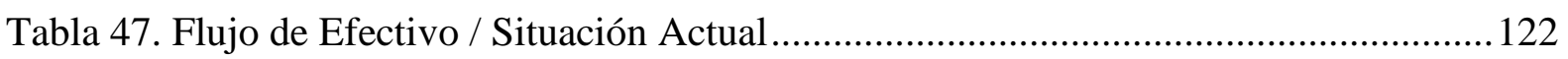

Tabla 48. Flujo de Efectivo / Situación con Estrategias ........................................................ 123

Tabla 49. VAN Y TIR y ratios financieros/ Sin Estrategia .............................................. 124 
Tabla 50. VAN Y TIR y ratios financieros/ Con Estrategia .............................................. 125

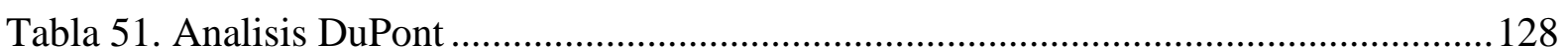

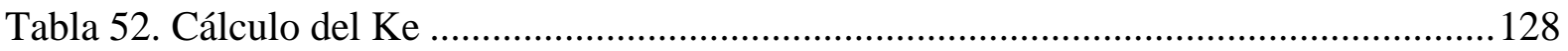




\section{Índice de Figuras}

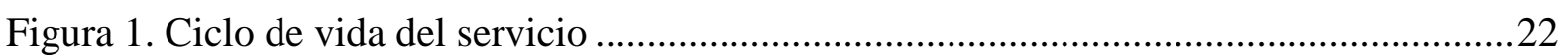

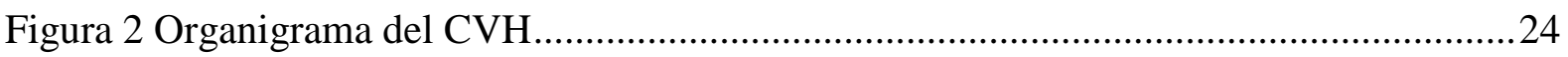

Figura 3. Proyeccion Crecimiento Poblacional ................................................................. 43

Figura 4. Distribucion Poblacional Urbano- Rural ........................................................... 44

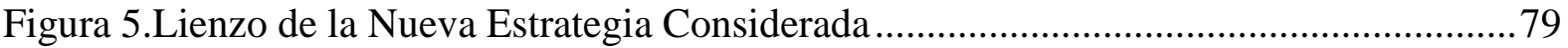

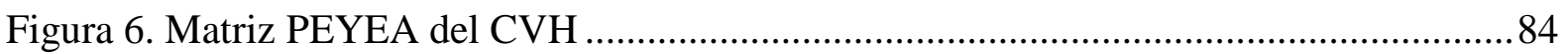

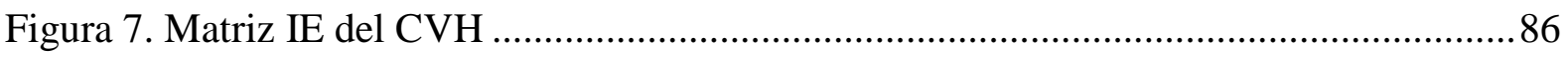

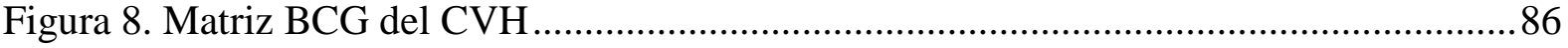

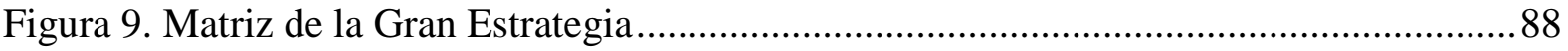

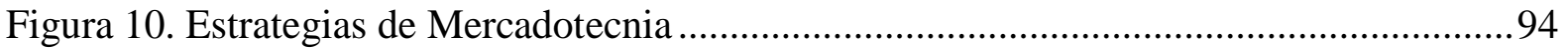

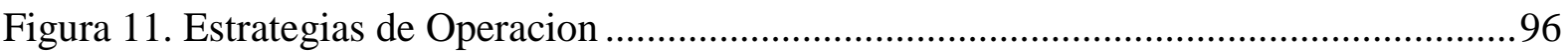

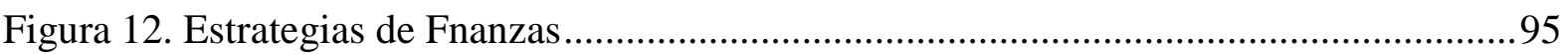

Figura 13. Estrategias de Recursos Humanos .................................................................. 96

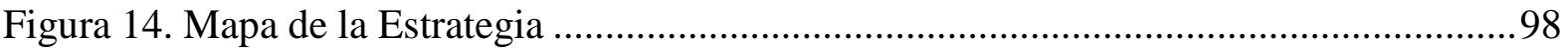


Índice de Anexos

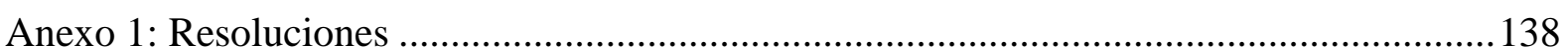

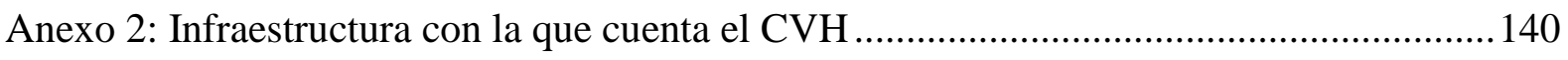

Anexo 3: Fotos de la Renovación del Sistema Electrico Media Tension - I Etapa................ 163

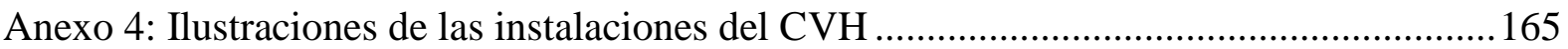

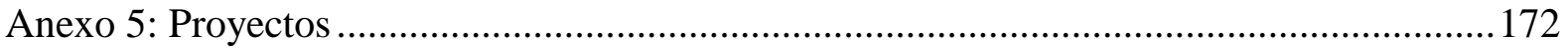

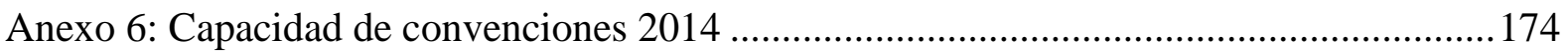

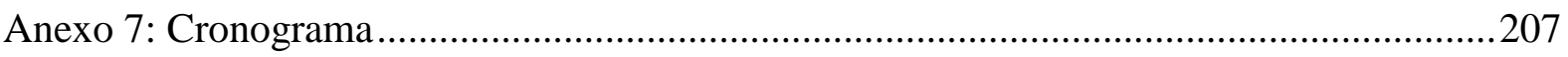

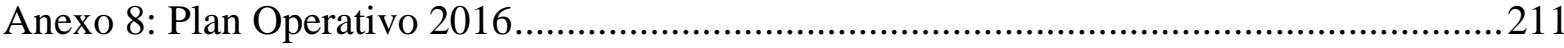

Anexo 9: Estado de Ganancias y Pérdidas Proyectado.......................................................215

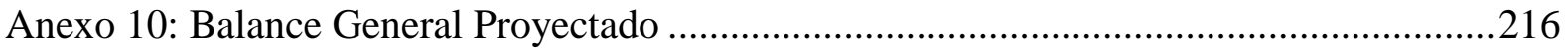

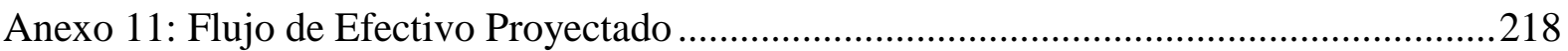

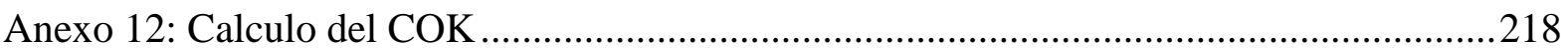

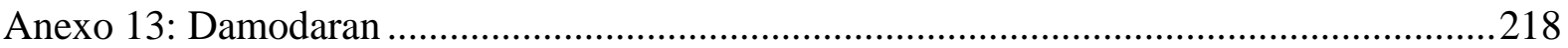

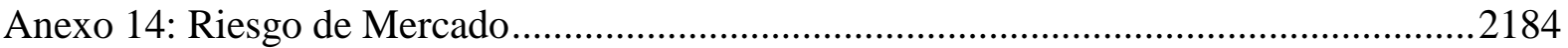




\section{Introducción}

La meta final de este Plan Estratégico es lograr alcanzar los objetivos estratégicos para el CVH, así como el diseño de estrategias que permitan mejorar la situación del CVH.

Para poder llevar a cabo esta tarea, es necesario la elaboración de diferentes matrices que se desarrollarán en los siguientes capítulos y ayudará a poder elegir la estrategia adecuada para el logro de objetivos del plan estratégico del CVH por medio de la ventaja competitiva que se va a desarrollar en este plan.

A continuación, un pequeño resumen de cada capítulo:

Capítulo 1: Generalidades

Se realizará los precedentes de la investigación, se determinará la problemática de la cual se basará nuestro plan estratégico y su argumento, se explicará los objetivos (general y específico). También se explicará las limitaciones que se tuvo.

\section{Capítulo 2: La Empresa}

Explicaremos precedentes del CVH y su desarrollo del ciclo de vida, detallaremos el organigrama de la empresa en la actualidad y explicaremos la coyuntura de este rubro y su parte financiera.

Capítulo 3: Formulación De La Visión, Misión y Valores de la Empresa

En este capítulo se desarrollará la misión, visión y valores actuales de la empresa y los propuestos por nuestro grupo para el centro vacacional.

\section{Capítulo 4: Análisis Externo}

Se procederá a señalar y detallar los aspectos externos que afectan al CVH.

Posteriormente describiremos sus efectos y desarrollaremos la matriz de factores externos.

Capítulo 5: Análisis de la Industria 
Se describirá la oferta y la demanda, es decir, la industria y el mercado respectivamente. Y se comparará con las empresas que sobresalen en el mercado para permitir ver cuáles son las ventajas y desventajas que tiene el CVH.

Capítulo 6: Análisis Interno

Se describirá las actividades de la cadena de valor y se hará una comparativa de las principales competencias del $\mathrm{CVH}$.

Además se hará el Benchmarking y la comparativa entre los primeros de la industria de las actividades de la cadena de valor y la matriz EFI.

Capítulo 7: Formulación de los objetivos y diseño de las estrategias

En el siguiente capítulo se desarrollarán los objetivos estratégicos con sus respectivos análisis y con las respectivas matrices.

Capítulo 8: Selección de la Estrategia.

Para continuar, mostraremos las estrategias de cada una de las matrices y los escenarios de cada una de ellas para poder así seleccionar las estrategias que implementaremos.

Capítulo 9: Implantación de la Estrategia

En este capítulo presentaremos los objetivos que se desean alcanzar, además se indicarás las iniciativas y los responsables por medio del mapa de la estrategia.

Capítulo 10: Evaluación

En este último capítulo, se realizará la parte cualitativa del proyecto y nos indicará si el proyecto es sustentable o no.

Con los indicadores mencionados podremos saber si el plan estratégico para el centro vacacional Huampaní es factible y beneficioso o no para ser presentado a los gerentes del lugar y poder sacar adelante al centro vacacional. 


\section{CAPÍTULO I}

\section{GENERALIDADES}

\subsection{Antecedentes de la investigación}

El CVH ha emprendido el reto de hacer frente a los nuevos cambios sociales, económicos, culturales y políticos que se están dando a nivel nacional e internacional. Estos cambios relacionados con la incorporación de las nuevas tecnologías de la información para el desarrollo de sus actividades, la creciente competencia por los recursos económicos, las nuevas demandas sociales y económicas, darán lugar a que la institución deba afrontar una serie de retos con perspectiva de futuro.

En este camino, la planificación estratégica se convierte para el CVH en un instrumento eficaz para dar respuesta a situaciones de cambio, es por ello, que elaboraron el plan estratégico institucional 2013 - 2016 que fue presentado en septiembre del 2013. El documento en mención sirve como antecedente y guía permanente de las acciones para el logro de resultados que queremos lograr.

Como parte de las conclusiones del plan estratégico 2013 - 2016, las acciones han sido evaluadas anualmente, a través de la medición de los indicadores de resultados propuestos y que se orientarían al sistema de monitoreo implementado para tal fin. Así mismo, a nivel operativo, se determinó el grado de cumplimiento de cada una de las líneas de acción que contiene con el propósito de concretar la programación de los años siguientes y determinar las estrategias y acciones a reorientar a nivel de la planificación operativa del CVH.

Finalmente, por las razones antes señaladas, el PEI 2017 - 2021 que propone nuestro grupo de investigación, tiene el mismo propósito de ser un documento flexible, que se deberá evaluar en forma global al finalizar el 2021, ya que los cambios en los que estará inmerso el CVH harán necesario volver a realizar un diagnóstico, tanto externo como interno, para poder 
adaptarnos a ellos y tener mayores probabilidades de conseguir los objetivos como institución.

Cabe destacar que nuestro plan estratégico 2017 - 2021 estará enfocado al centro vacacional (alojamiento, esparcimiento y restaurante) y al centro de convenciones, dejando de lado el Colegio Mayor Secundario Presidente del Perú debido que es una entidad independiente del CVH, que se rige por las políticas y reglamentos del Ministerio de Educación sin permitir ningún tipo de modificación.

Con la creación en el 2011 del Colegio Mayor Secundario Presidente del Perú el cual representaba la ocupabilidad del $75 \%$ de las instalaciones, el CVH desarrolla parcialmente sus servicios al público en general ya que mayormente es conocido el CVH como un colegio, por consiguiente, a partir del 2015 se viene desarrollando a través del Ministerio de Educación una considerable promoción del Colegio (Ministerio de Educación, 2017).

\subsection{Determinación del problema u oportunidad}

El CVH, como conjunto, es una institución dependiente del Ministerio de Educación, y que actúa como una entidad privada. Al no tener un plan estratégico para el siguiente periodo, el CVH se encontraría desarrollando su administración sin objetivos a corto, mediano y largo plazo. Por consiguiente, el propósito es renovar el plan presente con instrumentos para conseguir que la población se acerque por los servicios ofertados, suprimiendo la capacidad instalada ociosa.

Con la aplicación de este plan estratégico, se quiere lograr que el CVH use el 100\% de las instalaciones. Sin embargo, el tema político se convierte en un problema al dejar de continuar las ideas que se plantea en cada instrumento de gestión. Cuando los gobiernos de turno entran, inmediatamente se cambia de directorio, y frente a ello se ven interrumpidas las 
actividades que se diseñan en cada plan estratégico, lo cual no permite cumplir los objetivos de mediano y largo plazo.

\subsection{Justificación del proyecto}

Este PEI 2017 - 2021 es creado para poder guiar en sus decisiones y laborales al directorio y colaboradores de la institución para incrementar la cuota de mercado y la rentabilidad, además de mejor el servicio a los clientes.

La justificación de la presente investigación radica en mejorar la infraestructura y los servicios que se ofrece a los clientes para que mejoren su experiencia en el CVH.

\subsection{Objetivos generales y específicos}

\subsubsection{Objetivo general}

Elaborar un plan estratégico para el CVH que permita alcanzar altos niveles de calidad en la prestación de los servicios que se brindan.

\subsubsection{Objetivos específicos}

1. Analizar el ambiente interno y externo del CVH.

2. Analizar la industria de convenciones y hotelera en la que participa el CVH.

3. Elaborar y escoger las estrategias administrativas, financieras y de operaciones.

4. Implementar las estrategias para el $\mathrm{CVH}$.

5. Mejorar los diferentes servicios ofrecidos en el CVH a través de la optimización de los servicios, adecuándose a las exigencias del mercado.

6. Ampliar el mercado buscando nuevos clientes a través de la colocación del servicio de convenciones y hospedaje con nuevas promociones. 
7. Optimizar los sistemas administrativos y operativos para que ayude al $\mathrm{CVH}$ a mantener y mejorar su rentabilidad y esto beneficie a la calidad en el servicio que se desea brindar.

8. Establecer en la estructura organizacional una formación de verificación de estándares.

9. Lograr el compromiso de los colaboradores con los objetivos de la institución.

10. Determinar el monto que se va a requerir para implementar la estrategia seleccionada.

11. Analizar el impacto económico y financiero al CVH.

\subsection{Alcances y limitaciones de la investigación}

Una de las limitaciones más importante es que el CVH depende del Ministerio de Educación lo cual no permite obtener información de primera mano y no permite realizar modificaciones a sus decretos.

Otra de las limitaciones del CVH es su antigua infraestructura, no permitiendo reubicar algunas instalaciones a pesar de las últimas remodelaciones y también porque en esta institución se encuentre el Colegio. 


\section{CAPÍtULO II}

\section{LA EMPRESA}

\subsection{Antecedentes de la empresa}

Según el Decreto Supremos N 36-95-ED, El CVH “es una institución pública descentralizada del sector educación con personería jurídica de derecho público, con autonomía técnica, administrativa, económica y financiera que se rige por el D.L N ${ }^{\circ} 756 ”$ " El CVH es una entidad de tratamiento empresarial. La empresa "inició actividades en la década del 50 con una gran capacidad de atención para su tiempo: más de un millar de personas tanto en alojamiento como en alimentación, distribuidos en 91 bungalows con capacidad para 478 personas y 7 pabellones más 1 albergue juvenil con capacidad para 520 personas".

El CVH, "fue creado en el marco del desarrollo de los centros de esparcimientos climáticos, mediante la Ley № 10844 del 27 de marzo de 1947, e inaugurado el 24 de julio de 1955, con el propósito de brindar servicios hoteleros, esparcimiento, recreación y deporte a la población"1.

El CVH, como antes mencionado, está constituido por el centro vacacional (alojamiento, recreación y restaurante), centro de convenciones y el colegio Mayor Secundario Presidente del Perú. Para fines de este trabajo, nosotros no vamos a considerar el Colegio, ya que es una entidad aparte con regulaciones distintas.

El propósito del CVH es "atender convenciones, eventos de índole cultural y otros servicios relacionados con servicios de hospedaje, alimentación, recreación y deporte al sector público como al sector privado".

El CVH es un centro vacacional que ofrece los servicios de convenciones, capacitación, alojamiento y restaurante en un amplio ambiente. El enfoque donde se desarrolla el CVH está muy segmentado y no presenta alta capacidad para atender a no

\footnotetext{
${ }^{1}$ En el Anexo 1, se puede apreciar la Resolución de creación del CVH.
} 
menos de 1500 personas, lo cual se cubre actualmente de manera poco usual adaptando las instalaciones de los lugares donde se realizan las convenciones.

A mediados del año 2010 que el CVH, tiene su capacidad al 100\% en sus tres rubros (alojamiento, convenciones y restaurantes), constituyéndose el colegio Mayor Secundario Presidente del Perú su cliente fijo y constante que genera, ocupa y atiende el $75 \%$ de dicha capacidad lo que años anteriores era una capacidad ociosa por los intervalos de los eventos, es a partir de este año donde la marca Huampaní surge como líder dentro de las empresas del rubro de las convenciones donde comienza su liderazgo en la calidad y excelencia de ese $25 \%$ cliente público, particular al que debemos centrar todos nuestros esfuerzos. Es en estos momentos que el CVH, al tener el 100\% de sus instalaciones ocupadas, va a requerir, desde la alta dirección; el personal administrativo; el personal operativo, la responsabilidad de una preparación adecuada y esfuerzos para ir mejorando la atención y sus servicios. Es en estos tiempos que la misión se convierta en una real visión.

Y en estos procesos de construcción del futuro del CVH, se continuará con la modernización de su infraestructura, equipos y desarrollará un programa integral de un nuevo espacio para esparcimiento.

\subsection{Descripción del negocio}

El CVH, fue creado por Ley $\mathrm{N}^{\circ} 10884$ el 15.03.1947 e inaugurado el 24.07.1955. Mediante Resolución Suprema No 146-75-VC-4400 del 11 de junio de 1975, el CVH "es transferido en calidad de aporte de capital del estado a la empresa de administración de inmuebles del Perú, EMADI-PERU, perteneciente al sector vivienda y construcción”.

Mediante Decreto Supremo DS No 018-91-VC del 27 de agosto de 1991, "se incorpora oficialmente al CVH a la estructura orgánica del Ministerio de Educación, como órgano de ejecución, con autonomía económica y administrativa, autofinanciada sin afectar recursos del estado, transfiriéndose al $\mathrm{CVH}$ el inmueble e instalaciones referidos en el 
Decreto Supremo No 159-78-VC. Asimismo, se faculta al Ministerio de Educación para que mediante decreto supremo apruebe el estatuto del CVH”.

Mediante Decreto Supremo DS No 36-95-ED del 24 de Abril de 1995, "se aprueba el estatuto del $\mathrm{CVH}$, mediante el cual se define al centro como una institución pública descentralizada del sector educación, con personería jurídica de derecho público, con autonomía técnica, administrativa, económica y financiera que se rige por el decreto legislativo $\mathrm{N}^{\mathrm{o}} 756$ y por el estatuto mencionado, y su régimen presupuestal se sujeta a las normas que aprueba la dirección nacional de presupuesto público del Ministerio de Economía y Finanzas".

\subsection{Ciclo de vida del producto}

El CVH está en una etapa de madurez dentro del ciclo de vida del producto.

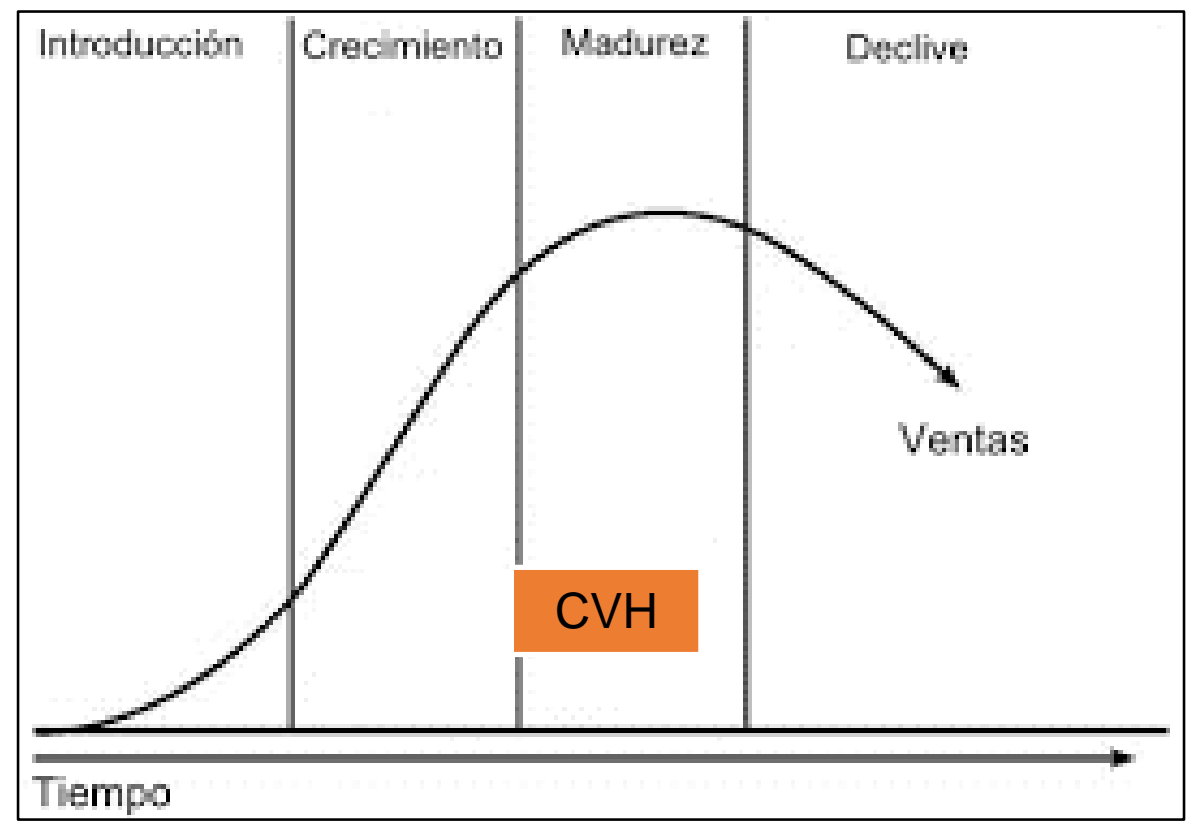

Figura 1. Ciclo de vida del producto. Adaptado del Libro Marketing (p. 273), por Kotler y Armstrong, 2012, México: Pearson. Copyright 2012 por Pearson Educación. Elaboración propia.

La justificación que el CVH se encuentra en la etapa de madurez es el estancamiento de las ventas durante los últimos cincos años, en lo que va del año 2013 las ventas se 
posicionaron en S/. 9,164,831.00, en el 2014 las mismas se incrementaron en S/.

9,623,073.00, del 2015 (S/. 10,104,227.00) al 2016 (S/. 10,609, 438) el incremento de ingresos fue de $1.9 \%$, el cual debería tener un mejor posicionamiento en cuanto al ratio de crecimiento.

$\mathrm{Al}$ encontrarse en la etapa de madurez el CVH debe de aplicar estrategias como la diferenciación del servicio para incrementar su cuota de mercado y de esa manera ser rentable en su rubro y evitar llegar a la etapa de declive. 


\subsection{Estructura organizacional actual de la empresa}

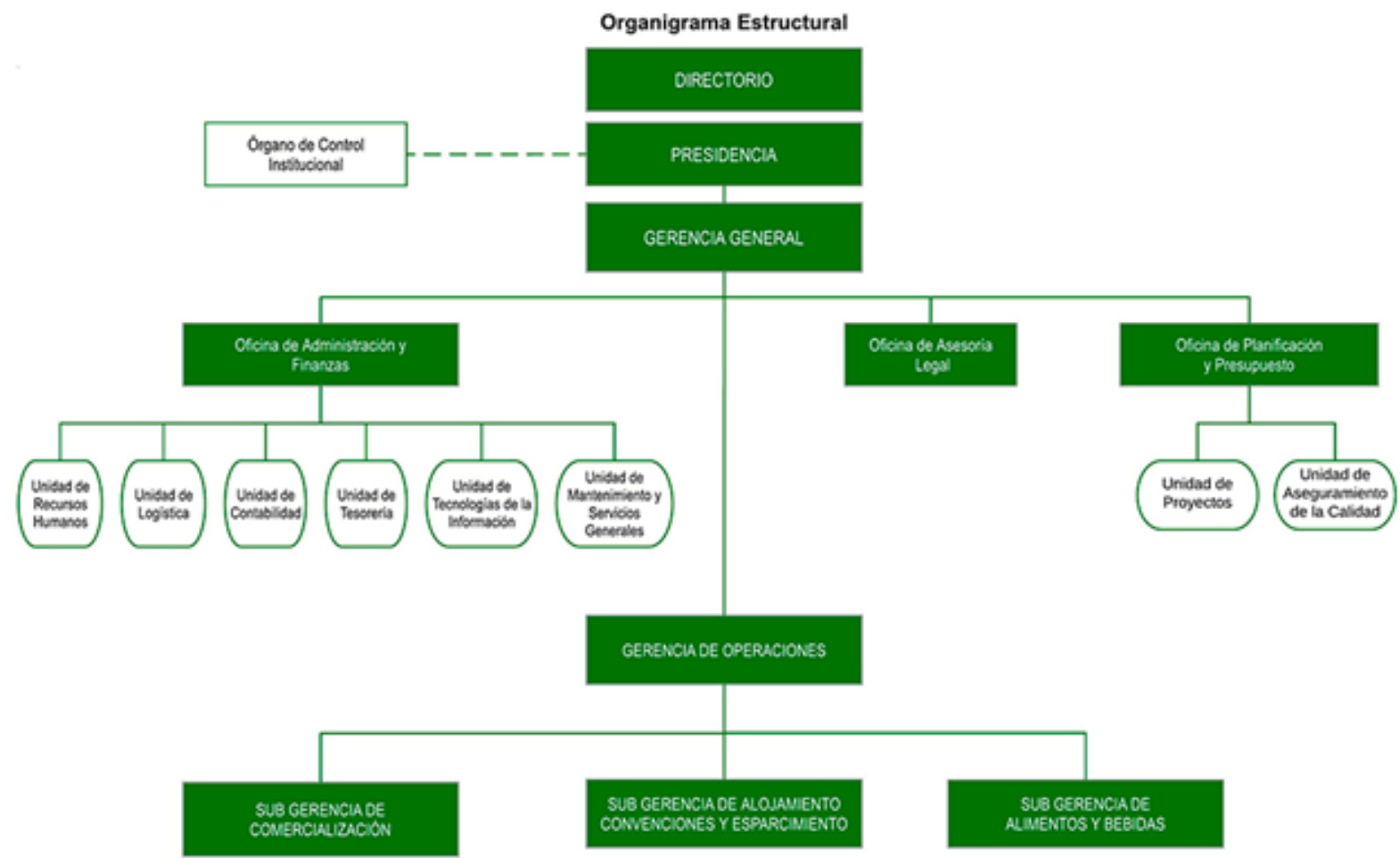

Figura 2. Organigrama del CVH Adaptado de Gerencia de RRHH del CVH, 2015.

\subsection{Situación de mercado y financiero de la industria}

La ubicación del CVH es excelente puesto que está situada en un distrito fuera de todo el bullicio de Lima. Dentro de esta área geográfica, existen una serie de centros de convenciones y hospedaje, lo cual lo convierte en uno de los competidores directos dentro del mercado en su categoría.

En los últimos años, el rubro de centro de convenciones ha tenido un importante crecimiento gracias a las realizaciones de eventos a nivel mundial, esto crea la necesidad de invertir y ampliar los salones en centros de convenciones.

De acuerdo a Tnews (2015) sobre las proyecciones de inversión en los centros de convenciones, indica “que en el periodo del 2015 al 2019 se proyectarían inversiones hoteleras en el segmento de 3, 4 y 5 estrellas de US\$ 1211,5 millones, lo que contemplaría un total de 93 hoteles nuevos, 6 ampliaciones y 3 remodelaciones. Gracias a estas inversiones, se 
generarían 7676 nuevas habitaciones en el país. Se estimaría que los proyectos que no tienen definido el número de habitaciones y los montos de inversión agregarían cerca de 1800 habitaciones adicionales, así como 275 millones de dólares de inversión”.

Como podemos apreciar, la oferta competitiva del CVH se encuentra en los centros hoteleros que cuentan dentro de sus instalaciones con lugares para convenciones. El cuadro que a continuación detalla los diferentes centros vacacionales y de recreación que son considerados competencia directa ya sea en habitaciones o en salones, con algunas de sus más resaltantes características:

Tabla 1

Competencia directa de centro de convenciones y recreación en Lima

\begin{tabular}{|c|c|c|c|c|c|c|}
\hline $\begin{array}{l}\text { Hotel/ Centro } \\
\text { de } \\
\text { Convenciones } \\
\text { CC }\end{array}$ & Tipo & Estre & Distri & Salón & Capacidad & Habitaciones \\
\hline $\begin{array}{l}\text { Double Tree } \\
\text { by Hilton }\end{array}$ & $\begin{array}{l}\text { Hotel } \\
-\mathrm{CC}\end{array}$ & 5 & Miraflores & 3 & 400 & 241 \\
\hline $\begin{array}{l}\text { Decameron } \\
\text { El Pueblo }\end{array}$ & $\begin{array}{l}\text { Hotel } \\
-\mathrm{CC}\end{array}$ & 5 & Chaclacayo & 19 & 1225 & 230 \\
\hline Los Delfines & $\begin{array}{l}\text { Hotel } \\
\text { y CC }\end{array}$ & 4 & Miraflores & 14 & 1,000 & 220 \\
\hline $\begin{array}{l}\text { C. Javier } \\
\text { Prado }\end{array}$ & $\mathrm{CC}$ & & La Victoria & 3 & 650 & -- \\
\hline Swissotel & $\begin{array}{l}\text { Hotel } \\
\text { y CC }\end{array}$ & 5 & San Isidro & 12 & 1,000 & 345 \\
\hline Westin Lima & $\begin{array}{l}\text { Hotel } \\
\text { y CC }\end{array}$ & 5 & San Isidro & 17 & $10-2,000$ & 301 \\
\hline
\end{tabular}

Nota: Adaptado del Informe del HSDO 2014. Elaboración propia.

El mercado objetivo del CVH ha variado debido a la sobre oferta, ahora compite tanto con los Apart hoteles como con los hoteles de 5 y 4 estrellas.

Situación financiera del CVH. La institución no era eficiente ni rentable, durante muchos años han incurrido en pérdidas y habían perdido su capital de trabajo y hasta su 
patrimonio. La estructura de la organización era inadecuada, no existiendo un ROF y MOF solo en proyecto, y una organización informal en operación.

El CVH ha presentado pérdidas en sus estados financieros entre los años 1978 y 1990. De 1990 al 2003 obtuvo resultados positivos, pero con valores bajos, reflejando así que su actividad no ha sido eficiente durante muchos años. A lo largo de esos años se ha perdido el $87 \%$ de los ingresos, es decir, 10 años de ingresos.

Según el Plan Operativo (2009) realizado por el Centro Vacacional, "El CVH tiene por finalidad atender convenciones, eventos culturales y otros servicios afines con servicios de hospedaje, alimentación, recreación y deporte al sector público como al sector privado".

La infraestructura del CVH consta de bungalows remodelados, 3 edificios con salas de capacitación y un edificio de dos pisos para talleres de laboratorio de última tecnología para competir con los demás centros de convenciones.

El CVH tiene la opción de ser un gran competidor en el mercado siempre y cuando modernice sus instalaciones y ofrezca servicios de calidad.

$\mathrm{El} \mathrm{CVH}$ anteriormente ha tenido pérdidas financieramente por malos manejos del directorio lo cual afectó su situación financiera por varios años. A partir del 2004 con el cambio del directorio se inició la recuperación del CVH por medio de un programa que dio resultados positivos, en el 2005 ese programa también fue satisfactorio, pero en el año 2006 e no tuvo éxito ya que no se cumplieron todas las actividades del programa, la que no se llegó a cumplir fue la ampliación de mercado que recién estamos cumpliendo con este punto para desarrollarlo. Su cumplimiento ayudó a mejorar el uso de nuevos recursos debido a que ha efectuado la inversión todo el año 2010.

Entre los años 2008 -2015, el CVH ha dado resultados positivos al resolverse el problema de la capacidad de atención. Este período marca una fase de recuperación de las actividades operativas. 
En los últimos años se ha invertido en la renovación y mejoramiento de las edificaciones y la modernización de sus 6 edificios $(2,3,4,5,6$, y 7), los cuales ahora cuentan con habitaciones con baño privado e ingresos independientes.

El Gobierno de Corea realizó donativos en equipos de última generación los cuales fueron instalados en el casino del CVH bajo el nombre de Centro de Acceso a la Información Perú - Corea ayudando a la modernización del centro de convenciones del CVH.

Desde mediados del año 2010 al Centro Vacacional Huampaní (CVH),tiene su capacidad al $100 \%$ en sus tres rubros (alojamiento, convenciones y restaurantes), constituyéndose el Colegio Mayor Secundario Presidente del Perú su cliente fijo y constante que genera, ocupa y atiende el $75 \%$ de dicha capacidad lo que años anteriores era una capacidad ociosa por los intervalos de los eventos ,es a partir de este año donde la marca Huampaní surge como líder dentro de las empresas del rubro de las convenciones donde comienza su liderazgo es a la calidad y excelencia de ese $25 \%$ cliente público, particular al que debemos centrar todos nuestros esfuerzos. Es en estos momentos que el Centro Vacacional Huampaní (CVH), al tener el 100\% de sus instalaciones ocupadas va requerir desde la alta dirección, el personal administrativo, el personal operativo la responsabilidad de una preparación, adecuación y esfuerzos para ir mejorando la atención y sus servicios, es en estos tiempos que la misión se convierta en una real visión.

Y en estos procesos de construcción del futuro del Centro Vacacional Huampaní, deberá continuar con la modernización, de su infraestructura, equipos y desarrollará un programa integral de nuevo espacio para esparcimiento.

En balance, calculando el acumulado de las pérdidas netas durante ese periodo, observamos una pérdida total de S/. 19,225,542.00 nuevos soles y en positivo se ha ganado S/. 643,660.00 nuevos soles, siendo la pérdida neta de S/. 18,581,882.00 nuevos soles; 
durante sólo 15 años, se excede al valor del patrimonio del 2003 de S/. 17,1021,982.00 nuevos soles.

El flujo de efectivo del CVH durante el periodo 2005 -2013 ha provenido de operaciones y registrados valores bajos, representando en promedio el $1.0 \%$ de ingreso durante el periodo, es decir S/. 35,000 aproximadamente. 


\section{CAPÍTULO III}

\section{FORMULACIÓN DE VISIÓN, MISIÓN Y VALORES DE LA EMPRESA}

\subsection{Visión}

\subsubsection{Visión actual de la empresa}

La visión actual del Centro Vacacional Huampani es "El CVH será el espacio por excelencia por la calidad, flexibilidad y eficacia en sus servicios para la realización de eventos de entrenamiento, debate y reflexión de las comunidades educativas, empresariales de gobierno y sociales".

\subsubsection{Análisis de la visión actual}

La tabla 2 permitirá comprobar si el enunciado de la visión contiene todos los elementos indicados.

Tabla 2

Matriz para evaluar la visión en la actualidad

\begin{tabular}{|l|l|}
\hline Visión & $\begin{array}{l}\text { "El CVH será un ambiente por excelencia por su } \\
\text { calidad, flexibilidad y eficacia en sus servicios, } \\
\text { para la realización de eventos de entrenamiento, } \\
\text { debate y reflexión de las comunidades educativas, } \\
\text { empresariales de gobierno y sociales". }\end{array}$ \\
\hline Marco Competitivo & $\begin{array}{l}\text { Si, brinda servicios de convenciones a instituciones } \\
\text { del Estado y empresas privadas. }\end{array}$ \\
\hline Objetivos & No, no cuenta no visión a futuro. \\
\hline Ventaja competitiva & $\begin{array}{l}\text { Si, cuenta con características que ayuda a mejorar } \\
\text { el servicio. }\end{array}$ \\
\hline $\begin{array}{l}\text { Proyección a largo } \\
\text { plazo }\end{array}$ & No, no se enfoca en un periodo de tiempo. \\
\hline
\end{tabular}

Nota. Visión actual tomada del CVH. Adaptado de Conceptos de administración estratégica (p. 45), por F. David, 2013, México, Pearson Educación. Copyright 2013 por Pearson Educación. Elaboración propia.

\subsubsection{Matriz de la visión propuesta para la empresa}

A continuación, se presenta la matriz de la visión propuesta. 
Tabla 3

Matriz de evaluación de la visión de la propuesta

\begin{tabular}{|l|l|}
\hline Visión propuesta & $\begin{array}{l}\text { El CVH busca convertirse en la institución líder, } \\
\text { enfocada a realizar convenciones, seminarios, } \\
\text { debates, en las cuales participen instituciones } \\
\text { educativas, empresas del estado y privadas que } \\
\text { otorga soluciones de esparcimiento para llegar a } \\
\text { ser un espacio de ata calidad y eficiencia de sus } \\
\text { servicios al finalizar el } 2021 .\end{array}$ \\
\hline Marco Competitivo & $\mathrm{Si}$ \\
\hline Objetivos & $\mathrm{Si}$ \\
\hline Ventaja competitiva & $\mathrm{Si}$ \\
\hline $\begin{array}{l}\text { Proyección a largo } \\
\text { plazo }\end{array}$ & $\mathrm{Si}$ \\
\hline
\end{tabular}

Nota. Adaptado de Conceptos de administración estratégica (p. 45), por F. David, 2013, México, Pearson Educación. Copyright 2013 por Pearson Educación.

Elaboración propia.

\subsubsection{Visión propuesta}

El CVH busca convertirse en la institución líder, enfocada a realizar convenciones, seminarios, debates, en las cuales participen instituciones educativas, empresas del estado y privadas que otorga soluciones de esparcimiento para llegar a ser un espacio de ata calidad y eficiencia de sus servicios al finalizar el 2021.

\subsection{Misión}

\subsubsection{Misión actual de la empresa}

La misión actual del CVH es "Brindar oportunidades académicas, culturales, empresariales y sociales, de primer orden y de escala institucional, local, regional y nacional, a las comunidades educativas, empresariales, de gobierno y social, ofreciendo ambientes, servicios y apoyo logístico con los más altos estándares de calidad" 


\subsubsection{Análisis de la misión actual}

Tabla 4

Análisis de la misión actual

\begin{tabular}{|l|l|}
\hline Misión & $\begin{array}{l}\text { "Brindar oportunidades académicas, culturales, } \\
\text { empresariales y sociales, de primer orden y de } \\
\text { escala institucional, local, regional y nacional, a las } \\
\text { comunidades educativas, empresariales, de } \\
\text { gobierno y social, ofreciendo ambientes, servicios } \\
\text { y apoyo logístico con los más altos estándares de } \\
\text { calidad" }\end{array}$ \\
\hline Producto & $\mathrm{Si}$ \\
\hline Mercado & $\mathrm{Si}$ \\
\hline Clientes & $\mathrm{Si}$ \\
\hline Competencias & $\mathrm{Si}$ \\
\hline Imagen & $\mathrm{No}$ \\
\hline
\end{tabular}

Nota. Misión actual tomada del CVH. Adaptado de Conceptos de administración estratégica (p. 51), por F. David, 2013, México, Pearson Educación. Copyright 2013 por Pearson Educación. Elaboración propia.

\subsubsection{Elementos de la misión propuesta para la empresa}

Tabla 5

Análisis de la misión de la propuesta

\begin{tabular}{lll}
\hline $\begin{array}{l}\text { Elementos de la } \\
\text { Misión }\end{array}$ & Situación Actual & Situación Futura \\
\hline Producto & $\begin{array}{l}\text { Oportunidades académicas, } \\
\text { culturales, empresariales y } \\
\text { sociales. }\end{array}$ & $\begin{array}{l}\text { Eventos de esparcimiento, } \\
\text { académicos, culturales, } \\
\text { empresariales y sociales. }\end{array}$ \\
\hline Mercado & Institucional & $\begin{array}{l}\text { Institucional, público en } \\
\text { general y empresarial. }\end{array}$ \\
\hline Clientes & $\begin{array}{l}\text { Comunidades educativas, } \\
\text { empresariales, de gobierno y } \\
\text { sociales. }\end{array}$ & $\begin{array}{l}\text { empresariales, de gobierno y } \\
\text { sociales. }\end{array}$ \\
\hline Competencias & Aplicación de estándares de & $\begin{array}{l}\text { Aplicación de estándares de } \\
\text { calidad. }\end{array}$ \\
\hline calidad. & $\begin{array}{l}\text { Responsable con la sociedad } \\
\text { mediante el cuidado del } \\
\text { ambiente. }\end{array}$ \\
\hline
\end{tabular}

Nota. Adaptado de Conceptos de administración estratégica (p. 48), por F. David, 2013, México, Pearson Educación. Copyright 2013 por Pearson Educación. Elaboración propia. 


\subsubsection{Misión propuesta}

El CVH tiene como propósito fundamental brindar atención para eventos de esparcimiento, académicos, corporativos e integración a nivel nacional a las diversas instituciones, brindando una adecuada infraestructura con la mejor calidad, siguiendo los lineamientos de responsabilidad.

\subsection{Valores}

\subsubsection{Valores actuales de la empresa}

De acuerdo al CVH sus valores son los siguientes:

\section{Vocación de Servicio}

"Todo el personal del CVH debe estar comprometido con su trabajo y poder brindar un servicio de alta calidad y un buen ambiente de trabajo.".

\section{Respeto}

"Respetar a las personas dentro y fuera del trabajo y respetar las ideas para tener así fomentar un ambiente de integración.”.

\section{Puntualidad}

"Cumplir con las horas de trabajo y realizar las actividades dentro tiempos establecidos".

\section{4. $\quad$ Lealtad}

“Todo funcionario y servidor del CVH debe lealtad a la máxima autoridad dependiente del ministerio de educación, por lo que debe actuar con fidelidad y solidaridad con los miembros que conforman la institución, en cumplimiento de las órdenes que les imparta la alta dirección, en la medida que reúnan las formalidades del caso y tengan por objeto la realización de actos de servicio que se vinculen con las funciones a su cargo, salvo 
los supuestos de arbitrariedad o ilegalidad manifiestas, las que deberá poner en conocimiento de la alta dirección del CVH".

\section{Liderazgo}

"Se busca lograr un compromiso común por medio del trabajo en equipo".

\section{Responsabilidad}

"Es cumplir de forma puntual con los trabajos y con el uso adecuado de los recursos, pues a través de estos medios se podrá ser competitivos".

\section{Transparencia}

"Se debe ser claros y no omitir ningún tipo de información".

\section{Honestidad}

"Ser honestos con nuestros compañeros de trabajos, con los clientes y con la organización”.

\subsubsection{Análisis de los valores actuales}

Los colaboradores del CVH deben de tener valores que estén alineados con los objetivos del centro vacacional. Además de los valores mencionados anteriormente el grupo propone valores que estén relacionados a la responsabilidad social.

\subsubsection{Elementos de los valores propuestos para la empresa}

Los valores propuestos son:

- $\quad$ Clientes: Brindar un alto servicio que produzcan beneficio y mantenga una prolongada confianza.

- Colaboradores: Mostrar respeto a los colaboradores y familiares.

- $\quad$ Proveedores: Establecer vínculos a largo plazo con socios responsables, que practican la honestidad y el respeto. 
- Comunidad: Contribuir a su desarrollo, generando riqueza, no utilizar mano de obra infantil, y respetar las jornadas laborales y la salud de los trabajadores.

- Medio ambiente: Cuidar al medio ambiente y hacer uso adecuado de sus recursos.

- $\quad$ Competidores: Evitar malas prácticas hacia la competencia.

\subsubsection{Valores propuestos}

\section{Identificación con la empresa}

El colaborador del CVH debe sentirse identificado con la institución y sus metas para el logro de las mismas.

\section{Honradez}

Un colaborador honrado con la empresa y con sus principios enfocados al servicio de los clientes.

\section{Cuidado al medio ambiente}

Preservación, hacer un buen uso de los recursos y así promover sostenibilidad en el desarrollo.

\section{Trabajo en equipo}

El trabajo en equipo significa que la gente tratará de cooperar, utilizando sus habilidades individuales y proporcionando retroalimentación constructiva, a pesar de cualquier conflicto personal entre individuos.

\section{Innovación}

Contar con la última información de tecnología y así poder mejorar en los procesos e innovar en los servicios para lograr la calidad total.

\subsection{Alineamiento estratégico de la Visión, Misión, y valores de la empresa}

Se muestra la alineación de la ideología empresarial del CVH. 
Tabla 6

Alineamiento estratégico de la Visión, Misión, y valores de la empresa

\begin{tabular}{|c|c|c|}
\hline Visión & Misión & Valores \\
\hline $\begin{array}{l}\text { El CVH busca } \\
\text { convertirse en la } \\
\text { institución líder, } \\
\text { enfocada a realizar } \\
\text { convenciones, } \\
\text { seminarios, debates, en } \\
\text { las cuales participen } \\
\text { instituciones educativas, } \\
\text { empresas del estado y } \\
\text { privadas que otorga } \\
\text { soluciones de } \\
\text { esparcimiento para llegar } \\
\text { a ser un espacio de ata } \\
\text { calidad y eficiencia de } \\
\text { sus servicios al finalizar } \\
\text { el } 2021 \text {. }\end{array}$ & $\begin{array}{l}\text { "Brindar oportunidades } \\
\text { académicas, culturales, } \\
\text { empresariales y sociales, de } \\
\text { primer orden y de escala } \\
\text { institucional, local, regional y } \\
\text { nacional, a las comunidades } \\
\text { educativas, empresariales, de } \\
\text { gobierno y social, ofreciendo } \\
\text { ambientes, servicios y apoyo } \\
\text { logístico con los más altos } \\
\text { estándares de calidad" }\end{array}$ & $\begin{array}{l}\text { 1.Identificación con la empresa } \\
\text { 2. Honradez } \\
\text { 3. Cuidado al medio ambiente } \\
\text { 4. Trabajo en equipo } \\
\text { 5. Innovación }\end{array}$ \\
\hline
\end{tabular}

Nota. Adaptado de Conceptos de administración estratégica (p. 47), por F. David, 2013, México, Pearson Educación. Copyright 2013 por Pearson Educación. Elaboración propia.

Con la misión, Visión y Valores propuestos, se pretende llegar al cumplimiento de los objetivos a largo plazo y que estén orientados en el tiempo del Plan Estratégico Propuesto 


\section{CAPÍTULO IV}

\section{ANÁLISIS EXTERNO}

\subsection{Tendencias de las variables del entorno}

\subsubsection{Análisis Político - Gubernamental}

En la actualidad nos encontramos en un período de transición ya que el gobierno entrante recién está tomando posesión de los diferentes ministerios y de las facultades otorgadas, generando un ambiente de preocupación para el directorio del CVH, debido que es parte del Ministerio de Educación y Economía, y esto puede generar cambios en los diferentes puestos y se deberá tener en cuenta en el Plan Estratégico del CVH.

La personería jurídica del CVH depende del Ministerio de Educación y en gestiones anteriores los procesos estratégicos se han visto interrumpidos por las nuevas administraciones que empezaron a liderar el CVH.

\subsubsection{Análisis Económico}

El aspecto económico es un punto importante para el país y para la ejecución de este Plan Estratégico ya que, si el país no cuenta con estabilidad económica, habrá menos inversión y no cubrirá la demanda para el sector.

El CVH pudo mejorar su situación financiera gracias al aumento de la demanda y la inversión privada y también por el crecimiento de la productividad, además de la mejora en las políticas que se aplicó al país lo cual se vio reflejado en el crecimiento del país como en el del CVH

Según Diario El Comercio, "BCR proyecta una desaceleración en el PBI a 2.5\% para finales de 2017, mientras que para el 2018 se espera que la economía peruana crezca en 3.7\%”, según nuevo informe del BCR. 
Al terminar el año 2018, se proyecta crecer a un 3.7\%, por lo tanto, para el CVH se espera un crecimiento de entre $2 \%$ y $3 \%$, lo cual se convierte en un ratio promedio del sector a tomar en cuenta para el crecimiento de la empresa.

Los clientes (que son las empresas públicas y privadas), mientras tengan crecimiento económico mantendrán o mejorarán su inversión en eventos institucionales. Todas las empresas, tienen la responsabilidad de optimizar el uso de sus recursos, por eso, ello se torna en una oportunidad de negocio que deben aprovechar los directivos del CVH.

El crecimiento económico es un objetivo importante para un país, el cual debe mantener para asegurar el bienestar de la población, este factor influye positivamente a la funcionalidad del CVH.

Análisis del sector de hospedaje que afecta el CVH. Según Semana Económica (2015) “El País es el mercado más atrayente para las inversiones hoteleras en la región”. "En este momento en que ha cambiado la situación económica mundial, el Perú no ha tenido cambios trascendentales en su situación [económica]". "Además las reglas de juego para hacer negocios son muy similares a las del primer mundo". (Arturo García, presidente de la Sahic).

De acuerdo a Semana Económica (2015) señaló que una de las ventajas del Perú es el acceso que tiene a Estados Unidos gracias a sus tratados de libre comercio (TLC) y su posición geográficamente estratégica. "El Perú se ha convertido en un hub de negocios en la región. Actualmente se vienen desarrollando diversas marcas que tienen mucha carga de negocios, por eso para nosotros el Perú es importante" (Luis Marabelli, vicepresidente de desarrollo para Latinoamérica y el Caribe de Wyndam (hoteles Costa del Sol y Ramada en el Perú).

Según Boletín Hotelero (2015) "la diversidad también tiene un papel importante en el atractivo del Perú como destino de inversiones hoteleras: Hay muchas cosas que hacen que el 
Perú sea un mercado interesante para los hoteleros. Es un destino tanto para viajes de placer como para viajes de negocios" (David Berg, CEO de Carlson Hospitality Group) en el ámbito geográfico las oportunidades de desarrollo se ven tanto en Lima como en provincias. Lima es un destino muy atractivo para los negocios y en provincias hay mucho por desarrollar más allá del Cusco.

Con el crecimiento de la economía las inversiones hoteleras tuvieron una pequeña desaceleración debido que el costo de los terrenos hotelero aumentaron de valor pero actualmente esta a cambiado debido a los diferente convenios con empresas nacionales e internacionales.

Según el informe de la Sociedad Hoteles del Perú (SHP) "la inversión hotelera estimada en el país para el período 2015-2018 sería de US\$ 1211 millones de dólares y se trataría de 102 nuevos proyectos que sumarían 7676 habitaciones en hoteles de 3, 4 y 5 estrellas” (Koechli., 2015, pág. 12).

Durante el año 2016, el PBI alcanzó el 4\%. Este factor económico es un indicador importante para que el CVH siga en crecimiento, teniendo una economía estable los objetivos de la empresa se estarán cumpliendo de forma eficaz. Por otro lado, al finalizar el 2017 algunos analistas y consultoras en cuestiones económica están de acuerdo en que la economía seguirá en crecimiento de acuerdo al BCR.

\subsubsection{Análisis Legal}

El CVH como institución, dependiente del ministerio de educación, tiene amplia dependencia legal de las bases que proponga el ministerio en mención. De acuerdo a las bases legales, del CVH cuenta con los siguientes documentos legales:

- Decreto legislativo $\mathrm{N}^{\circ} 756$, del 13.11.91, que define la naturaleza jurídica del $\mathrm{CVH}$, precisando que es una persona jurídica de derecho público interno del sector educación, autofinanciada, sin afectar recursos del tesoro público, que tiene por 
finalidad "prestar servicios hoteleros, esparcimiento, recreación y deporte, así como apoyar la ejecución de convenciones, eventos culturales y otros servicios afines con capacidad para el desarrollo de actividades y eventos deportivos”.

- $\quad$ Decreto supremo $\mathrm{N}^{\circ}$ 36-95-ED del 24.0495, que aprueba el estatuto del CVH.

- $\quad$ Resolución suprema $\mathrm{N}^{\circ}$ 007-2012-ED, que designa a los miembros del directorio del CVH.

- $\quad$ Resolución ministerial N 125-2013-PCM, que "aprueba el plan de implementación de la política nacional de modernización de la gestión pública 2013-2016”. Los inversionistas interesados en emprendimientos hoteleros requieren precisar y tomar varias decisiones tales como el público objetivo o tipo(s) de cliente(s) al que van a dirigir las inversiones, el destino en el que se deberá localizar el establecimiento, los servicios que deberá ofrecer para ser exitoso; así mismo es muy importante establecer las características que deberá tener el establecimiento. En correspondencia a las decisiones anteriores y como resultado de dicho análisis se definirá la infraestructura que hará posible dicha oferta de servicios, a fin de lograr una propuesta hotelera que facilite una gestión exitosa con la consecuente rentabilidad. Es decir, estaremos cubriendo desde la ubicación hasta la definición del concepto y la categoría del hotel.

Teniendo en consideración lo señalado en los primero párrafos, los inversionistas que proyecten establecimientos cumpliendo estrictamente los requerimientos señalados en el Reglamento de Establecimientos de Hospedaje del Perú, no cubrirán las expectativas de la mayoría de turistas a los que quieran dirigirse como público objetivo, ya que cada vez el huésped es más exigente; cabe señalar que el Reglamento de Establecimientos de Hospedaje del Perú establece la clasificación hotelera y los requisitos mínimos para cada clase y categoría, sin embargo los establecimientos que solamente se proponen alcanzar a cumplir esta normatividad no serán competitivos en el mercado actual. Con el ingreso al mercado 
peruano de cadenas hoteleras internacionales que tienen estándares de marca, los establecimientos que no sigan las tendencias actuales para satisfacer las expectativas del cliente cada vez más exigente y variante, quedarán relegados a un segundo nivel dentro de la categoría en la que desean competir. Por otro lado, el establecimiento hotelero deberá cumplir, además del Reglamento de Establecimientos de Hospedaje del Perú, otras normas como son la Normatividad Municipal correspondiente a la ubicación específica, el Reglamento Nacional de Edificaciones y las Normas de Defensa Civil.

\subsubsection{Análisis cultural - demográfico}

\section{Entorno Cultural}

Hoy en día las personas optan por disfrutar los fines de semana y feriados en familia fuera del bullicio de la ciudad, escogiendo los centros de esparcimientos, como uno de ellos, el CVH.

Respecto a los eventos, las personas han tomado la costumbre de asistir a convenciones que son netamente culturales, este estilo de vida va creciendo de manera paulatina y ello se ve reflejado en otras actividades como teatros, la feria del libro, las exposiciones de tipo gastronómico que congregan una gran cantidad de visitantes. Es por ello que el factor cultural se convierte en una oportunidad de negocio para el CVH.

Análisis de la actividad turística. La actividad turística está pasando por cambios por eso debe de mejorar sus procesos e instalaciones debido que los actuales consumidores son más exigente, además por la entrada de nuevos competidores que son las cadenas hoteleras a nivel mundial.

Aliaga (2015) consideró que "la consolidación del mercado, nuevas inversiones y el incremento de la oferta configuran un panorama ampliamente dinámico para el turismo en los siguientes años. Frente a ello, es importante conocer qué factores son determinantes y qué 
características tendrá el crecimiento de la industria hotelera en el país” (p. 9). Por lo tanto, Aliaga también señalaría que "la industria hotelera nacional ha experimentado su periodo de mayor expansión a nivel histórico en la última década. Hasta el año 2005, el número de marcas hoteleras internacionales presentes en el mercado peruano alcanzaba apenas la docena, mientras que al 2015 ese número está más que duplicado”.

"Pocos hubieran podido imaginar el gran impulso del sector hotelero en un ambiente económico internacional prolongadamente adverso y con pronósticos poco positivos para el desempeño de las economías desarrolladas, de las cuales preexiste una importante dependencia, más aún cuando a fines de los años noventa e inicios de los años 2000 la hotelería peruana padeció los efectos de una sobreoferta de habitaciones, con tarifas y niveles de ocupación bajos" (Aliaga, 2015).

“En efecto, el Perú pasó de cerca de un millón de turistas internacionales para finales del año 2002 a más de 3.2 millones para el año 2014, lo que implicó una tasa de crecimiento anual de aproximadamente $10 \%$. Asimismo, con relación a las divisas generadas por la actividad turística, se pasó de US\$ 837 millones en el 2002 a cerca de US\$ 4 mil millones en el 2014, creciendo a razón del 12\% anual, con lo cual no solo se incrementó el número de turistas internacionales, sino también su nivel de gasto individual, pasando de un promedio de US\$ 786 a US\$ 1,216 en el mismo periodo" (Aliaga, 2015).

"Basta decir que el crecimiento económico del país durante el periodo en mención haría lo propio con el mercado turístico interno y sobre todo con el desarrollo del segmento corporativo, con mención aparte acerca del desarrollo de grandes eventos internacionales en el país, que según estadísticas del International Congress and Convention Association (ICCA), presentaron al 2013 como el año con el mayor número de eventos internacionales a nivel histórico" (Aliaga, 2015). 
Aliaga (2015) justificaría que "como consecuencia de este sólido crecimiento, el nivel de inversión hotelera tuvo un claro despegue. Las tasas de retorno exhibidas por los proyectos hoteleros empezarían, luego de muchos años, a ser bastante atractivas y, con ello, muchas marcas hoteleras de renombre buscarían posicionarse en el mercado hotelero peruano. Así, cadenas hoteleras tales como Hilton, Accor, Marriott, Starwood, Radisson, entre otras, poseen a la fecha por lo menos un hotel operativo, proyectos en construcción y todas sin excepción están a la búsqueda de nuevas ubicaciones en diferentes partes del país. Y es esto último el aspecto más notable de este boom hotelero: su alcance nacional."

El crecimiento del rubro hotelero es importante y trascendental, tal como lo considera Aliaga (2015) afirmando que "el aumento de la oferta hotelera, tal como se ha descrito, no ha sido un fenómeno único de los mercados hoteleros tradicionales, tales como las ciudades de Lima o Cusco, sino además en mercados secundarios del norte, centro y sur del país. Muestra de ello es la incursión de marcas locales como Casa Andina en destinos como Pucallpa, Tumbes, Chiclayo y Trujillo, o de otro lado, marcas internacionales como Hilton (Double Tree) y Starwood (Luxury Collection) en Paracas” (pág. 10).

"De esta forma, considerando que una de las principales motivaciones de viaje de los pasajeros responde al desarrollo de negocios (con excepción de destinos turísticos consolidados), se posee un claro indicador de lo que representa este segmento para la hotelería en diferentes ciudades y que de hecho está teniendo eco en el desarrollo de nuevas propuestas de hospedaje." (Aliaga, 2015).

"Un recuento del nivel de inversión hotelera en el último lustro, provisto por la Sociedad Hoteles del Perú (SHP), señala un incremento de 3,194 habitaciones adicionales, con un total de 41 hoteles y una inversión global de US\$ 550 millones, con una gran participación de hoteles de 4 y 5 estrellas (75\% del total)” (Aliaga Romero, 2015). 
"Por un lado, es interesante comprobar cómo el mercado ha sido capaz de asimilar esta nueva oferta, mostrando al mismo tiempo una mejora en la ocupación promedio (4 y 5 estrellas) a nivel nacional, que al 2014 tiene un valor de $63 \%$ y una tasa de crecimiento histórica de cerca del 9\%. La ciudad de Lima, como es de esperar, tiene un comportamiento similar con una ocupación promedio (4 y 5 estrellas) de $67 \%$ y un crecimiento histórico del 6.6\%. De otro lado, las tarifas también han mostrado una evolución positiva, con un promedio de más de US\$200 en los segmentos de lujo (5 estrellas) y de más de US\$ 100 en segmentos de alta gama (4 estrellas) en Lima, situación que no es muy distinta en provincias, con presencia hotelera sofisticada como Cusco o Arequipa” (Aliaga, 2015).

\section{Entorno Demográfico.}

Estos últimos años, el Perú está teniendo un crecimiento sostenido en su población. Según el INEI este sería el crecimiento proyectado de la población al 2021 (INEI, 2017).

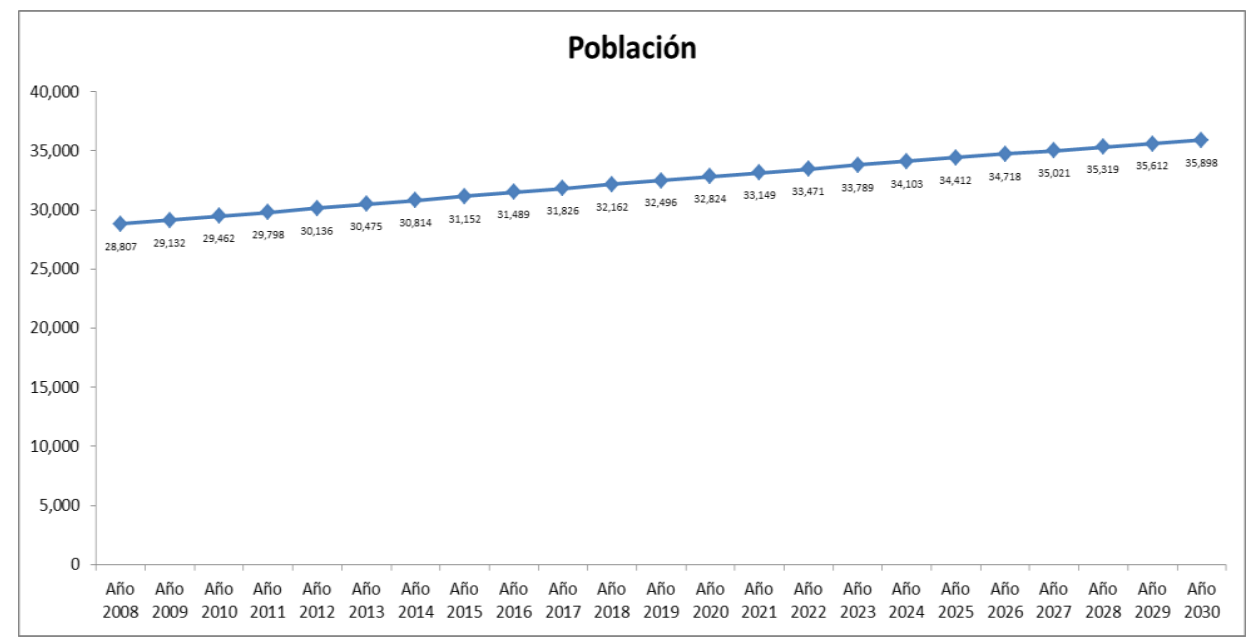

Figura 3. Proyección Crecimiento Poblacional. Adaptado de INEI (2017)

Si bien este crecimiento es sostenido, es la población urbana la que continúa con el crecimiento sostenido a diferencia del rural que en un aproximado de 5 años cae en casi 1 millón de personas como se puede observar en el gráfico adjunto: 


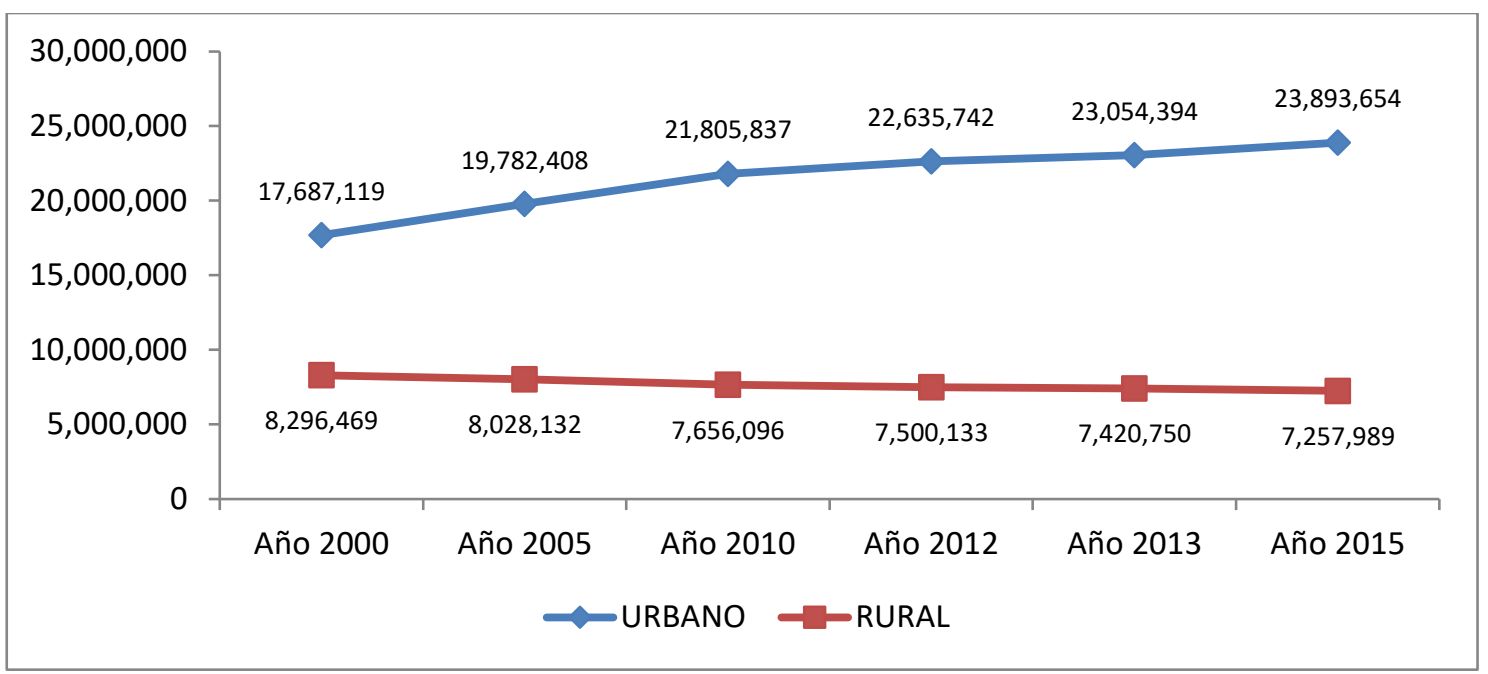

Figura 4. Distribución Poblacional Urbano - Rural Nota: INEI (2017)

“Conforme al último reporte del INEI sobre este tema, en el Perú hay 31 millones 151 mil 643 habitantes y se estima que, para el año del bicentenario de la independencia, esta cifra pase los 33 millones, cifra que se debe tomar en cuenta para lograr un crecimiento y desarrollo óptimo como nación" (INEI, 2015). El crecimiento demográfico favorece al CVH, debido a que brinda una oportunidad de visitantes a medida que el segmento poblacional al cual se orienta el servicio crece de manera sostenible. Es importante tomar en cuenta este indicador ya que permite tener una visión más exacta del crecimiento de la demanda de la población objetivo.

Este Cuadro presentado por PROMPERU muestra que los viajeros hoy en día prefieren viajar con el motivo de descansar y/o relajarse fuera del bullicio de la ciudad.

\begin{tabular}{|l|c|}
\hline Motivador de viaje & Total \% \\
\hline Descansar/relajarse & 40 \\
\hline Salir con la familia & 19 \\
\hline Conocer nuevos lugares & 18 \\
\hline Diversión & 10 \\
\hline Conocer atractivos turísticos & 6 \\
\hline Salir de la rutina & 5 \\
\hline Conocer otras costumbre & 2 \\
\hline Total 100\% & \\
\hline
\end{tabular}

Nota: PROMPERU 


\subsubsection{Análisis Tecnológico}

La tecnología se viene innovando día a día, ayudando a mejorar las

telecomunicaciones en el país lo cual brinda optimización de tiempo y ahorro de costos, lamentablemente a nivel nacional no cuentan con la debida modernización ya que todo se centraliza en las principales ciudades de la capital.

Solo ciertas empresas se están orientando a contar con las certificaciones internacionales y cumplir con los estándares para estar a la vanguardia.

Para el CVH la tecnología es un punto muy importante porque actualmente no cuenta con certificaciones y acreditaciones que ayuden a la mejorar los estándares de calidad, siendo una desventaja para la empresa.

Se mejorará la red inalámbrica, se mejorará la página web del CVH, se implementará la facturación electrónica, y se mejorará el sistema de ventas y eventos (MICROS INFOHOTEL)

\subsubsection{Análisis ecológico}

Hoy en día el aspecto ecológico es muy importante a nivel nacional e internacional por el cuidado del medio ambiente y el uso racional de los insumos hacen sostenibles a una empresa. Las organizaciones deben de guiarse de los reglamentos de las entidades como INRENA, CONAM y MINAM, encargadas de supervisión del nuevo código ambiental y de su ejecución.

En los últimos años el CVH está desarrollando actividades relacionadas a la preservación del medio ambiente como los programas de reciclaje, reúso de aguas servidas para el riego de las áreas verdes, entre otras.

\subsection{Impacto en clientes/ proveedores de cada una de las variables del entorno}

El análisis de las variables del entorno se realiza según el siguiente procedimiento: 
- $\quad$ Reconoce la tendencia de la variable, sea a través de pronósticos o de investigaciones.

- $\quad$ Establecer cómo afectará los cambios esperados de la misma a los clientes y proveedores de la industria en la que participa el $\mathrm{CVH}$.

- $\quad$ Estimar como ese cambio pronosticado podría finalmente afectar al CVH.

A continuación, se presentan las tendencias del entorno, el efecto en los clientes y en la empresa y si la tendencia ocasiona una oportunidad o amenaza.

Tabla 7

Análisis político - gubernamental/ impacto cliente - proveedores

\begin{tabular}{ll}
\hline Tendencia & Impacto Clientes \\
\hline $\begin{array}{l}\text { El } 2017 \text { es considerado como un año } \\
\text { de decisiones por el nuevo mandatario. }\end{array}$ & Cambio en la cantidad de empresas del \\
\hline Cambios en la directiva de & Cambio del directorio debido al ingreso \\
administración que tiene el CVH en el & de un nuevo presidente. \\
momento. &
\end{tabular}

Nota: Elaboración propia

Tabla 8

Análisis económico/ Impacto cliente - proveedores

\begin{tabular}{ll}
\hline Tendencia & Impacto Clientes \\
\hline Las empresas y personas poseen un & Clientes potenciales podrán adquirir más \\
mayor poder adquisitivo. & servicios al CVH. \\
Aumento del PBI en el sector de & La solidez económica del país hace \\
servicios y principalmente el hotelero & prosperar la situación económica de las \\
para el 2017. & empresas, clientes del CVH. \\
\hline
\end{tabular}

Nota: Elaboración propia

Tabla 9

Análisis legal/ impacto cliente - proveedores

\begin{tabular}{ll}
\hline Tendencia & Impacto Clientes \\
\hline $\begin{array}{l}\text { Se tiene normas que respaldan la } \\
\text { operatividad del CVH. }\end{array}$ & $\begin{array}{l}\text { Seguridad para la ejecución de alianzas } \\
\text { estratégicas con instituciones del Estado. }\end{array}$ \\
\hline
\end{tabular}

Nota: Elaboración propia 
Tabla 10

Análisis cultural-demográfico/ Impacto cliente - proveedores

\begin{tabular}{ll}
\hline Tendencia & Impacto Clientes \\
\hline Mayor afluencia de asistir a eventos. & $\begin{array}{l}\text { Clientes potenciales van a preferir } \\
\text { establecimientos con mayor } \\
\text { capacidad. }\end{array}$ \\
$\begin{array}{l}\text { Amplia tendencia de opciones de } \\
\text { diversión, entretenimiento de la mano con } \\
\text { la cultura en Lima. }\end{array}$ & $\begin{array}{l}\text { Clientes cuentan con una mayor } \\
\text { entretenimiento y cultura en Lima y } \\
\text { fuera de Lima. }\end{array}$ \\
$\begin{array}{l}\text { La cultura de pasar en familia fuera de } \\
\text { casa tiene una tendencia importante en } \\
\text { relación al crecimiento que vienen } \\
\text { teniendo todos los establecimientos que lo } \\
\text { ofrecen. }\end{array}$ & $\begin{array}{l}\text { Mayor exigencia y búsqueda de } \\
\text { nuevas opciones familiares fuera de } \\
\text { casa. }\end{array}$ \\
\hline
\end{tabular}

Nota: Elaboración propia

Tabla 11

Análisis tecnológico/ Impacto cliente - proveedores

\begin{tabular}{|l|l|}
\hline Tendencia & Impacto Clientes \\
\hline $\begin{array}{l}\text { La nueva tecnología hace obsoleta a la } \\
\text { existente. }\end{array}$ & $\begin{array}{l}\text { Clientes optan por tecnología a la } \\
\text { vanguardia. }\end{array}$ \\
\hline
\end{tabular}

Nota: Elaboración propia

Tabla 12

Análisis ecológico/ Impacto cliente - proveedores

\begin{tabular}{|l|l|}
\hline Tendencia & Impacto Clientes \\
\hline $\begin{array}{l}\text { Uso de fuente de energía orgánica y } \\
\text { reciclable. }\end{array}$ & $\begin{array}{l}\text { Clientes interesados en energía } \\
\text { orgánica. }\end{array}$ \\
\hline $\begin{array}{l}\text { Los clientes buscan que las empresas } \\
\text { sigan los lineamientos de } \\
\text { responsabilidad social. }\end{array}$ & $\begin{array}{l}\text { Mayor conciencia ambiental por parte } \\
\text { de los clientes. }\end{array}$ \\
\hline
\end{tabular}

Nota: Elaboración propia 


\subsection{Efecto en la empresa de cada una de las variables del entorno}

Tabla 13

Análisis Político - Gubernamental/ Impacto cliente - proveedores

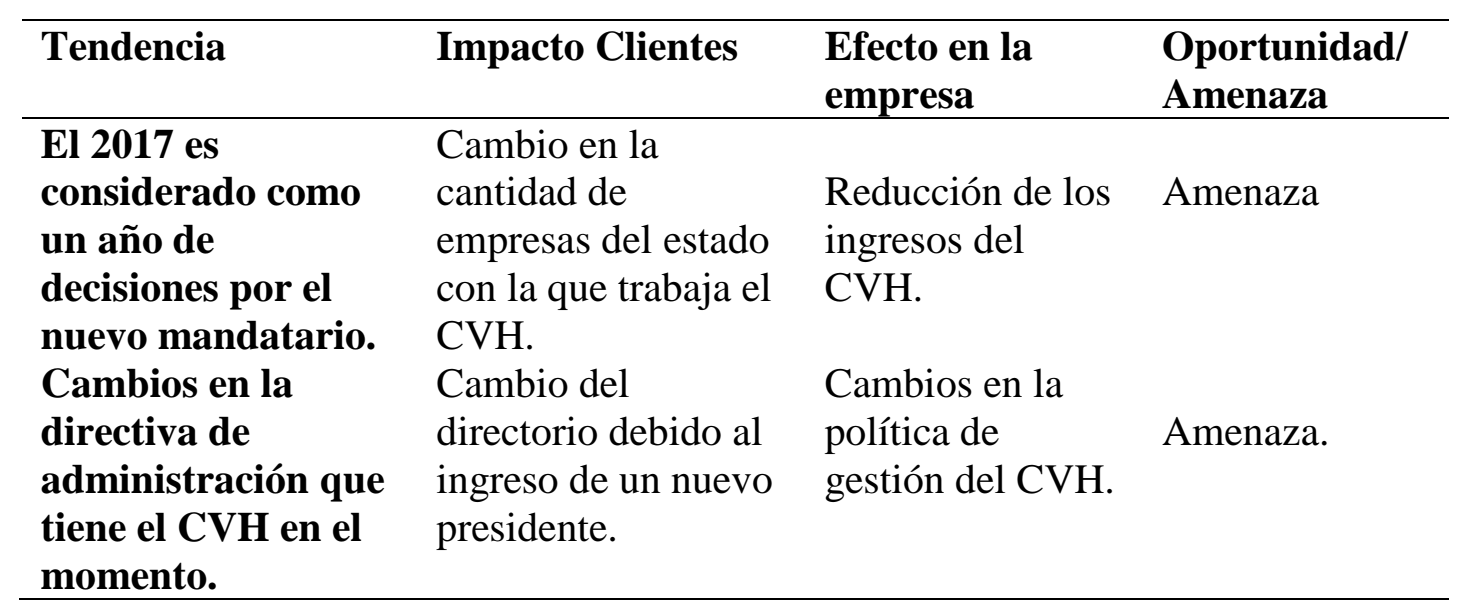

Nota: Elaboración propia

Tabla 14

Análisis económico/ Impacto cliente - proveedores

\begin{tabular}{|c|c|c|c|}
\hline Tendencia & Impacto Clientes & $\begin{array}{l}\text { Efecto en la } \\
\text { empresa }\end{array}$ & $\begin{array}{l}\text { Oportunidad/ } \\
\text { Amenaza }\end{array}$ \\
\hline $\begin{array}{l}\text { Las empresas y } \\
\text { personas poseen un } \\
\text { mayor poder } \\
\text { adquisitivo. } \\
\text { Aumento del PBI } \\
\text { en el sector de } \\
\text { servicios y } \\
\text { principalmente el } \\
\text { hotelero para el } \\
2017 \text {. }\end{array}$ & $\begin{array}{l}\text { Clientes } \\
\text { potenciales podrán } \\
\text { adquirir más } \\
\text { servicios al CVH. } \\
\text { La solidez } \\
\text { económica del } \\
\text { país hace } \\
\text { prosperar la } \\
\text { situación } \\
\text { económica de las } \\
\text { empresas, clientes } \\
\text { del CVH. }\end{array}$ & $\begin{array}{l}\text { Inversión en } \\
\text { nuevos servicios } \\
\text { que podría } \\
\text { ofrecer el CVH. } \\
\text { Crecimiento de } \\
\text { atención a nuevos } \\
\text { clientes } \\
\text { institucionales. }\end{array}$ & Oportunidad \\
\hline
\end{tabular}

Nota: Elaboración propia 
Tabla 15

Análisis legal/ Impacto cliente - proveedores

\begin{tabular}{llll}
\hline Tendencia & Impacto Clientes & $\begin{array}{l}\text { Efecto en la } \\
\text { empresa }\end{array}$ & $\begin{array}{l}\text { Oportunidad/ } \\
\text { Amenaza }\end{array}$ \\
\hline $\begin{array}{l}\text { Se tiene normas que } \\
\text { respaldan la } \\
\text { operatividad del }\end{array}$ & $\begin{array}{l}\text { Seguridad para la } \\
\text { realización de }\end{array}$ & $\begin{array}{l}\text { Alianzas } \\
\text { alianzas }\end{array}$ & $\begin{array}{l}\text { estratégicas con } \\
\text { CVH. }\end{array}$ \\
& $\begin{array}{l}\text { estratégicas con } \\
\text { instituciones del }\end{array}$ & $\begin{array}{l}\text { instituciones del } \\
\text { Estado. }\end{array}$ & \\
& Estado. & & \\
\hline
\end{tabular}

Nota: Elaboración propia

Tabla 16

Análisis Cultural/ Impacto cliente - proveedores

\begin{tabular}{|c|c|c|c|}
\hline Tendencia & Impacto Clientes & $\begin{array}{l}\text { Efecto en la } \\
\text { empresa }\end{array}$ & $\begin{array}{l}\text { Oportunidad/ } \\
\text { Amenaza }\end{array}$ \\
\hline $\begin{array}{l}\text { Mayor afluencia de } \\
\text { asistir a eventos }\end{array}$ & $\begin{array}{l}\text { Clientes potenciales } \\
\text { van a preferir } \\
\text { establecimientos con } \\
\text { mayor capacidad. }\end{array}$ & $\begin{array}{l}\text { Oportunidad de } \\
\text { atención y mejora } \\
\text { de los servicios }\end{array}$ & Oportunidad \\
\hline $\begin{array}{l}\text { Amplia tendencia } \\
\text { de opciones de } \\
\text { diversión, } \\
\text { entretenimiento de } \\
\text { la mano con la } \\
\text { cultura en Lima. }\end{array}$ & $\begin{array}{l}\text { Clientes cuentan con } \\
\text { una mayor cantidad } \\
\text { de opciones de } \\
\text { diversión, } \\
\text { entretenimiento y } \\
\text { cultura en Lima y } \\
\text { fuera de Lima. }\end{array}$ & $\begin{array}{l}\text { Amenaza frente } \\
\text { al crecimiento y } \\
\text { aparición de } \\
\text { nuevas empresas } \\
\text { del rubro. }\end{array}$ & Amenaza \\
\hline $\begin{array}{l}\text { La cultura de pasar } \\
\text { en familia fuera de } \\
\text { casa tiene una } \\
\text { tendencia } \\
\text { importante en } \\
\text { relación al } \\
\text { crecimiento que } \\
\text { vienen teniendo } \\
\text { todos los } \\
\text { establecimientos } \\
\text { que lo ofrecen. }\end{array}$ & $\begin{array}{l}\text { Mayor exigencia y } \\
\text { búsqueda de nuevas } \\
\text { opciones familiares } \\
\text { fuera de casa. }\end{array}$ & $\begin{array}{l}\text { Oportunidad de } \\
\text { ampliación y } \\
\text { mejoramiento de } \\
\text { los servicios. }\end{array}$ & Oportunidad \\
\hline
\end{tabular}

Nota: Elaboración propia 
Tabla 17

Análisis tecnológico/ Impacto cliente - proveedores

\begin{tabular}{|l|l|l|l|}
\hline Tendencia & Impacto Clientes & $\begin{array}{l}\text { Efecto en la } \\
\text { empresa }\end{array}$ & $\begin{array}{l}\text { Oportunidad/ } \\
\text { Amenaza }\end{array}$ \\
\hline $\begin{array}{l}\text { La nueva tecnología } \\
\text { hace obsoleta a la } \\
\text { existente. }\end{array}$ & $\begin{array}{l}\text { Clientes optan por } \\
\text { tecnología a la } \\
\text { vanguardia. }\end{array}$ & $\begin{array}{l}\text { Innovación en los } \\
\text { canales de ventas y } \\
\text { en la prestación de } \\
\text { servicios. }\end{array}$ & Oportunidad \\
\hline
\end{tabular}

Nota: Elaboración propia

Tabla 18

Análisis ecológico/ Impacto cliente - proveedores

\begin{tabular}{|c|c|c|c|}
\hline Tendencia & Impacto Clientes & Efecto en la empresa & $\begin{array}{l}\text { Oportunidad/ } \\
\text { Amenaza }\end{array}$ \\
\hline $\begin{array}{l}\text { Uso de fuente de } \\
\text { energía orgánica y } \\
\text { reciclable }\end{array}$ & $\begin{array}{l}\text { Clientes interesados } \\
\text { en energía orgánica. }\end{array}$ & $\begin{array}{l}\text { Conocimiento de las } \\
\text { propensiones más } \\
\text { actuales de energías } \\
\text { renovables. }\end{array}$ & Oportunidad \\
\hline $\begin{array}{l}\text { Los clientes buscan } \\
\text { que las empresas } \\
\text { sigan los lineamientos } \\
\text { de responsabilidad } \\
\text { social }\end{array}$ & $\begin{array}{l}\text { Mayor conciencia } \\
\text { ambiental por parte } \\
\text { de los clientes. }\end{array}$ & $\begin{array}{l}\text { Conocimiento de } \\
\text { tendencias ecológicas. } \\
\text { Conocimiento de } \\
\text { insumos reciclables. }\end{array}$ & Oportunidad \\
\hline $\begin{array}{l}\text { No se cuenta con un } \\
\text { Plan de gestión de } \\
\text { medio ambiente. }\end{array}$ & $\begin{array}{l}\text { Ubicación del CVH } \\
\text { en zona accidentada } \\
\text { geográficamente. }\end{array}$ & $\begin{array}{l}\text { Posibles desastres } \\
\text { naturales. } \\
\text { Deficiente } \\
\text { infraestructura de } \\
\text { transporte para llegar al } \\
\text { CVH. }\end{array}$ & Amenazas \\
\hline
\end{tabular}

Nota: Elaboración propia

\subsection{Oportunidades y amenazas}

\section{Oportunidades}

- El clima que rodea al CVH plantea una gran oportunidad de atención y mejora la salud y atención a los clientes.

- Alianzas estratégicas con las diversas instituciones del estado Peruano.

- La adaptación de tecnologías y procesos actuales de gestión aumentarían la capacidad operativa del CVH. 
- El nivel de cultura de la sociedad orientada a la familia, lo cual favorecería a la disminución de la capacidad ociosa.

- Culturalmente se tienen una serie de alternativas relacionadas con la incorporación de parques, ambientes de recreación, formación de teatros y restaurantes.

- Ubicación geográfica del CVH en una zona de clima cálido todo el año.

- Estabilidad macroeconómica del Perú.

- Implementación de políticas de cultura por parte del estado peruano.

\section{Amenazas}

- Desastres naturales en la zona de ubicación del CVH (Huaycos)

- Cambios en la política de continuidad del colegio Mayor.

- Nivel muy alto de expectativa de los visitantes.

- Los cambios pueden hacer surgir nuevos competidores en el mercado.

- El no actualizar la tecnología, pone en desventaja a la empresa.

- Ambiente político con turbulencias debido a la nueva gestión del gobierno (2016).

\subsection{Matriz de Evaluación de Factores Externos (EFE)}

Esta matriz nos ayuda a conocer las oportunidades y amenazas que debe de aprovechar y enfrentar el CVH. De acuerdo a David (2013) se sigue los siguientes pasos para elaborar la matriz EFE:

- Seleccionar las oportunidades y amenazas que debe de enfrentar el CVH.

- Asignar una ponderación en un rango de 0 a 1 de cada una de las fortalezas y debilidades. La suma de la ponderación debe ser igual a 1.

- Luego se asigna un valor a cada oportunidad y amenaza, siguiendo las siguientes escalas: 4 (es una respuesta superior), 3 (es una respuesta mayor al promedio), 2 (es una respuesta promedio) y 1 (es una respuesta deficiente). 
- Los resultados se multiplican con la calificación de cada factor para obtener la ponderación final.

- Finalmente, si el resultado es 1 o cerca 1 se interpreta que no se tiene la capacidad suficiente para dar respuestas a los factores externos. Si el resultado es mayor a 2 se considera que el CVH si tiene la capacidad para responder a las amenazas y oportunidades del mercado.

Tabla 19

Matriz Evaluación de Factores Externos para el CVH

\begin{tabular}{|c|c|c|c|c|}
\hline \multicolumn{5}{|c|}{ Matriz efe del CVH } \\
\hline & Factores determinantes de éxito & Peso & Valor & Ponderación \\
\hline \multicolumn{5}{|c|}{ Oportunidades } \\
\hline 1 & $\begin{array}{l}\text { El clima que rodea al CVH plantea una gran oportunidad de atención y mejora la salud y } \\
\text { atención a los clientes. }\end{array}$ & 0.12 & 3 & 0.36 \\
\hline 2 & Alianzas estratégicas del Estado para ser sede de eventos. & 0.12 & 3 & 0.36 \\
\hline 3 & Adoptar nuevas tecnologías y procesos de gestión para las operaciones del CVH. & 0.12 & 3 & 0.36 \\
\hline 4 & $\begin{array}{l}\text { Cultura de la sociedad orientada a la familia, incorporación de parques, restaurantes, } \\
\text { ambientes de recreación, otros. }\end{array}$ & 0.08 & 2 & 0.16 \\
\hline 5 & Ubicación geográfica del CVH en una zona de clima cálido todo el año. & 0.08 & 2 & 0.16 \\
\hline 6 & Estabilidad macroeconómica del Perú. & 0.04 & 2 & 0.08 \\
\hline \multirow[t]{2}{*}{7} & Implementación de políticas de cultura por parte del Estado Peruano. & 0.04 & 2 & 0.08 \\
\hline & & 0.6 & & 1.56 \\
\hline & Amenazas & & & \\
\hline 1 & Desastres naturales en la zona de ubicación del CVH (Huay cos) & 0.10 & 3 & 0.3 \\
\hline 2 & Cambios en la política de continuidad del Colegio Mayor. & 0.08 & 3 & 0.24 \\
\hline 3 & Nivel muy alto de expectativa de los visitantes & 0.10 & 2 & 0.2 \\
\hline 4 & Los cambios pueden llegar a impulsar nuevos competidores. & 0.04 & 3 & 0.12 \\
\hline 5 & El CVH se encontraría en desventaja al no actualizar la tecnología & 0.04 & 2 & 0.08 \\
\hline \multirow[t]{3}{*}{6} & Ambiente políticos con turbulencias debido al nuevo mandatario. & 0.04 & 2 & 0.08 \\
\hline & & 0.40 & & 1.02 \\
\hline & Total & 1 & & 2.58 \\
\hline
\end{tabular}

Nota. Adaptado de Administración estratégica (p. 81), por F. David, 2013, México, Pearson Educación. Copyright 2013 por Pearson Educación. Elaboración propia

Con el valor obtenido que es 2.58 demuestra que el CVH puede aprovechar las oportunidades y reducir las amenazas que lo rodea, se debe de aprovechar las oportunidades tales como el cambio en la cultura de la sociedad, la buena ubicación geográfica que cuenta el CVH y la implementación de políticas de cultura por parte del Colegio Mayor. También se debe de enfocar en la mejora de tecnología y estar alerta a los cambios políticos que depende el CVH. 
Se indica también que la ponderación se ha realizado con la participación de un colaborador del $\mathrm{CVH}$, ello para determinar criterios que vayan de acuerdo con la realidad de la institución. 


\section{CAPÍtULO V}

\section{ANÁLISIS DE LA INDUSTRIA}

\subsection{Descripción del Mercado (demanda) e Industria (Oferta)}

En el Perú, principalmente en Lima, la demanda de convenciones viene creciendo, pero en Lima la oferta no cuenta con centros de convenciones con ocupablidad para más de 10 mil personas.

Tampoco se cuenta con lugares apropiados para ferias que alberguen importantes eventos como Mistura o la Expo alimentaria. Por ejemplo, solamente para hacer la infraestructura del COP 20 en el Pentagonito se invirtió S/. 70 millones, son casi US \$30 millones que se armaron y desarmaron. Por otro lado, se cuenta con el alquiler del Jockey Plaza para hacer una feria y definitivamente los organizadores deben tener un presupuesto alto. Actualmente se cuenta con el centro de convenciones de Lima el cual está ubicado en san Borja.

Por ejemplo, en el año 2016 tuvimos los siguientes eventos que fueron realizados la mayoría en hoteles superando mucho los presupuestos y la capacidad era muy poca.

- Del 21 al 22 de enero. Aviation Week MRO Latín American. Evento que reúne a empresarios del rubro aéreo. Se dio en el hotel Sheraton con aproximadamente 400 personas.

- Del 14 al 17 de marzo. IV congreso Mundial de Reservas Biosfera y el XXVII Consejo Internacional de Coordinación UNESCO. Evento que reúne a los más destacados profesionales del rubro ambiental. Se dio en el centro de convenciones de Lima 27 de enero con aproximadamente 1400 personas.

- Del 14 al 20 de noviembre. APEC. Se realizó en el centro de convenciones de Lima con una audiencia de 1500 personas aproximadamente.

En este ano, 2017, se realizaron los siguientes eventos: 
- V congreso Regional Iberoamericano de Medicina Familia. Aproximadamente 1300 personas.

- $\quad$ Del 14 al 17 de marzo. XXII Congreso Latinoamericano de Cirugía. Con aproximadamente 2700 asistentes.

- $\quad$ Del 5 al 7 de Julio. EXPO ARCON 2017. Con aproximadamente 65000 asistentes

- $\quad$ Del 10 al 20 de Setiembre. Primer Congreso Mundial del Comité Olímpico Internacional. Con 5000 asistentes

Como podemos apreciar, en los últimos meses Lima está siendo sede de importantes eventos lo cual demuestra que hay mercado potencial por atender y es una oportunidad para el CVH captar esos clientes potenciales por medio de estrategias., siendo beneficioso para su rentabilidad.

En relación con las proyecciones que se tiene de la oferta, podemos citar la construcción del Centro de Convenciones de Lima, como competidor directo del CVH; es un centro de convenciones que se ubica en San Borja, situado alrededor del Museo de la Nación y la Biblioteca Nacional, en un área de 10.884 metros. El complejo tendrá la capacidad para albergar alrededor de 10 mil personas, contará con 18 salas y cuatro niveles de sótanos y 4 pisos de auditorio

\subsection{Descripción de las cinco fuerzas competitivas de la industria}

De acuerdo a Porter, las cinco fuerzas son un modelo estratégico para analizar el nivel de competencia dentro de una industria y si la industria es atractiva para la inversión y rentabilidad. Se mide por los siguientes rangos: "muy poco atractiva, poco atractiva, neutral, atractiva y muy atractiva" para la industria.

Se evalúa de la siguiente manera:

- $\quad$ Establecer los factores a evaluar.

- $\quad$ Aplicar la escala de Likert para ver la atractividad de la industria. 
- $\quad$ Se multiplica el porcentaje con la calificación que se asignó a cada uno de los factores para obtener la ponderación de cada una de ellas.

Realización de la matriz general tomando en cuenta la evaluación promedio de las cinco fuerzas.

Se va a determinar el grado de atractividad de la industria al obtener el promedio de la evaluación.

\subsubsection{Sustitutos}

Tabla 20

Disponibilidad de sustitutos

\begin{tabular}{|l|c|c|c|}
\hline \multicolumn{1}{|c|}{ Factores } & Peso & Calificación & $\begin{array}{c}\text { Puntaje } \\
\text { ponderado }\end{array}$ \\
\hline Disponibilidad de sustitutos cercanos & $25 \%$ & 3 & 0.75 \\
\hline Nivel de diferenciación del servicio & $25 \%$ & 4 & 1.00 \\
\hline Costos de cambio & $20 \%$ & 2 & 0.40 \\
\hline $\begin{array}{l}\text { Agresividad y rentabilidad del } \\
\text { productor de sustitutos }\end{array}$ & $15 \%$ & 4 & 0.60 \\
\hline Valor / precio del sustituto & $15 \%$ & 5 & 0.75 \\
\hline TOTAL & $100 \%$ & & 3.50 \\
\hline
\end{tabular}

Nota: Basado en el análisis de Porter, adaptado de Administración Estratégica (p. 64), por Thompson, Peteraf, Gamble \& Strickland, 2012, México: Mc Graw Hill. Copyright 2012 por Mc Graw Hill / Interamericana Editores S.A. de C.V. Elaboración propia.

La siguiente ponderación fue dada con un colaborador del CVH, Sr. Pedro Castellanos.

\begin{tabular}{|l|c|c|c|}
\hline \multicolumn{1}{|c|}{ Factores } & Peso & Calificación & $\begin{array}{c}\text { Puntaje } \\
\text { ponderado }\end{array}$ \\
\hline Disponibilidad de sustitutos cercanos & $25 \%$ & 3 & 0.75 \\
\hline Nivel de diferenciación del servicio & $25 \%$ & 4 & 1.00 \\
\hline Costos de cambio & $20 \%$ & 2 & 0.40 \\
\hline $\begin{array}{l}\text { Agresividad y rentabilidad del } \\
\text { productor de sustitutos }\end{array}$ & $15 \%$ & 4 & 0.60 \\
\hline Valor / precio del sustituto & $15 \%$ & 4 & 0.60 \\
\hline TOTAL & $100 \%$ & & 3.35 \\
\hline
\end{tabular}

Nota: Basado en el análisis de Porter, adaptado de Administración Estratégica (p. 64), por Thompson, Peteraf, Gamble \& Strickland, 2012, México: Mc Graw Hill. Copyright 2012 por Mc Graw Hill / Interamericana Editores S.A. de C.V. Elaboración propia. 
Conclusión: La fuerza de los sustitutos no representa un obstáculo importante en el manejo del CVH.

\subsubsection{Barreras de entrada}

Tabla 21

Barreras de entrada

\begin{tabular}{|l|c|c|c|}
\hline \multicolumn{1}{|c|}{ Factores } & Peso & Calificación & $\begin{array}{c}\text { Puntaje } \\
\text { ponderado }\end{array}$ \\
\hline Diferenciación del servicio & $10 \%$ & 2 & 0.20 \\
\hline Identificación de marca & $15 \%$ & 3 & 0.45 \\
\hline Costos de cambio (recuperabilidad) & $20 \%$ & 4 & 0.80 \\
\hline Acceso a tecnología de punta & $5 \%$ & 3 & 0.15 \\
\hline Acceso a equipos & $5 \%$ & 3 & 0.15 \\
\hline Regulaciones gubernamentales de entrada/renovación & $5 \%$ & 2 & 0.10 \\
\hline Regulaciones gubernamentales para operación & $5 \%$ & 2 & 0.10 \\
\hline Globalización (riesgo de...) & $15 \%$ & 3 & 0.45 \\
\hline Efecto de la experiencia (curva de aprendizaje) & $20 \%$ & 5 & 1.00 \\
\hline TOTAL & $100 \%$ & & 3.40 \\
\hline
\end{tabular}

Nota: Basado en el análisis de Porter, adaptado de Administración Estratégica (p. 62), por Thompson, Peteraf, Gamble \& Strickland, 2012, México: Mc Graw Hill. Copyright 2012 por Mc Graw Hill / Interamericana Editores S.A. de C.V. Elaboración propia.

La siguiente ponderación fue dada con un colaborador del CVH, Sr. Pedro Castellanos.

\begin{tabular}{|c|c|c|c|}
\hline Factores & Peso & Calificación & $\begin{array}{c}\text { Puntaje } \\
\text { ponderado }\end{array}$ \\
\hline Diferenciación del servicio & $10 \%$ & 3 & 0.30 \\
\hline Identificación de marca & $15 \%$ & 2 & 0.30 \\
\hline Costos de cambio (recuperabilidad) & $20 \%$ & 4 & 0.80 \\
\hline Acceso a tecnología de punta & $5 \%$ & 3 & 0.15 \\
\hline Acceso a equipos & $5 \%$ & 3 & 0.15 \\
\hline Regulaciones gubernamentales de entrada/renovación & $5 \%$ & 2 & 0.10 \\
\hline Regulaciones gubernamentales para operación & $5 \%$ & 2 & 0.10 \\
\hline Globalización (riesgo de...) & $15 \%$ & 4 & 0.60 \\
\hline Efecto de la experiencia (curva de aprendizaje) & $20 \%$ & 3 & 0.60 \\
\hline TOTAL & $100 \%$ & & 3.10 \\
\hline
\end{tabular}

Nota: Basado en el análisis de Porter, adaptado de Administración Estratégica (p. 62), por Thompson, Peteraf, Gamble \& Strickland, 2012, México: Mc Graw Hill. Copyright 2012 por Mc Graw Hill / Interamericana Editores S.A. de C.V. Elaboración propia.

Conclusión: Los factores de las barreras de entrada son neutrales para el CVH. 


\subsubsection{Clientes}

Tabla 22

Poder de los clientes

\begin{tabular}{|l|c|c|c|}
\hline \multicolumn{1}{|c|}{ Factores } & Peso & Calificación & $\begin{array}{c}\text { Puntaje } \\
\text { ponderado }\end{array}$ \\
\hline Número de clientes importantes & & & \\
\hline - Personas naturales/jurídicas que buscan el servicio & $13 \%$ & 1 & 0.13 \\
\hline - Empresas e Instituciones del Estado Peruano & $5 \%$ & 5 & 0.25 \\
\hline Propensión del cliente al uso de sustitutos & $18 \%$ & 4 & 0.72 \\
\hline Costo del cambio & $18 \%$ & 1 & 0.18 \\
\hline Sensibilidad del cliente al precio & $18 \%$ & 1 & 0.18 \\
\hline Diferenciación del servicio & $18 \%$ & 3 & 0.54 \\
\hline Amenaza del cliente de integrarse hacia atrás & $10 \%$ & 5 & 0.50 \\
\hline TOTAL & $100 \%$ & & 2.50 \\
\hline
\end{tabular}

Nota: Basado en el análisis de Porter, adaptado de Administración Estratégica (p. 69), por Thompson, Peteraf, Gamble \& Strickland, 2012, México: Mc Graw Hill. Copyright 2012 por Mc Graw Hill / Interamericana Editores S.A. de C.V. Elaboración propia.

La siguiente ponderación fue dada con un colaborador del CVH, Sr. Pedro Castellanos.

\begin{tabular}{|l|c|c|c|}
\hline \multicolumn{1}{|c|}{ Factores } & Peso & Calificación & $\begin{array}{c}\text { Puntaje } \\
\text { ponderado }\end{array}$ \\
\hline Número de clientes importantes & & & \\
\hline - Personas naturales/jurídicas que buscan el servicio & $13 \%$ & 2 & 0.26 \\
\hline - Empresas e Instituciones del Estado Peruano & $5 \%$ & 5 & 0.25 \\
\hline Propensión del cliente al uso de sustitutos & $18 \%$ & 4 & 0.72 \\
\hline Costo del cambio & $18 \%$ & 2 & 0.36 \\
\hline Sensibilidad del cliente al precio & $18 \%$ & 2 & 0.36 \\
\hline Diferenciación del servicio & $18 \%$ & 3 & 0.54 \\
\hline Amenaza del cliente de integrarse hacia atrás & $10 \%$ & 4 & 0.40 \\
\hline TOTAL & $100 \%$ & & 2.89 \\
\hline
\end{tabular}

Nota: Basado en el análisis de Porter, adaptado de Administración Estratégica (p. 69), por Thompson, Peteraf, Gamble \& Strickland, 2012, México: Mc Graw Hill. Copyright 2012 por Mc Graw Hill / Interamericana Editores S.A. de C.V. Elaboración propia.

Conclusión: El poder de los clientes con respecto a la atractividad del sector es neutral, pero el CVH debe de modernizarse para evitar que los clientes quieran ir a la competencia. 


\subsubsection{Proveedores}

Tabla 23

Poder de los proveedores

\begin{tabular}{|c|c|c|c|}
\hline Factores & Peso & falificación & $\begin{array}{c}\text { Puntaje } \\
\text { ponderado }\end{array}$ \\
\hline \multicolumn{4}{|l|}{ Número de proveedores importantes de: } \\
\hline - Alimentos y bebidas, viveres & $10 \%$ & 3 & 0.30 \\
\hline - Lenceria para las habitaciones: sabanas, colchones, etc. & $10 \%$ & 3 & 0.30 \\
\hline \multicolumn{4}{|l|}{ Disponibilidad de sustitutos de proveedores } \\
\hline - Alimentos y bebidas, viveres & $10 \%$ & 1 & 0.10 \\
\hline - Lenceria para las habitaciones: sabanas, colchones, etc. & $15 \%$ & 1 & 0.15 \\
\hline Costo de cambio de proveedor & $10 \%$ & 2 & 0.20 \\
\hline Amenaza de proveedores de integrarse hacia adelante & $5 \%$ & 3 & 0.15 \\
\hline Amenaza de la industria de integrarse hacia atrás & $5 \%$ & 2 & 0.10 \\
\hline Contribución de los proveedores a la calidad o servicio & $15 \%$ & 2 & 0.30 \\
\hline Contribución de los costos por parte de los proveedores & $15 \%$ & 5 & 0.75 \\
\hline Importancia de la industria a la rentablilidad de los proveedores & $5 \%$ & 1 & 0.05 \\
\hline TOTAL & $100 \%$ & & 2.40 \\
\hline
\end{tabular}

Nota: Basado en el análisis de Porter, adaptado de Administración Estratégica (p. 66), por Thompson, Peteraf, Gamble \& Strickland, 2012, México: Mc Graw Hill. Copyright 2012 por Mc Graw Hill / Interamericana Editores S.A. de C.V. Elaboración propia.

La siguiente ponderación fue dada con un colaborador del CVH, Sr. Pedro Castellanos.

\begin{tabular}{|c|c|c|c|}
\hline Factores & Peso & Falificaciór & $\begin{array}{c}\text { Puntaje } \\
\text { ponderado }\end{array}$ \\
\hline \multicolumn{4}{|l|}{ Número de proveedores importantes de: } \\
\hline - Alimentos y bebidas, viveres & $10 \%$ & 3 & 0.30 \\
\hline - Lenceria para las habitaciones: sabanas, colchones, etc. & $10 \%$ & 4 & 0.40 \\
\hline \multicolumn{4}{|l|}{ Disponibilidad de sustitutos de proveedores } \\
\hline - Alimentos y bebidas, viveres & $10 \%$ & 2 & 0.20 \\
\hline - Lenceria para las habitaciones: sabanas, colchones, etc. & $15 \%$ & 2 & 0.30 \\
\hline Costo de cambio de proveedor & $10 \%$ & 3 & 0.30 \\
\hline Amenaza de proveedores de integrarse hacia adelante & $5 \%$ & 2 & 0.10 \\
\hline Amenaza de la industria de integrarse hacia atrás & $5 \%$ & 3 & 0.15 \\
\hline Contribución de los proveedores a la calidad o servicio & $15 \%$ & 1 & 0.15 \\
\hline Contribución de los costos por parte de los proveedores & $15 \%$ & 4 & 0.60 \\
\hline Importancia de la industria a la rentablilidad de los proveedores & $5 \%$ & 2 & 0.10 \\
\hline TOTAL & $100 \%$ & & 2.60 \\
\hline
\end{tabular}

Nota: Basado en el análisis de Porter, adaptado de Administración Estratégica (p. 66), por Thompson, Peteraf, Gamble \& Strickland, 2012, México: Mc Graw Hill. Copyright 2012 por Mc Graw Hill / Interamericana Editores S.A. de C.V. Elaboración propia.

Conclusión: El poder de negociación de los proveedores es neutral ya que en el mercado existen variedad de proveedores con diferentes características y precio. 


\subsubsection{Competencias en el mismo sector}

Tabla 24

Poder de los competidores

\begin{tabular}{|l|c|c|c|}
\hline \multicolumn{1}{|c|}{ Factores } & Peso & Calificación & $\begin{array}{c}\text { Puntaje } \\
\text { ponderado }\end{array}$ \\
\hline Número de competidores iguales & $15 \%$ & 4 & 0.60 \\
\hline Crecimiento relativo de la industria & $20 \%$ & 1 & 0.20 \\
\hline Costo fijos & $10 \%$ & 4 & 0.40 \\
\hline Características del servicio & $15 \%$ & 3 & 0.45 \\
\hline Capacidad de producción & $10 \%$ & 2 & 0.20 \\
\hline Diversidad de competidores & $15 \%$ & 4 & 0.60 \\
\hline Compromisos estratégicos & $15 \%$ & 5 & 0.75 \\
\hline TOTAL & $100 \%$ & & 3.20 \\
\hline
\end{tabular}

Nota: Basado en el análisis de Porter, adaptado de Administración Estratégica (p. 57), por Thompson, Peteraf, Gamble \& Strickland, 2012, México: Mc Graw Hill. Copyright 2012 por Mc Graw Hill / Interamericana Editores S.A. de C.V. Elaboración propia.

La siguiente ponderación fue dada con un colaborador del CVH, Sr. Pedro Castellanos.

\begin{tabular}{|l|c|c|c|}
\hline \multicolumn{1}{|c|}{ Factores } & Peso & Calificación & $\begin{array}{c}\text { Puntaje } \\
\text { ponderado }\end{array}$ \\
\hline Número de competidores iguales & $15 \%$ & 4 & 0.60 \\
\hline Crecimiento relativo de la industria & $20 \%$ & 2 & 0.40 \\
\hline Costo fijos & $10 \%$ & 3 & 0.30 \\
\hline Características del servicio & $15 \%$ & 3 & 0.45 \\
\hline Capacidad de producción & $10 \%$ & 2 & 0.20 \\
\hline Diversidad de competidores & $15 \%$ & 4 & 0.60 \\
\hline Compromisos estratégicos & $15 \%$ & 4 & 0.60 \\
\hline TOTAL & $100 \%$ & & 3.15 \\
\hline
\end{tabular}

Nota: Basado en el análisis de Porter, adaptado de Administración Estratégica (p. 57), por Thompson, Peteraf, Gamble \& Strickland, 2012, México: Mc Graw Hill. Copyright 2012 por Mc Graw Hill / Interamericana Editores S.A. de C.V. Elaboración propia.

Conclusión: Muestra ser un sector atractivo debido al crecimiento del mercado y al bajo número de competidores. 


\subsection{Matriz de atractividad de cada una de las cinco fuerzas}

Tabla 25

Matriz de atractividad

\begin{tabular}{|l|c|c|}
\hline \multicolumn{1}{|c|}{ Factores } & Puntaje & Grado \\
\hline Barreras de entrada & 3.40 & Atractiva \\
\hline Rivalidad entre competidores & 3.20 & Atractiva \\
\hline Poder de los proveedores & 2.40 & Poco atractivo \\
\hline Poder de los compradores & 2.50 & Poco atractivo \\
\hline Disponibilidad de sustitutos & 3.50 & Muy atractiva \\
\hline TOTAL & 3.00 & \\
\hline
\end{tabular}

Nota: Basado en el análisis de Porter, adaptado de Administración Estratégica (p. 55), por Thompson, Peteraf, Gamble \& Strickland, 2012, México: Mc Graw Hill. Copyright 2012 por Mc Graw Hill / Interamericana Editores S.A. de C.V. Elaboración propia.

\subsection{Análisis del Grado de atractividad de la industria}

El resultado del análisis del grado de atractividad de la industria muestra que los factores que tienen mayor impacto a la industria del CVH son las barreras de entrada y la poca rivalidad entre los actuales competidores.

Con el desarrollo de estrategias de diferenciación y una ventaja competitiva se podrá lograr la los objetivos planteados para el CVH.

\subsection{Matriz de Perfil Competitivo MPC}

En la siguiente matriz se indicarán 9 factores claves de éxito que se compararán con 2 empresas de la competencia del rubro de convenciones (Swissotel y Centro de Convenciones Javier Prado) por su buena ubicación y por estar enfocados a la realización de eventos a instituciones. 
Tabla 26

Matriz perfil competitivo (MPC)

\begin{tabular}{|c|c|c|c|c|c|c|c|}
\hline \multicolumn{8}{|l|}{ Matriz PC del CVH } \\
\hline \multirow[t]{2}{*}{ Factores claves de éxito } & \multirow[b]{2}{*}{ Peso } & \multicolumn{3}{|c|}{$\mathrm{CVH}$} & \multicolumn{2}{|c|}{ Swissotel Lima } & \multirow{2}{*}{$\begin{array}{l}\text { Centro de } \\
\text { Convenciones } \\
\text { Javier Prado } \\
\text { Pond. }\end{array}$} \\
\hline & & Valor & Pond. & Valor & Pond. & Valor & \\
\hline Desarrollo e inversión en tecnología. & 0.17 & 1 & 0.17 & 2 & 0.34 & 3 & 0.51 \\
\hline $\begin{array}{l}\text { Cadena de valor (distribución, } \\
\text { comercialización, equipos). }\end{array}$ & 0.15 & 1 & 0.15 & 2 & 0.30 & 3 & 0.45 \\
\hline Calidad del servicio al cliente. & 0.12 & 2 & 0.24 & 3 & 0.36 & 3 & 0.36 \\
\hline $\begin{array}{l}\text { Disponibilidad de áreas y factores } \\
\text { climáticos favorables. }\end{array}$ & 0.11 & 3 & 0.33 & 3 & 0.33 & 3 & 0.33 \\
\hline Variedad de servicios. & 0.13 & 4 & 0.52 & 3 & 0.39 & 3 & 0.39 \\
\hline Bajos costos logísticos. & 0.11 & 1 & 0.11 & 3 & 0.33 & 3 & 0.33 \\
\hline Capacidad financiera. & 0.08 & 1 & 0.08 & 2 & 0.16 & 3 & 0.24 \\
\hline Participación de mercado. & 0.07 & 1 & 0.07 & 3 & 0.21 & 3 & 0.21 \\
\hline Costos de mano de obra. & 0.06 & 3 & 0.18 & 2 & 0.12 & 2 & 0.12 \\
\hline Total & & 1.00 & & 1.85 & & 2.52 & 2.94 \\
\hline
\end{tabular}

Nota. Adaptado de Administración estratégica (p. 83), por F. David, 2013, México, Pearson Educación. Copyright 2013 por Pearson Educación. Elaboración propia

El resultado de 1.85 coloca al CVH en el último lugar, al competir con Swissotel y el Centro de Convenciones Javier Prado, que son parte de la competencia con servicios bien consolidados en el mercado nacional. Se observa que la ventaja más importante de dichas instalaciones es la calidad de servicio al cliente. Por el contrario, se debe destinar fondos en tecnología e investigación y disminuir sus costos logísticos para lograr ser un buen competidor. 


\section{CAPÍTULO VI \\ ANÁLISIS INTERNO}

\subsection{Descripción de las actividades de la cadena de valor de la empresa.}

\subsubsection{Logística interna}

Por medio de esta área se puede tener un control de los servicios que se realizarán en el CVH y de esa manera va a permitir tener un alto grado de calidad y que los recursos sean aprovechados al máximo. Para cumplir con la logística interna, se realizaran las siguientes actividades:

- Marketing y ventas: El CVH tiene el servicio de un encargado de eventos, el cual tiene la función de contactar, negociar, guiar y concretar los eventos para así fidelizar a los clientes.

Además, esta área se encargará de realizar el servicio de post venta, el cual nos permitirá contar con un feedback de nuestros clientes y nos ayudará a mejorar nuestros servicios y así poder obtener más clientes frecuentes.

- Personal de contacto y servicio: Los colaboradores tiene la facultad para la recepción de los clientes y brinden información sobre las instalaciones, servicios y eventos a realizar.

- Soporte físico: Realizado por el servicio en habitaciones, por medio del sistema de registro de clientes (check in), además las habitaciones cuentan sistemas de seguridad como caja fuerte.

- Prestación del servicio: La finalidad de la organización es prestar un alto servicio de calidad a sus clientes cumpliendo su necesidades y expectativas, ofreciendo variedad en sus servicios y en una infraestructura segura.

Se van a realizar estas actividades:

- Variedad de servicios: hospedaje, restaurante, juegos recreativos, canchas de fulbito, piscina, discoteca y salas para eventos. 
- Estrategias de precios para clientes corporativos.

- Precios competitivos de acuerdo a la competencia.

- Control en costos operativos, se busca tener una buena comunicación con los proveedores del CVH.

- Servicios logísticos va a ayudar a mejor la rapidez, eficacia y seguridad n la entrega d los servicios.

- Cuenta con constante mantenimiento de las instalaciones del CVH, habitaciones, piscina, los auditorios, para poder mantener la calidad en las instalaciones del CVH.

- Control de calidad de las instalaciones y servicios que se darán antes de ser ofrecidos al público interno y externo.

- El transporte es tercerizado para los que se trasladen desde una ubicación en cualquier distrito de Lima. El CVH no cuenta con unidades propias, por lo tanto, cuando el cliente solicita el servicio de transporte se solicita apoyo a una empresa de turismo y el costo se incluye en el presupuesto que se le entregue al cliente.

\subsubsection{Análisis de las actividades de apoyo}

\section{Abastecimiento}

El CVH cuenta con proveedores con alto nivel de calidad los cuales permite brindar un servicio de calidad y obtener la satisfacción del cliente. Con este proceso bien establecido, ayuda a que el CVH tenga una ventaja competitiva con respecto a los estándares de calidad en infraestructura, insumos y servicios. 


\section{Tecnología}

Se cuenta con sistemas eléctricos de seguridad (grupo electrógeno propio) en todo el contorno de las áreas del $\mathrm{CVH}$ con la finalidad de salvaguardar los activos que se tienen. También las oficinas y la caseta de seguridad mantienen computadoras personales que permiten desarrollar la gestión administrativa.

\section{Gestión de recursos humanos}

El área de recursos humanos va a tomar como prioridad contratar a colaboradores que tengan estudios y experiencia en el rubro de hospedaje y convenciones.

Además, va a realizar constantes capacitaciones a los colaboradores, y va a realizar actividades de integración y programas de motivación.

\section{Infraestructura directiva}

Se cuenta con instalaciones distribuidas en 31 hectáreas ubicadas en Huampaní, donde se tienen los almacenes, oficinas administrativas, discoteca, canchas de fútbol, sala de eventos, comedores y los bungalows. 
Tabla 27

Análisis de la Cadena de Valor del CVH

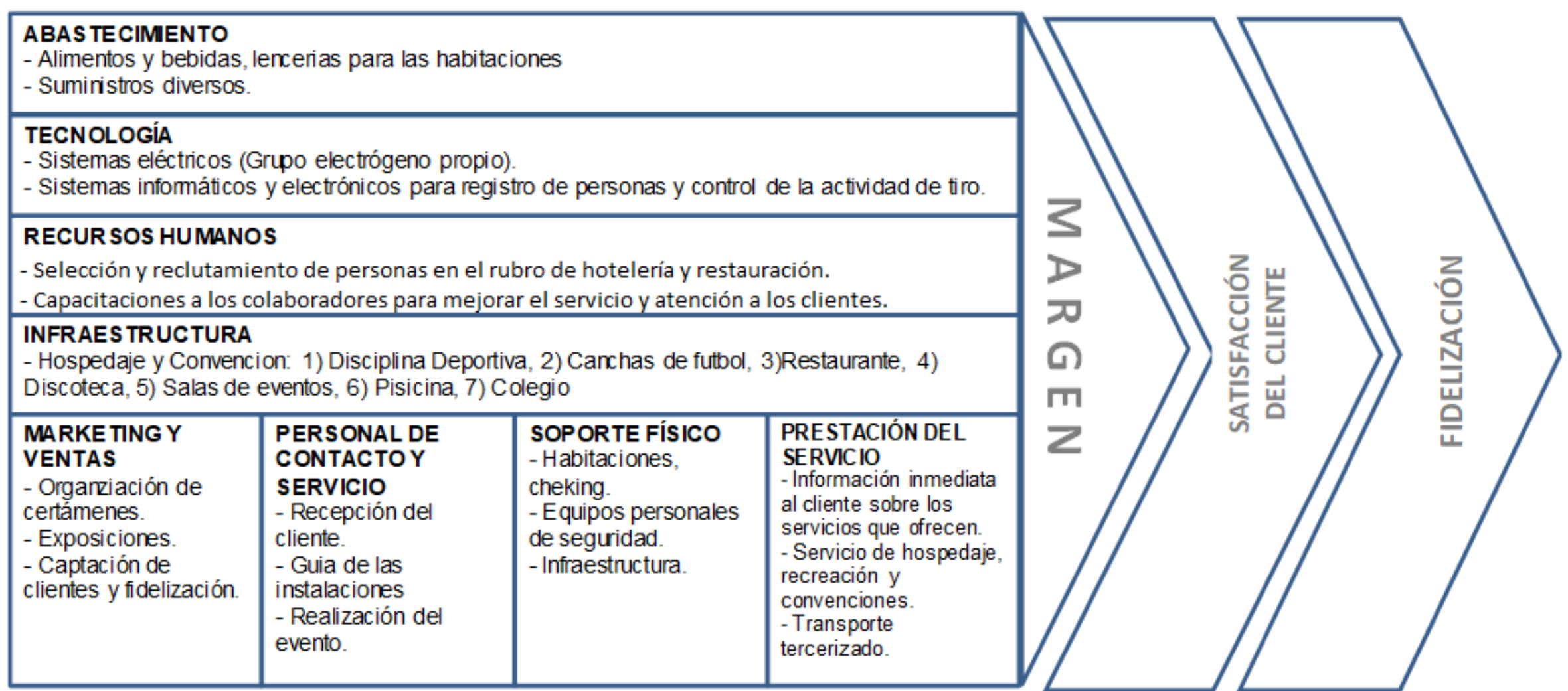

Fuente: Eaboración propia

Nota. Adaptado de Administración estratégica (p. 108), por Thompson, Peteraf, Gamble \& Strickland, 2012, México: Mc Graw Hill Educación. Copyright 2012 por Mc Graw-Hill Interamericana Editores S.A. de C.V. Elaboración propia 


\subsection{Indicadores de cada una de las actividades de la cadena de valor}

- Para el CVH, los colaboradores son un factor importante ya que de ellos depende el servicio que brindara. El proceso de selecciones es por medio de convocatoria publicadas en el portal de Transparencia del CVH y en diarios locales, y la contratación es por CAS.

- El personal que se contrate, debe encajar en el perfil de cada puesto. "Las competencias centrales son cualidades intrínsecas del grupo empresarial que lo impulsan al éxito económico, y estas cualidades se expresan a través del aprendizaje colectivo en la organización del CVH, específicamente cómo coordinar diversas habilidades de producción e integrar múltiples corrientes de tecnología en las empresas de grupo y en los productos finales". (Álvarez, 2003: 126).

\subsection{Benchmarking y comparación con los líderes de la industria de cada una de las} actividades de la cadena de valor

En este punto, se busca agrupar a las empresas diferenciándolas en sus atributos y dependerá de ello, el grupo en que se les asigne.

Según Thompson y Strickland, en la tabla 28 se ha realizado un análisis comparativo del $\mathrm{CVH}$ con dos de sus competencias. Las ponderaciones establecidas son de 0 a 3 , siendo el valor 3 muy bien implementado, 2 lo consideran pero necesita mejorar, 1 lo consideran eventualmente y 0 no lo consideran. Con estos resultados nos permite ver las fortelzar y debilidades del CVH en relación a la competencia y de esta forma va a ayudar a mejorar en las debilidades. 
Tabla 28

Benchmarking y comparación con los líderes

\begin{tabular}{|c|c|c|c|}
\hline Actividades en la cadena de valor & $\mathrm{CVH}$ & Swissotel Lima & $\begin{array}{c}\text { Centro } \\
\text { Convenciones } \\
\text { Javier Prado }\end{array}$ \\
\hline Marketing y ventas & 1 & 3 & 3 \\
\hline Personal de contacto y servicio & 2 & 3 & 3 \\
\hline \multicolumn{4}{|l|}{ Soporte Físico: } \\
\hline - Servicio de habitaciones & 2 & 3 & 2 \\
\hline - Check In & 2 & 2 & 2 \\
\hline - Equipos personales de seguridad & 2 & 3 & 2 \\
\hline - Infraestructura & 2 & 3 & 3 \\
\hline \multicolumn{4}{|l|}{ Prestación de servicios: } \\
\hline - Hospedaje & 2 & 3 & 3 \\
\hline - Restaurante & 2 & 3 & 3 \\
\hline - Juegos recreativos & 3 & 1 & 1 \\
\hline - Canchas de fulbito & 3 & 2 & 2 \\
\hline - Piscina & 2 & 3 & 3 \\
\hline - Discoteca & 2 & 1 & 1 \\
\hline - Sala para eventos & 2 & 3 & 3 \\
\hline - Estrategia de precios & 2 & 2 & 2 \\
\hline - Servicios logísticos & 2 & 2 & 2 \\
\hline - Transporte & 0 & 3 & 3 \\
\hline \multicolumn{4}{|l|}{ Abastecimiento: } \\
\hline - Planificación de mantenimiento & 2 & 3 & 3 \\
\hline - Empresas prestadoras de servicios & 2 & 3 & 3 \\
\hline - Calidad de servicio & 2 & 3 & 2 \\
\hline - Seguridad del servicio & 2 & 3 & 2 \\
\hline \multicolumn{4}{|l|}{ Tecnologia: } \\
\hline - Sistemas eléctricos de seguridad & 2 & 3 & 3 \\
\hline - Equipos informáticos administrativos & 2 & 3 & 3 \\
\hline - Equipos informáticos para el servicio & 1 & 3 & 3 \\
\hline \multicolumn{4}{|l|}{ Gestión de Recursos Humanos: } \\
\hline - Participación de personal profesional & 2 & 3 & 2 \\
\hline - Compromiso laboral & 2 & 3 & 3 \\
\hline \multicolumn{4}{|l|}{ Infraestructura directiva: } \\
\hline - Amplitud de la instalaciones & 3 & 2 & 2 \\
\hline $\begin{array}{c}\text { Puntos Totales } \\
\end{array}$ & 51 & 69 & 64 \\
\hline
\end{tabular}

$0=$ No lo consideran, $1=$ Lo consideran eventualmente, $2=$ Lo consideran pero necesita mejorar

$3=$ Muy bien implementado

Nota. Adaptado de Administración estratégica (p. 112), por Thompson, Peteraf, Gamble \& Strickland, 2012, México: Mc Graw Hill Educación. Copyright 2012 por Mc Graw-Hill Interamericana Editores S.A. de C.V. Elaboración propia 


\subsection{Determinar las competencias de la empresa}

La estrategia que vamos a plantear para el CVH es la diferenciación, orientada en la calidad del servicio y se contara con apoyo de la tecnología, capacitaciones y también se implementara la estrategia de penetración permitiéndonos establecer precios poco inferiores a comparación de la competencia para así incrementarlos.

\subsection{Identificación y determinación de las ventajas competitivas de la empresa}

Para lograr la ventaja competitiva el CVH se guiará de los siguientes elementos:

\section{a) Logro de eficiencia superior}

Se busca desarrollar las competencias de los colaboradores por medio de constantes capacitaciones para mejorar e innovar el servicio y trato al cliente y esto genere lealtad del cliente y compromiso por parte de los colaboradores.

\section{b) Logro de calidad superior}

- Enfocado en contar con equipos de calidad y concentrarnos en el logro de la calidad total en los servicios para lograr un liderazgo participativo.

\section{c) Ventaja competitiva a nivel de negocios}

Nuestra ventaja competitiva es la diferenciación y enfoque. Con respecto a la diferenciación en el CVH, se logará por medio de modernizar la infraestructura, tecnología moderna y contacto con colaboradores con altos conocimientos del rubro. El enfoque en el mercado a organizaciones estatales y personas naturales que busquen la realización de convenciones y/o eventos, también en el servicio de hospedaje.

\subsection{Matriz de Evaluación de Factores Internos EFI}

En la matriz EFI “evaluaremos las fortalezas y debilidades para el CVH. Luego lo comparamos con la matriz EFI para que nos oriente a la selección de la estrategia. 
Según David (2013), la matriz EFI ayuda a identificar los factores importantes y con estos resultados podemos determinar la posición competitiva del CVH.

Para identificar las debilidades y fortalezas del CVH se realizaron los siguientes pasos:

- Se seleccionaron las fortalezas y debilidades del CVH.

- Luego se le asigna un peso el cual el total debe de dar el 100 por ciento.

- $\quad$ Lo siguiente es ponderar. Para las debilidades de 0 a 2 y para las fortalezas de 3 a 4

- Los valores se multiplican con el peso y luego se suman los valores para cada una de las actividades.

- $\quad$ Si el total es mayor 2.5 se considera que el CVH se encuentra en una posición competitiva alta en el mercado y si el valor es menor, el CVH estaría en una posición débil en el mercado.

Tabla 29

Matriz evaluación de factores internos para el CVH

MATRIZ DE EVALUACIÓN DEFACTORES INTERNOS

(Matriz EFI)

\begin{tabular}{|c|c|c|c|}
\hline Matriz EFI del CVH & PESO & CALIFICACIÓN & $\begin{array}{c}\text { PESO } \\
\text { PONDERADO }\end{array}$ \\
\hline \multicolumn{4}{|l|}{ FORTALEZAS } \\
\hline Infraestructura moderna y segura. & $9 \%$ & 4 & 0.36 \\
\hline Centro de Convenciones con capacidad masiva sobre 4 mil asistentes & $21 \%$ & 4 & 0.84 \\
\hline Servicio de alto nivel. & $15 \%$ & 4 & 0.60 \\
\hline Bajos costos por "tercerización" & $15 \%$ & 4 & 0.60 \\
\hline Colaboradores adecuado y calificado & $7 \%$ & 4 & 0.28 \\
\hline Estrategia con empresas institucionales & $8 \%$ & 4 & 0.32 \\
\hline \multicolumn{4}{|l|}{ DEBILIDADES } \\
\hline Falta de sistemas actualizados & $5 \%$ & 2 & 0.10 \\
\hline Deficiencia del stema de medios de transporte para ir al CVH & $4 \%$ & 1 & 0.04 \\
\hline Pocas estrategias de marketing & $4 \%$ & 2 & 0.08 \\
\hline Falta de capacitación especializada y financiada por el CVH & $6 \%$ & 1 & 0.06 \\
\hline Curva de experiecia reciente. & $6 \%$ & 1 & 0.06 \\
\hline TOTAL & $100 \%$ & & 3.34 \\
\hline
\end{tabular}

$4=$ una respuesta superior, $3=$ una respuesta superior a la media, $2=$ una respuesta media y $1=$ mala respuesta

Nota. Adaptado de Administración estratégica (p. 123), por F. David, 2013, México, Pearson Educación. Copyright 2013 por Pearson Educación. Elaboración propia 
Conclusión: El resultado 3.34 indica que las fortalezas son superiores a las debilidades. Se puede apreciar que las fortalezas tienen una calificación similar y esto equilibra asignar los recursos estratégicamente 


\section{CAPÍTULO VII}

\section{FORMULACIÓN DE LOS OBJETIVOS Y DISEÑO DE LAS ESTRATEGIAS}

\subsection{Alcance y planteamiento de los objetivos estratégicos}

\subsubsection{Objetivos estratégicos}

\section{a) Perspectiva financiera}

- Aumento de rentabilidad a 19.97\% a finales del 2021.

- $\quad$ Aumento de Ingresos a 18\% a finales del 2021.

- Disminución de gastos operativos a 6\% a finales del 2021.

Los objetivos de la perspectiva financiera que se plantean obedecen a un análisis histórico realizado, tomando en cuenta los Estados Financieros históricos de los años 2007 - 2015. El crecimiento en este escenario normal obedece a una perspectiva de sostenimiento moderado, tomando en cuenta indicadores que pueden ir crecimiento de manera conforme el mercado lo permite.

\section{b) Perspectiva clientes}

- Fidelización de clientes a 40\% a finales del 2021.

- Incremento en la satisfacción del cliente a 100\% a finales del 2021.

- Aumentar la cuota de mercado del rubro de Convenciones del CVH a 52\% a finales del 2021.

Los objetivos relacionados con la perspectiva del cliente han sido estandarizados tomando en cuenta la información proporcionada por los encargados del CVH. La cuota de mercado a la que se hace referencia se basa en el portafolio de productos que tiene la institución. Por lo tanto, se debe determinar que una buena parte de los ingresos que generan rentabilidad se encuentran sostenidos en el rubro de la realización de Convenciones. La información referencial que sustenta los porcentajes de crecimiento se basa calculando la facturación de la industria de reuniones de Lima en el rubro de Convenciones que se generó en los últimos 
cinco años llegándose a facturar 2,000 millones de dólares en ingresos para la actividad en estudio (Canales, 2016). La participación total de mercado al 2021 proyecta crecer en un nivel de facturación de S/. 2,102,531,406 millones, en proyección el CVH debería tomar una cuota de mercado en un orden de $30 \%$, en concordancia con otros indicadores como el crecimiento de ventas se estaría creciendo en un orden del 2.0 por ciento mensual.

\section{c) Procesos internos}

- A finales del 2021 se tiene la meta de atender al 100\% a clientes corporativos.

- A finales del 2021 se va a mejorar los instructivos de abastecimiento y seguridad de insumos.

En el producto Convenciones, los clientes corporativos son los que le dan un mayor soporte de ingresos al CVH, la realización de este tipo de eventos permitirá cumplir con el logro de las metas que se plantean para poder ejecutar el plan estratégico en estudio.

\section{d) Aprendizaje y desarrollo}

- Mejorar los sistemas en la empresa del ERP (SAP) en el 100\% de las áreas.

- Implementar el ISO 9001.2015 a través de la autorregulación de los procesos en un $100 \%$.

- Aumentar productividad de los colaboradores al 100\%.

- Progreso en el desarrollo de habilidades a través de capacitaciones a los colaboradores.

- Manejo del conocimiento por sistema de información aumentando la inversión en $10 \%$.

- Las metas personales deben estar alineadas con los objetivos de la institución a un $90 \%$. 
Es importante contar con colaboradores que se encuentren comprometidos con el CVH, esta perspectiva va de la mano con el desarrollo de la imagen institucional que debe fortalecer el CVH.

\subsubsection{Análisis de los objetivos estratégicos}

\section{a) Perspectiva financiera}

- $\quad$ Aumento de la rentabilidad a 19.97\% a finales del año 2021.

- $\quad$ Aumento de los Ingresos a 18\% a finales del año 2021.

La estrategia del crecimiento de los ingresos se debe al aumento de las estrategias del equipo de marketing al generar que los clientes perciban mejor calidad en los servicios que brinda el CVH y de esta manera crear clientes fidelizados. También la estrategia es aumentar la cuota del mercado por medio de alianzas estratégicas con empresas dirigidas a la captación de clientes corporativos para la realización de eventos.

- Disminución de gastos operativos a 6\% a finales del 2021.

El CVH para reducir los costos logísticos va a priorizar en tercerizar los procesos para obtener un ahorro del 6\% en relación con los gastos operativos actuales (S/. 150,000). De tal manera que todo el equipo del CVH esté preparado en el negocio en sí.

Se deben ejecutar los objetivos específicos a continuación:

- Optimizar la rentabilidad.

- Aumento de ingresos (introducir venta de paquetes corporativos en clientes nuevos o instituciones en las que actualmente no se tiene presencia).

- Reducción de gastos operativos.

Indicadores estratégicos:

- Incremento de ingresos del CVH.

- Disminución de gastos operativos. 
- EVA (Economic Value Added)

- Incremento de la Rentabilidad

Se va a tomar como referencia los resultados de los últimos cuatro años del CVH ya que al obtener los indicadores históricos va a servir a determinar y lograr las metas. Las estrategias que tiene el CVH son el crecimiento de ingresos y la reducción de gastos operativos para así lograr el incremento de las utilidades a $18 \%$.

\section{b) Perspectiva clientes}

- Fidelización de clientes a 40\% a finales del 2021.

La cartera de clientes del CVH ha crecido en los últimos años debido que cuenta con clientes corporativos fidelizados.

En estos últimos años, Perú ha sido sede de diversos eventos internacionales, atendidos por la competencia, por eso una de las estrategias de fidelización es aumentar el desarrollo de eventos y conferencias.

- Aumento de satisfacción del cliente a 10 puntos a finales del 2021.

Los indicadores estratégicos:

- Número de clientes fidelizados.

- Nivel de satisfacción de clientes.

- Aumentar la cuota de mercado a 52\% a finales del 2021

Se va a desarrollar la estrategia de investigación de mercado, realizando un seguimiento de todos los proyectos que ameritan ser presentados en conferencias y se realicen en centros de convenciones que se vienen trabajando en el Perú, esta estrategia definitivamente incrementa las probabilidades de que cuando los clientes puedan contratar las instalaciones del $\mathrm{CVH}$ para sus presentaciones. Así mismo, otra estrategia para incrementar la cuota de mercado proveniente de la investigación de mercado es la incursión en el mercado empresarial ofreciendo la realización de eventos ya sean capacitaciones, conferencias, 
presentaciones, etc. Además, el CVH debe de tener buenas relaciones con sus clientes actuales y potenciales.

Indicadores estratégicos:

- Porcentaje de participación de mercado (número de clientes)

\section{c) Procesos internos}

- Atención general a clientes corporativos a 100\% a finales del 2021.

El CVH tiene que implementar estrategias con ventajas competitivas que permitan tener información de sus clientes y brindar la información a sus clientes en el momento que ellos soliciten para así dar respuestas a sus inquietudes y/o quejas, de esta manera se logre la satisfacción de los clientes y captar nuevos clientes.

Indicador estratégico:

- Número de clientes que se brindó el servicio diferenciado entre el total de clientes.

- Proceso de suministro y seguridad de insumos a 100\% en el 2021.

El CVH elaborará manuales del buen uso de insumos para el restaurante y lavandería para asegurar la seguridad de los colaboradores y clientes. Se implementará reportes de uso de los insumos, traslados y manipulación para así evitar incidencias ya que uno de los objetivos del CVH es mantener cero incidencias.

\section{d) Aprendizaje y desarrollo}

- Aumentar productividad de los colaboradores al 100\%.

Para el área de Recursos Humanos, es importante que los colaboradores cuenten con competencias como habilidades, talentos y conocimientos para desarrollar la estrategia.

El objetivo de recursos humanos es:

Por medio de la capacitación a los colaboradores, se va a desarrollar y mejorar sus competencias, con la finalidad de acercarnos a los clientes fidelizados y potenciales clientes. 
- Con los programas de capacitación, se busca cubrir las brechas de competencia en un $100 \%$ en el año 2021

- Desarrollo de habilidades a través de la capacitación del personal al 100\%.

El CVH va a desarrollar actividades relacionadas a mejorar el clima laboral para cumplir con su objetivo de contar con colaboradores identificados con la organización y constante evaluará el grado de compromiso por medio de encuestas.

Se programarán capacitaciones constantes y recompensas para mejorar el servicio y motivar a los colaboradores a mejoras continuas.

- Manejo del conocimiento por sistema de información aumentando la inversión en $10 \%$.

A partir del último trimestre del 2017, se iniciará la ejecución de un nuevo y potente sistema de información ERP que reemplazará al actualmente existente sistema de información (antigüedad de 10 años), el cual significará una importante inversión (aprox. US\$ 6,000.00) para el CVH, pero el cual repercutirá en el plan de modernización a que el CVH esté abocado, para afrontar retos que llegaran con el crecimiento y la cada vez más pujante competencia.

Una de las principales cualidades del ERP en el punto de vista comercial, logístico y de operaciones, es que el CVH prácticamente dinamizará una serie de operaciones logísticas, clientes y de producción. Esta forma de operar, la consideramos que dentro del rubro de servicios es una innovación, pero esto es viable gracias a la confianza que el CVH ha generado en estos últimos años.

- Las metas personales deben estar alineadas con los objetivos de la institución a un $90 \%$.

El CVH se enfoca en obtener colaboradores que tengan claros los objetivos y alineen las metas con ellas por medio del trabajo en equipo. 
La estrategia a usar es alinear los objetivos e incentivos con las estrategias del CVH.

Los colaboradores deben de ser conscientes que su desempeño ayuda a lograr los objetivos estratégicos del CVH y se han fijado incentivos, como brindar estudios de post grado y maestría para los colaboradores con alto desempeño.

El inductor de actuación es:

El CVH hará una encuesta de cima laboral y guiará todas sus actividades para lograr un indicador de $100 \%$ al 2021.

Con este indicador la empresa se concentrará a lograr un mejor ambiente de trabajo para todos y que después de un corto periodo los colaboradores tengan sus objetivos alineados con los de la empresa.

\subsection{Diseño y formulación de estrategias}

\subsubsection{Modelo del Océano Azul}

\subsubsection{Lienzo de la estrategia actual de la empresa}

El CVH tiene una variedad de particularidades ligadas a los cuatro componentes que lo conforman:

Gerencias: El directorio, representante del Ministerio de Educación, toman las decisiones junto con las gerencias.

Jefaturas: Designados de acuerdo a concurso y se encuentran con contrato CAS.

Empleados: Se encuentran distribuidos en las diferentes áreas y oficinas del CVH.

Operarios: Realizan la parte operativa en las diferentes áreas: jardinería, lavandería, cocina, limpieza, hotelería. 


\subsubsection{Matriz (eliminar, reducir, incrementar, crear)}

Tabla 30

Matriz de las cuatro acciones

\begin{tabular}{|l|l|}
\hline $\begin{array}{l}\text { Eliminar } \\
\text { Puestos de Gerencia y Jefaturas. }\end{array}$ & $\begin{array}{l}\text { Incrementar } \\
\text { Trabajo en equipo en el área de Recursos Humanos. } \\
\text { Puestos relacionados a la operación. } \\
\text { Capacitación en servicios y liderazgo logísticos y operativos. } \\
\text { Mejorar los procesos en la atención al cliente. }\end{array}$ \\
\hline $\begin{array}{l}\text { Reducir } \\
\text { La diferenciación entre áreas. }\end{array}$ & $\begin{array}{l}\text { Crear } \\
\text { Escalas de sueldos de acorde a las funciones e incentivos de } \\
\text { acuerdo al desempeño laboral } \\
\text { Incorporar sistemas tecnológicos que ayude a RRHH y a las } \\
\text { áreas operativas. } \\
\text { Implementar sistemas de información. }\end{array}$ \\
\hline
\end{tabular}

Nota. Adaptado de La Estrategia del Océano Azul (p. 39), por R. Mauborgne y W. Chan

Kim, 2013, México, Cargraphics S.A. de C.V. Copyright 2012 por Carbajal Educación S.A.S. Elaboración propia

\subsubsection{Lienzo de la nueva estrategia considerada}

La figura 5 muestra el lienzo de la nueva estrategia considerada, los datos se obtuvieron de la matriz de las 4 acciones. Muestra que acciones se deben de eliminar, reducir, incrementar y crear por medio de los cuadrantes que va desde muy alto a muy bajo.

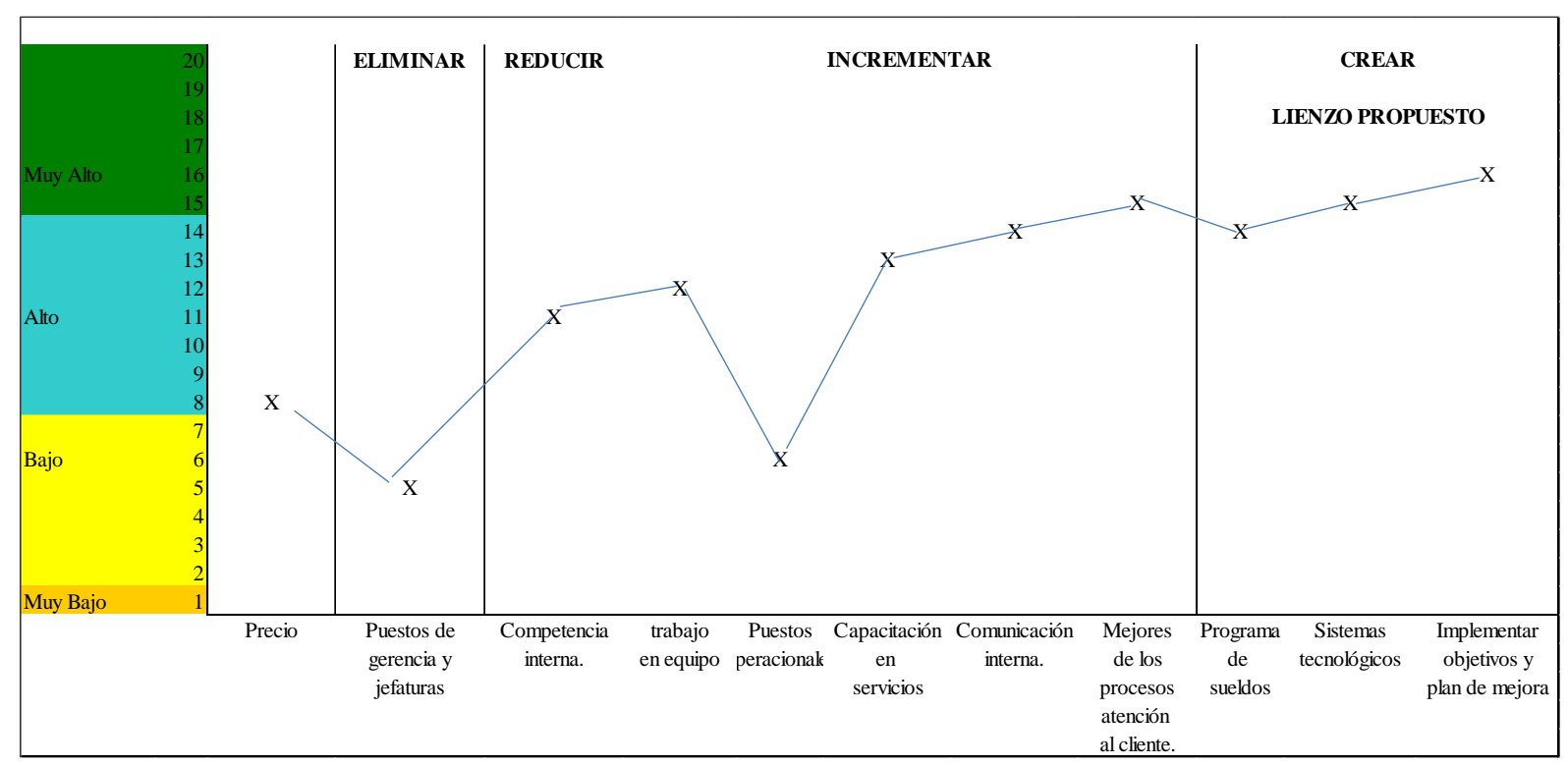

Figura 5. Lienzo de la nueva estrategia considerada

Nota. Adaptado de La Estrategia del Océano Azul (p. 35), por R. Mauborgne y W. Chan

Kim, 2013, México, Cargraphics S.A. de C.V. Copyright 2012 por Carbajal Educación S.A.S. Elaboración propia 
La matriz señala que se debe de reducir y/o eliminar puesto de gerencia y jefaturas que no son necesarias para la operatividad del CVH y se debe de reducir la competencia interna.

Respecto a incrementar, aconseja mejorar el trabajo en equipo, la comunicación interna y los procesos en atención al cliente, y aumentar los puestos operativos y las capacitaciones.

Señala que cree programas de sueldos y recompensas para motivar a los colaboradores y además, crear sistemas tecnológicos y planes de mejora.

\subsubsection{Matrices de la formulación de estrategias}

\subsubsection{Matriz FODA}

De acuerdo a David (2013) la matriz FODA se enfoca hacia factores importantes para el éxito del negocio. Resalta las fortalezas y las debilidades en comparación con la competencia y el entorno. 
Tabla 31

Matriz FODA

\begin{tabular}{|c|c|}
\hline \multirow{7}{*}{ FODA - CVH } & FORTALEZAS-F \\
\hline & 1.- Infraestructura moderna y segura. \\
\hline & $\begin{array}{l}\text { Centro de Convenciones con capacidad masiva sobre } 4 \\
\text { mil asistentes }\end{array}$ \\
\hline & 3.- $\quad$ Servicio de alto nivel \\
\hline & 4.- $\quad$ Bajos costos por "tercerización" \\
\hline & 5.- Colaboradores adecuados y calificados. \\
\hline & 6.- Estrategias con empresas institucionales. \\
\hline
\end{tabular}

\begin{tabular}{|ll|}
\hline DEBILIDADES-D \\
\hline \hline 1.- & Falta de sistemas actualizados \\
\hline 2.- & $\begin{array}{l}\text { Deficiencia de sistema de medios de transporte para ir al } \\
\text { CVH. }\end{array}$ \\
\hline 3.- & Pocas estrategias de marketing \\
\hline 4.- & $\begin{array}{l}\text { Falta de capacitación especializada y financiada por el } \\
\text { CVH }\end{array}$ \\
\hline 5.- & Curva de experiencia reciente. \\
\hline & \\
\hline
\end{tabular}

\begin{tabular}{|l|}
\hline OPORTUNIDADES-O \\
\hline \hline $\begin{array}{l}\text { El clima que rodea al CVH plantea una gran } \\
\text { oportunidad de atención y mejora la salud y } \\
\text { atención a los clientes. }\end{array}$ \\
\hline 2.- \\
$\quad \begin{array}{l}\text { Alianzas estratégicas del Estado para ser sede de } \\
\text { eventos. }\end{array}$ \\
\hline $\begin{array}{l}\text { Adoptar nuevas tecnologías y procesos de gestión } \\
\text { para las operaciones del CVH. }\end{array}$ \\
\hline $\begin{array}{l}\text { Cultura de la sociedad orientada a la familia, } \\
\text { incorporación de parques, restaurantes, ambientes } \\
\text { de recreación, otros. }\end{array}$ \\
\hline
\end{tabular}

\section{ESTRATEGIAS - FO}

Crear un ambiente de recreación, medio ambiente,

cuidado de la ecología que ayude a cumplir la meta. (O1 F4)

2 Alianzas estratégicas con empresas privadas y estatales para ser sede de sus eventos. (O1 - O3 - O 4 - F2)

3 Realización de eventos culturales donde se ofrezcan danzas tradicionales del país, exhibiciones culturales y de - teatro, festival gastronómico y afines. (O5 - O1 - O5 - O6)

\section{ESTRATEGIAS - DO}

1. Tercerizar el servicio de transporte turístico para facilita el acceso al CVH. (D1 - 02 - O3)

2. Creación de alianzas estratégicas con instituciones com PROMPERU (D2 - O3 - O4) 
Sigue....

5. Ubicación geográfica del CVH en una zona de clima cálido todo el año.

6.- $\quad$ Estabilidad macroeconómica del Perú.

7.- Implementación de políticas de cultura por parte del Estado Peruano.

\begin{tabular}{|ll|}
\hline AMENAZAS-A \\
\hline \hline $\begin{array}{l}\text { Desastres naturales en la zona de ubicación del CVH } \\
\text { (Huaycos) }\end{array}$ \\
\hline 2.- & $\begin{array}{l}\text { Cambios en la política de continuidad del Colegio } \\
\text { Mayor. }\end{array}$ \\
\hline 3.- & Nivel muy alto de expectativa de los visitantes. \\
\hline 4.- & $\begin{array}{l}\text { Los cambios pueden llegar a impulsar nuevos } \\
\text { competidores. }\end{array}$ \\
\hline 5.- & $\begin{array}{l}\text { El CVH se encontraría en desventaja al no actualizar } \\
\text { la tecnología }\end{array}$ \\
\hline 6.- & $\begin{array}{l}\text { Ambiente político con turbulencias debido al nuevo } \\
\text { mandatario. }\end{array}$ \\
\hline
\end{tabular}

\begin{tabular}{|l|}
\hline ESTRATEGIAS - FA \\
\hline \hline 1 Plan de marketing para consolidación del CVH (F1 - A4) \\
\hline- \\
2 Mejorar la infraestructura en las zonas de riesgo con mallas \\
$-\quad$ y cercos para evitar desbordes (A1 - A5 - F3) \\
\hline $\begin{array}{l}3 \\
\text { - Verificación de los distintos convenios y contratos que se } \\
-\end{array}$ tiene y tendrá con el Estado Peruano (A2 - F5 - F6) \\
\hline 4 Mantenimiento y renovación de las áreas del CVH (piscina, \\
canchas y juegos recreativos). (A4, F3 - F4) \\
\hline
\end{tabular}

3.- Por medio del área de Marketing va a dar a conocer a los
clientes el costo beneficio del CVH. (D3 -O3)

4.- Marketing: Crear acciones para posicionar la marca (D2- D3 $-\mathrm{O} 2)$

\section{ESTRATEGIAS - DA}

1.- Promover capacitaciones a los colaboradores en el rubro de convenciones. (D2 - A2 - A3)

Elaborar un plan operativo de acuerdo a cada área. (D1 - D3 - A1)

Implementar capacitaciones, incentivos y reconocimientos a

3.- los colaboradores de acuerdo a sus logros para así

motivarlos y mejorar sus rendimientos. (D1 - A4 - A5 - A6)

Nota. Adaptado de Administración estratégica (p. 177), por F. David, 2013, México, Pearson Educación. Copyright 2013 por Pearson

Educación. Elaboración propia 


\subsubsection{Matriz Peyea}

De acuerdo a David (2013), la matriz PEYEA ayuda a evaluar y elegir las mejores estrategias para implementarla en el CVH. La Tabla 32 muestra los factores desarrollados, la valoración otorgada comparándolo con la importancia de cada factor. De esta valoración resultan cuatro puntos que permitirá elaborar el polígono y detectar el vector que presentará la estrategia más idónea para el CVH.

Tabla 32

\section{MATRIZ PEYEA PARA EL CVH}

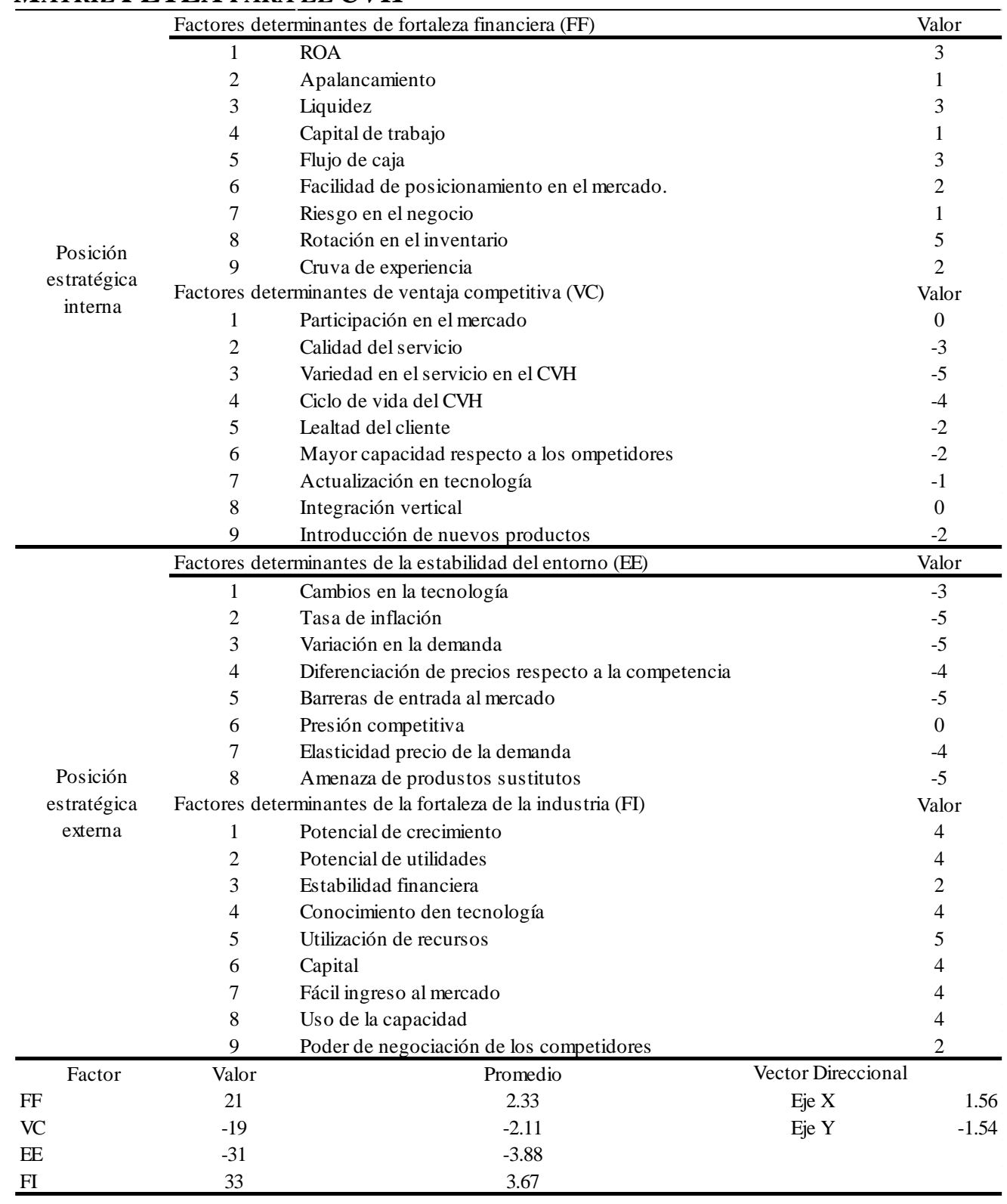

Nota. Adaptado de Administración estratégica (p. 182), por F. David, 2013, México, Pearson Educación. Copyright 2013 por Pearson Educación. Elaboración propia 
En cuanto a los factores que se han tomado en cuenta en la parte de fortalezas financieras, se considera la liquidez neta, este factor es importante por el porcentaje no menor del $20 \%$ que se establece como un parámetro.

Los resultados muestran el vector en el cuadrante conservadora debido a que es un mercado en crecimiento dinámico, pero en la actualidad la posición del CVH es lenta, las estrategias estarán dirigidas a adoptar nuevos productos y obtener ingresos en mercados atractivos vinculados con lo cultural, entretenimiento e integración empresarial.

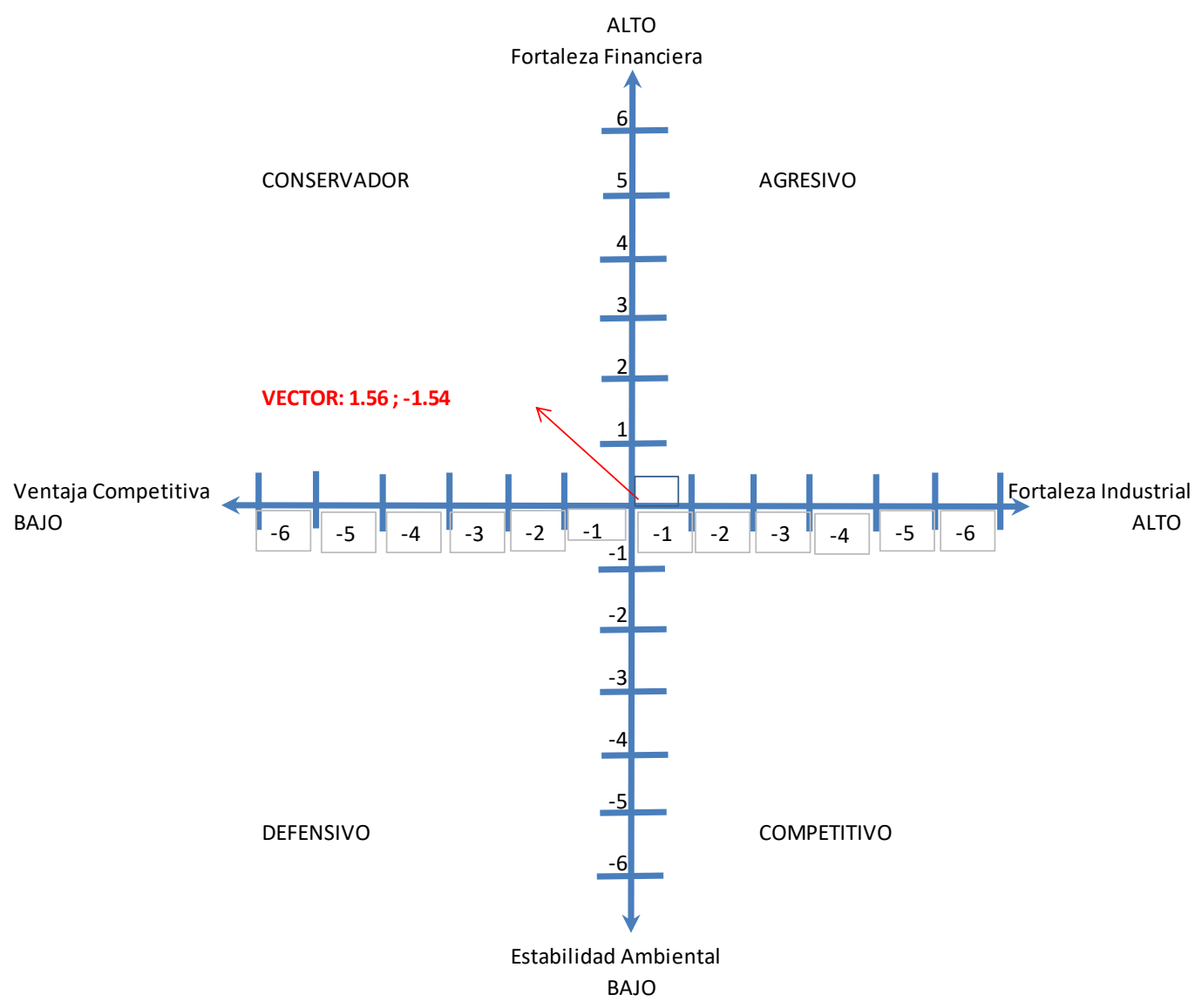

Figura 6. Matriz PEYEA del CVH

Nota. Adaptado de Administración estratégica (p. 180), por F. David, 2013, México, Pearson Educación. Copyright 2013 por Pearson Educación. Elaboración propia

Según David (2013), la matriz muestra cuatro cuadrantes que podrían ser la postura del CVH, agresiva, competitiva, conservadora y defensiva, el cual sirve para diseñar estrategias para la empresa, como liderazgo en costos, diferenciación y enfoque. 
De acuerdo a la matriz PEYEA muestra al CVH una postura conservadora, resultado de los valores $\mathrm{x}=1.56, \mathrm{y}=-1.54 \mathrm{y}$ de los factores que involucra a la matriz

Las estrategias a seguir son las siguientes:

\section{Diversificación conglomerada.}

1. Ampliación y construcción de instalaciones modernas en las áreas del CVH para así tener mayor ventaja competitiva en el servicio que brinda, además ampliar los auditorios para las convenciones, áreas recreativas y bungalows.

2. Enfocada en remodelar la infraestructura e invertir en tecnología para captar cuota de mercado.

\section{Segmentación de mercados}

1. Convenios con instituciones del Estado y empresas privadas. Teniendo como fortaleza su ubicación y la capacidad instalada.

2. Incrementar la participación en el rubro de convenciones y eventos a nivel del estado. La estrategia está basada en su ubicación geográfica y su ventaja competitiva hacia los principales competidores.

3. Dar a conocer el servicio de hospedaje corporativo. Esta estrategia está basada aprovechar la capacidad instalada y la calidad en el servicio.

\section{Enfoque en diferenciación}

1. Contratar personal idóneo para la realización de eventos de tipo turístico - cultural.

2. Implementar servicio de transporte hacia el CVH.

\subsubsection{Matriz Interna Externa}

De acuerdo a David (2013), la matriz cuenta con nueve cuadrantes y dos dimensiones, cada una de las dimensiones está relacionada a los resultados de las matrices EFE y EFI. De 
este modo, el eje X se vincula con el resultado de la matriz EFI, y el eje Y con el resultado que se obtiene también de la matriz EFE.

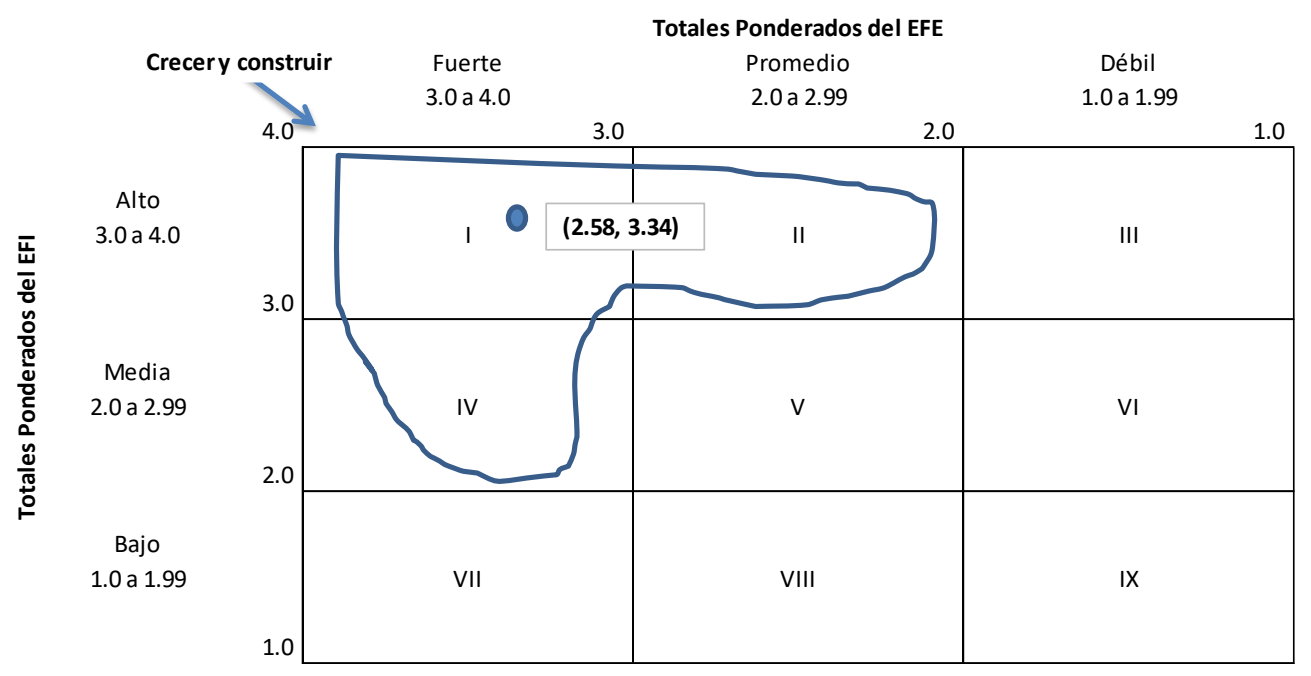

Figura 7. Matriz IE del CVH

Nota. Adaptado de Administración estratégica (p. 187), por F. David, 2013, México, Pearson Educación. Copyright 2013 por Pearson Educación. Elaboración propia

La estrategia a seguir es "Crecer y construir".

\subsubsection{Matriz Boston Consulting Group}

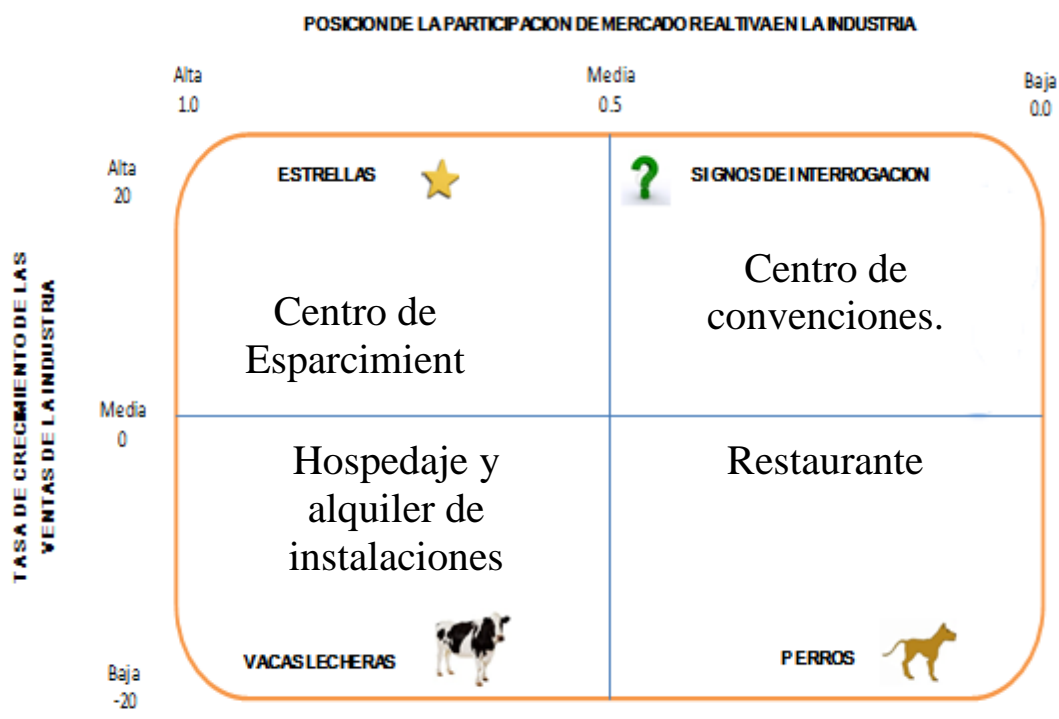

Figura 8. Matriz BCG del CVH

Nota. Adaptado de Administración estratégica (p. 185), por F. David, 2013, México, Pearson Educación. Copyright 2013 por Pearson Educación. Elaboración propia 
La matriz BCG sirve para formular las estrategias de los diferentes servicios que brinda el CVH, para este caso, se pueden obtener mayores posibilidades de éxito evaluando por separado cada servicio del CVH. En la Figura 8, se visualiza la matriz para el CVH, en la que se muestra que, aunque el servicio en el cual se enfoca este plan estratégico se ubica en interrogante, existe una gran diferencia en la participación de la realización de convenciones en las instalaciones del CVH con respecto a los servicios de realización de eventos, hospedaje y recreación, dado que el CVH tiene como ventaja competitiva su ubicación y su capacidad instalada.

\subsubsection{Matriz de la Gran Estrategia}

Según David (2013), la matriz de la gran estrategia (GE), explica la situación de las estrategias del CVH con relación al crecimiento del mercado y de la posición competitiva. Actualmente se sitúa en el cuadrante II donde el CVH tiene un rápido crecimiento en el mercado y tiene una posición competitiva débil. 


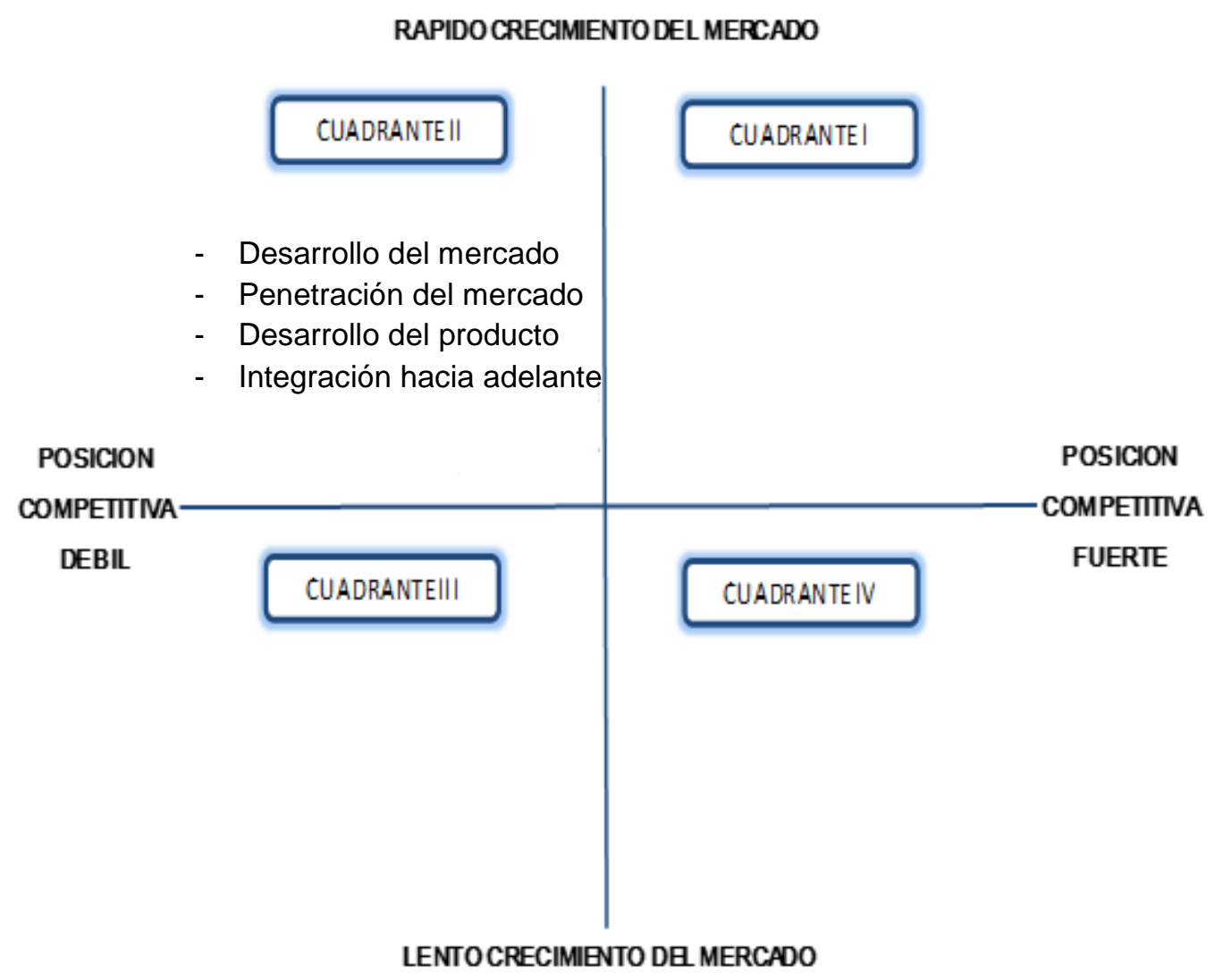

Figura 9. Matriz de la Gran Estrategia Nota. Adaptado de Administración estratégica (p. 190), por F. David, 2013, México, Pearson Educación. Copyright 2013 por Pearson Educación. Elaboración propia

De acuerdo a los resultados de esta matriz las estrategias a seguir son las siguientes: desarrollo del mercado, desarrollo del producto, penetración del mercado e integración hacia adelante. 


\section{CAPÍTULO VIII}

\section{SELECCIÓN DE LA ESTRATEGIA}

\subsection{Método Factores Estratégicos Claves}

\subsubsection{Criterios de selección}

La selección de las estrategias es dada por los resultados de las matrices FODA, PEYEA, BCG, IE y GE, de las cuales se eligen las que más se repiten, en este caso nos hemos quedado con 8 estrategias para poder desarrollar le ventaja competitiva en el rubro. Las estrategias que no fueron elegidas van a servir como alternativas si se presenta alguna eventualidad.

\subsubsection{Selección de la estrategia}

Las estrategias elegidas son las siguientes:

1. Alianzas con el Estado Peruano y organizaciones privadas proporcionándoles ambientes para sus eventos.

2. Ejecución de eventos culturales donde se ofrezcan danzas tradicionales del país, festival gastronómico y afines.

3. Tercerizar el servicio de transporte turístico para facilitar el acceso al CVH.

4. Creación de alianzas estratégicas con instituciones como PROMPERU.

5. Reforzamiento de las zonas de riesgo con mallas y cercados para evitar desbordes.

6. Fomentar relaciones con empresas del sector participando en congresos.

7. Revisar la formulación de contratos con el Estado Peruano.

8. Plan de RRHH: Mejoramiento de competencias para la globalización (incentivos). 


\subsection{Matriz de Planeación Estratégica Cuantitativa MPEC}

La matriz MPEC es un instrumento que evalúa las posibles estrategias, basándose en los factores críticos de éxitos (externos e internos) mencionados anteriormente, como se presenta en la Tabla 39. Esta matriz permite al CVH identificar las mejores estrategias para el negocio, partiendo de la valoración de los factores externos e internos que lo influyen.

Según David (2013), los pasos para desarrollar la matriz son:

1. Factores críticos para la selección, tomados de las matrices EFE y EFI.

2. A cada uno de los factores se asigna un puntaje que va de 0 a 1 para las amenazas, oportunidades, debilidades y fortalezas, siendo el grado de atractividad el siguiente $1=$ no atractiva, $2=$ poco atractiva, $3=$ atractiva y $4=$ muy atractiva.

3. La calificación de cada una de las estrategias se obtienen multiplicando las ponderaciones con el puntaje de cada estrategia.

4. Sumar las calificaciones de cada una de las estrategias para elegir la estrategia que tenga mayor puntaje de atractividad. 
Tabla 33

Matriz Planeación Estratégica Cuantitativa MPEC

\begin{tabular}{|c|c|c|c|c|c|c|c|}
\hline \multirow{2}{*}{\begin{tabular}{|l} 
\\
OPORTUNIDADES \\
\end{tabular}} & \multirow[b]{2}{*}{ Ponderación } & \multicolumn{6}{|c|}{ ESTRATEGIAS ALTERNATIVAS } \\
\hline & & \multicolumn{2}{|c|}{$\begin{array}{l}\text { Diferenciación en el } \\
\text { servicio del CVH }\end{array}$} & \multicolumn{2}{|c|}{$\begin{array}{l}\text { Desarrollo de nuevos } \\
\text { servicios en el CVH }\end{array}$} & \multicolumn{2}{|c|}{$\begin{array}{l}\text { Diferenciación en } \\
\text { Innovación }\end{array}$} \\
\hline $\begin{array}{l}\text { El clima que rodea al CVH plantea una gran oportunidad de } \\
\text { atención y mejora la salud y atención a los clientes. }\end{array}$ & $1.00 \%$ & - & - & - & - & - & - \\
\hline Alianzas estratégicas del Estado para ser sede de eventos. & $1.50 \%$ & - & - & - & - & - & - \\
\hline $\begin{array}{l}\text { Adoptar nuevas tecnologías y procesos de gestión para las } \\
\text { operaciones del } \mathrm{CVH} \text {. }\end{array}$ & $2.00 \%$ & 0 & - & 0 & - & 2 & 0.04 \\
\hline $\begin{array}{l}\text { Cultura de la sociedad orientada a la familia, incorporación de } \\
\text { parques, restaurantes, ambientes de recreación, otros. }\end{array}$ & $6.00 \%$ & 4 & 0.24 & 0 & - & 0 & - \\
\hline $\begin{array}{l}\text { Ubicación geográfica del CVH en una zona de clima cálido todo el } \\
\text { año. }\end{array}$ & $1.00 \%$ & 0 & - & 0 & - & 0 & - \\
\hline Estabilidad macroeconómica del Perú. & $5.00 \%$ & 1 & 0.05 & 3 & 0.15 & 3 & 0.15 \\
\hline $\begin{array}{l}\text { Implementación de políticas de cultura por parte del Estado } \\
\text { Peruano. }\end{array}$ & $5.00 \%$ & 3 & 0.15 & 3 & 0.15 & 2 & 0.10 \\
\hline \multicolumn{8}{|l|}{ AMENAZAS } \\
\hline Desastres naturales en la zona de ubicación del CVH (Huaycos) & $6.00 \%$ & 0 & - & 0 & - & 2 & 0.12 \\
\hline Cambios en la política de continuidad del Colegio Mayor. & $6.00 \%$ & 2 & 0.12 & 0 & - & 0 & - \\
\hline Deficiente infraestructura de transporte para Ilegar al CVH & $2.50 \%$ & 1 & 0.03 & 1 & 0.03 & 1 & 0.03 \\
\hline Los cambios pueden Ilegar a impulsar nuevos competidores. & $5.50 \%$ & 1 & 0.06 & 1 & 0.06 & 0 & - \\
\hline El CVH se encontraría en desventaja al no actualizar la tecnología & $6.50 \%$ & 3 & 0.20 & 0 & - & 0 & - \\
\hline Ambiente político con turbulencias debido al nuevo Gabinete. & $2.00 \%$ & 3 & 0.06 & 3 & 0.06 & 0 & - \\
\hline \multicolumn{8}{|l|}{ FORTALEZAS } \\
\hline Infraestructura moderna y segura & $5.00 \%$ & 0 & - & 3 & 0.15 & 3 & 0.15 \\
\hline $\begin{array}{l}\text { Centro de Convenciones con capacidad masiva sobre } 4 \text { mil } \\
\text { asistentes }\end{array}$ & $7.50 \%$ & 2 & 0.15 & 4 & 0.30 & 1 & 0.08 \\
\hline Servicio de alto nivel & $5.00 \%$ & 4 & 0.20 & 4 & 0.20 & 4 & 0.20 \\
\hline Bajos costos por "tercerización" & $5.00 \%$ & 2 & 0.10 & 2 & 0.10 & 2 & 0.10 \\
\hline Colaboradores adecuados y calificados & $3.50 \%$ & 3 & 0.11 & 4 & 0.14 & 3 & 0.11 \\
\hline Estratégias con empresas institucionales. & $4.00 \%$ & 4 & 0.16 & 0 & - & 0 & - \\
\hline \multicolumn{8}{|l|}{ DEBILIDADES } \\
\hline Falta de sistemas actualizados & $7.50 \%$ & 1 & 0.08 & 1 & 0.08 & 0 & - \\
\hline Pocas estrategias de marketing & $7.50 \%$ & 1 & 0.08 & 0 & - & 0 & - \\
\hline Curva de experiecia reciente. & $5.00 \%$ & 0 & - & 2 & 0.10 & 1 & 0.05 \\
\hline TOTAL & $100.00 \%$ & & 1.76 & & 1.51 & & 1.12 \\
\hline
\end{tabular}

Nota. Adaptado de Administración estratégica (p. 192), por F. David, 2013, México, Pearson

Educación. Copyright 2013 por Pearson Educación. Elaboración propia

\subsection{Método de Escenarios}

\subsubsection{Descripción de escenarios considerados}

A continuación, se plantea dos escenarios para implementar la estrategia de

diferenciación de servicio durante el periodo del Plan Estratégico y así determinar el efecto

de cada uno de los escenarios.

Escenario 1:

El Estado se enfoca en el cuidado del medio ambiente y políticas culturales, sociales y educativas lo cual va a permitir a acceder a un mejor nivel socio económico. 
En el aspecto político el Gobierno va a ejercer una postura democrática para crear un ambiente propicio para la mejora del país. Y en el aspecto económico, va ser optimista por las inversiones y exportaciones de capital nacional y extranjero, permitiendo mayor competitividad.

\section{Escenario 2:}

Las actividades del Gobierno no obtuvieron los resultados esperados por los constantes cambios de Gabinete y por diferencias en el Congreso; en el aspecto social, la pobreza, violencia e inseguridad aumentó; la economía, el PBI no creció como se proyectaba y la tasa de desempleó aumentó.

\subsubsection{Comparación de Estrategias con Escenarios}

Tabla 34.

Selección de la Estrategia con Escenarios

\begin{tabular}{|l|l|}
\hline \multicolumn{1}{|c|}{ Escenario 1 } & \multicolumn{1}{|c|}{ Escenario 2 } \\
\hline $\begin{array}{l}\text { Diferenciación de servicio que brinda el } \\
\text { CVH }\end{array}$ & $\begin{array}{l}\text { Diferenciación de servicio que brinda el } \\
\text { CVH }\end{array}$ \\
\hline Desarrollo de nuevos servicios en el CVH & \\
\hline
\end{tabular}

Nota. Elaboración propia

La estrategia escogida es la siguiente: Diferenciación del servicio que ofrecerá el

CVH. En esta matriz se relacionan las estrategias con los objetivos estratégicos, así se puede ver como la estrategia que se ha seleccionado se desarrolla adecuadamente en los diferentes escenarios. 
Tabla 35

Matriz de Estrategias vs. Objetivos a Largo Plazo

\begin{tabular}{|c|c|c|c|c|c|c|c|c|c|c|}
\hline \multicolumn{2}{|r|}{ Estrategias para el $\mathrm{CVH}$} & \multicolumn{9}{|c|}{ Objetivos a largo plazo } \\
\hline Ítem & Estrategia Seleccionada & $\begin{array}{c}\begin{array}{c}\text { Aumento de la } \\
\text { rentabilidad a } \\
19.97 \% \text { a fines } \\
\text { del año } 2021\end{array}\end{array}$ & \begin{tabular}{|c} 
Aumento de \\
los ingresos a \\
$18 \%$ a finales \\
del año 2021
\end{tabular} & $\begin{array}{c}\text { Disminucion de } \\
\text { gastos } \\
\text { operativos a } \\
6 \% \text { a finales del } \\
\text { año } 2021\end{array}$ & $\begin{array}{c}\text { Fidelización de } \\
\text { clientes de } 40 \% \\
\text { a finales del } \\
\text { año } 2021\end{array}$ & $\begin{array}{c}\text { Aumentar la } \\
\text { cuota de } \\
\text { mercado a 52\% } \\
\text { a finales del } \\
\text { año } 2021\end{array}$ & \begin{tabular}{|c} 
Atención \\
general a \\
clientes \\
corporativos a \\
$100 \%$ a finales \\
del año 2021
\end{tabular} & $\begin{array}{c}\text { Proceso de } \\
\text { abastecimiento } \\
\text { y seguridad a } \\
100 \% \text { a finales } \\
\text { del año } 2021\end{array}$ & $\begin{array}{c}\text { Manejo del } \\
\text { sistema de } \\
\text { información } \\
\text { aumentando la } \\
\text { inversión en } \\
10 \%\end{array}$ & $\begin{array}{c}\text { Las metas } \\
\text { personales } \\
\text { deben estar } \\
\text { alineadas con } \\
\text { los objetivos } \\
\text { un } 90 \%\end{array}$ \\
\hline EST 1 & Alianzas estrategicas con empresas privadas y estatales para ser sedes de sus eventos. & Sí & Sí & Sí & Sí & Sí & Sí & Sí & & Sí \\
\hline EST2 & $\begin{array}{l}\text { Desarrollo de eventos culturales donde se ofrezcan danzas tradicionales del país, festival } \\
\text { gastronómico y afines. }\end{array}$ & Sí & Sí & & Sí & Sí & Sí & Sí & & Sí \\
\hline EST3 & Tercerizar el servicio de transporte turístico para facilitar el acceso al CVH. & Sí & Sí & Sí & Sí & & & & & \\
\hline EST 4 & Creación de alianzas estratégicas con instituciones como PROMPERU. & Sí & Sí & Sí & & & & & & \\
\hline EST5 & Reforzamiento de las zonas de riesgo con mallas y cercados para evitar desbordes. & & & Sí & & & & Sí & Sí & \\
\hline EST6 & Fomentar relaciones con empresas del sector participando en congresos. & Sí & Sí & & Sí & Sí & Sí & & & Sí \\
\hline EST7 & Revisar la formulación de contratos con el Estado Peruano. & Sí & Sí & & Sí & Sí & & & & \\
\hline EST8 & Plan de RRHH: Mejoramiento de competencias para la globalización (incentivos). & & & Sí & & & & Sí & & Sí \\
\hline
\end{tabular}

Nota. Adaptado de El proceso estratégico: Un enfoque de gerencia (p. 364), por F. D’Alessio, 2008, México, Pearson Educación. Copyright 2008 por Pearson Educación. Elaboración propia. 


\subsection{Descripción de estrategia seleccionada}

\section{Diferenciación del servicio que brinda el CVH}

La estrategia seleccionada va ayudar a implementar y mantener una ventaja competitiva ya que se enfocará en la calidad en el servicio e innovación en los productos y servicios a ofrecer para así genera un valor agregado al CVH.

La segunda y tercera estrategias, se rechazaron debido que el CVH cuenta con una larga trayectoria y la marca está posicionada en el mercado, al desarrollar estas estrategias tomarían mucho tiempo e inversión lo cual en esos momentos no es una buena decisión para el CVH.

\subsection{Descripción de estrategia contingente}

\subsubsection{Marketing}

En esta área se seleccionó la estrategia de penetración de mercado por contar con productos existentes en un mercado existente. Y la estrategia de contingencia será la de desarrollo de productos.

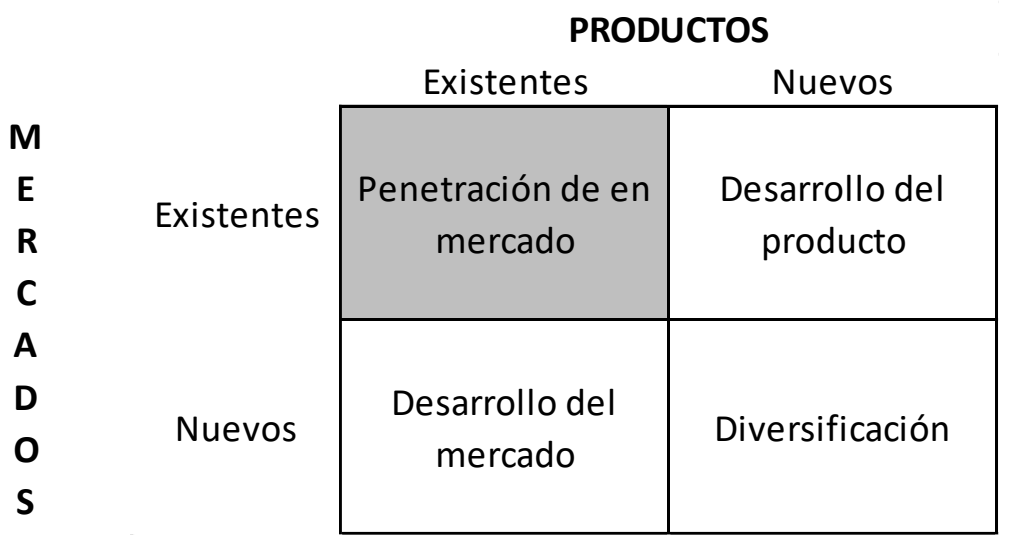

Figura 10.

Nota: Adaptado del artículo Estrategias para la diversificación (113-124), por I. Ansoff, 1957, Harvard Business review. Elaboración Propia. 


\subsubsection{Operaciones}

La estrategia seleccionada es la mejora de procesos y servicio. La estrategia de contingencia es la de desarrollo de productos.

PROCESOS

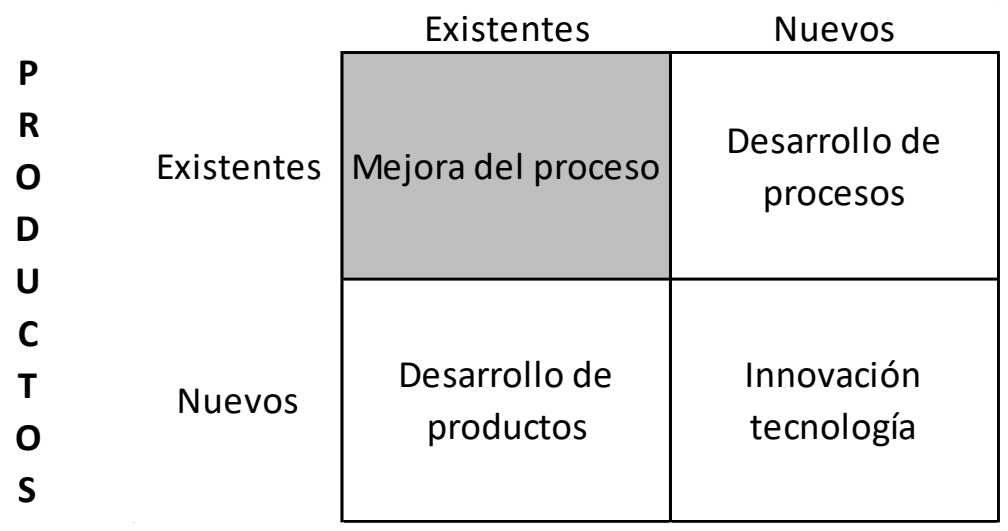

Figura 11. Estrategias de operación

Nota: Adaptado del artículo Estrategias para la diversificación (113-124), por I. Ansoff, 1957, Harvard Business review. Elaboración Propia.

\subsubsection{Finanzas}

Las estrategias a desarrollar son el desarrollo de fuentes de financiamiento y la diversificación de inversiones y financiamiento.

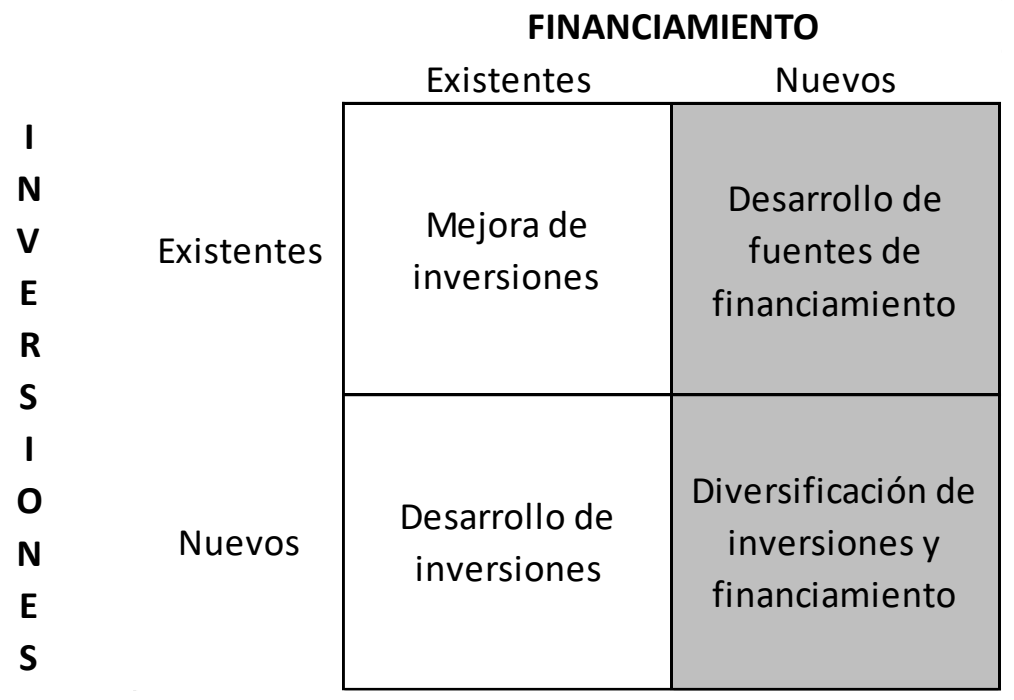

Figura 12. Estrategias de finanzas

Nota: Adaptado del artículo Estrategias para la diversificación (113-124), por I. Ansoff, 1957, Harvard Business review. Elaboración Propia. 


\subsubsection{Recursos Humanos}

Se necesita desarrollar las competencias de los colaboradores, y capacitar adecuadamente al nuevo personal mediante la inducción.

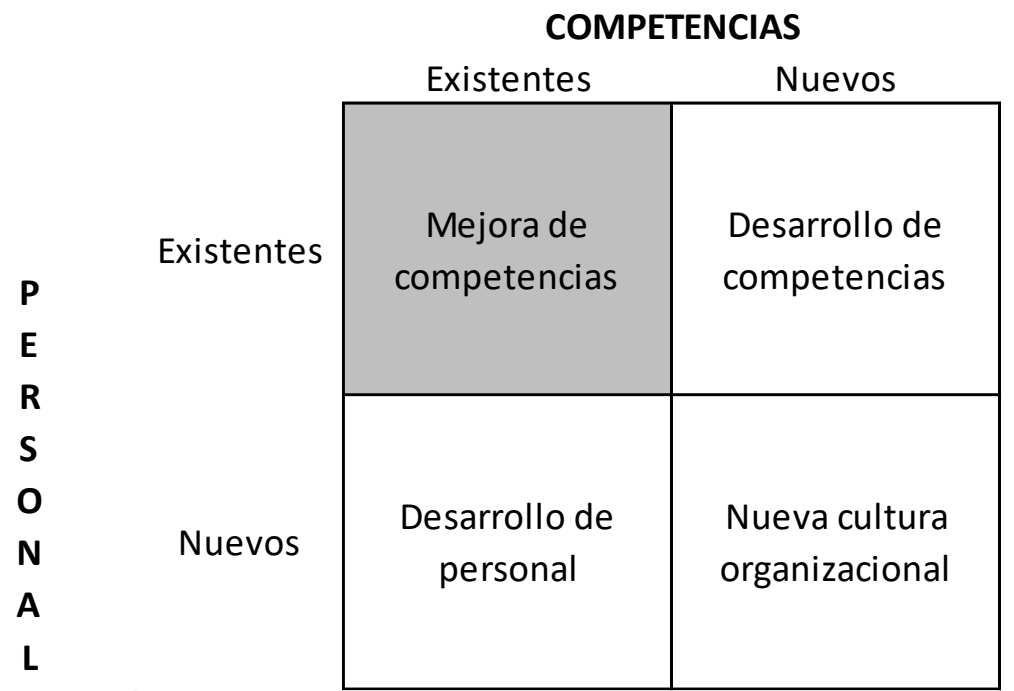

Figura 13. Estrategias de recursos humanos

Nota: Adaptado del artículo Estrategias para la diversificación (113-124), por I. Ansoff, 1957, Harvard Business review. Elaboración Propia.

\subsubsection{Medio Ambiente}

Preservación del medio ambiente con programas de responsabilidad social dirigidos a la comunidad y al CVH.

Programa de reciclaje que deben de practicar los clientes y los colaboradores.

Revisión periódica de las instalaciones y de los muros de contención que se encuentran aledaños a las zonas de riesgo que tiene el CVH, verificación constante de los caudales que tiene el río que pasa por las inmediaciones. 


\section{CAPÍTULO IX}

\section{IMPLANTACIÓN DE LA ESTRATEGIA}

\subsection{Mapa de la Estrategia}

Según R. Kaplan y D. Norton, el mapa de la estrategia tiene la finalidad de detallar los objetivos de cada una de las perspectivas y relacionarlas para cumplir el objetivo principal que el generar valor a la junta directiva. 


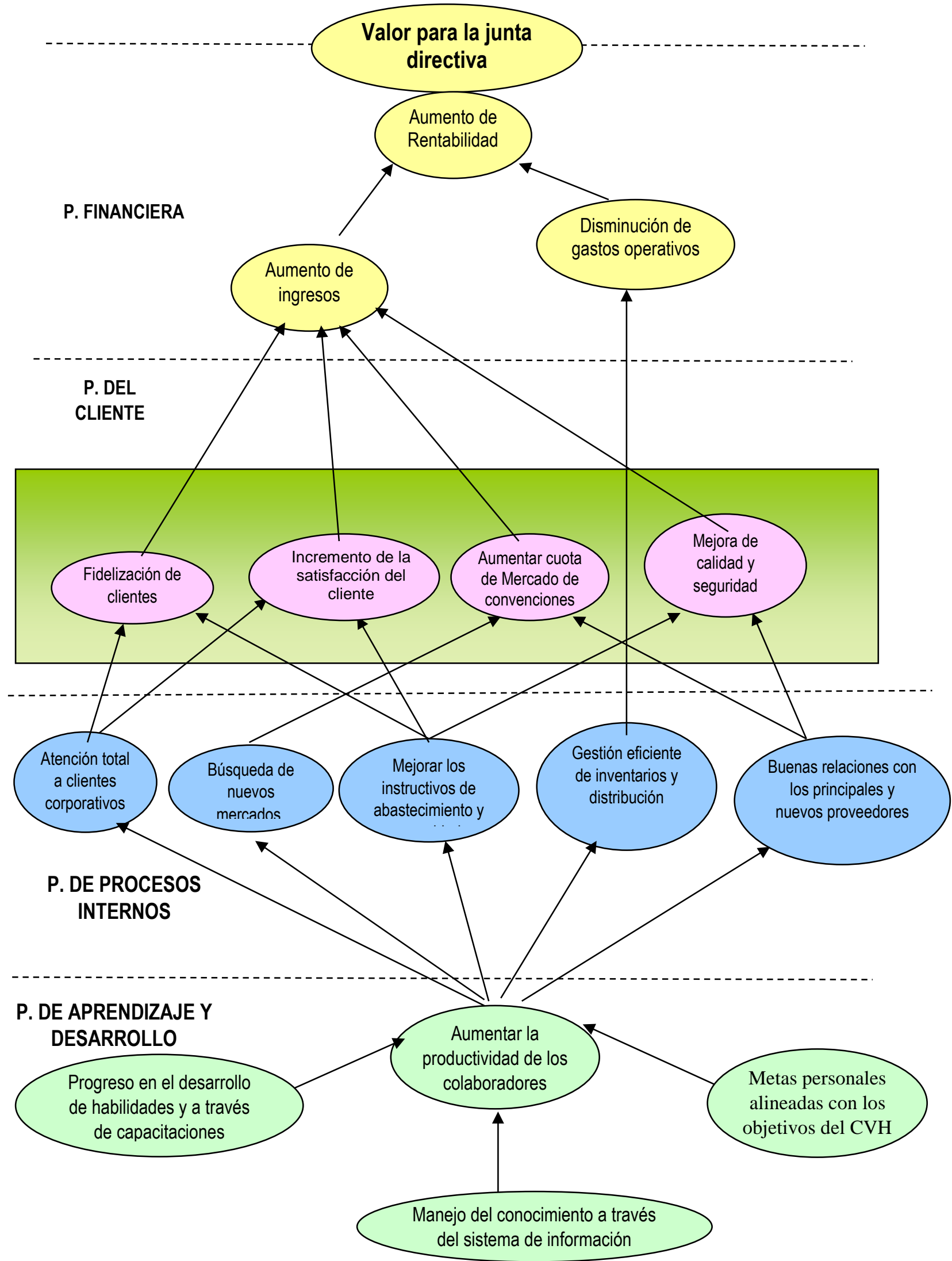

Figura 14. Mapa de la estrategia

Nota. Adaptado de Cuadro de mando integral (p. 24), por R. Kaplan R. y D. Norton, 2000,

Barcelona. Copyright 1996 por Ediciones Gestión 2000. Elaboración propia. 


\subsection{Objetivos específicos según el mapa de la estrategia}

Los objetivos que el CVH desea conseguir en un corto plazo.

Tabla 36

Objetivos específicos

\begin{tabular}{|l|l|}
\hline \multirow{2}{*}{ PERSPECTIVA } & OBJETIVO ESTRATÉGICO \\
\hline \multirow{4}{*}{ FINANCIERA } & Aumento de Rentabilidad \\
\cline { 2 - 2 } & Aumento de Ingresos \\
\cline { 2 - 2 } CLIENTES & Disminución de gastos operativos \\
\cline { 2 - 2 } & Implementar valor agregado \\
\hline & Fidelización de clientes \\
\cline { 2 - 2 } & $\begin{array}{l}\text { Incremento en la satisfacción del cliente } \\
\text { Aumentar la cuota de mercado del rubro de convenciones del } \\
\text { CVH }\end{array}$ \\
\cline { 2 - 2 } & Mejora de calidad y seguridad \\
\hline
\end{tabular}

Nota. Adaptado de Cuadro de mando integral (p. 59), por R. Kaplan R. y D. Norton, 2000, Barcelona. Copyright 1996 por Ediciones Gestión 2000. Elaboración propia.

\begin{tabular}{|l|l|}
\hline \multirow{4}{*}{ PROCESOS INTERNOS } & Atención total a clientes corporativos \\
\cline { 2 - 2 } & $\begin{array}{l}\text { Búsqueda de nuevos mercados } \\
\text { Mejorar los instructivos de abastecimiento y seguridad } \\
\text { de insumos. }\end{array}$ \\
\cline { 2 - 2 } & Gestión eficiente de inventarios y distribución. \\
\cline { 2 - 2 } $\begin{array}{l}\text { Buenas relaciones con los principales y nuevos } \\
\text { proveedores. }\end{array}$ \\
\hline DESARROLLO & Aumentar productividad de los colaboradores. \\
\cline { 2 - 2 } & $\begin{array}{l}\text { Progreso en el desarrollo de habilidades a través de } \\
\text { capacitaciones a los colaboradores. }\end{array}$ \\
\cline { 2 - 2 } & Manejo del conocimiento por sistema de información. \\
\cline { 2 - 2 } & $\begin{array}{l}\text { Las metas personales deben estar alineadas con } \\
\text { objetivos del CVH. }\end{array}$ \\
\hline
\end{tabular}

Nota. Adaptado de Cuadro de mando integral (p. 59), por R. Kaplan R. y D. Norton, 2000, Barcelona. Copyright 1996 por Ediciones Gestión 2000. Elaboración propia. 


\subsection{Indicadores para cada uno de los objetivos específicos}

De acuerdo a R. Kaplan y D. Norton, se detallará los indicadores estratégicos para cada una de las perspectivas y se pondrá objetivos para cada año durante el periodo del Plan Estratégico.

Tabla 37

Indicadores para cada uno de los objetivos específicos

\begin{tabular}{|c|c|c|c|c|c|}
\hline PERSPECTIVA & $\begin{array}{l}\text { INDICADORES } \\
\text { ESTRATÉGICOS }\end{array}$ & 2016 & 2017 & 2018 & 2019 \\
\hline \multirow{4}{*}{ FINANCIERA } & Aumento de la Rentabilidad & $11.81 \%$ & $13.44 \%$ & $15.07 \%$ & $16.70 \%$ \\
\hline & $\begin{array}{l}\text { Porcentaje de ingresos (crecer de } \\
2 \text { a } 3 \% \text { ) }\end{array}$ & $9 \%$ & $11 \%$ & $12.75 \%$ & $14.50 \%$ \\
\hline & Disminución de gastos operativos & $5 \%$ & $5 \%$ & $5 \%$ & $6 \%$ \\
\hline & Valor económico agregado & 127,000 & 132,000 & 135,000 & 137,000 \\
\hline \multirow{5}{*}{ CLIENTES } & $\%$ de clientes fidelizados & $28 \%$ & $30 \%$ & $35 \%$ & $40 \%$ \\
\hline & Nivel de satisfacción de clientes & 8 & 8 & 8 & 9 \\
\hline & $\begin{array}{l}\text { \% de participación de mercado } \\
\text { (Nro. de clientes) }\end{array}$ & $36 \%$ & $40 \%$ & $40 \%$ & $41 \%$ \\
\hline & $\begin{array}{l}\% \text { de insumos y materiales que } \\
\text { generan alarma }\end{array}$ & $17 \%$ & $10 \%$ & $5 \%$ & $0 \%$ \\
\hline & $\begin{array}{l}\% \text { de mejora de calidad y } \\
\text { seguridad }\end{array}$ & $96 \%$ & $97 \%$ & $97 \%$ & $98 \%$ \\
\hline
\end{tabular}

Nota. Adaptado de Cuadro de mando integral (p. 161), por R. Kaplan R. y D. Norton, 2000, Barcelona. Copyright 1996 por Ediciones Gestión 2000. Elaboración propia.

\begin{tabular}{|l|l|c|c|c|c|}
\hline PERSPECTIVA & INDICADORES ESTRATÉGICOS & $\mathbf{2 0 1 6}$ & $\mathbf{2 0 1 7}$ & $\mathbf{2 0 1 8}$ & $\mathbf{2 0 1 9}$ \\
\hline \multirow{5}{*}{$\begin{array}{l}\text { PROCESOS } \\
\text { INTERNOS }\end{array}$} & Clientes atendidos /total de clientes & $60 \%$ & $80 \%$ & $90 \%$ & $100 \%$ \\
\cline { 2 - 6 } & Eventos concretados/total de eventos & $20 \%$ & $25 \%$ & $30 \%$ & $40 \%$ \\
\cline { 2 - 6 } & $\begin{array}{l}\text { Abastecimientos realizados/total abastecimiento } \\
\text { proyectados }\end{array}$ & $91 \%$ & $94 \%$ & $97 \%$ & $100 \%$ \\
\cline { 2 - 6 } & $\%$ de requerimientos no según orden de compra & $5 \%$ & $3 \%$ & $2 \%$ & $1 \%$ \\
\cline { 2 - 6 } & Días que los insumos permanecen en el almacén & 15 & 13 & 7 & 5 \\
\cline { 2 - 6 } & Pedidos no cumplidos/total de pedidos ofrecidos & $6 \%$ & $5 \%$ & $3 \%$ & $1 \%$ \\
\cline { 2 - 6 } & $\%$ de convenios con proveedores & $40 \%$ & $50 \%$ & $60 \%$ & $70 \%$ \\
\hline \multirow{3}{*}{$\begin{array}{l}\text { APRENDIZAJE } \\
\text { Y DE } \\
\text { DESARROLLO }\end{array}$} & Cantidad de promociones & 4 & 8 & 8 & 8 \\
\cline { 2 - 6 } & Desarrollo de competencias por parte de recursos humanos & $40 \%$ & $70 \%$ & $85 \%$ & $100 \%$ \\
\cline { 2 - 6 } & Adquisición de sistema de información /por colaborador & $\$ 1000$ & $\$ 2000$ & $\$ 3000$ & $\$ 3000$ \\
\cline { 2 - 6 } & Incremento de buen clima laboral & $30 \%$ & $40 \%$ & $50 \%$ & $80 \%$ \\
\hline
\end{tabular}

Nota. Adaptado de Cuadro de mando integral (p. 161), por R. Kaplan R. y D. Norton, 2000, Barcelona. Copyright 1996 por Ediciones Gestión 2000. Elaboración propia. 


\subsection{Metas para cada uno de los objetivos específicos}

Para la propuesta de las metas que se desean alcanzar al año 2017 se ha tomado como referencia el plan operativo proyectado al 2016 (ver anexo 8) que ha sido formulado por la Gerencia General del CVH en base al plan propuesto en el año 2015, dejando de lado actividades que se van a realizar en los siguientes años, debido que el CVH debe de ir pagando sus deudas antes de sumergirse en nuevas inversiones.

Tabla 38

Metas para los objetivos específicos

\begin{tabular}{|l|r|}
\hline PERSPECTIVA FINANCIERA & META 2017 \\
\hline OBJETIVO & $13.44 \%$ \\
\cline { 2 - 2 } Aumento de Rentabilidad & US\$ 132,000 \\
\hline Aumento de Ingresos & $11 \%$ \\
\hline Disminución de Gastos operativos & $5 \%$ \\
\hline
\end{tabular}

Nota: Elaboración propia

\begin{tabular}{|l|r|}
\hline PERSPECTIVA CLIENTES & \multicolumn{2}{|c|}{} \\
\hline OBJETIVO & META 2017 \\
\hline Fidelizar clientes & 8 \\
\hline Incremento de la satisfacción de clientes & $40.00 \%$ \\
Aumentar la cuota de mercado en el rubro de convenciones & $97.00 \%$ \\
\hline Mejora de calidad y seguridad & \\
\hline
\end{tabular}

Nota: Elaboración propia

\begin{tabular}{|l|r|}
\hline PERSPECTIVA DE PROCESOS INTERNOS \\
\hline OBJETIVO & META 2017 \\
\hline Atención total de clientes & $75.00 \%$ \\
\hline Búsqueda de nuevos mercados & $30.00 \%$ \\
\hline Mejorar los instructivos de abastecimiento y seguridad & $97.00 \%$ \\
\hline $\begin{array}{l}\text { Gestión eficiente de inventarios de distribución } \\
\text { Buenas relaciones con los principales y nuevos proveedores }\end{array}$ & $40.00 \%$ \\
\hline
\end{tabular}

Nota: Elaboración propia 


\begin{tabular}{|l|r|}
\hline PERSPECTIVA DE APRENDIZAJE Y CRECIMIENTO \\
\hline OBJETIVO & META 2017 \\
\hline Aumentar productividad de los colaboradores & $700 \%$ \\
\hline $\begin{array}{l}\text { Progreso en el desarrollo de habilidades a través de } \\
\text { capacitaciones a los colaboradores }\end{array}$ & $\$ 2,000.0$ \\
\hline Manejo de conocimiento por sistema de información & $40.00 \%$ \\
\hline $\begin{array}{l}\text { Las metas personales deben estar alineadas con objetivos del } \\
\text { CVH }\end{array}$ & \\
\hline
\end{tabular}

Nota: Elaboración propia

\subsection{Iniciativas}

Se va a presentar las iniciativas para cada uno de los objetivos de las distintas perspectivas.

Tabla 39

\section{Iniciativas}

\begin{tabular}{|c|l|}
\hline \multicolumn{2}{|c|}{ PERSPECTIVA FINANCIERA } \\
\hline OBJETIVO & \multicolumn{1}{|c|}{ INICIATIVAS } \\
\hline \multirow{2}{*}{ Aumento de Rentabilidad } & • Control de gastos. \\
\cline { 2 - 2 } & - Control de endeudamiento. \\
\hline \multirow{2}{*}{$\begin{array}{c}\text { Aumento de Ingresos } \\
\text { Disminución de Gastos } \\
\text { operativos }\end{array}$} & • Captación de nuevos clientes. \\
\cline { 2 - 2 } & $\begin{array}{l}\text { - Plan de fidelización y calidad total } \\
\text { usuario. }\end{array}$ \\
\cline { 2 - 2 } & - Tercerización de soporte \\
\hline
\end{tabular}

Nota. Adaptado de Cuadro de mando integral (p. 161), por R. Kaplan R. y D. Norton, 2000, Barcelona. Copyright 1996 por Ediciones Gestión 2000. Elaboración propia. 


\begin{tabular}{|c|c|}
\hline \multicolumn{2}{|c|}{ PERSPECTIVA CLIENTES } \\
\hline OBJETIVO & INICIATIVAS \\
\hline \multirow[b]{2}{*}{ Fidelizar clientes } & - Programa de mejora de atención a clientes. \\
\hline & $\begin{array}{l}\text { - Capacitaciones internas y externas relacionadas a } \\
\text { convenciones. }\end{array}$ \\
\hline \multirow{2}{*}{$\begin{array}{c}\text { Incremento de la satisfacción de } \\
\text { clientes } \\
\end{array}$} & - Implementar servicio de post venta. \\
\hline & - Programa de calidad en el servicio. \\
\hline \multirow{2}{*}{$\begin{array}{l}\text { Aumentar la cuota de mercado en } \\
\text { el rubro de convenciones }\end{array}$} & - Supervisión de nuevos proyectos. \\
\hline & - Dar a conocer los productos del CVH \\
\hline \multirow{4}{*}{ Mejora de calidad y seguridad } & - Incrementar las políticas de seguridad. \\
\hline & $\begin{array}{l}\text { - Capacitaciones sobre el uso adecuado de los } \\
\text { insumos. }\end{array}$ \\
\hline & $\begin{array}{l}\text { - Tener buenas relaciones con los principales } \\
\text { proveedores. }\end{array}$ \\
\hline & - Mejorar los procesos de control de calidad \\
\hline
\end{tabular}

Nota. Adaptado de Cuadro de mando integral (p. 161), por R. Kaplan R. y D. Norton, 2000, Barcelona. Copyright 1996 por Ediciones Gestión 2000. Elaboración propia.

\begin{tabular}{|c|c|}
\hline \multicolumn{2}{|c|}{ PERSPECTIVA DE PROCESOS INTERNOS } \\
\hline OBJETIVO & INICIATIVAS \\
\hline \multirow{2}{*}{ Atención total de clientes } & - Programa de manejo de eventos. \\
\hline & - Programa de coaching voluntario. \\
\hline \multirow{2}{*}{ Búsqueda de nuevos mercados } & $\begin{array}{l}\text { - Seguimiento de nuevos proyectos que incentiven la } \\
\text { inversión. }\end{array}$ \\
\hline & $\begin{array}{l}\text { - Establecer estrecha relación con los empresas } \\
\text { institucionales. }\end{array}$ \\
\hline \multirow{2}{*}{$\begin{array}{l}\text { Mejorar los instructivos de } \\
\text { abastecimiento y seguridad }\end{array}$} & $\begin{array}{l}\text { - Implementar programas relacionados en contar con } \\
\text { insumos mínimos frente a la escasez. }\end{array}$ \\
\hline & - Mejorar políticas de seguridad. \\
\hline $\begin{array}{l}\text { Gestión eficiente de inventarios } \\
\text { de distribución }\end{array}$ & $\begin{array}{l}\text { - Establecer un planeamiento de compras de } \\
\text { productos que son de poca durabilidad. }\end{array}$ \\
\hline $\begin{array}{l}\text { Buenas relaciones con los } \\
\text { principales y nuevos proveedores }\end{array}$ & $\begin{array}{l}\text { - Programa de cumplimiento de los estándares de } \\
\text { seguridad y adquirir certificaciones. }\end{array}$ \\
\hline
\end{tabular}

Nota. Adaptado de Cuadro de mando integral (p. 161), por R. Kaplan R. y D. Norton, 2000, Barcelona. Copyright 1996 por Ediciones Gestión 2000. Elaboración propia. 


\begin{tabular}{|c|c|}
\hline \multicolumn{2}{|c|}{ PERSPECTIVA DE APRENDIZAJE Y CRECIMIENTO } \\
\hline OBJETIVO & INICIATIVAS \\
\hline \multirow{2}{*}{$\begin{array}{l}\text { Aumentar productividad de los } \\
\text { colaboradores }\end{array}$} & - Programa de capacitaciones \\
\hline & - Política de promociones \\
\hline \multirow{2}{*}{$\begin{array}{l}\text { Progreso en el desarrollo de } \\
\text { habilidades a través de } \\
\text { capacitaciones a los } \\
\text { colaboradores }\end{array}$} & - Constantes capacitaciones \\
\hline & $\begin{array}{l}\text { - Asignar competencias por áreas y desarrollo } \\
\text { individual }\end{array}$ \\
\hline \multirow{2}{*}{$\begin{array}{l}\text { Manejo de conocimiento por } \\
\text { sistema de información }\end{array}$} & - Capacitación en sistemas \\
\hline & - Establecer recursos \\
\hline \multirow{2}{*}{$\begin{array}{c}\text { Las metas personales deben estar } \\
\text { alineadas con los objetivos del } \\
\text { CVH }\end{array}$} & - Programa de liderazgo \\
\hline & - Coaching \\
\hline
\end{tabular}

Nota. Adaptado de Cuadro de mando integral (p. 161), por R. Kaplan R. y D. Norton, 2000, Barcelona. Copyright 1996 por Ediciones Gestión 2000. Elaboración propia.

\subsection{Responsable de cada una de las iniciativas}

En la Tabla 40 se visualiza el área responsable de cada uno de los objetivos.

Tabla 2640

Responsables por iniciativas

\begin{tabular}{|c|c|}
\hline \multicolumn{2}{|c|}{ PERSPECTIVA FINANCIERA } \\
\hline OBJETIVO & $\begin{array}{c}\text { RESPONSABLE } \\
\text { DEL OBJETIVO }\end{array}$ \\
\hline Aumento de Rentabilidad & Gerente Financiero \\
\hline Aumento de Ingresos & Gerente General \\
\hline $\begin{array}{c}\text { Disminución de Gastos } \\
\text { operativos }\end{array}$ & $\begin{array}{c}\text { Gerente de } \\
\text { Administración }\end{array}$ \\
\hline
\end{tabular}

Nota. Adaptado de Cuadro de mando integral (p. 161), por R. Kaplan R. y D. Norton, 2000, Barcelona. Copyright 1996 por Ediciones Gestión 2000. Elaboración propia. 


\begin{tabular}{|c|c|}
\hline \multicolumn{2}{|c|}{ PERSPECTIVA CLIENTES } \\
\hline OBJETIVO & $\begin{array}{c}\text { RESPONSABLE } \\
\text { DEL OBJETIVO }\end{array}$ \\
\hline Fidelizar de Clientes & Gerente de ventas \\
\hline $\begin{array}{c}\text { Incremento de la satisfacción de } \\
\text { clientes }\end{array}$ & Gerente de ventas \\
\hline $\begin{array}{c}\text { Aumentar la cuota de mercado en } \\
\text { el rubro de convenciones }\end{array}$ & Gerente General \\
\hline & \\
\hline $\begin{array}{c}\text { Mejora de calidad y seguridad } \\
\text { Gerente General }\end{array}$ & \\
\hline
\end{tabular}

Nota. Adaptado de Cuadro de mando integral (p. 161), por R. Kaplan R. y D. Norton, 2000, Barcelona. Copyright 1996 por Ediciones Gestión 2000. Elaboración propia.

\begin{tabular}{|c|c|}
\hline \multicolumn{2}{|c|}{ PERSPECTIVA DEPROCESOS INTERNOS } \\
\hline OBJETIVO & $\begin{array}{c}\text { RESPONSABLE } \\
\text { DEL OBJETIVO }\end{array}$ \\
\hline $\begin{array}{c}\text { Gerente de } \\
\text { Adminis tración total de clientes }\end{array}$ \\
\hline $\begin{array}{c}\text { Mejorar los instructivos de } \\
\text { abastecimiento y seguridad }\end{array}$ & $\begin{array}{c}\text { Gerente de } \\
\text { Logística }\end{array}$ \\
\hline $\begin{array}{c}\text { Gestión de eficiencia de } \\
\text { inventarios de distribución } \\
\text { proyectos }\end{array}$ & $\begin{array}{c}\text { Gerente de } \\
\text { Administración y } \\
\text { Finanzas }\end{array}$ \\
\hline $\begin{array}{c}\text { Buenas relaciones con los } \\
\text { principales y nuevos proveedores }\end{array}$ & $\begin{array}{c}\text { Director de } \\
\text { relaciones Publicas }\end{array}$ \\
\hline
\end{tabular}

Nota. Adaptado de Cuadro de mando integral (p. 161), por R. Kaplan R. y D. Norton, 2000, Barcelona. Copyright 1996 por Ediciones Gestión 2000. Elaboración propia. 


\begin{tabular}{|c|c|}
\hline \multicolumn{2}{|c|}{$\begin{array}{c}\text { PERSPECTIVA DE APRENDIZAJEY } \\
\text { CRECIMIENTO }\end{array}$} \\
\hline OBJETIVO & $\begin{array}{l}\text { RESPONSABLE } \\
\text { DEL OBJETIVO }\end{array}$ \\
\hline $\begin{array}{l}\text { Aumentar la productividad de } \\
\text { loss empleados }\end{array}$ & $\begin{array}{c}\text { Gerente de } \\
\text { Recursos Humanos }\end{array}$ \\
\hline $\begin{array}{c}\text { Progreso en el desarrollo de } \\
\text { habilidades a través des } \\
\text { capacitaciones a los } \\
\text { colaboradores }\end{array}$ & $\begin{array}{c}\text { Gerente de } \\
\text { Recursos Humanos }\end{array}$ \\
\hline $\begin{array}{l}\text { Manejo de conocimiento por } \\
\text { sistemas de información }\end{array}$ & $\begin{array}{c}\text { Gerente de } \\
\text { Recursos Humanos }\end{array}$ \\
\hline $\begin{array}{l}\text { Las metas personales deben estar } \\
\text { alineadas con objetivos del CVH }\end{array}$ & $\begin{array}{c}\text { Gerente de } \\
\text { Recursos Humanos }\end{array}$ \\
\hline
\end{tabular}

Nota. Adaptado de Cuadro de mando integral (p. 161), por R. Kaplan R. y D. Norton, 2000, Barcelona. Copyright 1996 por Ediciones Gestión 2000. Elaboración propia.

\subsection{Presupuesto de cada una de las iniciativas}

La estrategia que se ha seleccionado es la diferenciación del servicio la cual se logrará cumpliendo las iniciativas propuestas las cuales está relacionada con las cuatro perspectivas (financiera, clientes, procesos internos, y aprendizaje y crecimiento). En el siguiente cuadro se presenta dichas iniciativas con sus respectivos presupuestos. 
Tabla 41

Presupuesto por iniciativa

\begin{tabular}{|c|c|}
\hline \multicolumn{2}{|l|}{ PERSPECTIVA FINANCIERA } \\
\hline INICIATIVAS ESTRATEGICAS & PRESUPUESTO S/. \\
\hline Control de gastos & $\mathrm{S} / .9,000.00$ \\
\hline Control de endeudamiento & $\mathrm{S} / 2,700.00$ \\
\hline Captación de nuevos clientes & $\mathrm{S} / .5,800.00$ \\
\hline Plan de fidelización y calidad total & $\mathrm{S} / .12,000.00$ \\
\hline Desarrollo de programas de reducción de gastos por usuario & $\mathrm{S} / .2,700.00$ \\
\hline Tercerización de soporte & $\mathrm{S} / .2,300.00$ \\
\hline
\end{tabular}

Nota. Adaptado de Cuadro de mando integral (p. 161), por R. Kaplan R. y D. Norton, 2000, Barcelona. Copyright 1996 por Ediciones Gestión 2000. Elaboración propia.

En el programa de control de gastos se planea invertir S/. 9,000, en cuanto a control de endeudamiento se destinaría a gastos de asesorías y modificaciones de formatos invirtiendo S/. 2,700; respecto a la captación de nuevos clientes la inversión sería de S/. 5,800. Por otro lado, el plan de fidelización y calidad total, la inversión asciende a S/.12,000. Por lo tanto, también se planifica contar con investigaciones de mercado de eventos. Y para la implementación de programas de reducción de gastos por usuario se planea realizar una inversión de S/. 2,700 y S/. 2,300 para la tercerización de soporte.

En el siguiente cuadro de la Perspectiva Clientes, se tiene va realizar una inversión de S/. 37,650. Se busca impulsar la diferenciación del servicio con distintas actividades orientadas al servicio al cliente y mejorar los procesos de calidad. 


\begin{tabular}{|c|c|}
\hline \multicolumn{2}{|l|}{ PERSPECTIVA CLIENTES } \\
\hline INICIATIVAS & PRESUPUESTO S/. \\
\hline Programa de mejora de atención a clientes & $\mathrm{S} / .5,300.00$ \\
\hline $\begin{array}{l}\text { Capacitaciones internas y externas relacionadas a } \\
\text { convenciones }\end{array}$ & $\mathrm{S} / .4,150.00$ \\
\hline Implementar de servicio de post venta & $\mathrm{S} / .4,000.00$ \\
\hline Programa de calidad en el servicio & $\mathrm{S} / .3,000.00$ \\
\hline Supervisión de proyectos institucionales & $\mathrm{S} / .3,400.00$ \\
\hline Dar a conocer los productos del CVH & $\mathrm{S} / .2,900.00$ \\
\hline Incrementar las políticas de seguridad & $\mathrm{S} / .3,400.00$ \\
\hline Capacitaciones sobre el uso adecuado de los insumos & $\mathrm{S} / .2,000.00$ \\
\hline Tener buenas relaciones con los principales proveedores & $\mathrm{S} / .4,500.00$ \\
\hline Mejorar los procesos de control de calidad & $\mathrm{S} / .5,000.00$ \\
\hline
\end{tabular}

Nota. Adaptado de Cuadro de mando integral (p. 161), por R. Kaplan R. y D. Norton, 2000, Barcelona. Copyright 1996 por Ediciones Gestión 2000. Elaboración propia.

Con respecto a la realización de actividades en la perspectiva clientes, se a determinado realizar un programa de mejora de atención a clientes de forma oportuna donde se invertirá S/.5,300.00, en las actividades que se realicen en el programa de capacitaciones internas y externas relacionadas a convenciones la inversión es de S/. 4,150.00, en cuanto al servicio de post venta la inversión a será de S/. 4,000. También se va a implementar un programa de calidad en el servicio con una inversión de S/. 3,000.00, en cuanto a las actividades de nuevos proyectos institucionales la inversión a realizar es de S/. 3,400. En relación a dar a conocer los productos del CVH se a previsto una inversión S/. 2,900 la cual consiste en capacitaciones a los colaboradores. También se debe contar con conocimientos para aplicar políticas de seguridad de alto nivel y se debe de contar con los servicios de asesorías y capacitaciones de acuerdo al cronograma de actividades el monto a invertir será de $S / .3,400$. 
También ser realizará capacitaciones sobre el uso adecuado de los insumos invirtiendo S/. 2,000. Respecto a tener buenas relaciones con los principales proveedores se deberá invertir S/. 4,5000. Y finalmente se deberán mejorar los procesos de control de calidad donde la inversión será de S/. 5,000.

A continuación, se desarrolla la Perspectiva de procesos internos, siendo importantes para el cumplimiento y puesta en marcha del objetivo estratégico.

\begin{tabular}{|l|c|}
\hline \multicolumn{2}{|c|}{ PERSPECTIVA DE PROCESOS INTERNOS } \\
\hline \multicolumn{1}{|c|}{ INICIATIVAS } & PRESUPUESTO S/. \\
\hline Programa de manejo de eventos & S/.8,300.00 \\
\hline Programa de coaching voluntario & S/.4,100.00 \\
\hline Seguimiento de nuevos proyectos que incentivan la inversión & S/.2,900.00 \\
\hline \begin{tabular}{l} 
Establecer estrecha relación con las empresas insititucionales \\
\hline $\begin{array}{l}\text { Implementar programas relacionados en contar con insumos } \\
\text { mínimos frente a la escasez }\end{array}$
\end{tabular} & S/.4,000.00 \\
\hline Mejorar políticas de seguridad $.2,200.00$ \\
\hline $\begin{array}{l}\text { Establecer un planteamiento de compras de productos que } \\
\text { son de poca durabilidad }\end{array}$ & S/.2,300.00 \\
\hline $\begin{array}{l}\text { Programa de cumplimiento de los estándares de seguridad y } \\
\text { adquirir certificaciones }\end{array}$ & S/.5,200.00 \\
\hline
\end{tabular}

Nota. Adaptado de Cuadro de mando integral (p. 161), por R. Kaplan R. y D. Norton, 2000, Barcelona. Copyright 1996 por Ediciones Gestión 2000. Elaboración propia.

En cuanto al Programa de manejo de eventos, es fundamental debido que al implementar la estrategia de diferenciación tiene como objetivo el servicio al cliente y se invertirán S/ 8,300. También se implementará un Programa de coaching voluntario donde el monto de inversión será de S/. 4,100. Por lo tanto, se contará con la propuesta de seguimiento de nuevos proyectos que incentiven la inversión, esta iniciativa está relacionada con el marketing. En cuanto establecer estrecha relación con las empresas institucionales se invertirá S/. 4,000. También es adecuado implementar un "Programa de prevención de 
abastecimiento" ante la escasez de insumos críticos y su inversión será de S/2,200. Se debe mejorar políticas de seguridad para lo cual se contará con capacitaciones de manera constante, la inversión será de S/2,300. En relación a la compra de pocos productos que tiene corta vida se implementar el programa de compras que tendrá la inversión de S/. 3,700. Y respecto a la seguridad y certificaciones la inversión será de S/. 5,200.00.

\begin{tabular}{|c|c|}
\hline \multicolumn{2}{|c|}{ PERSPECTIVA DE APRENDIZAJE Y CRECIMIENTO } \\
\hline INICIATIVAS & PRESUPUESTO S $/$. \\
\hline Programas de capacitaciones & $\mathrm{S} / .12,350.00$ \\
\hline Políticas de promociones & $\mathrm{S} / .1,000.00$ \\
\hline Constantes capacitaciones & $\mathrm{S} / .3,400.00$ \\
\hline Asignar competencias por áreas y desarrollo individual & $\mathrm{S} / .3,000.00$ \\
\hline Capacitación en sistema & S/.5,800.00 \\
\hline Establecer recursos & $\mathrm{S} / .0 .00$ \\
\hline Programa de liderazgo & $\mathrm{S} / .5,500.00$ \\
\hline Coaching & $\mathrm{S} / .5,000.00$ \\
\hline
\end{tabular}

Nota. Adaptado de Cuadro de mando integral (p. 161), por R. Kaplan R. y D. Norton, 2000, Barcelona. Copyright 1996 por Ediciones Gestión 2000. Elaboración propia.

En relación a las iniciativas de Perspectiva de Aprendizaje y Crecimiento, se implementará talleres de capacitación y coaching la programación será para el año 1 y se tendrá una inversión de S/. 12,350. También al establecer políticas de promociones se desarrollará un plan de promoción de puestos y políticas de constantes capacitaciones. Se deberán fijar competencias por áreas y desarrollo individual con una inversión de S/. 3,000.00; se implementará un Programa de capacitación en sistemas el cual es importante para poder mejorar la estrategia relacionada con los clientes. También se programará talleres 
de liderazgo y la implementación de actividades de coaching para lo cual se invertirán S/. 10,500 .

\subsection{Cronograma de cada una de las iniciativas}

En este punto se desarrolla un cronograma para cada una de las actividades y un responsable que se hará cargo de su ejecución (ver anexo 7). 


\section{CAPÍTULO X}

\section{EVALUACIÓN}

\subsection{Evaluación Cualitativa}

Según David (2013), la evaluación de estrategias es importante para las organizaciones ya que permite identificar los problemas que se puedan presentar y de esa manera la organización pueda tomar las decisiones oportunamente antes que la situación genere inconvenientes.

\subsubsection{Criterios de Evaluación}

Según Rumelt (1980), se evalúa a las estrategias por medio de los siguientes criterios:

- $\quad$ “Congruencia: la estrategia no deberá presentar inconsistencias entre las metas y las políticas.

- Consonancia: la estrategia deberá representar una respuesta clara a los cambios en las variables del entorno.

- Ventaja: la estrategia deberá ser la base para la creación o mantenimiento de la ventaja competitiva en la empresa.

- Viabilidad: la estrategia no deberá sobrecargar los recursos disponibles ni crear problemas que no se puedan resolver".

\subsubsection{Comparación de la estrategia con los criterios}

La metas y objetivos del CVH, está orientadas a cumplir la estrategia de diferenciación de servicio. (Congruencia).

Los variables del entorno externo es favorable para el resurgimiento del $\mathrm{CVH}$, llegando a alcanzar la estrategia de diferenciación de servicio. (Consonancia). 
La estrategia de diferenciación de servicio debe estar enfocada en cumplir las necesidades y expectativas de los clientes para que esto beneficie al CVH a lograr la ventaja competitiva. (Ventaja).

El presupuesto proyectado para la implementación de la estrategia está acorde con los ingresos y gastos del $\mathrm{CVH}$, siendo las principales iniciativas las capacitación a colaboradores del rubro de convenciones. (Viabilidad).

\subsection{Evaluación Financiera de la Estrategia}

\subsubsection{Proyección de estados financieros (situación actual y con la nueva estrategia)}

La evaluación financiera de la estrategia seleccionada se medirá por medio de las proyecciones de los estados financieros. Estamos tomando como base los estados financieros de 2012 del CVH para realizar las proyecciones de los años del periodo del Plan Estratégico del CVH.

Para la proyección de los EEFF no se va a tomar en cuenta los 2 millones de soles que son entregados por el Gobierno Central, ya que el CVH depende del Ministerio de Educación. Esto quiere decir que solo se está tomando en cuenta los ingresos generados por las operaciones internas del CVH.

Tabla 2742

Principales variables y supuestos

Indicadores proyectados/ con Estrategia Perspectiva Financiera

\begin{tabular}{|lllllll|}
\hline & 2016 & 2017 & 2018 & 2019 & 2020 & 2021 \\
Inc. Utilidad & $11.81 \%$ & $13.44 \%$ & $15.07 \%$ & $16.70 \%$ & $18.33 \%$ & $19.97 \%$ \\
Inc. Ingresos & $9 \%$ & $11 \%$ & $12.75 \%$ & $14.50 \%$ & $16.13 \%$ & $18 \%$ \\
& & & & & & \\
Red. Gast. Operativos & $5 \%$ & $5 \%$ & $5 \%$ & $5 \%$ & $5 \%$ & $6 \%$ \\
\hline
\end{tabular}

Nota: Elaboración propia. 


\section{Indicadores proyectados/ sin Estrategia}

Perspectiva Financiera

\begin{tabular}{|lllllll|}
\hline & 2016 & 2017 & 2018 & 2019 & 2020 & 2021 \\
Inc. Utilidad & $9 \%$ & $11 \%$ & $12 \%$ & $12 \%$ & $13 \%$ & $14 \%$ \\
Inc. Ingresos & $10 \%$ & $12 \%$ & $13 \%$ & $14 \%$ & $15 \%$ & $15 \%$ \\
& $6 \%$ & $3 \%$ & $3 \%$ & $2 \%$ & $2 \%$ & $2 \%$ \\
\hline
\end{tabular}

Nota: Elaboración propia.

\subsubsection{Estados de resultados (situación actual y con la nueva estrategia)}

El Estado de Ganancias y Pérdidas del CVH está expresado en nuevos soles. Y los resultados de los ejercicios 2012 - 2014 son tomados como información histórica, y en el año 2012 han sido negativos debido a una gestión con bajos resultados por la que pasó el CVH en la década de los años 2000. Debemos de tomar en cuenta que desde el año 2013 solo se está considerando el 30\% que proviene del Gobierno central, para el año 2013 se tuvieron S/. 786,313, en el 2014 se tuvieron ingresos por S/ 825,629 y para el 2015 se asignó S/.866,911.

Se realiza una proyección de 3\% para los próximos años ya que ello es proporcional de acuerdo al crecimiento de ventas. Debemos tomar en cuenta que gracias a esto el estado de ganancias y pérdidas a partir del año 2013 da utilidades positivas y ello también se debe a la estrategia adoptada por el directorio del CVH.

Con la implementación del plan estratégico 2017 se muestra una mejora en el nivel de ingresos, con el apoyo de las estrategias que se deben aplicar y de esa manera llegar al nivel de ventas que se espera conseguir. En la tabla 43 se puede apreciar el estado de resultados proyectado para los siguientes 5 años. 
Tabla 43

Estado de Resultados, Situación Actual

\begin{tabular}{|c|c|c|c|c|c|c|c|c|c|c|c|c|c|c|c|}
\hline & 2007 & 2008 & 2009 & 2010 & 2011 & 2012. & 2013 & 2014 & 2015 & 2016 & 2017 & 2018 & 2019 & 2020 & 2021 \\
\hline \multicolumn{16}{|l|}{ Ventas Netas } \\
\hline A terceros & $1,530,564$ & $1,886,634$ & $1,434,854$ & $2,298,471$ & $3,325,225$ & 4,758,398 & $9,164,831$ & $9,623,073$ & $10,104,227$ & $10,609,438$ & $11,139,910$ & $11,696,905$ & $12,281,750$ & $12,895,838$ & $13,540,630$ \\
\hline \multicolumn{16}{|l|}{ A empresas vinculadas } \\
\hline \multicolumn{16}{|l|}{ Otros ingresos operacionales } \\
\hline \multicolumn{16}{|l|}{ A terceros } \\
\hline \multicolumn{16}{|l|}{ A empresas vinculadas } \\
\hline TOTAL INGRESOS BRUTOS & $1,530,564$ & $1,886,634$ & $1,434,854$ & $2,298,471$ & $3,325,225$ & 4,758,398 & $9,164,831$ & $9,623,073$ & $10,104,227$ & $10,609,438$ & $11,139,910$ & $11,696,905$ & $12,281,750$ & $12,895,888$ & $13,540,630$ \\
\hline Costo de ventas & $2,533,181$ & $2,670,270$ & $2,934,519$ & $3,258,415$ & $1,787,474$ & $2,078,199$ & $3,773,321$ & $-3,961,987$ & $-4,160,086$ & $-4,368,091$ & $-4,586,495$ & $-4,815,820$ & $-5,056,611$ & $-5,309,442$ & $-5,574,914$ \\
\hline \multicolumn{16}{|l|}{ A terceros } \\
\hline \multicolumn{16}{|l|}{ A empresas vinculadas } \\
\hline UTILLDAD BRUTA & $1,002,617$ & 783,636 & $1,499,665$ & 959,944 & $1,587,751$ & $2,680,199$ & $5,391,510$ & $5,661,086$ & $5,944,140$ & $6,241,347$ & $6,558,415$ & $6,881,085$ & $7,225,140$ & $7,586,396$ & $\begin{array}{l}7,965,716 \\
\end{array}$ \\
\hline Gastos de administración & 927,265 & $1,125,175$ & 955,876 & 842,965 & $2,034,018$ & $1,488,329$ & $1,247,039$ & $-1,309,390$ & $-1,374,860$ & $-1,443,603$ & $-1,515,783$ & $-1,591,572$ & $-1,671,151$ & $-1,754,708$ & $-1,842,444$ \\
\hline Gastos de ventas & 73,205 & 52,334 & 80,084 & 138,296 & $1,102,409$ & $2,776,059$ & $-3,053,664$ & $-3,206,348$ & $-3,366,665$ & $-3,534,998$ & $-3,711,748$ & $-3,897,336$ & $-4,092,202$ & $-4,296,813$ & $-4,511,653$ \\
\hline Otros ingresos & & & 488,251 & 321,239 & & 82,443 & \begin{tabular}{l|l|}
786,313 \\
\end{tabular} & 825,629 & 866,911 & 990,256 & 955,769 & $1,003,557$ & $1,053,735$ & $1,106,422$ & $1,161,743$ \\
\hline Otros Gastos & & & 216,137 & 45,630 & 563,870 & 725,576 & 600,281 & $-630,295$ & $-661,810$ & $-694,900$ & $.729,645$ & $-766,128$ & $-804,434$ & $-844,656$ & $-886,888$ \\
\hline UTILIDAD OPERATIVA & $2,003,087$ & $1,961,145$ & $2,263,511$ & $1,665,596$ & $2,162,546$ & $2,227,322$ & $1,276,840$ & $1,340,682$ & $1,407,716$ & $1,478,102$ & $1,552,007$ & $1,629,607$ & $1,711,087$ & $1,796,642$ & $1,886,474$ \\
\hline \multicolumn{16}{|l|}{ OTROS INGRESOS (GASTOS) } \\
\hline \begin{tabular}{|l|l|l} 
ngresos diversos \\
\end{tabular} & 222,780 & 176,684 & & & 306,821 & & & $\cdot$ & $\cdot$ & $\cdot$ & $\cdot$ & $\cdot$ & $\cdot$ & $\cdot$ & - \\
\hline Ingresosos excepcionales & 364,049 & 208,929 & & & & & & $\cdot$ & - & - & $\cdot$ & $\cdot$ & - & $\cdot$ & \\
\hline Ingresesos financieros & 397 & 1,859 & 1,066 & 106 & & & & $\cdot$ & $\cdot$ & $\cdot$ & $\cdot$ & $\cdot$ & $\cdot-1$ & $\cdot$ & \\
\hline Cargas Excepcionales & 387,094 & 159,035 & & & 183,229 & 321,116 & 154,606 & $-162,336$ & $-170,453$ & $-178,976$ & $-187,925$ & -197,321 & $-207,187$ & $-217,546$ & $-228,423$ \\
\hline Cargas Financieras & 17,441 & 34,898 & 37,290 & 47,496 & 39,624 & 37,331 & 36,258 & $-38,071$ & $-39,974$ & $-41,973$ & $-44,072$ & $-46,275$ & $-48,589$ & $-51,018$ & $-53,569$ \\
\hline REI del Ejercicio & 21,332 & & & & & & & & & & & & & & \\
\hline RESULTADO ANTES DE PARTIDAS EXTRAORDINARIAS, PARI- & $1,799,064$ & $1,767,606$ & $2,299,735$ & $1,712,986$ & $2,078,578$ & $2,585,768$ & $1,085,976$ & $1,140,275$ & $1,197,289$ & 1,257,153 & 1,320,011 & $1,386,011$ & 1,455,312 & $1,528,077$ & 1,604,481 \\
\hline \multicolumn{16}{|l|}{\begin{tabular}{|l|l|} 
Participaciones & \\
\end{tabular}} \\
\hline \multicolumn{16}{|l|}{ Impuesto a la renta } \\
\hline RESULTADO ANTES DE PARTIDAS EXTRAORDINARIAS & $1,799,064$ & $1,767,606$ & 2,299,735 & $1,712,986$ & $2,078,578$ & $2,585,768$ & $1,085,976$ & $1,140,275$ & $1,197,289$ & $1,257,153$ & $1,320,011$ & $1,386,011$ & 1,455,312 & $1,528,077$ & 1,604,481 \\
\hline \multicolumn{16}{|l|}{ Ingresosos extraordinarios } \\
\hline \multicolumn{16}{|l|}{ Gastos extraordinarios } \\
\hline RESULTADO ANTES DE INTERES MINORITARIO & $1,799,064$ & $1,767,606$ & 2,299,735 & $1,712,986$ & $2,078,578$ & $2,585,768$ & $1,085,976$ & $1,140,275$ & $1,197,289$ & $1,257,153$ & $1,320,011$ & $1,386,011$ & 1,455,312 & $1,528,077$ & 1,604,481 \\
\hline \multicolumn{16}{|l|}{ Interés minunitario } \\
\hline UTILIDAD (PERDIDA) DEL EJERCICIO & $1,799,064$ & $1,767,606$ & $2,299,735$ & 1,712,986 & $2,078,578$ & $2,585,768$ & $1,085,976$ & $1,140,275$ & 1,197,289 & 1,257,153 & 1,320,011 & $1,386,011$ & $1,455,312$ & $1,528,077$ & $1,604,481$ \\
\hline BESULTADO DEL EJERCICIO & $1,799,064$ & $1,767,606$ & $2,299,735$ & $1,712,986$ & $2,078,578$ & $-2,585,768$ & $1,085,976$ & $1,140,275$ & $1,197,289$ & $1,257,153$ & $1,320,011$ & $1,386,011$ & $1,455,312$ & $1,528,077$ & $1,604,481$ \\
\hline
\end{tabular}

Nota. Recuperado de

http://www.transparencia.gob.pe/enlaces/pte_transparencia_enlaces.aspx?id_entidad=13099\&id_tema=5\&ver=\#.Wx3In0gvzIU. Elaboración propia. 
Situación nueva estrategia: Con la implementación de la estrategia se generan gastos operativos y dan un impacto positivo en la generación de ingresos. No se ha planteado realizar inversiones mayores debido a que se plantean utilizar los ingresos que se lleguen a generar. 
Tabla 44

Estado de Resultados, Situación Nueva Estrategia

CENTRO VACACIONAL HUAMPANI

Estado de Ganancias y Pérdidas/ Con Estrategia

Al 31 de diciembre de 2007 - 2021

(en nuevos soles)

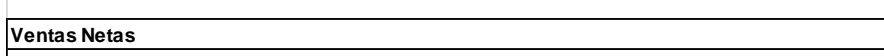

A terceros

\begin{tabular}{|l}
\hline A terceros \\
\hline empresas vinculadas \\
\hline
\end{tabular}

A empresas vinculadas

A terceros

A empresas vinculadas

TOTAL INGRESOS BRUTOS

\begin{tabular}{|l|}
\hline Costo de ventas \\
\hline A terceros
\end{tabular}

\begin{tabular}{|l|}
\hline A terceros \\
\hline A empresas vinculadas \\
\hline
\end{tabular}

A empresas vincula

Gastos de administración

Gastos de ventas

Otros ingresos

Otros Gastos
UTILIDAD OPERATIVA

DTROS INGRESOS (GASTOS)

\begin{tabular}{|l} 
Ingresos diversos \\
\hline Ingresos excepcion
\end{tabular}

ingresos excepcionale

ingresos financieros

Cargas Excepcionale

Cargas Financieras

REI del Ljercicio

Participaciones

\begin{tabular}{l} 
Impuesto a la renta \\
\hline RESULTADO ANTES DE PARTIDAS EXTRAORDINARIAS \\
\hline
\end{tabular}

Ingresos extraordinarios

Gastos extraordinario

RESULTADO ANTES DE INTERES MINORITARIO

Interés minuritario

UTILIDAD (PERDIDA) DEL EJERCICIO

RESULTADO DEL EJERCICIO

\begin{tabular}{|c|c|c|c|c|c|}
\hline 2016 & 2017 & 2018 & 2019 & $202 C$ & 2021 \\
\hline $10,710,480.10$ & $11,031,795$ & $11,583,384.23$ & $12,046,720$ & $12,649,055.58$ & $13,660,980$ \\
\hline & & & & & \\
\hline & & & & & \\
\hline & & & & & \\
\hline $10,710,480$ & $11,031,795$ & $11,583,384$ & $12,046,720$ & $12,649,056$ & $13,660,980$ \\
\hline$-4,368,091$ & $-4,586,495$ & $-4,815,820$ & $-5,056,611$ & $-5,309,442$ & $-5,574,914$ \\
\hline & & & & & \\
\hline $6,342,389$ & $6,445,299$ & $6,767,564$ & $6,990,109$ & $7,339,614$ & $8,086,066$ \\
\hline$-1,429,854.37$ & $-1,487,048.54$ & $-1,546,530.48$ & $-1,592,926.40$ & $-1,640,714.19$ & $-1,689,935.62$ \\
\hline$-3,551,831.62$ & $-3,747,182.36$ & $-3,953,277.39$ & $-4,071,875.71$ & $-4,194,031.98$ & $-4,319,852.94$ \\
\hline $884,248.78$ & $901,933.75$ & $919,972.43$ & $929,172.15$ & $938,463.88$ & $947,848.51$ \\
\hline$-675,046.00$ & $-688,546.92$ & $-702,317.86$ & $-709,341.04$ & $-716,434.45$ & $-723,598.79$ \\
\hline $1,569,906$ & $1,424,455$ & $1,485,411$ & $1,545,138$ & $1,726,897$ & $2,300,528$ \\
\hline- & - & - & - & - & - \\
\hline - & - & - & - & - & - \\
\hline - & - & - & - & - & - \\
\hline & - & - & & & - \\
\hline$-178,976$ & $-187,925$ & $-197,321$ & $-207,187$ & $-217,546$ & $-228,423$ \\
\hline$-41,973$ & $-44,072$ & $-46,275$ & $-48,589$ & $-51,018$ & $-53,569$ \\
\hline & & & & & \\
\hline $1,348,957$ & $1,192,459$ & $1,241,815$ & $1,289,362$ & $1,458,333$ & $2,018,535$ \\
\hline 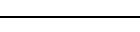 & & 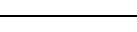 & 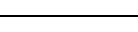 & & \\
\hline $1,348,957$ & $1,192,459$ & $1,241,815$ & $1,289,362$ & $1,458,333$ & $2,018,535$ \\
\hline & & & & & \\
\hline $1,348,957$ & $1,192,459$ & $1,241,815$ & $1,289,362$ & $1,458,333$ & $2,018,535$ \\
\hline 1348.957 & 1192.459 & 1241815 & 1289.362 & 1458.333 & 2018535 \\
\hline $1,348,957$ & $1,192,459$ & $1,241,815$ & $1,289,362$ & $1,458,333$ & $2,018,535$ \\
\hline
\end{tabular}

Nota. Recuperado de

http://www.transparencia.gob.pe/enlaces/pte_transparencia_enlaces.aspx?id_entidad=13099\&id_tema=5\&ver=\#.Wx3In0gvzIU. Elaboración propia. 


\subsubsection{Balance general (situación actual y con la nueva estrategia)}

En las tablas 45 y 46 se presentan los balances generales proyectados con y sin estrategia.

Los resultados que se presentan se han confeccionado en función a los presupuestos que tenemos del $\mathrm{CVH}$, tal es el caso de las cuentas por pagar, cuentas por cobrar, el costo de los activos, el capital y todas las demás cuentas que componen el estado financiero.

El balance proyectado nos mostrará cual será el patrimonio líquido del CVH. En la gestión del 2012 se aprecia que el saldo de caja se encuentra en S/. 247,109 y para el ejercicio 2015 mejora este saldo en S/. 264,900, para el año 2019 se aprecia un aumento considerable de caja que se posiciona en S/. 463,312.

Con relación al capital como parte del patrimonio contable, este saldo se mantiene en S/. 11, 172,469, ya que no existe un aumento de capital en la gestión de estudio. El escenario financiero demuestra que el balance de situación es positiva en función a los saldos que se visualiza en el cuadro lo cual está reflejado con la implementación del plan estratégico. 
Tabla 45

Balance General / Situación Actual

CENTRO VACACIONAL HUAMPANI

Balance General Proyectado

(en nuevos soles)

\begin{tabular}{|c|c|c|c|c|c|c|c|c|c|c|c|c|c|c|c|}
\hline & 2007 & 2008 & 2009 & 2010 & 2011 & 2012 & 2013 & 2014 & 2015 & 2016 & 2017 & 2018 & 2019 & 2020 & 2021 \\
\hline \multirow{2}{*}{\multicolumn{16}{|c|}{\begin{tabular}{|l|} 
ACTIVO \\
ACTIVO CORRIENTE \\
Caja y Bancos \\
\end{tabular}}} \\
\hline & 208,310 & 258,194 & 133,840 & 51,624 & 353,253 & 247,109 & 200,303 & 230,348 & 264,900 & 304,635 & 350,330 & 402,880 & 463,312 & 532,809 & 612,730 \\
\hline $\begin{array}{l}\text { Valores Negociables } \\
\text { Cuentas por cobrar Comerciales }\end{array}$ & 715,892 & $1,048,672$ & 826,382 & & & & $1,085,976$ & $1,248,872$ & $1,436,203$ & $1,651,634$ & $1,899,379$ & $2,184,286$ & $2,511,928$ & \begin{tabular}{c|c|}
$-\cdot$ \\
$3,101,688$ \\
\end{tabular} & $\begin{array}{r}- \\
3,769,630.91 \\
\end{array}$ \\
\hline Menos : Provición Cobranza dudosa & 87,469 & 64,155 & & & & & & & & & & & & & \\
\hline $\begin{array}{l}\text { Cuentas por Cobrar a vinculados } \\
\text { Otras cuentas por cobrar }\end{array}$ & & 56,184 & 25,420 & $1,207,252$ & 597,770 & $8,672,794$ & $\begin{array}{ll}3,567,129 \\
19090\end{array}$ & $\begin{array}{ll}3,388,772 \\
130,19 \\
\end{array}$ & $3,219,334$ & $\begin{array}{ll}3,058,367 \\
10,020 \\
\end{array}$ & $2,905,449$ & $2,760,176$ & $2,622,167$ & $2,491,059$ & $\frac{2,366,506}{709714}$ \\
\hline $\begin{array}{l}\text { Otras cuentas por cobrar } \\
\text { Menos : Provición CCobranza dudosa }\end{array}$ & $\frac{97,043}{34,995}$ & 13,012 & & 94,270 & 63,605 & 12,576 & $1,188,859$ & $1,129,416$ & $1,072,946$ & $1,019,298$ & 968,333 & & 873,921 & & 788,714 \\
\hline $\begin{array}{l}\text { Menos: : Provcion Coobranza audosa } \\
\text { Existencias }\end{array}$ & 99,183 & 98,464 & 83,848 & 127,571 & 121,727 & 111,539 & 137,110 & 157,676 & 181,328 & 208,527 & 239,806 & 275,777 & 317,143 & 364,715 & 419,422 \\
\hline Menos : Prov desva. De existencia & 790975 & 972791 & 650213 & 318207 & 127017 & 3775 & & & & & & & & & \\
\hline $\begin{array}{l}\text { Gastoss pagadosopor antitipo } \\
\text { TOTAL ACTIVO CORRIENTE }\end{array}$ & $\begin{array}{r}792,475 \\
1,790,439\end{array}$ & $2,357,138$ & $\begin{array}{ll}1,721,833 \\
1,833\end{array}$ & $\frac{310,027}{1,799,044}$ & $\frac{1,264,302}{1,302}$ & $\begin{array}{r}3,2 / 5 \\
\mathbf{9 , 0 4 7 , 2 9 4}\end{array}$ & $6,179,377$ & $6,155,086$ & 6.174 .71 & $6,242.461$ & 6.363 .297 & $6,543,036$ & $6,788,472$ & $7,320,495$ & $7,957,003$ \\
\hline \multirow{2}{*}{\multicolumn{16}{|c|}{\begin{tabular}{|l|} 
ACTIVO NO CORRIENTE \\
Cuentas por cobrar a largo plazo \\
Cuentas por cobrar a viculadas a largo plazo
\end{tabular}}} \\
\hline & & & & & & & & & & & & & & & \\
\hline Cuentas por cobrar a vinculadas a largo plazo & & & & & & & & & & & & & & & \\
\hline $\begin{array}{l}\text { Otras ctas por cobrara a largo plazo } \\
\text { Inversiones permanentes }\end{array}$ & 39731 & 39731 & 39731 & 39731 & $\frac{266,215}{39731}$ & 39731 & 39731 & 45.690 & 52.544 & 60125 & 69.89 & 79013 & 91900 & 105694 & 12153 \\
\hline Menos : Fluctuaciones de valores y cobranza & 05,101 & & & & & $16,057,359$ & & $20,615,214$ & $20,821,366$ & $\begin{aligned} 6,0,425 \\
21,029,579 \\
\end{aligned}$ & $\begin{array}{r}6,4999 \\
21,239,875 \\
\end{array}$ & $\frac{1,913}{21,452,274}$ & $\begin{aligned} 91,9600 \\
21,666,797\end{aligned}$ & $\begin{array}{ll}10,83,684 \\
21,883,465\end{array}$ & $\begin{aligned} 12,1537 \\
22,102,299 \\
\end{aligned}$ \\
\hline Inmuebles, Maquinaria y Equipo & $20,651,299$ & $20,705,732$ & $20,623,366$ & $\begin{array}{l}17,165,872 \\
\end{array}$ & $16,755,247$ & 341,104 & 554,344 & 565,431 & 576,740 & 588,275 & 600,040 & 612,041 & 624,282 & 636,767 & 649,50 \\
\hline 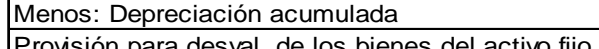 & $2,415,246$ & $2,969,661$ & $3,319,512$ & & & & & & - & & - & & & & \\
\hline $\begin{array}{l}\text { Provisión para desval. de los bienes del activo fijo } \\
\text { Activos intangibles }\end{array}$ & 42,467 & 46,351 & 46,351 & & & & & $\div$ & - & $\div$ & - & - & - & - & \\
\hline Menos: Amortización Acumulada intangible & & & 8,284 & & & & & & & & & & & & \\
\hline Impto a la Renta y Particip. diferidos activos & 335524 & & 84041 & 268664 & 217129 & 86541 & 91670 & $10-1$ & 120 & 12949 & 1623 & 184380 & 212039 & 213845 & \\
\hline TOTAL ACTIVO NO CORRIENTE & $18,653,785$ & $17,822,653$ & $17,466,593$ & $\begin{array}{l}20,0004 \\
17,474,267\end{array}$ & $17,27,1,331$ & $\frac{0.0,041}{16,524,835}$ & $21,096,848$ & $\frac{105,421}{21,331,756}$ & $\frac{121,234}{21,571,884}$ & $\frac{139,419}{21,817,699}$ & $\frac{1100,332}{22,069,737}$ & $\frac{184,382}{22,328,609}$ & $\frac{212,039}{22,595,017}$ & $\frac{243,845}{22,869,762}$ & $\frac{288,422}{23,153,761}$ \\
\hline TOTAL ACTIVO & $20,444,224$ & $20,179,791$ & $19,188,426$ & $19,273,311$ & $18,542,633$ & $25,572,129$ & $27,276,225$ & $27,486,842$ & $27,746,594$ & $28,060,160$ & $28,433,034$ & $28,871,645$ & $29,383,490$ & $30,190,257$ & $31,110,764$ \\
\hline \multirow{2}{*}{\multicolumn{16}{|c|}{$\begin{array}{l}\text { PASIVO Y PATRIMONIO } \\
\text { PASIVO CORRIENTE }\end{array}$}} \\
\hline & & & & & & & & & & & & & & & \\
\hline Sobregiros y Pagarés bancarios & & 35,275 & & & & & & & & & & & & & \\
\hline Cuentas : & 183,412 & & 111,979 & & & & & & & & & & & & \\
\hline Cuentas po & 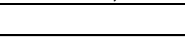 & 141,659 & 285,446 & 667,213 & 277,541 & $1,744,798$ & $1,084,713$ & $1,247,420$ & $1,434,533$ & $1,649,713$ & $1,897,170$ & $2,181,745$ & $2,509,007$ & $2,885,358$ & $3,318,162$ \\
\hline Otras cuentas por & 127,571 & 262,634 & 116,863 & $\frac{15,878}{9831}$ & $\frac{17,104}{27658}$ & 43,019 & 122,772 & 141,188 & 162,366 & 186,721 & 214,729 & 246,938 & 283,979 & 326,576 & 375,562 \\
\hline $\begin{array}{l}\text { Parte ece. Leudas a a arago plazo } \\
\text { TOTAL PASIVO CORRIENTE }\end{array}$ & 310,983 & 439,568 & 514,288 & $\begin{array}{ll}50,01,472 \\
781,472\end{array}$ & $\frac{2,0,000}{322,303}$ & $1,787,817$ & $1,207,485$ & $1,388,608$ & $1,596,899$ & $1,836,434$ & $2,111,899$ & $2,428,684$ & $2,792,986$ & $3,211,934$ & $3,693,724$ \\
\hline \multicolumn{16}{|l|}{$\begin{array}{l}\text { PATAL PASIVO CORRIINIE } \\
\text { PASIVO NO CORRIENTE } \\
\text { DeIddG }\end{array}$} \\
\hline Deudas a largo plazo & $1,992,328$ & & 16,292 & $1,035,273$ & 980,690 & $1,003,800$ & 891,213 & $1,024,894$ & $1,178,629$ & $1,355,423$ & $1,558,736$ & $1,792,547$ & $2,061,429$ & $2,370,643$ & $2,726,240$ \\
\hline $\begin{array}{l}\text { Cuentas por pagar a vinculados } \\
\text { Incresos dificids }\end{array}$ & & $\begin{array}{ll}1,680,855 \\
2002\end{array}$ & $1,099,353$ & & & $\begin{array}{r}15,646 \\
6179210 \\
\end{array}$ & $\begin{array}{r}16,832 \\
0.09197\end{array}$ & $\begin{array}{r}19,357 \\
11,90,730 \\
\end{array}$ & $\begin{array}{r}22,260 \\
1570010\end{array}$ & $\begin{array}{r}25,599 \\
1,2000\end{array}$ & $\begin{array}{r}29,439 \\
\end{array}$ & $\begin{array}{r}33,855 \\
1050070 \\
\end{array}$ & $\begin{array}{r}38,934 \\
11002360\end{array}$ & 44,774 & $\begin{array}{r}51,490 \\
11062360\end{array}$ \\
\hline Imgresos a diferidos & & & & & & & & & & & & & & & $11,862,360$ \\
\hline TOTAL PASIVO NO CORRIENTE & $1,992,328$ & $1,701,948$ & $1,115,645$ & $1,035,273$ & 980,690 & & $10,899,992$ & $12,534,990$ & $13,779,937$ & 13,794, & $13,828,656$ & $13,884,2$ & $13,962,722$ & $14,277, \mathbf{2}$ & $14,640,089$ \\
\hline TOTAL PASIVO & $2,303,311$ & $2,141,516$ & $1,629,933$ & $1,816,745$ & $1,302,993$ & $9,375,498$ & $12,107,477$ & $13,923,598$ & $15,376,836$ & & $15,940,554$ & $16,313,165$ & $16,755,709$ & $17,489,711$ & $18,333,813$ \\
\hline \multicolumn{16}{|l|}{$\begin{array}{l}\text { Contingencia } \\
\text { Interés minoritario }\end{array}$} \\
\hline \multicolumn{16}{|l|}{ PATRIMONIO } \\
\hline Capital & $4,073,990$ & $4,073,990$ & $4,073,990$ & $4,073,990$ & $11,172,469$ & $11,172,469$ & $11,172,469$ & $11,172,469$ & $11,172,469$ & $11,172,469$ & $11,172,469$ & $11,172,469$ & $11,172,469$ & $11,172,469$ & 1 \\
\hline Capital Adicional & $7,098,479$ & $7,098,479$ & $7,0988,479$ & $7,098,479$ & & & & & & & & & & & \\
\hline $\begin{array}{l}\text { Acciones de inversión } \\
\text { Excedente de Revaluación }\end{array}$ & $3,877,359$ & $\begin{array}{l}\frac{3,877,359}{2,756,051} \\
\end{array}$ & $3,877,359$ & & & & & & & & & & & & \\
\hline Reservas & 200109 & 202005 & 25 & 501007 & 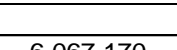 & 50214 & & & & & & & & & \\
\hline $\begin{array}{l}\text { Resultados acumulados } \\
\text { Resultado del eiercicio }\end{array}$ & $3,091,085$ & 232,395 & $\frac{2,808,396}{299735}$ & $6,284,097$ & $6,067,170$ & $5,024,102$ & $\begin{array}{l}2,910,3002 \\
108596\end{array}$ & $\begin{array}{l}1,250,499 \\
1140,275\end{array}$ & 1197289 & 1.257 & 132 & 1386011 & 1455331 & 1.528077 & 1604.481 \\
\hline TOTAL PATRIMONIO & $18,140,913$ & $18,038,274$ & $17,558,489$ & $\overline{17,456,566}$ & $\overline{17,239,640}$ & $16,196,632$ & $15,168,748$ & $13,563,243$ & $12,369,758$ & & 12,49 & $12,558,481$ & $12,627,781$ & $12,700,547$ & $\frac{1,04,401}{12,776,951}$ \\
\hline TOTAL PASIVO Y PATRIMONIO & $20,444,224$ & $20,179,790$ & $19,188,422$ & $19,273,311$ & $18,542,633$ & $25,572,129$ & $27,276,222$ & $27,486,841$ & $27,746,594$ & $28,060,161$ & $28,433,035$ & $28,871,645$ & $29,383,490$ & $30,190,258$ & $31,110,764$ \\
\hline
\end{tabular}

Nota. Recuperado de http://www.transparencia.gob.pe/enlaces/pte_transparencia_enlaces.aspx?id_entidad=13099\&id_tema=5\&ver=\#.Wx3In0gvzIU. Elaboración propia. 
Tabla 46

Balance General / Situación con Estrategia

CENTRO VACACIONAL HUAMPANI

alance General Proyectado/ Con Estrategia

31 de diciembre de 2007 - 2021

(en nuevos soles)

\begin{tabular}{|c|c|c|c|c|c|c|c|c|c|c|c|c|c|c|c|}
\hline \multirow{3}{*}{\begin{tabular}{|l|} 
ACTIVO \\
ACTIVO CORRIENTE \\
Caja y Bancos \\
\end{tabular}} & 2007 & 2008 & 2009 & 2010 & 2011 & 2012 & 2013 & 2014 & 2015 & 2016 & 2017 & 2018 & 2019 & 2020 & 2021 \\
\hline & & & & & & & & & & & & & & & \\
\hline & 208,310 & 258,194 & 133,840 & 51,624 & 353,253 & 247,109 & 200,303 & 230,348 & 264,900 & 304,635 & 350,330 & 402,880 & 463,312 & 532,809 & $982,021.05$ \\
\hline $\begin{array}{l}\text { Valores Negociables } \\
\text { Cuentas por cobrar Comerciales }\end{array}$ & 715,892 & & 826382 & & & & 1085.976 & 1.248 .872 & $1.436,203$ & 2.243 .471 .75 & $2,749,744$ & 3.321 .407 .04 & $3,957,021$ & $4,893,453.26$ & $\begin{aligned}- \\
592564525 \\
\end{aligned}$ \\
\hline Menos : Provición Cobranza dudosa & 87,469 & 64,155 & $00,00 c_{-1}$ & & & & 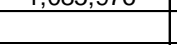 & | & & 2, & & $\begin{array}{lll} & 0\end{array}$ & & 年, & \\
\hline Cuentas por Cobrar a vinculados & & 56,184 & 25,420 & $1,207,252$ & 597,770 & $8,672,794$ & $3,567,129$ & $3,388,772$ & $3,219,334$ & $3,058,367$ & $2,905,449$ & $2,760,176$ & $2,622,167$ & $2,491,059$ & $2,366,506$ \\
\hline \begin{tabular}{|l|} 
Otras cuentas por cobrar \\
Menos : Procicion Cobranza dudosa
\end{tabular} & $\frac{97,043}{34995}$ & & & 94,270 & 63,605 & 12,576 & $1,188,859$ & $1,129,416$ & $1,072,946$ & $1,019,298$ & 968,333 & 919,917 & 873,921 & 830,225 & 788,714 \\
\hline $\begin{array}{l}\text { Menoss : Provición Cobranza dudosa } \\
\text { Existencias }\end{array}$ & $\frac{34,995}{99,183}$ & $\frac{13,012}{98,464}$ & 83,848 & 127.571 & 121,727 & 111,539 & 137,110 & 157,676 & 181.328 & 208.527 & 239.806 & 275,777 & 317,143 & 364.715 & $\frac{-}{419422}$ \\
\hline & & & & & & & & & & & & 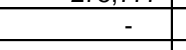 & 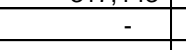 & ( & \\
\hline Gastos pagados por anticipo & 792,475 & 972,791 & 652,343 & 318,327 & 127,947 & 3,275 & & & & & & & & & \\
\hline TOTAL ACTIVO CORRIENTE & $1,790,439$ & $2,357,138$ & $1,721,833$ & $1,799,044$ & $1,264,302$ & $9,047,294$ & $6,179,377$ & $6,155,086$ & $6,174,711$ & $6,834,299$ & $7,213,662$ & $7,680,157$ & $8,233,565$ & $9,112,261$ & $10,482,308$ \\
\hline ACTIVO NO CORRIENTE & & & & & & & & & & & & & & & \\
\hline Cuentas por cobrar a largo plazo & & & & & & & & & & & & & & & \\
\hline \begin{tabular}{|l} 
Cuentas por cobrar a vinculadas a largo plazo \\
Otras tcas porc cobrara a larao plazzo
\end{tabular} & & & & & & & & & & & & & & & \\
\hline $\begin{array}{l}\text { Urtas ctas por cobrar a alago plazo } \\
\text { Inversiones permanentes }\end{array}$ & 39,731 & 39,731 & 39,731 & 39,731 & $\frac{26,6,15}{39,731}$ & 39,731 & 39,731 & 45,690 & 52,544 & 60.425 & 69.489 & 79.913 & 91.900 & 105.684 & 121.537 \\
\hline Menos : Fluctuaciones de valores y cobranza & 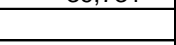 & & & & & $16,057,359$ & $20,411,103$ & $20,615,214$ & $20,821,366$ & $21,029,579$ & $21,239,875$ & $21,452,274$ & $21,666,797$ & $21,883,465$ & $\begin{aligned} 12,102,299 \\
229\end{aligned}$ \\
\hline Inmuebles, Maquinaria y Equipo & $20,651,299$ & $20,705,732$ & $20,623,366$ & $17,165,872$ & $16,755,247$ & 341,104 & 554,344 & 565,431 & 576,740 & 588,275 & 600,040 & 612,041 & 624,282 & 636,767 & 649,503 \\
\hline 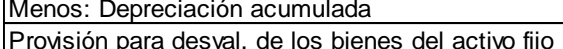 & $2,415,246$ & $2,969,661$ & $3,319,512$ & & & & & & & & & & & & \\
\hline $\begin{array}{l}\text { Proussion para desval. de los bienes del activo tijo } \\
\text { Activos intangibles }\end{array}$ & 42,467 & 46,351 & 46,351 & & & & & - & & & & & & & \\
\hline Menos: Amortización Acumulada intangible & & & 8,284 & & & & & & & & & & & & \\
\hline Impto a la Renta y Particip. diferidos activos & & & & & & & & & & & & & & & \\
\hline $\begin{array}{l}\text { Otros activos } \\
\text { TOOALA ACTIV NO COBPIENTE }\end{array}$ & $\begin{array}{r}335,534 \\
18,65795 \\
\end{array}$ & $\begin{array}{r}500 \\
1782653\end{array}$ & $\begin{array}{r}84,941 \\
170503\end{array}$ & $\frac{268,664}{1707067}$ & $\begin{array}{r}217,139 \\
17279231\end{array}$ & $\begin{array}{r}86,641 \\
16,52025\end{array}$ & $\begin{aligned} 91,670 \\
21,050,98\end{aligned}$ & $\begin{aligned} 105,421 \\
2131756\end{aligned}$ & $\begin{aligned} 121,234 \\
2157,084 \\
\end{aligned}$ & $\begin{array}{r}139,419 \\
21817609\end{array}$ & $\frac{160,332}{120}$ & $\begin{aligned} 184,382 \\
2020,600\end{aligned}$ & 212,039 & 243,845 & 280,422 \\
\hline $\begin{array}{l}\text { TOTAL ACCIV NO CORRIENTE } \\
\text { TOTAL ACTIVO }\end{array}$ & $\begin{array}{l}\frac{18,653,785}{20,444,224} \\
2.04\end{array}$ & $\begin{array}{l}\frac{17,822,653}{20,179,791} \\
2.96\end{array}$ & $\begin{array}{l}\frac{17,46,693}{19,188,426} \\
-1\end{array}$ & $\frac{17,474,67}{19,273,311}$ & $\frac{17,274,331}{18,542,633}$ & 年, $\frac{16,57,235}{25,129}$ & $\begin{array}{l}21,096,648 \\
27,276,225\end{array}$ & 27,431,786,842 & 21,571,884 27,594 & $\begin{array}{ll}21,817,699 \\
28,651,998\end{array}$ & $\begin{array}{l}22,069,737 \\
29,283,399\end{array}$ & $\begin{array}{l}22,328,609 \\
30,008,766\end{array}$ & $\frac{22,595,017}{30,82,582}$ & $\frac{22,869,762}{31,982,023}$ & $\begin{array}{l}23,153,761 \\
33,636,069\end{array}$ \\
\hline PASIVO Y PATRIMONIO & & & & & & & & & & & & & & & \\
\hline $\begin{array}{l}\text { PASIVO CORRIENTE } \\
\text { PAST } \\
\end{array}$ & & & & & & & & & & & & & & & \\
\hline $\begin{array}{l}\text { Sobregiros y Pagarés bancarios } \\
\text { Cuentas por cobrar comerciales }\end{array}$ & 182412 & 35,275 & & & & & & & & & & & & & \\
\hline $\begin{array}{l}\text { Cuentas por cobrar comercrales } \\
\text { Cuentas por pagar a vinculados }\end{array}$ & 183,412 & 141.659 & $\frac{111,999}{285,446}$ & 667,213 & 277,541 & $1,744,798$ & $1,084.713$ & $1,247,420$ & $1.434,533$ & $1,649,713$ & $1,897,170$ & 2181745 & $2,509,007$ & $2.885,358$ & \\
\hline Otras cuentas por pagar & 127,571 & 262,634 & 116,863 & 15,878 & 17,104 & $\begin{array}{r}4,43,019 \\
43,019 \\
\end{array}$ & $\frac{1,007,772}{122,772}$ & 141,188 & $\frac{1,44,2006}{162,366}$ & $\frac{1.04,107}{186,721}$ & $\frac{1,01,140}{214,729}$ & $\frac{2,101,45}{246,938}$ & 283,979 & $\frac{2,000,050}{326,576}$ & $\begin{array}{llll}3,510,162 \\
375,562 \\
\end{array}$ \\
\hline $\begin{array}{l}\text { Parte cte. Deudas a Largo plazo } \\
\text { TOTAL PASIVO CORIENTE }\end{array}$ & 310,983 & 439,568 & 514,288 & $\frac{98,381}{781,42}$ & $\frac{27,658}{322,303}$ & 1787817 & 1207.485 & 1388,608 & 1596899 & 1836.434 & 2111899 & 2,428684 & 2792986 & 3211934 & $\frac{-}{3693724}$ \\
\hline & & & & & & & & & & & & & & & \\
\hline $\begin{array}{l}\text { PASIVO NO CORRIENTE } \\
\text { Deudas a larao plazo }\end{array}$ & 1.992 .328 & 然 & 16,292 & $1.035,273$ & 980.690 & $1.003,800$ & 891,213 & 1024894 & 1178629 & 1355423 & 214286737 & 2894660 - 350 & 348909555 & 4045916 & \\
\hline Cuentas por pagar a vinculados & & $1,680,855$ & $1,099,353$ & & & 15,646 & $\frac{01,160}{16,832}$ & $\begin{array}{r}r, 204,894 \\
19,357 \\
\end{array}$ & 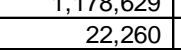 & $\begin{array}{l}1,350,423 \\
25,599 \\
\end{array}$ & $\frac{2,14,000,439}{29,439}$ & $\frac{2,04,005}{33,855}$ & $\begin{array}{ll}3 \\
38,489,534 \\
38,934 \\
\end{array}$ & $\begin{aligned} 4,05,916 \\
44,774 \\
\end{aligned}$ & $\begin{aligned} 4,602,, 803 \\
51,490 \\
\end{aligned}$ \\
\hline Ingresos diferidos & & 21,093 & & & & $6,478,319$ & $9,991,947$ & $11,490,739$ & $12,579,048$ & $12,413,082$ & $12,240,480$ & $12,058,079$ & $11,862,360$ & $11,862,360$ & $11,862,360$ \\
\hline Impt a la renta y partic. Diferidos pasivo & & & & & & & & & & & & & & & \\
\hline TOTAL PASIVO NO CORRIENTE & $\frac{1,992,328}{232311}$ & $1,701,948$ & $1,115,645$ & $1,035,273$ & 980,690 & $7,587,681$ & $10,899,992$ & $12,534,990$ & $\frac{13,779,937}{1507030}$ & $\frac{13,794,104}{1560,50.9}$ & $14,412,787$ & $\frac{14,986,595}{1701509}$ & $15,390,389$ & $15,953,049$ & $16,566,653$ \\
\hline & $2,303,311$ & $2,141,516$ & $1,629,933$ & $1,816,745$ & $1,302,993$ & 9,375,498 & $12,107,477$ & 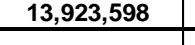 & $15,376,836$ & $15,630,538$ & $16,524,685$ & $17,415,278$ & $18,183,375$ & $19,164,983$ & $20,260,377$ \\
\hline \begin{tabular}{|l} 
Inntingencia \\
Interés minoritario \\
\end{tabular} & & & & & & & & & & & & & & & \\
\hline PATRIMONIO & & & & & & & & & & & & & & & \\
\hline Capital & $4,073,990$ & $4,073,990$ & $4,073,990$ & $4,073,990$ & $11,172.469$ & $11,172,469$ & $11,172.469$ & 11.172 .469 & 11.172469 & 11.172469 & 11.172469 & 11.172469 & 11.172469 & 11.172 .469 & $11,172,469$ \\
\hline Capital Adicional & $7,098,479$ & $7,098,479$ & $7,098,479$ & $7,098,479$ & & & & & & & & & 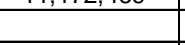 & $x, 1,1,+00$ & \\
\hline Acciones de inversión & & $3,877,359$ & & & & & & & & & & & & & \\
\hline Excedente de Revaluación & $3,877,359$ & $2,756,051$ & $3,877,359$ & & & & & & & & & & & & \\
\hline $\begin{array}{l}\text { Reservas } \\
\text { Resultados acumulados }\end{array}$ & $3.091,085$ & 232,395 & $2,808,396$ & $6,284,097$ & $6,067,170$ & $5,024,162$ & $2,910,302$ & & & & & & & & \\
\hline Resultado del ejercicio & 年, & & 299,735 & & & & $1,085,976$ & $1,140,275$ & $1,197,289$ & $1,848,991$ & $1,586,244$ & $1,421,019$ & $1,472,738$ & $1,644,570$ & $2,203,223$ \\
\hline TOTAL PATRIMONIO & $18,140,913$ & $18,038,274$ & $17,558,489$ & $17,456,566$ & $17,239,640$ & $\begin{array}{ll}16,196,632 \\
1,57,30\end{array}$ & $15,168,748$ & $13,563,243$ & $12,369,758$ & $13,021,460$ & $12,758,713$ & $12,593,488$ & $12,645,207$ & $12,817,040$ & $13,375,692$ \\
\hline TOTAL PASIVO Y PATRIMONIO & $20,444,224$ & $20,179,790$ & $19,188,422$ & $19,273,311$ & & $25,572,129$ & & & & & & & & & $33,636,069$ \\
\hline
\end{tabular}

Nota. Recuperado de http://www.transparencia.gob.pe/enlaces/pte_transparencia_enlaces.aspx?id_entidad=13099\&id_tema=5\&ver=\#.Wx3In0gvzIU. Elaboración propia 


\subsubsection{Flujo de efectivo (situación actual y con la nueva estrategia)}

En la tabla 47, se muestra un estado financiero coherente, en el periodo 2012 se aprecia un saldo de caja de S/.70, 542, lo cual muestra una situación financiera con resultados negativos para el CVH. Sin embargo, se implementaron políticas de reducción de costos que ha ayudado al desarrollo de una mejor gestión y mejorado los saldos de caja y la liquidez del CVH. En el año 2017 con la implementación del plan estratégico el saldo de caja mejora considerablemente obteniéndose un saldo de caja de S/. 85,744 y para el año 2019 se llega a situar el saldo de caja en S/. 94,533.

En cuanto a los egresos que se reflejan en el estado que se presenta también tenemos un equilibrio de costos, lo cual permitirá lograr el saldo de caja que hemos presentado. 
Tabla 47

Flujo de Efectivo / Situación Actual (Expresado en Soles)

\begin{tabular}{|c|c|c|c|c|c|c|c|c|c|c|c|c|c|c|c|}
\hline & 2007 & 2008 & 2009 & $2010 \mid$ & 2011 & 2012 & 2013 & 2014 & 2015 & 2016 & $2017 \mid$ & 2018 & 2019 & 2020 & 2021 \\
\hline Ingresos & $1,530,564$ & 1,886,634 & $1,434,854$ & $2,298,471$ & $3,325,225$ & \begin{tabular}{|l|}
$4,758,398$ \\
\end{tabular} & 9,164,831 & \begin{tabular}{l|l|}
$9,623,073$ \\
\end{tabular} & $10,104,227$ & $10,609,438$ & $11,139,910$ & $11,696,905$ & \begin{tabular}{|l|l}
$12,281,750$ \\
\end{tabular} & 12,895,838 & $13,540,630$ \\
\hline \multicolumn{16}{|l|}{ Gastos } \\
\hline Compras de MP - CV & $2,533,181$ & $2,670,270$ & $2,934,519$ & $3,258,415$ & $1,787,474$ & $2,078,199$ & $3,773,321$ & $3,961,987$ & $4,160,086$ & $4,368,091$ & $4,586,495$ & $4,815,820$ & $5,056,611$ & $5,309,442$ & $5,574,914$ \\
\hline Gastos de Administración & 927,265 & $1,125,175$ & 955,876 & 842,965 & $2,034,018$ & $1,488,329$ & $1,247,039$ & $1,309,390$ & $1,374,860$ & $1,443,603$ & $1,515,783$ & $1,591,572$ & $1,671,151$ & $1,754,708$ & $1,842,444$ \\
\hline \begin{tabular}{|l|} 
Gastos de Ventas \\
\end{tabular} & 73,205 & 52,334 & 80,084 & 138,296 & $1,102,409$ & $2,776,059$ & $3,053,664$ & $3,206,348$ & $3,366,665$ & $3,534,998$ & $3,711,748$ & $3,897,336$ & $4,092,202$ & $4,296,813$ & $4,511,653$ \\
\hline Otros Gastos de ventas & $\cdot$ & $\cdot$ & 216,137 & 45,630 & 563,870 & 725,576 & 600,281 & 630,295 & 661,810 & 694,900 & 729,645 & 766,128 & 804,434 & 844,656 & 886,888 \\
\hline Cargas Financieras & 17,441 & 34,898 & 37,290 & 47,496 & 39,624 & 37,331 & 36,258 & 38,071 & 39,974 & 41,973 & 44,072 & 46,275 & 48,589 & 51,018 & 53,569 \\
\hline \begin{tabular}{|c|} 
Cargas Excepcionales \\
\end{tabular} & 387,094 & 159,035 & - & $\cdot$ & 183,229 & 321,116 & 154,606 & 162,336 & 170,453 & 178,976 & 187,925 & \begin{tabular}{ll|}
197,321 \\
\end{tabular} & 207,187 & 217,546 & 228,423 \\
\hline Imprevistos & 45,917 & 37,733 & 28,697 & 45,969 & 66,505 & 95,168 & 229,121 & 240,577 & 252,606 & 265,236 & 278,498 & 292,423 & 307,044 & 322,396 & 338,516 \\
\hline FLUJO DE CAJA ECONÓMICO & $2,453,539$ & $2,192,811$ & $2,817,749$ & $2,080,300$ & $2,451,904$ & $2,763,380$ & 70,542 & 74,069 & 77,772 & 81,661 & 85,744 & 90,031 & 94,533 & 99,259 & 104,222 \\
\hline Saldo Final de Caja & $2,453,539$ & $2,192,811$ & $2,817,749$ & $2,080,300$ & $2,451,904$ & $2,763,380$ & 70,542 & 74,069 & 77,772 & 81,661 & 85,744 & 90,031 & 94,533 & 99,259 & 104,222 \\
\hline
\end{tabular}

\begin{tabular}{|l|r|r|r|r|}
\hline & & Año 1 & Año 2 & Año 3 \\
\hline INVERSIÓN DEL PLAN ESTRATÉGICO S/. & 140,900 & 81,661 & 85,744 & 90,031 \\
\hline
\end{tabular}

\begin{tabular}{|l|r|}
\hline COK & $17 \%$ \\
\hline UNA ECONOMICO & $5 / .40,025$ \\
\hline TR & $37 \%$ \\
\hline
\end{tabular}

\section{Nota. Recuperado de}

http://www.transparencia.gob.pe/enlaces/pte_transparencia_enlaces.aspx?id_entidad=13099\&id_tema=5\&ver=\#.Wx3In0gvzIU. Elaboración propia. 
Tabla 48

Flujo de Efectivo / Situación con Estrategias (Expresado en Soles)

\begin{tabular}{|c|c|c|c|c|c|c|c|c|c|c|c|c|c|c|c|}
\hline & 2007 & 2008 & 2009 & 2010 & 2011 & 2012 & 2013 & 2014 & 2015 & 2016 & 2017 & 2018 & 2019 & 2020 & 2021 \\
\hline Ingresos & $1,530,564$ & $1,886,634$ & $1,434,854$ & $2,298,471$ & $3,325,225$ & $4,758,398$ & $9,164,831$ & $9,623,073$ & $10,104,227$ & $11,114,649$ & $11,225,796$ & $11,450,312$ & $11,908,324$ & $12,503,740$ & $13,504,039$ \\
\hline & & & & & & & & & & & & & & & \\
\hline \multicolumn{16}{|l|}{ Gastos } \\
\hline Compras de MP - CV & $2,533,181$ & $2,670,270$ & $2,934,519$ & $3,258,415$ & $1,787,474$ & $2,078,199$ & $3,773,321$ & $3,961,987$ & $4,160,086$ & $4,368,091$ & $4,586,495$ & $4,815,820$ & $5,056,611$ & $5,309,442$ & $5,574,914$ \\
\hline Gastos de Administración & 927,265 & $1,125,175$ & 955,876 & 842,965 & $2,034,018$ & $1,488,329$ & $1,247,039$ & $1,309,390$ & $1,374,860$ & $1,416,106$ & $1,458,589$ & $1,502,347$ & $1,547,417$ & $1,593,840$ & $1,641,655$ \\
\hline Gastos de Ventas & 73,205 & 52,334 & 80,084 & 138,296 & $1,102,409$ & $2,776,059$ & $3,053,664$ & $3,206,348$ & $3,366,665$ & $3,467,665$ & $3,571,695$ & $3,678,846$ & $3,789,211$ & $3,902,888$ & $4,019,974$ \\
\hline Otros Gastos de ventas & $\cdot$ & $\cdot$ & 216,137 & 45,630 & 563,870 & 725,576 & 600,281 & 630,295 & 661,810 & 668,428 & 675,112 & 681,863 & 688,682 & 695,569 & 702,524 \\
\hline \begin{tabular}{|l|} 
Cargas Financieras \\
\end{tabular} & 17,441 & 34,898 & 37,290 & 47,496 & 39,624 & 37,331 & 36,258 & 38,071 & 39,974 & 41,973 & 44,072 & 46,275 & 48,589 & 51,018 & 53,569 \\
\hline Cargas Excepcionales & 387,094 & 159,035 & $\cdot$ & $\cdot$ & 183,229 & 321,116 & 154,606 & 162,336 & 170,453 & 178,976 & 187,925 & 197,321 & 207,187 & 217,546 & 228,423 \\
\hline Imprevistos & 45,917 & 37,733 & 28,697 & 45,969 & 66,505 & 95,168 & 229,121 & 240,577 & 252,606 & 265,236 & 278,498 & 292,423 & 307,044 & 322,396 & 338,516 \\
\hline FLUJO DE CAJA ECONÓMICO & $2,453,539$ & $2,192,811$ & $2,817,749$ & $2,080,300$ & $2,451,904$ & $2,763,380$ & 70,542 & 74,069 & 77,772 & 708,175 & 423,410 & 235,417 & 263,583 & 411,042 & 944,464 \\
\hline & & & & & & & & & & & & & & & \\
\hline Saldo Final de Caja & $2,453,539$ & $2,192,811$ & $2,817,749$ & $2,080,300$ & $2,451,904$ & $2,763,380$ & 70,542 & 74,069 & 77,772 & 708,175 & 423,410 & 235,417 & 263,583 & 411,042 & 944,464 \\
\hline
\end{tabular}

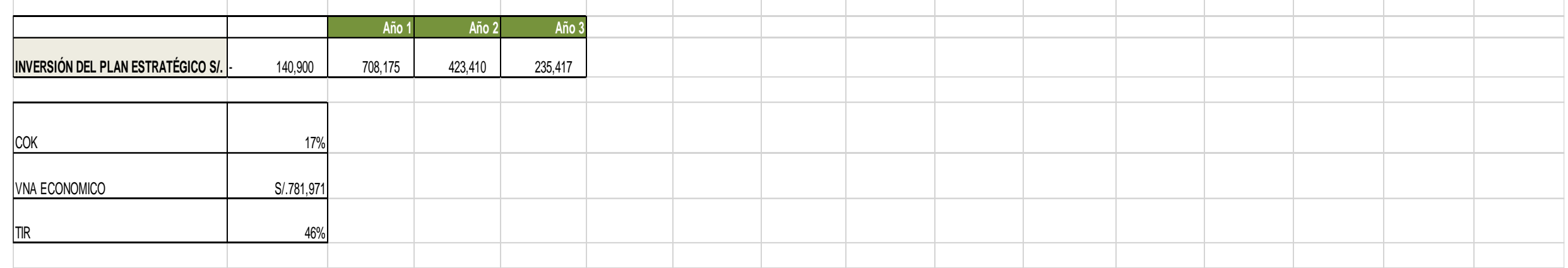

Nota. Recuperado de

http://www.transparencia.gob.pe/enlaces/pte transparencia_enlaces.aspx?id_entidad=13099\&id_tema=5\&ver=\#.Wx3In0gvzIU. Elaboración propia. 


\subsubsection{Evaluación financiera (VAN, TIR y ratios financieros)}

En la tabla 49 y 50 se aprecia el valor actual neto (VAN), la tasa interna de retorno (TIR), el costo de capital económico (COK) con y sin estrategia, y los indicadores financieros reflejados en el análisis Dupont.

La TIR ha sido de $37 \%$, lo cual indica que en el escenario normal hay un resultado positivo en rentabilidad financiera. En cuanto al VAN los resultados también son positivos S/. 39,681, para lograr la rentabilidad es recomendable que el CVH llegue al nivel de ventas del escenario normal o en todo caso en el optimista. Con la implementación del Plan Estratégico se alcanza una TIR de 56\%. Se debe tener en cuenta la tasa interna de retorno que es un indicador establecido como política de la empresa y superar el $20 \%$ es una política empresarial.

Con las tablas presentadas se demuestra que con la implementación del plan estratégico se mejora los estados financieros del CVH.

Tabla 49

VAN Y TIR y ratios financieros/ Sin Estrategia

\begin{tabular}{|c|c|c|c|c|}
\hline & & Año 1 & Año 2 & Año 3 \\
\hline INVERSIÓN DEL PLAN ESTRATÉGICO S/. & 140,900 & 81,661 & 85,744 & 90,031 \\
\hline
\end{tabular}

\begin{tabular}{|l|l|}
\hline COK & $17.38 \%$ \\
\hline VNA ECONOMICO & S/.39,681 \\
\hline TIR & $37 \%$ \\
\hline
\end{tabular}

Nota. Elaboración propia. 
Tabla 50

VAN Y TIR y ratios financieros/ Con Estrategia

\begin{tabular}{|l|l|l|l|l|}
\hline & & Año 1 & Año 2 & Año 3 \\
\hline INVERSIÓN DEL PLAN & - & & & \\
ESTRATÉGICO S/. & 140,900 & 199,473 & 12,028 & 29,420 \\
\hline
\end{tabular}

\begin{tabular}{|l|l|}
\hline COK & $17.38 \%$ \\
\hline VNA ECONOMICO & S/ 47,677 \\
\hline TIR & $56 \%$ \\
\hline
\end{tabular}

Nota: Elaboración propia. 
Tabla 51

Análisis DuPont-Ratios-

\begin{tabular}{|c|c|c|c|c|c|c|c|c|c|c|c|c|c|c|c|}
\hline & & & & & & Análisis Dur & & & & & & & & & \\
\hline & 2,007 & 2,008 & 2,009 & 2,010 & 2,011 & 2,012 & 2,013 & 2,014 & 2,015 & 2,016 & 2,017 & 2,018 & 2,019 & 2,020 & 2,021 \\
\hline Margen de utilidad neta & $-117.54 \%$ & $-93.69 \%$ & $-160.28 \%$ & $-74.53 \%$ & $-62.51 \%$ & $-54.34 \%$ & $11.85 \%$ & $11.85 \%$ & $11.85 \%$ & $11.85 \%$ & $11.85 \%$ & $11.85 \%$ & $11.85 \%$ & $11.85 \%$ & $11.85 \%$ \\
\hline Rotacion de activos totales & 0.07 & 0.09 & 0.07 & 0.12 & 0.18 & 0.19 & 0.34 & 0.35 & 0.36 & 0.38 & 0.39 & 0.41 & 0.42 & 0.43 & 0.44 \\
\hline Multiplicador financiero & 1.13 & 1.12 & 1.09 & 1.10 & 1.08 & 1.58 & 1.80 & 2.03 & 2.24 & 2.26 & 2.28 & 2.30 & 2.33 & 2.38 & 2.43 \\
\hline ROA & $-8.80 \%$ & $-8.76 \%$ & $-11.99 \%$ & $-8.89 \%$ & $-11.21 \%$ & $-10.11 \%$ & $3.98 \%$ & $4.15 \%$ & $4.32 \%$ & $4.48 \%$ & $4.64 \%$ & $4.80 \%$ & $4.95 \%$ & $5.06 \%$ & $5.16 \%$ \\
\hline \multirow[t]{3}{*}{ ROE } & $-9.92 \%$ & $-9.80 \%$ & $-13.10 \%$ & $-9.81 \%$ & $-12.06 \%$ & $-15.96 \%$ & $7.16 \%$ & $8.41 \%$ & $9.68 \%$ & $10.11 \%$ & $10.57 \%$ & $11.04 \%$ & $11.52 \%$ & $12.03 \%$ & $12.56 \%$ \\
\hline & & & & & & Liquide: & & & & & & & & & \\
\hline & 2,007 & 2,008 & 2,009 & 2,010 & 2,011 & 2,012 & 2,013 & 2,014 & 2,015 & 2,016 & 2,017 & 2,018 & 2,019 & 2,020 & 2,021 \\
\hline Capital de trabajo & $1,023,385$ & $1,405,330$ & $1,044,070$ & 179,195 & 474,980 & 358,648 & $1,423,388$ & $1,636,897$ & $1,882,431$ & $2,164,796$ & $2,489,515$ & $2,862,943$ & $3,292,384$ & $3,999,211$ & $4,801,783$ \\
\hline Capital de trabajo neto & $1,150,956$ & $1,526,305$ & 875,487 & $(472,141)$ & 214,542 & $(1,343,132)$ & 461,447 & 530,664 & 610,264 & 701,804 & 807,074 & 928,135 & $1,067,356$ & $1,440,429$ & $1,859,183$ \\
\hline Ratio corriente & 5.76 & 5.36 & 3.35 & 2.30 & 3.92 & 5.06 & 5.12 & 4.43 & 3.87 & 3.40 & 3.01 & 2.69 & 2.43 & 2.28 & 2.15 \\
\hline Prueba acida & 5.44 & 5.14 & 3.18 & 2.14 & 3.55 & 5.00 & 5.00 & 4.32 & 3.75 & 3.29 & 2.90 & 2.58 & 2.32 & 2.17 & 2.04 \\
\hline Relevancia activo corriente & 0.09 & 0.12 & 0.09 & 0.09 & 0.07 & 0.35 & 0.23 & 0.22 & 0.22 & 0.22 & 0.22 & 0.23 & 0.23 & 0.24 & 0.26 \\
\hline Ratio de capital de trabajo & 0.06 & 0.08 & 0.05 & $(0.02)$ & 0.01 & $(0.05)$ & 0.02 & 0.02 & 0.02 & 0.03 & 0.03 & 0.03 & 0.04 & 0.05 & 0.06 \\
\hline Ratio de efectivo (activos totales) & 0.01 & 0.01 & 0.01 & 0.00 & 0.02 & 0.01 & 0.01 & 0.01 & 0.01 & 0.01 & 0.01 & 0.01 & 0.02 & 0.02 & 0.02 \\
\hline \multirow[t]{3}{*}{ Ratio de efectivo (ventas) } & 0.14 & 0.14 & 0.09 & 0.02 & 0.11 & 0.05 & 0.02 & 0.02 & 0.03 & 0.03 & 0.03 & 0.03 & 0.04 & 0.04 & 0.05 \\
\hline & & & & & & Activida & & & & & & & & & \\
\hline & 2,007 & 2,008 & 2,009 & 2,010 & 2,011 & 2,012 & 2,013 & 2,014 & 2,015 & 2,016 & 2,017 & 2,018 & 2,019 & 2,020 & 2,021 \\
\hline Rotacion de cuentas por cobrar & 2.14 & 1.80 & 1.74 & 1.90 & 5.56 & 0.55 & 2.57 & 2.84 & 3.14 & 3.47 & 3.83 & 4.24 & 4.68 & 5.18 & 5.72 \\
\hline PPC & 168.38 & 200.10 & 207.34 & 189.09 & 64.72 & 656.15 & 140.12 & 126.77 & 114.70 & 103.78 & 93.89 & 84.95 & 76.86 & 69.54 & 62.92 \\
\hline Rotacion de inventarios & 25.54 & 27.12 & 35.00 & 25.54 & 14.68 & 18.63 & 27.52 & 25.13 & 22.94 & 20.95 & 19.13 & 17.46 & 15.94 & 14.56 & 13.29 \\
\hline PPI & 14.10 & 13.27 & 10.29 & 14.09 & 24.52 & 19.32 & 13.08 & 14.33 & 15.69 & 17.19 & 18.82 & 20.62 & 22.58 & 24.73 & 27.08 \\
\hline Rotacion de cuentas por pagar & 13.81 & 10.17 & 12.82 & 205.22 & 104.51 & 48.31 & 30.73 & 28.06 & 25.62 & 23.39 & 21.36 & 19.50 & 17.81 & 16.26 & 14.84 \\
\hline PPP & 26.07 & 35.41 & 28.07 & 1.75 & 3.44 & 7.45 & 11.71 & 12.83 & 14.05 & 15.39 & 16.85 & 18.46 & 20.22 & 22.14 & 24.25 \\
\hline Rotacion de activos fijos netos & 0.08 & 0.11 & 0.08 & 0.13 & 0.19 & 0.29 & 0.43 & 0.45 & 0.47 & 0.49 & 0.50 & 0.52 & 0.54 & 0.56 & 0.58 \\
\hline Rotacion de activos totales & 0.07 & 0.09 & 0.07 & 0.12 & 0.18 & 0.19 & 0.34 & 0.35 & 0.36 & 0.38 & 0.39 & 0.41 & 0.42 & 0.43 & 0.44 \\
\hline Rotacion de activos operativos & 4.56 & $3,773.27$ & 16.89 & 8.56 & 15.31 & 54.92 & 99.98 & 91.28 & 83.34 & 76.10 & 69.48 & 63.44 & 57.92 & 52.89 & 48.29 \\
\hline Brecha de rotaciones & 4.49 & $3,773.17$ & 16.82 & 8.44 & 15.13 & 54.73 & 99.64 & 90.93 & 82.98 & 75.72 & 69.09 & 63.03 & 57.50 & 52.46 & 47.85 \\
\hline Ciclo operativo & 182.48 & 213.38 & 217.62 & 203.18 & 89.23 & 675.47 & 153.20 & 141.10 & 130.39 & 120.96 & 112.72 & 105.57 & 99.44 & 94.27 & 90.00 \\
\hline \multirow[t]{3}{*}{ Ciclo de conversion de efectivo } & 156.41 & 177.97 & 189.55 & 201.43 & 85.79 & 668.02 & 141.49 & 128.27 & 116.34 & 105.57 & 95.86 & 87.11 & 79.22 & 72.13 & 65.75 \\
\hline & & & & & & Endeudami & & & & & & & & & \\
\hline & 2,007 & 2,008 & 2,009 & 2,010 & 2,011 & 2,012 & 2,013 & 2,014 & 2,015 & 2,016 & 2,017 & 2,018 & 2,019 & 2,020 & 2,021 \\
\hline Grado de endeudamiento & 0.11 & 0.11 & 0.08 & 0.09 & 0.07 & 0.37 & 0.44 & 0.51 & 0.55 & 0.56 & 0.56 & 0.57 & 0.57 & 0.58 & 0.59 \\
\hline Endeudamiento sobre patrimonio & 0.13 & 0.12 & 0.09 & 0.10 & 0.08 & 0.58 & 0.80 & 1.03 & 1.24 & 1.26 & 1.28 & 1.30 & 1.33 & 1.38 & 1.43 \\
\hline Grado de propiedad & 0.89 & 0.89 & 0.92 & 0.91 & 0.93 & 0.63 & 0.56 & 0.49 & 0.45 & 0.44 & 0.44 & 0.43 & 0.43 & 0.42 & 0.41 \\
\hline Multiplicador financiero & 1.13 & 1.12 & 1.09 & 1.10 & 1.08 & 1.58 & 1.80 & 2.03 & 2.24 & 2.26 & 2.28 & 2.30 & 2.33 & 2.38 & 2.43 \\
\hline \multirow[t]{3}{*}{ Pasivo LP / total activos } & $9.75 \%$ & $8.43 \%$ & $5.81 \%$ & $5.37 \%$ & $5.29 \%$ & $29.67 \%$ & $39.96 \%$ & $45.60 \%$ & $49.66 \%$ & $49.16 \%$ & $48.64 \%$ & $48.09 \%$ & $47.52 \%$ & $47.29 \%$ & $47.06 \%$ \\
\hline & & & & & & Rentabilid & & & & & & & & & \\
\hline & 2,007 & 2,008 & 2,009 & 2,010 & 2,011 & 2,012 & 2,013 & 2,014 & 2,015 & 2,016 & 2,017 & 2,018 & 2,019 & 2,020 & 2,021 \\
\hline Margen Operativo & $-130.87 \%$ & $-103.95 \%$ & $-157.75 \%$ & $-72.47 \%$ & $-65.03 \%$ & $-46.81 \%$ & $13.93 \%$ & $13.93 \%$ & $13.93 \%$ & $13.93 \%$ & $13.93 \%$ & $13.93 \%$ & $13.93 \%$ & $13.93 \%$ & $13.93 \%$ \\
\hline Margen bruto & $-65.51 \%$ & $-41.54 \%$ & $-104.52 \%$ & $-41.76 \%$ & $46.25 \%$ & $56.33 \%$ & $58.83 \%$ & $58.83 \%$ & $58.83 \%$ & $58.83 \%$ & $58.83 \%$ & $58.83 \%$ & $58.83 \%$ & $58.83 \%$ & $58.83 \%$ \\
\hline Margen neto & $-117.54 \%$ & $-93.69 \%$ & $-160.28 \%$ & $-74.53 \%$ & $-62.51 \%$ & $-54.34 \%$ & $11.85 \%$ & $11.85 \%$ & $11.85 \%$ & $11.85 \%$ & $11.85 \%$ & $11.85 \%$ & $11.85 \%$ & $11.85 \%$ & $11.85 \%$ \\
\hline ROA & $-8.80 \%$ & $-8.76 \%$ & $-11.99 \%$ & $-8.89 \%$ & $-11.21 \%$ & $-10.11 \%$ & $3.98 \%$ & $4.15 \%$ & $4.32 \%$ & $4.48 \%$ & $4.64 \%$ & $4.80 \%$ & $4.95 \%$ & $5.06 \%$ & $5.16 \%$ \\
\hline ROE & $-9.92 \%$ & $-9.80 \%$ & $-13.10 \%$ & $-9.81 \%$ & $-12.06 \%$ & $-15.96 \%$ & $7.16 \%$ & $8.41 \%$ & $9.68 \%$ & $10.11 \%$ & $10.57 \%$ & $11.04 \%$ & $11.52 \%$ & $12.03 \%$ & $12.56 \%$ \\
\hline
\end{tabular}

Utilidad neta / Ventas Activos /Activos totales Margen utilidad neta $x$ rotacion activos ROA x multiplicador financiero

Existencias + cuentas por cobrar + efectivo apital de trabajo - cuentas por pagar tivo corriente - existencias // pasivo cte Activo corriente / Activos totales capital de trabajo neto / activos totales Efectivo y equivalentes/total activo Efectivo y equivalentes / total ingresos

ventas / cuentas por cobrar $360 /$ rotacion cxc

Costos de ventas / inventario $360 /$ rotacion de inventarios Costo de ventas / cuentas por pagar
$360 /$ rotacion de cxp

Ventas / activos fijos netos Ventas / Activos totales Ventas / Activos operativos rot act operativos - rot act totales PPI + PPC
CO - PPP

Pasivo total / total activos Pasivo total / patrimonio Patrimonio neto / activo total total activos / patrimonio Pasivo LP / total activos

Utilidad Operativa / ventas Utilidad bruta / ventas utilidad neta / ventas Utilidad neta/ total activos Utilidad neta / Patrimonio 
En el análisis Dupont se aprecia que en el año 2015 el margen de utilidad neta es positivo en $11.85 \%$ y el ROA $9.68 \%$ en el 2015 . Sin embargo, para los siguientes períodos los indicadores financieros mejoran considerablemente. Los ratios de rentabilidad que se han hallado muestran que los objetivos planteados para el CVH se pueden alcanzar siempre y cuando se apliquen las estrategias diseñadas y se logre llegar al nivel de ventas esperado.

\subsection{Cálculo de la Tasa de Descuento}

\subsubsection{Costo de Oportunidad (Ke)}

\subsubsection{Cálculo del CAPM}


Tabla 52

Cálculo del Ke

\begin{tabular}{|l|l|}
\hline BETA DESAPALANACADA (ver anexo 11) & $\mathbf{0 . 9 4}$ \\
\hline DEUDA & $\mathbf{7 0 \%}$ \\
\hline PATRIMONIO & $\mathbf{3 0 \%}$ \\
\hline IR & $\mathbf{2 8 . 0 0 \%}$ \\
\hline BETA APALANCADA & $\mathbf{2 . 5 2}$ \\
\hline RENDIMIENTO ACTIVO LIBRE DE RIESGO & $5.16 \%$ \\
\hline RENDIMIENTO DE MERCADO & $9.03 \%$ \\
\hline KE & $\mathbf{1 4 . 9 3 \%}$ \\
\hline RIESGO PAIS (ver anexo 10) & $2.45 \%$ \\
\hline COK MODIFICADO & $\mathbf{1 7 . 3 8 \%}$ \\
\hline
\end{tabular}

Nota: Elaboración propia.

Para obtener el cálculo del Costo de Capital del CVH se necesita obtener el valor del

Ke para poder adquirir el valor mínimo de rentabilidad para que el directorio tome a decisión si es viable o no la inversión.

En la tabla 52 se puede visualizar que la deuda es de $70 \%$ y el patrimonio de $30 \%$, datos obtenido de los estados financieros del año 2016. Y el 28\% que es el impuesto a la renta fue obtenido de la fuente de Administración tributaria

La beta desapalancada es 0.94, la cual se obtuvo del análisis de Damoradam (anexo 11), tomando referencia el valor de la industria de entretenimiento, y el resultado de la beta apalancada es 2.52, indicando mejoramiento en su rentabilidad financiera.

Basándose en el análisis de Damoradan, el indicador de rendimiento activo de riesgo se obtuvo del promedio de los últimos 10 años de los T. Bond, alcanzando un valor de 5.16\%. 
Y también se calcula el rendimiento del mercado en base al promedio de los últimos diez años de S\&P 500 Dow Jones Índices, de acuerdo a la fuente el indicador fue de $9.03 \%$.

En conclusión, con los datos obtenidos se calculó el Costo de Capital del CVH el cual fue de $14.53 \%$, y para proyectar el costo de capital modificado se sumó los valores de Riesgo País $(2.45 \%)$ con el costo de capital, arrojando el valor de $17.38 \%$. 


\section{CONCLUSIONES}

1. El CVH se convierte en una empresa que depende del Ministerio de Educación, hasta antes del año 2010 el CVH ha tenido serios problemas de liquidez; sin embargo, debido a una estrategia de negocios que adoptó el directorio se pudo reflotar financieramente y económicamente e CVH.

2. El CVH se sitúa en un sector de negocios que actualmente gracias al impulso del turismo se encuentra con una tendencia creciente, lo que ha permitido que durante estos últimos cinco años el CVH se recupere de manera sostenida. En efecto el ambiente externo ha influido significativamente para su desarrollo.

3. Las estrategias de diferenciación y negocios que adopte el CVH tendrán un impacto positivo, todo ello deberá estar orientado al servicio al cliente, perspectiva que especifica mejorar los indicadores de servicio al cliente.

4. Con la implementación de este plan estratégico se va a mejorar el proceso de atención al cliente.

5. Con el adecuado uso del Balance Scorecard va a permitir tener un mejor control de las iniciativas de cada una de las estrategias y sus responsables.

6. Con la implementación del plan estratégico va ayudar a ver las mejoras tanto cualitativamente y cuantitativamente, con la finalidad de cumplir misión, visión y valores de este plan.

7. Analizando el entorno de la industria del CVH, el desarrollo de la estrategia va ser favorable para la organización ayudando con los objetivos estratégicos. 
8. El CVH en sus tiempos de apogeo era uno de los mejores centros vacacionales, siendo conocido en el mercado. Actualmente con el resurgimiento del CVH se va a dar a conocer sus centros de convenciones por su gran capacidad instalada. 


\section{RECOMENDACIONES}

1. Se recomienda seguir las misión, visión y valores propuestos para la mejora de la organización.

2. Se recomienda implementar las iniciativas propuestas para el logro de los objetivos y metas.

3. Ampliar la cuota de mercado de convenciones para aumentar la rentabilidad y ayudar a reducir la capacidad ociosa del centro vacacional.

4. Con el buen reclutamiento, inducción, capacitación de los colaboradores se tendrá el éxito esperado del plan estratégico ya que depende de ellos el servicio que se brinde.

5. Aplicando las estrategias se va a captar el mercado potencial de convenciones ya que los últimos años en el Perú se están realizando eventos de gran importancia.

6. Se recomienda establecer convenios con instituciones públicas y privadas para la realización de eventos y hacer uso del área de esparcimiento.

7. Se recomienda implementar un plan de servicio al cliente, para poder mejorar la atención y enfocarse hacia un modelo de negocio de éxito. 


\section{BIBLIOGRAFÍA}

David, F.R. (2013). Conceptos de administración estratégica. México: Pearson.

Kaplan, R \& Norton, D. (2000). El cuadro de mando integral: The Balanced Scorecard, España: Gestión 2000

Chan Kim, W. \& Mauborgne, R. (2013). La estrategia del océano azul. (3ª ed.). México: Cargraphics S.A.. de C.V. por Carbajal Educación S.A.S.

Thompson, A., Peteraf, M., Gamble, J. \& Strickland, A. (2012). Administración estratégica. (18 ${ }^{\mathrm{a}}$ ed.). México: McGrawHill/Interamericana Editores S.A.

Hitt, M., Ireland, R., Hoskisson, R. (1999). Administración estratégica: Competitividad y conceptos de globalización. ( $3^{\mathrm{a}}$ ed.). México: International Thompson Editores.

Rumelt, R. (2011). Good strategy, bad strategy. USA: Currency New York.

Porter, M. (2010). Ventaja competitiva: Creación y sostenibilidad de un rendimiento superior. Madrid: Ediciones pirámide.

Centro de Convenciones de Lima apunta a ser el más grande de Sudamérica. Recuperado de: http://www.andina.com.pe/agencia/noticia-centro-convenciones-lima-apunta-a-sermas-grande-sudamerica-533027.aspx 
Centro Vacacional Huampaní (2015). Resolución de Gerencia General № 286-2013-CVHGG (consultado el 22 de febrero de 2015). Recuperado de: http://www.huampani.gob.pe/transparencia2014/PEI_CVH\%2020132016\%20Aprobado_Transparencia.pdf

El Comercio (2014, diciembre). Así se verá el nuevo Centro de Convenciones de Lima. Recuperado de: http://elcomercio.pe/economia/peru/asi-se-vera-nuevo-centroconvenciones-lima-noticia-1722733

Gestión (2014, octubre). BCP estima que economía peruana crecerá 4.8\% en 2015 (consultado el 22 de octubre de 2014). Recuperado de: http://gestion.pe/economia/bcp-estima-que-economia-peruana-crecera-48-20152111791

Gestión (2014, setiembre). ¿Qué necesita el turismo de convenciones para despegar en el Perú? (consultado el 9 de marzo de 2015). Recuperado de: http://gestion.pe/economia/que-necesita-turismo-convenciones-despegar-peru2108317

Gestión (2015, febrero). Adex proyecta que economía peruana crecerá este año más que en el 2014 (consultado el 22 de febrero de 2015). Recuperado de: http://gestion.pe/economia/adex-proyecta-que-economia-peruana-crecera-este-anomas-que-2014-2124403 
La República (2015, agosto). El centro de convenciones de Lima listo en un 85\%.

Recuperado de: http://larepublica.pe/impresa/economia/359408-el-centro-deconvenciones-de-lima-listo-en-un-85

Ministerio de Economía (2014). Marco Macroeconómico Multianual 2013 - 2015 (consultado el 22 de febrero de 2015). Recuperado de: https://www.mef.gob.pe/contenidos/pol_econ/marco_macro/MMM2013_2015.pdf

Perú21 (2014, setiembre). Lima será sede de la COP20 en el 2014 (consultado el 22 de febrero de 2015). Recuperado de: http://peru21.pe/actualidad/lima-sede-cop20-20142159221

Aliaga, G. (2 de Junio de 2015). Proyectan inversiones hoteleras en Perú por US\$1211 Mlls hasta el 2018. (Tnews, Ed.). Recuperado de: http://www.tnews.com.pe/noticias/proyectan-inversiones-hoteleras-en-peru-hasta-el2018.htm.

Boletín Hotelero. (1 de Octubre de 2015). Cadenas internacionales de hoteles planean inversiones en el Perú. Recuperado de: http://boletinhotelero.com/nota?id=1055

Hurtado de Mendoza, C. (4 de Enero de 2016). Sector hotelero alista más de 100 proyectos hasta el 2018. Recuperado de: El Comercio: http://elcomercio.pe/economia/dia1/hoteles-sector-hotelero-alista-mas-100-proyectos-hasta-2018-noticia-1867637 
Koechli., J. (14 de Diciembre de 2015). Las inversiones hoteleras en Perú llegarían hasta US\$ 1,211 millones entre el 2015 2018. Recuperado de: http://hotelperunews.com/lasinversiones-hoteleras-en-peru-llegarian-hasta-us-1211-millones-entre-el-2015-y-2018/

DAMODARAN, Aswath. Betas by sector (en línea). US, 2016. (Citado 15 de Junio 2016). Excel. Recuperado de: http://www.stern.nyu.edu/ adamodar/pc/datasets/histretSP.xls

INVESTING, Rentabilidad-Bono de EEUU a 10 años. (en línea). US, 2016. (citado 15 de Junio 2016). Recuperado en: httlles.investing.com/rates-bonds/us.-10-year-bond-yieldhistorical-data

INVESTING, S\&P 500 (SPX). (en línea). US, 2016. (citado 15 de Junio 2016). Recuperado en: httplles.investing.com/indices/us-spx-500historical-data

AMBITO, Perú-Riesgo País (Embi + elaborado por JP Morgan). (en línea). Argentina, 2016. (citado 15 de Junio 2016). Recuperado de: httpllambito.com/economia/mercados/riesgo-pais 
ANEXOS 


\section{Anexo 1: Resoluciones}

\section{RESOLUCIÓN DE GERENCIA GENERAL N²86-2013-CVH-GG}

Huampani, 31 de diciembre de 2013

\section{VISTO:}

El Acuerdo $\mathrm{N}^{\circ} 5$ de la Sesión de Directorio $\mathrm{N}^{\circ}$ 016-2013-CVH, de fecha 31 de agosto de 2013 , que dispone la aprobación del Plan Estratégico Institucional (PEI) 2013-2016 del Centro Vacacional Huampani;

\section{CONSIDERADO:}

Que, el Decreto Ley N ${ }^{0} 25762$ - Ley Orgánica del Ministerio de Educación, de fecha 12 de octubre de 1992, establece en la segunda disposición complementaria que el Sector Educación comprende tambien a la empresa Centro Vacacional Huampani, que es una persona juridica de derecho público interno:

Que, mediante Decreto Supremo N $036-95-E D$, de fecha 24 de abril de 1995, se aprueba el Estatuto del Centro Vacacional Huampani, donde el articulo $5^{\circ}$ seńala que tiene por finalidad prestar servicios hoteleros, esparcimiento, recreación y deporte, asl como apoyar la ejecución de convenciones, eventos culturales y otros servicios, con capacidad para el desarrollo de actividades y eventos deportivos ejerciendo su competencia en el ámbito nacional a entidades públicas y privadas, universidades, colegios y público en general;

Que, mediante Decreto Supremo $\mathrm{N}^{\circ}$ 054-2011-PCM, de fecha 22 de junio de 2011, se aprueba el Plan Estratégico de Desarrollo Nacional, denominado Plan Bicentenario: El Perú hacia el 2021;

Que, mediante Resolución Ministerial N 0518-2012-ED, de fecha 19 de diciembre de 2012, se aprueba el Plan Estratégico Sectorial Multianual de Educación (PESEM) 2012-2016;

Que, mediante Decreto Supremo $\mathrm{N}^{*} 304-2012-\mathrm{EF}$, publicado el 30 de diciembre de 2012, se aprueba el Texto Único Ordenado de la Ley General del Sistema Nacional de Presupuesto, que rige a partir del 02 de enero de 2013 ;

Que, el numeral 71.1 del articulo 71 del Decreto Supremo $\mathrm{N}^{2}$ 304-2012-EF, establece que las entidades para la elaboración de sus Planes Operativos Institucionales y Presupuestos Institucionales deben tomar en cuenta su Plan Estratégico Institucional (PEI) que debe ser concordante con el Plan Estratégico de Desarroilo Nacional y los Planes Estratégicos Sectoriales Multianuales (PESEM), según sea el caso;

Que, mediante Resolución Ministerial N* 125-2013-PCM, de fecha 16 de mayo de 2013, se aprueba el Plan de Implementación de la Politica Nacional de Modernización de la Gestión Pública 2013-2016;

Que, mediante Resolución Suprema N $N^{\circ}$ 007-2012-ED, de fecha 09 de marzo de 2012 del Ministerio de Educación, se designan a los miembros del Directorio del Centro Vacacional Huampani, integrado por los siguientes profesionales: Máximo Rodolfo Gallo Quintana en calidad de Presidente, Jose Luis Liendo Sotornayor, Luzgarda Quillama Torres, Ana Patricia Andrade Pacora, Carmen Patricia Correa Arangoitia, y Felipe Augusto Injoque Espinoza; 


\section{III... REF; RESOLUCIÓN DE GERENCIA GENERAL N`286-2013-CVH-GG}

Que, la empresa Gobiz S.A. ha presentadio el documento denominado "Proceso de Alineamiento Estratégico del Centro Vacacional Huampani", cumpliendo a cabalidad con los terminos de referencia del servicio, por lo que la Presidencia del Directorio ha otorgado la conformidad correspondiente;

Que la Gerencia General conjuntamente con la Oficina de Planificación y Presupuesto, presentan el proyecto de Plan Estratégico Institucional (PEI) 2013-2016 del Centro Vacacional Huampanl, en base al documento denominado "Proceso de Alineamiento Estratégico",

Que, en el Acuerdo $\mathrm{N}^{*} 5$ de la Sesión de Directorio $\mathrm{N}^{*}$ 016-2013-CVH, de fecha 31 de agosto de 2013, se acuerda la aprobación del Plan Estratégico Institucional (PEI) 2013-2016 del Centro Vacacional Huampani;

Estando a lo acordado en la Sesión de Directorio $\mathrm{N}^{\circ}-016-2013-\mathrm{CVH}$ y a las atribuciones que el Estatuto, confiere al Gerente General del Centro Vacacional Huampani;

\section{SE RESUELVE:}

PRIMERO.- APROBAR, el Plan Estratégico Institucional (PEl) 2013-2016 del Centro Vacacional Huampani" en via de regularización, el mismo que en dieciocho (18) folios y el Anexo denominado Proceso de Alineamiento Estrategico, forman parte de la presente resolución.

SEGUNDO-- DISPONER, el cumplimiento de la presente Resolución por parte de todas las unidades orgánicas del Centro Vacacional Huampani.

TERCERO.- ENCARGAR, la publicación de la presente Resolución y su Anexo en el Portal de Transparencia Institucional del Centro Vacacional Huampani.

Registrese, comuniquese y archivese.

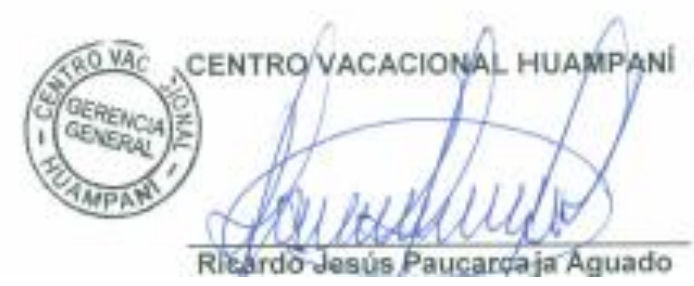


Anexo 2: Infraestructura con la que cuenta el CVH, recuperado de: http://www.huampani.gob.pe/

\section{I. ÁREA DE ALOJAMIENTO Y CONVENCIONES}

Esta área es la unidad orgánica de tercer nivel encargada de planificar, coordinar, dirigir y controlar los servicios de alojamiento, ambientes para convenciones, garantizando el cumplimiento de un adecuado estándar de calidad y confort.

\section{1. ÁREA DE ALOJAMIENTO:}

El área de alojamiento cuenta con:

34 Bungalows de 2 habitaciones

57 Bungalows de 3 habitaciones

* 11 Bungalows Ejecutivos

* 46 Bungalows Estándar

07 Edificios

$\begin{array}{lll}36 \text { Habitaciones dobles con baño privado } & - & \text { Edificio } 1 \\ 34 \text { Habitaciones dobles con baño privado } & - & \text { Edificio } 2 \\ 34 \text { Habitaciones dobles con baño privado } & - & \text { Edificio } 3 \\ 34 \text { Habitaciones dobles con baño privado } & - & \text { Edificio } 4 \\ 34 \text { Habitaciones dobles con baño privado } & - & \text { Edificio } 5 \\ 34 \text { Habitaciones dobles con baño privado } & - & \text { Edificio } 6 \\ 64 \text { Habitaciones dobles con baño privado } & - & \text { Edificio } 7\end{array}$

\subsubsection{Bungalows de dos Habitaciones (34 unidades):}

(Del 01 al 32; 250 y 264) 
A la fecha se cuenta con 34 bungalows de dos habitaciones; del 01 al 32, el $\mathrm{N}^{\circ}$ 250 y el No $264 ; 32$ bungalows se encuentran en la zona aledaña a la piscina y campos deportivos y los otros dos en la zona de los bungalows séxtuples.

Para el año 2014 estuvo programado el mantenimiento que incluye pintura, las refacciones y reparaciones por uso.

\subsubsection{Bungalows de tres Habitaciones ( 57 unidades)}

Se cuenta con 57 bungalows de tres habitaciones distribuidos del siguiente modo:

a) Bungalows de tres Habitaciones Ejecutivos del $N^{\circ} 225$ al $N^{\circ} 235$ (11 unidades):

Estos Bungalows constan de una salita de estar equipada con dos sillones y TV de 21" a color con señal de cable, un friobar, comedor equipado con mesa y 4 sillas, tres dormitorios con 2 camas de una plaza cada uno con colchones tipo ortopédicos, alfombrado; servicios higiénicos con agua caliente.

Para el año 2014 estuvo programado el mantenimiento que incluye pintura, refacciones y reparaciones por uso

b) Bungalows de tres Habitaciones Standard del 236 al 249, del 251 al 263 y del 265 al 283 (46 unidades):

Estos Bungalows constan de una salita de estar equipada con dos sillones y TV de 21" a color con señal de cable, un friobar; comedor, equipado con 
mesa y 4 sillas, tres dormitorios con 2 camas de una plaza cada uno con colchones tipo ortopédicos y de espuma; servicios higiénicos con agua caliente.

Para el año 2014 estuvo programado el mantenimiento que incluye pintura, refacciones y reparaciones por uso.

\section{Edificio $\mathbf{N}^{\circ} 01$}

En el primer piso se encuentra ubicado 20 habitaciones con puesta a la calle, la mitad con vista a la piscina y la otra mitad con vista a las áreas verdes. Las habitaciones del primer piso están amobladas con dos camas de una plaza, velados, TV de 21 " pantalla plana con señal de cable y lencería nuevas y colchones ortopédicos

En el segundo piso se encuentra distribuidos 16 habitaciones con terrazas, convertidas en matrimoniales al equiparlas con camas de dos plazas colchón ortopédico, velador y lencería nueva.

Actualmente, ocupado por el Colegio Mayor Secundario Presidente del Perú (CMSPP), que en sus 34 habitaciones que viene usando, cada habitación para tres personas en este sistema de un camarote y una cama simple de una plaza, teniendo en este edificio dos habitaciones de tipo simple para una persona o un camarote resumiendo la ocupabilidad total de este edificio 1 es de 106 Pax.

En el año 2014 se ha programado la preparación de los closets y además el mantenimiento que incluye pintado, resane de los ambientes.

\section{Edificio $\mathbf{N}^{\circ} 02$}

Este edificio está ubicado al lado del edificio 1 
Cuenta con 34 habitaciones con baño independiente, distribuidos en dos pisos de la siguiente forma:

En el primer piso se encuentra ubicados 20 habitaciones con puerta a la calle, la mitad con vista al edificio 1 y la otra mitad con vista a las áreas verdes y edificio 3. Las Habitaciones del primer piso están amobladas con un camarote de una plaza y baño privado y lencería nueva (edredones, toallas y sabanas), y colchones ortopédicos. En el segundo piso se encuentra distribuidos 14 habitaciones con terrazas, están amobladas con un camarote de una plaza y baño privado.

Se colocaron juegos de confortables para los Halls, estores para las ventanas de las habitaciones, TV de 21" pantalla plana con señal de cable para los Halls.

Actualmente, ocupado por el Colegio Mayor Secundario Presidente del Perú (CMSPP), que en sus 34 habitaciones que viene usando, cada habitación para tres personas en este sistema de un camarote y una cama simple de una plaza, teniendo en este edificio dos habitaciones de tipo simple para una persona o un camarote resumiendo la ocupabilidad total de este edificio 2 es de 100 Pax.

Para el año 2015 se ha programado la preparación de los closets y además el mantenimiento que incluye pintado, resane de los ambientes.

\section{Edificio $\mathbf{N}^{\circ} \mathbf{0 3}$}

Este edificio está ubicado al lado del Edificio 2.

Cuenta con 34 habitaciones con baño independiente, distribuidos en dos pisos de la siguiente forma:

En el primer piso se encuentra ubicados 20 habitaciones con puerta a la calle, la mitad con vista al edificio 2 y la otra mitad con vista a las áreas verdes y edificio 4. Las habitaciones del 
primer piso están amobladas con un camarote de una plaza, y baño privado y lencería nueva (edredones, toallas, sabanas) y colchones ortopédicos.

En el segundo piso se encuentra distribuidos 14 habitaciones con terrazas, están amobladas con un camarote de una plaza y baño privado.

Se colocaron juegos de confortables para los Halls, estores para las ventanas de las habitaciones, TV de 21 "pantalla plana con señal de cable para los Halls.

Actualmente, ocupado por el Colegio Mayor Secundario Presidente del Perú (CMSPP), que en sus 34 habitaciones que viene usando, cada habitación para tres personas en este sistema de un camarote y una cama simple de una plaza, teniendo en este edificio dos habitaciones de tipo simple para una persona o un camarote resumiendo la ocupabilidad total de este edificio 3 es de 100 Pax.

\section{a. Edificio $\mathbf{N}^{\circ} 04$}

En este edificio está ubicado al lado del edificio 3, Cuenta con 34 habitaciones con baño independiente, distribuidos en dos pisos de la siguiente forma:

En el primer piso se encuentra ubicados 20 habitaciones con puerta a la calle, la mitad con vista al edificio 3 y la otra mitad con vista a las áreas verdes y edificio 5. Las habitaciones del primer piso están amobladas con un camarote de una plaza y baño privado y lencería nueva (edredones, toallas, sabanas) y colchones ortopédicos.

En el segundo piso se encuentran distribuidas 14 habitaciones con terrazas, están amobladas con un camarote de una plaza closet incorporado y baño privado.

Se colocaron juegos de confortables para los Halls, estores para las ventanas de las habitaciones, TV de 21" pantalla plana con señal de cable para los Halls. 
Actualmente, ocupado por el Colegio Mayor Secundario Presidente del Perú (CMSPP), que en sus 34 habitaciones que viene usando, cada habitación para tres personas en este sistema de un camarote y una cama simple de una plaza, teniendo en este edificio dos habitaciones de tipo simple para una persona o un camarote resumiendo la ocupabilidad total de este edificio 4 es de 100 Pax.

Para el año 2015 se ha programado la preparación de los closets y además el mantenimiento que incluye pintado, resane de los ambientes.

\section{Edificio $\mathbf{N}^{0} 05$}

Este edificio está ubicado al lado del edificio 4, Cuenta con 36 habitaciones con baño independiente, distribuidos en dos pisos de la siguiente forma:

Cuenta con 34 habitaciones con baño independiente, distribuidos en dos pisos de la siguiente forma:

En el primer piso se encuentras ubicados 20 habitaciones con puerta a la calle, la mitad con vista a la cochera y la otra mitad con vista a las áreas verdes del chachikart y rotonda. Las habitaciones del primer piso están amobladas con una camarote de una plaza, y baño privado y lencería nueva (edredones, toallas, sabanas), y colchones ortopédicos.

En el segundo piso se encuentran distribuidas 14 habitaciones con terrazas, están amobladas con un camarote de una plaza y baño privado.

Se colocaron juegos reconfortables para los Halls, estores para las ventanas de las habitaciones TV de 21 "pantalla plana con señal de cable para los Halls. 
Actualmente, ocupado por el Colegio Mayor Secundario Presidente del Perú (CMSPP), que en sus 34 habitaciones que viene usando, cada habitación para tres personas en este sistema de un camarote y una cama simple de una plaza, teniendo en este edificio dos habitaciones de tipo simple para una persona o un camarote resumiendo la ocupabilidad total de este edificio 5 es de 100 Pax.

En el año 2014 se ha programado la preparación de los closets y además el mantenimiento que incluye pintado, resane de los ambientes.

\section{Edificio $\mathbf{N}^{\circ} 06$}

Este edificio está ubicado al lado del Chachikart.

Cuenta con 34 habitaciones con baño independiente, distribuidos en dos pisos de la siguiente forma:

En el primer piso se encuentras ubicados 20 habitaciones con puerta a la calle, la mitad con vista a la cochera y la otra mitad con vista a las áreas verdes del chachikart y rotonda. Las habitaciones del primer piso están amobladas con una camarote de una plaza, y baño privado y lencería nueva (edredones, toallas, sabanas), y colchones ortopédicos.

En el segundo piso se encuentran distribuidas 14 habitaciones con terrazas, están amobladas con un camarote de una plaza y baño privado.

Se colocaron juegos reconfortables para los Halls, estores para las ventanas de las habitaciones TV de 21 "pantalla plana con señal de cable para los Halls.

Actualmente, ocupado por el Colegio Mayor Secundario Presidente del Perú (CMSPP), que en sus 34 habitaciones que viene usando, cada habitación para tres personas en este sistema de un camarote y una cama simple de una plaza, teniendo en este edificio dos habitaciones de 
tipo simple para una persona o un camarote resumiendo la ocupabilidad total de este edificio 6 es de 100 Pax.

\section{b. Edificio $\mathbf{N}^{\circ} \mathbf{0 7}$}

- Del primer cuarto piso constan de 16 habitaciones en cada piso con baño privado.

- Se ha realizado la remodelación total de este edificio, adaptándolos con baños privados y el pintado exterior e interior, dotándolos de colchones ortopédicos, lencería (camarotes edredones sabanas almohadas y toallas) y estores para las ventanas.

- Cuentan con 64 habitaciones.

- Remodelación total de pisos.

- En el año 2017 se ha dotado para cada una de las habitaciones, además el mantenimiento que incluye pintado, resane y reparación si lo requiere, estos edificios carece de Halls cerrado, en el 2011 se remodelara y habilitara los Halls de vidrio templado añadiéndole juegos de confortable y se instalara TV en todos los ambientes, en el Frente oficinas de la Dirección CMSPP.

\section{c. Edificio Múltiple de capacitación (Ex Edificio Docente)}

En el cuarto piso de este edificio se encuentra ubicada La zona Múltiple de Descanso, que es utilizada para retiro y recuperación donde se pueden realizar terapias de relajamiento múltiples, (Ex Albergue).

Cuenta con dos Servicios higiénicos para damas y caballeros a los cuales se le efectúo mantenimiento en el ejercicio anterior un cambio de sanitarios luminarias y pintado interior En el primer nivel de este edificio lado “A “(Ex Planada Múltiple de Capacitación ) se encuentran ubicadas las 04 aulas destinadas a convenciones, en el segundo nivel 
lado "B" (Estacionamiento), el almacén central, almacén de activo fijo y el comedor de personal del Centro Vacacional Huampani (CVH) .

En el tercer nivel lado "B" (Estacionamiento), se encuentran ubicadas habitaciones y servicios Higiénicos para el personal del Centro Vacacional Huampani (CVH). En el Cuarto nivel se encuentra ubicado la Zona Múltiple de Descanso destinada para el alojamiento (Ex Albergue), antes descrito, destinado para alojamiento. Dentro del programa de mejoramiento y recuperación de ambiente, se a proyectado realizar un mantenimiento integral a este edificio para convertirlo en salas de convenciones.

\section{2 ÁREA DE CONVENCIONES}

a) Para la atención a los clientes se dispone de:

- Lobby ( Recepción)

- Lavandería

- Centro Médico del CVH - (Ex Tópico)

- 3 Pabellones de Aulas (1 ero y 2do piso)

- 1 Pabellones de Laboratorios (1ero y 2do piso)

b). Ambientes para Capacitación

- 01 Aula $\mathrm{N}^{\circ} 1$ primer piso (costado Edificio Múltiple de

Capacitación)

50pax

- 01 Aula No 2 segundo piso (costado Edificio Múltiple de

\section{Capacitación)}

50 pax

- 06 Aulas 1er piso (Costado Edificio Múltiple de 
Capacitación)

40 pax

- 02 aulas PRE fabricadas (Costado Edificio Múltiple de

\section{Capacitación)}

- Sala de lectura "A" (Ex sala Pachacutec)

- Sala de lectura “B” (Ex sala Mini market)

c). Auditorios

- Auditorio principal

- Auditorio Central (Ex sala Pachacutec)

d) Oficinas de Apoyo

Cuentan con cinco (05) oficinas de apoyo.
40 pax

80 pax

250 pax

800pax

\section{Lobby (recepción)}

Ambiente ubicado a la entrada del Edificio principal del $\mathrm{CVH}$, de dos pisos, donde se recibe a los clientes y se lleva el control y registro de alojados, eventos, etc. Está encargada de supervisar la óptima presentación de las habitaciones y salas de convenciones, así como la distribución en todo el Centro Vacacional Huampani).

En el 2014 se realizó lo siguiente:

- Decoración del Lobby (recepción)

- Cambio de luminarias

- Tablero electrónico

\section{Lavandería}


Ubicada en el sótano de la cocina; es la encargada de dar el servicio del lavado a las diferentes áreas del Centro Vacacional Huampani. Dado que nuestra venta está dirigida a grupo de convenciones, el objetivo de la lavandería se focaliza en el lavado de lencería de uso de alojamiento, convenciones, alimentos y bebidas, uniformes de los trabajadores y ropa de clientes.

Se encuentra equipada con las siguientes maquinarias: Lavadora industrial, exprimidora centrifuga industrial, secadora de ropa a vapor, planchadora industrial o "calandria", y un hervidor de jaboncillo. Estas máquinas necesitan mantenimiento.

Las máquinas que funcionan a vapor son: la secadora, la calandria y el hervidor. Las tuberías de vapor de aquellas por su antigüedad necesitan ser reemplazadas. E el 2013 se construyó un ambiente para acopio de prendas para el recojo y entrega de prendas.

\section{Centro Médico - Ex Tópico}

Ubicado frente a recepción y es atendido por 3 médicos y 2 dos enfermeras, brinda servicios médicos de primera calidad.

- 02 Camillas fijas

- Aspirador e instrumentos para tópico.

Para el 2015 el Centro Medico Huampani, modernizara sus instalaciones, instalando un lavador en el lado del tópico, además algunas zonas del centro médico se colocara mayólicas, además de la preparación de estantería para todos los documentos e instrumentos del centro 
médico, se mejorara las instalaciones eléctricas así como de luminarias, también se mejorara el stand y el lugar de los medicamentos.

\section{AMBIENTES PARA CAPACITACIÓN}

Son aulas con capacidad entre 40 y 80 personas, equipadas de mesas, sillas, proyector, pizarras acrílicas, punto de Internet a solicitud del cliente, siendo las siguientes:

- 02 Salas (1er y 2do. Piso) al costado Edificio Múltiple de capacitación (Docente.).

- 08 Aulas 1er. Piso al costado Edificio Múltiple de capacitación (Docente.).

- $\quad 02$ Salas (al costado de recepción)

01 sala de lectura A con una capacidad de 100 personas y con servicios higiénicos propios, oficina de apoyo y almacén.

01 sala de lectura $\mathbf{B}$ con una capacidad de 40 personas.

- 02 Pabellones o bloques de 2 pisos de ap. $1000 \mathrm{~m} 2$ para 12 ambientes de laboratorios.

- 03 Pabellones o bloques de 2 pisos de ap. $1300 \mathrm{~m} 2$ por un total de 24 aulas y 48 salitas de coordinación.

- 02 salas de uso múltiple para capacitación (acostado de recepción), Wiracocha y Coricancha. Estos dos ambientes pueden usarse para todo tipo de eventos, como a su vez sirve de sala capilla, teniendo cada una un desnivel que es utilizado como parte de ambiente de apoyo.

El edificio Casino por convenio entre el gobierno peruano y el gobierno de Corea se ha transformado en un Centro de Acceso a la Información, cuenta con equipos de 
cómputo de última generación (computadoras, impresoras, proyectores, muebles y enseres) y es administrado por el CVH. Se ha programado la renovación de los servicios higiénicos.

\section{AMBIENTES PARA AUDITORIO}

1. Auditorio Principal

Ubicado en el primer piso del Restaurante, equipado con 220 butacas aunque se puede adicionar de 60 a 80 sillas más.

Para el 2017 se ha programado el cambio de los 04 equipos de aire acondicionado, para confort y atención a nuestros clientes.

\section{Auditorio Central}

Ubicado frente al Lobby (recepción) es una estructura de piedra teniendo por techo un toldo de lona. En el ejercicio anterior se le dotó de luminarias especiales para auditorios y tres ventiladores de techo; tiene capacidad para 500 personas.

Para el 2017 está programado lo siguiente:

○ 09 ventiladores industriales

- Cambio de cubierta de lona en el auditorio central

- Mejorar las luminarias

- Se confeccionara nuevos estrados

\section{OFICINA DE APOYO}

Se cuenta con 05 oficinas de apoyo ubicado debajo de la terraza del comedor principal. Estas oficinas están equipadas con mobiliario, puntos de Internet y anexo telefónico. 


\section{Área de Alojamiento y convenciones}

Se ha programado para el 2017 lo siguientes:

- Mantenimiento Integral que incluye, pintado y resane de todos los ambientes (edificios y bungalow).

- Se instalara en cada habitación de los edificios 1, 2, 3, 4, 5,6 y 7 los closet en material de melamina acorde con la decoración de la habitación.

- Instalación de los 4 Halls de los edificios $\mathrm{N}^{\mathrm{a}} 7$ en vidrio y aluminio.

- Centro Medico está incluido dentro de la modernización, optimización y equipo para una atención del Centro Medico Huampani. (CVH).

- Para los diferentes ambientes del área sea solicitado comprar 40 ventiladores de pie

- Como un servicio adicional de alojamiento y convenciones se adquirirá 6 hornos microondas.

- Para la decoración y uso de todo el área y por reposición se adquirirá 20 televisores pantalla plana de 29 pulgadas.

- Se adquirirá un fax.

- Para mejorar el alquiler de equipos para convenciones se adquirirá 10 laptops.

- Continuando con la renovación de equipo para convenciones se solicita la compra de 10 computadoras.

- Se adquirirá 04 proyectores con ecram para brindar un mejor servicio y respuestas al requerimiento de nuestros clientes.

- En el programa de renovación de muebles por deterioro y uso se adquirirá 30 juegos de confortable para los Halls de los edificios. 
Para el área de Lavandería se va adquirir para el año 2017 lo siguiente:

- 01 lavadora de 100 kilos

- 01 secadora de 70 kilos

Dentro del programa de renovación por uso de lencería se adquirirá para el 2017 lo siguientes:

- 1500 sabanas de 1 plaza y media

- 1500 frazadas de 1 plaza y media

- 1500 cubrecamas de una plaza y media

- 1500 almohadas

- 1500 toallas

- 500 cortinas para duchas

- 200 manteles

- 174 cortinas para laboratorios y salas del CMSPP

- En la renovación y presentación del auditorio central se adquirirá un nuevo techo. 


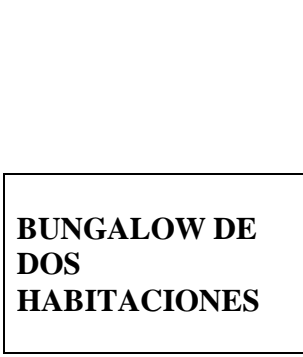

TOTAL

\begin{tabular}{|l|}
\hline BUNGALOW DE \\
TRES \\
HABITACIONES \\
\hline
\end{tabular}

TOTAL

TOTAL BUNGALOWS

\begin{tabular}{|l|} 
HABITACION \\
DOBLE \\
\hline
\end{tabular}
\begin{tabular}{|l|l} 
EDIFICIO & 01 \\
EDIFICIO & 02 \\
EDIFICIO & 03 \\
EDIFICIO & 04 \\
EDIFICIO 05 \\
EDIFICIO 06
\end{tabular}

TOTAL HAB. EDIFICIOS EDIFICIO 07 HABITACION DOBLE

EJECUTIVO
STANDARD

$$
57
$$

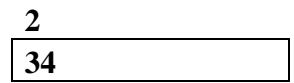

\begin{tabular}{ll}
11 \\
46 \\
\hline 57 \\
\hline
\end{tabular}

\section{1}

36
34
34
34
34
34

206

64
250-264

Del 284 al 348

CANTIDAD DE

CAMAS

128

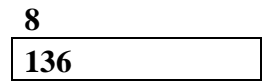

225 AL 235

66

236 AL 249-251 AL

253-

255 AL 263-266 AL

269

254-265-270 AL 283

$\begin{array}{ll}33 \text { AL } 64 & 72 \\ 65 \text { AL } 96 & 68 \\ 97 \text { AL 128 } & 68 \\ \text { 129 AL 160 } & 68 \\ \text { 161 AL 192 } & 68 \\ \text { 193 AL 224 } & 68\end{array}$

\section{TOTAL}

\begin{tabular}{|l|l|}
$\begin{array}{l}\text { Descanso múltiple de } \\
\text { capacitación }\end{array}$ & $\begin{array}{l}4 \text { Piso } \\
\text { Edificio } \\
\text { Docente }\end{array}$ \\
\cline { 1 - 2 }
\end{tabular}

361

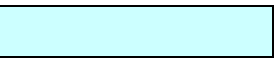

\section{2}

478

412

128

276 72

68

68

68

68

1018

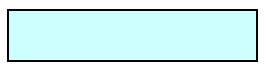




\section{II. ÁREA DE ALIMENTOS Y BEBIDAS:}

Esta área es la unidad orgánica de tercer nivel, encargada de planificar, organizar, dirigir, coordinar y supervisar los servicios de los restaurantes, bar, y cocinas para que preste las mejores atenciones de atención al cliente. Está comprendida por los siguientes ambientes:

- Restaurante principal

- Terraza del restaurant

- Cocina Principal

\section{Restaurante Principal}

El Restaurante Principal se encuentra ubicado en el segundo piso del Auditorio Principal equipado en total con 50 mesas con 4 sillas con capacidad para 200 personas; al lado derecho el ex Auditorio 2do piso que ahora ha sido ampliado para restaurante, equipado con 30 mesas con 4 sillas con capacidad para 120 personas.

\section{Ampliación del Restaurante}

En la terraza al lado del restaurante principal se ha efectuado un mantenimiento de pisos y techo, y se han construido baños para damas y caballeros. Se ha efectuado adquirió 80 mesas Y 320 sillas lo que daría una capacidad de atención adicional de 320 personas por vez. La capacidad total para atención en el restaurante será de 640 personas por vez.

\section{La terraza}

Ubicado al costado del restaurante principal. En la actualidad pueden ubicarse hasta 50 mesas lo que Daria una capacidad de atención de 200 personas por vez. 


\section{Cocina Principal}

La cocina principal es el centro de producción donde se elaboran los alimentos para atención a los clientes y grupos del restaurante.

\section{Para el 2017 está programado lo siguientes:}

- Adquisición de Maquina lavadora de vajillas

- Adquisición de Procesador de alimentos.

- Adquisición de maquina peladora de papas.

- Servicio de Construcción y redistribución de las cámaras de frío

- Adquisición de coches para traslado de platos.

- Adquisición de Software inforest

- Adquisición de estante con ruedas de 05 pisos

- Adicción de menaje de cocinas. 


\section{AREA DE OPERACIONES}

\section{(RECREACIÓN, ESPARCIMIENTO Y JARDINES)}

Esta área es la unidad orgánica de tercer nivel encargada de planificar, coordinar, dirigir y controlar los servicios de esparcimiento, recreación y jardines, garantizando el cumplimiento de un adecuado estándar de calidad y confort a través de las siguientes áreas:

1. Mantenimiento

2. Carpintería

3. Jardinería (áreas verdes)

4. Piscina

5. Limpieza Pública

\section{AREA DE MANTENIMIENTO}

Responsable del mantenimiento de las instalaciones maquinaria y equipos

\section{AREA DE CARPINTERIA}

Área encargada del constante mantenimiento y reparación del mobiliario de todas las instalaciones como mesas, sillas, camas, cómodas, veladores, fabricación de muebles para oficina, fabricación de dos sillones para cada salita de los 91 bungalow, recuperación de veladores, cómodas y sillas para equipar los edificios.

\section{AREA PISCINA}

En 2017 se ha programado:

- Pintado integral del área y de los SS.HH interior y exterior 


\section{AREAS VERDES}

Se requiere elaborar un plan de recuperación 2011 de las áreas verdes a fin de hacer accesible al público visitante y ampliar las posibilidades atractivas del Centro vacacional.

Se ha elaborado un plan de restauración que comprende las siguientes actividades:

\section{- OBRAS PRELIMINARES}

Comprende los trabajos previos de limpieza del terreno, quitando la maleza, retirando los desperdicios y elementos no deseables del lugar.

\section{- REFORESTACION}

Consiste en establecer especies forestales y ornamentales a fin de cubrir las zonas libres de vegetación. Para instalar la plantación, los hoyos serán de 40 x40cm llenado con la mejor tierra, de tal modo que permita el crecimiento de las plantas, las especies serán aquellas que no requieran de mucho agua como Cactus, Buganbillas, Pencas, gramíneas, molle y otros.

\section{CONSTRUCCION DE CUNETAS}

Consiste en instalar cunetas para hacer llegar el agua de regadío hacia los lugares de plantación, áreas verdes y zonas de instilación de jardines. Las cunetas serán de 20 x 30 para canales de derivación y 40 x 40 para canales de salida principal, en algunos trechos se empleará piedras para canalización.

\section{INSTALACION DE AREAS VERDES}

Consiste en instalar plantas de cobertura y enredaderas para cubrir las zonas sin vegetación, las plantas a instalar serán resistentes a sequía prolongada y mantenimiento mínimo. 


\section{- $\quad$ LETREROS INDICATIVOS}

Son señales indicativas que muestran la dirección de los senderos, las zonas de riesgo y ubicación de los lugares más importantes. Los letreros serán hechos de calamina plana pintados de acuerdo con los estándares de seguridad que estipula el Reglamento de Seguridad Industrial

\section{Rehabilitación del Estadio}

Consiste en realizar plantaciones alrededor del estadio con especies de árboles: Molle, álamos y otros.

Así mismo se requiere ampliar el área del estadio y plantar gras en zonas faltantes.

\section{Construcción de cerco perimétrico}

Consiste en dar mantenimiento al cerco perimétrico de Huampani, instalar plantas como cercos vivos con: Huarangillo, Uña de gato y otras especies adecuadas para cerco

\section{Revegetación laderas del Colegio Mayor. Lado del Laboratorio}

Consiste en cubrir de vegetación con especies rastreras en la zona de la ladera que da al laboratorio del Colegio Mayor.

Las especies a instalar serán: Buganvilla, Yedra etc.

Para el 2017 se ha programado lo siguientes:

- Para el año 2017 está programado lo siguientes:

- Adquisición del Tractor Podador de 15.5 HP 
- Instalación del Sistema móvil de riego Tecnificado (Aspersión)

- Adquisición de micro computadora e impresora.

- Adquisición de jardineros

- Adquisición de sopladores -aspiradora de hojas.

Para el área de operaciones 2017 se ha programado lo siguientes:

- Construcción de un pozo adicional con anillado de concreto .Este proyecto proporcionara la tranquilidad de abastecimiento del líquido elemento.

- Bomba sumergible de $10 \mathrm{hp}$, precisamente como complemento de seguridad y abastecimiento esto estaría asegurado la demanda de uso y consumo del CVH

- La adquisición de un grupo electrógeno de3 200 Kw. este equipo solucionara los problemas de caída y levante de consumo, por uso constante de fluido eléctrico, y por el aumento de consumo de potencia eléctrico.

- En la etapa de modernización la alta dirección del CVH elaboro un estudio en 2 etapas de la baja tensión y siendo este ambicioso para el 2015 se realizara la conclusión del Proyecto integral de baja tensión del CVH.

- El 2018 es un año prometedor y de ejecución de grandes proyectos y es uno de ellos, la adquisición de 01 caldero para las instalaciones de la cocina del CVH esto mejora la respuesta de esta área ya que el que funciona actualmente tiene bastantes años.

- Para el 2017 se solucionara el tema de parque automotor del CVH y para esta tarea de reposición de los existentes, logística tiene previsto la adquisición de 03 vehículos.

- El transporte interno en las instalaciones del CVH son muy extensas, dado el espacio que ocupa, hay la necesidad de adquirir un Motofurgon de $125 \mathrm{cc}$. 
- El consumo de petróleo diésel del CVH Ha aumentado considerablemente y es esta necesidad que se convertirá en GLP, como solución del alto costo por consumo siendo este cambio más beneficioso.

- El transporte y almacenamiento por una red de gas y un tanque de 500 galones será la renovación de seguridad y equipamiento para el 2017.

- En el Proceso de cambio, modernización y adecuación de las instalaciones del CVH dada las exigencias en el área de convenciones y alojamiento es donde se habilitara 04 Halls para el edificio ${ }^{\circ} 7$, esto será en vidrio templado y aluminio.

Para el área de mantenimiento en el año 2017 se adquirirá:

- 01 taladro industrial 1HP

- 01 compresora de 2HP para pintar

- 01 hidrolavadora $13 \mathrm{HP}$

- 03 bicicletas para transporte rápido

Además de esta área de operaciones requiere los servicios de:

- Servicio de fumigación integral

- Servicio de seguridad del CVH

- Servicio de seguridad del CMSPP 
Anexo 3: Fotos de la Renovación del Sistema Electrico Media Tension - I Etapa
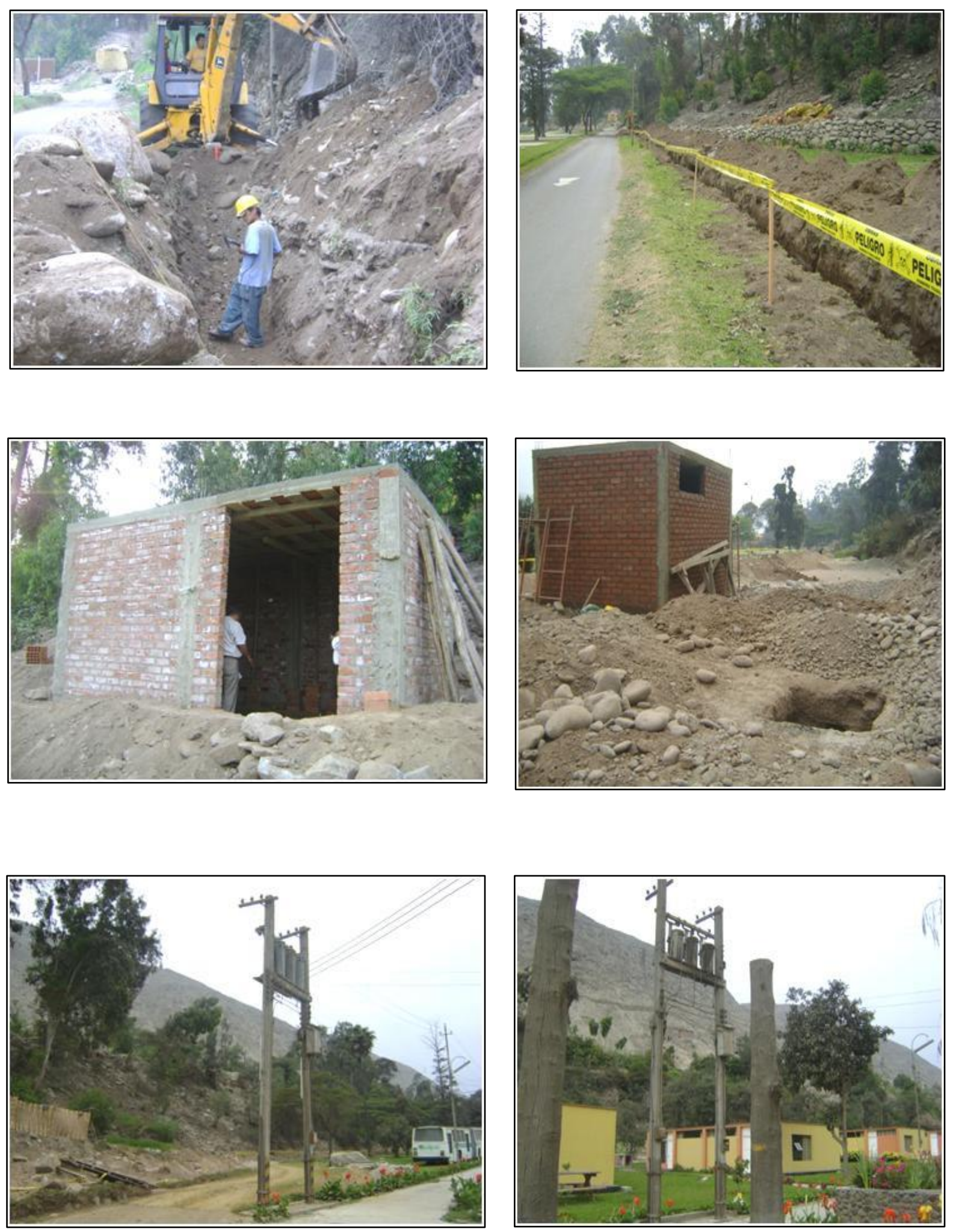

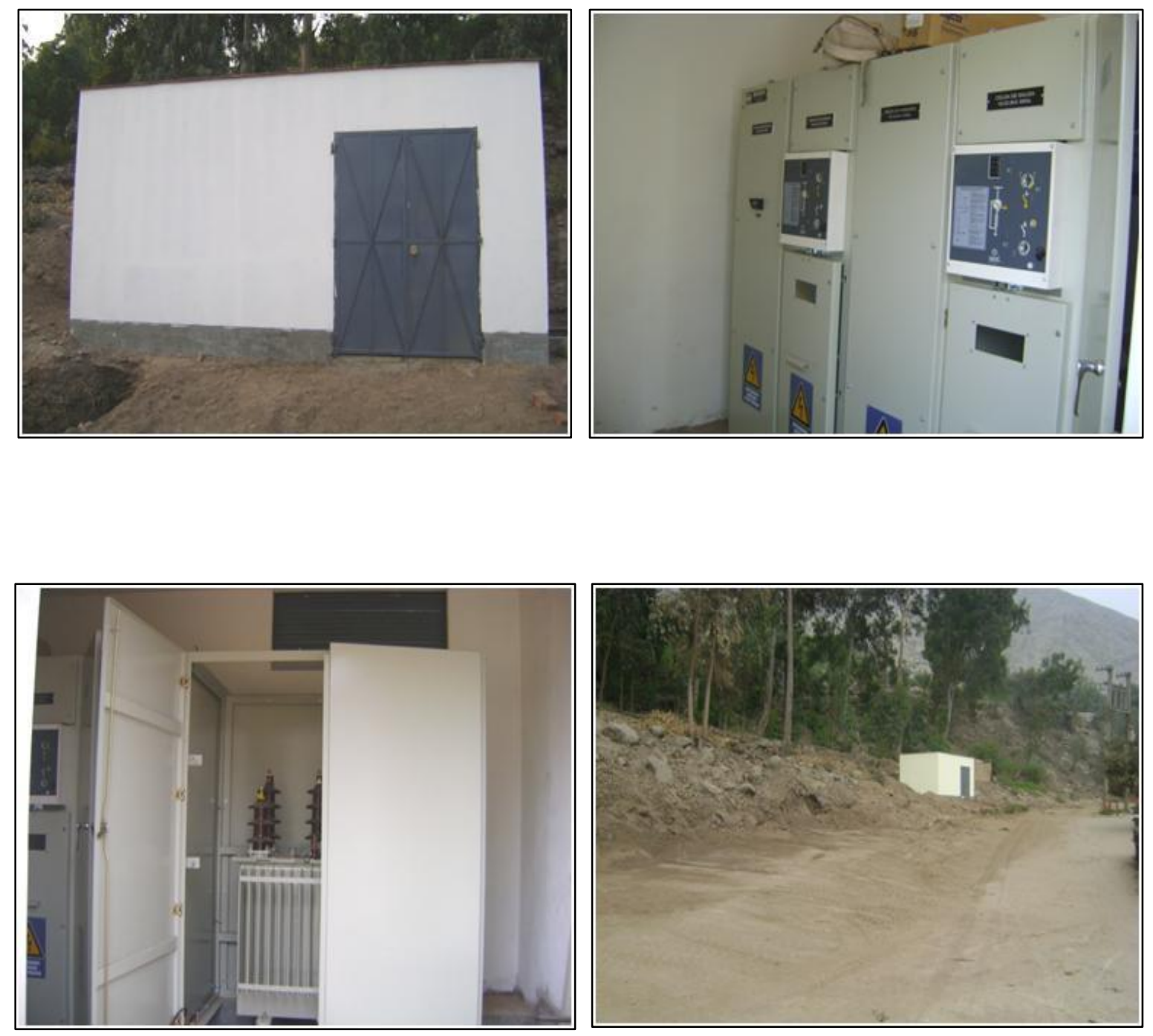
Anexo 4: Ilustraciones de las instalaciones del CVH
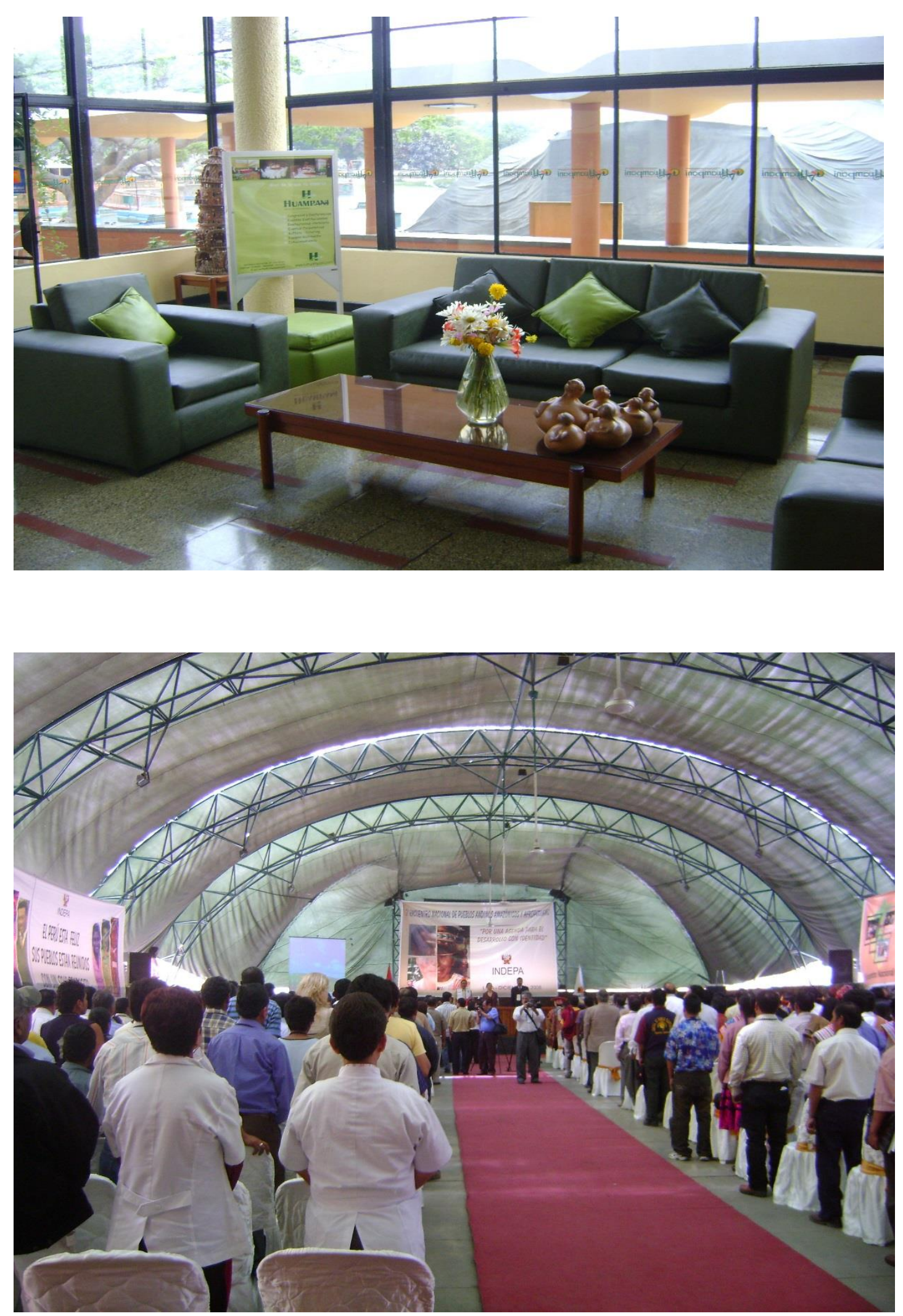

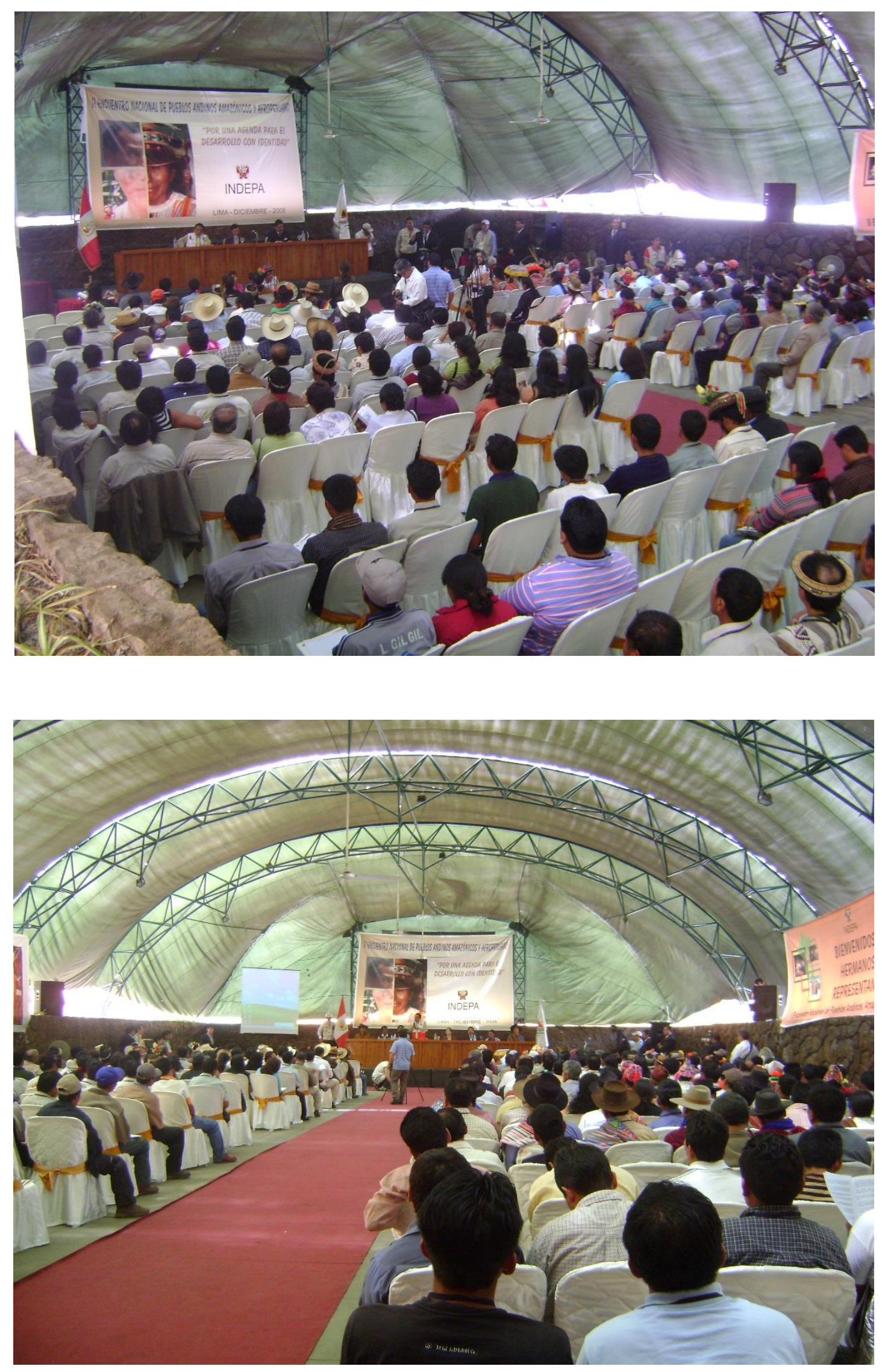

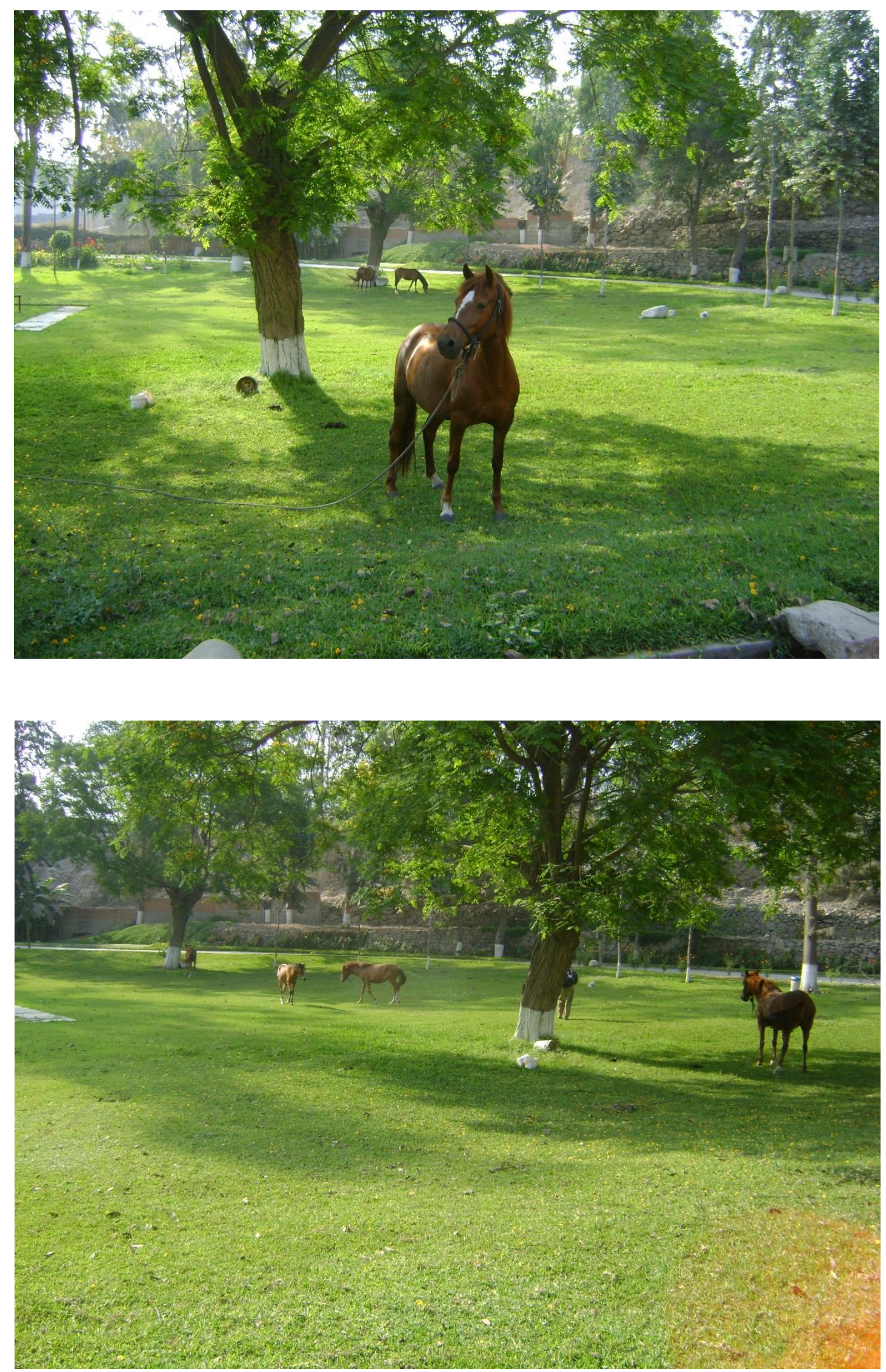

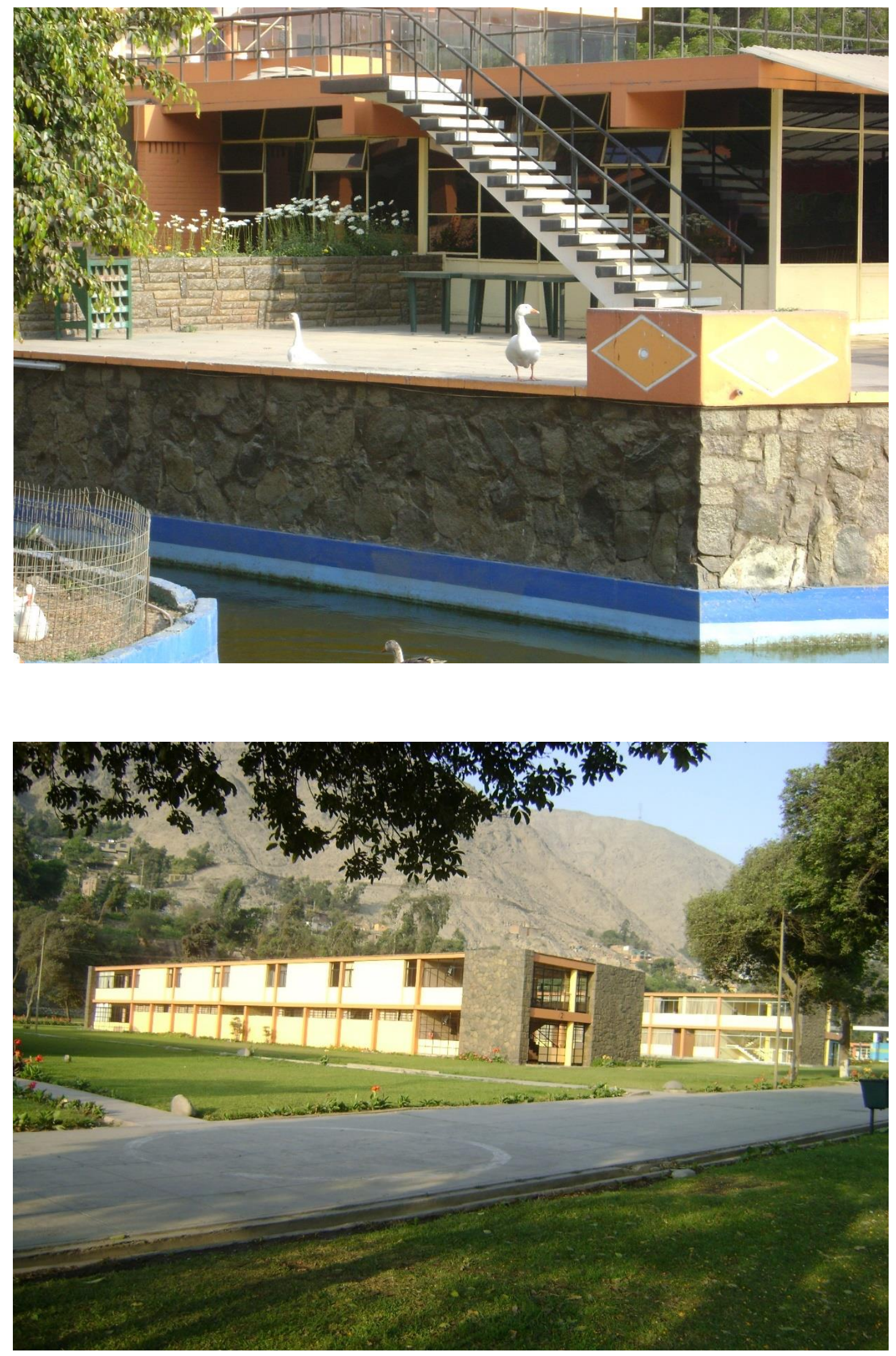

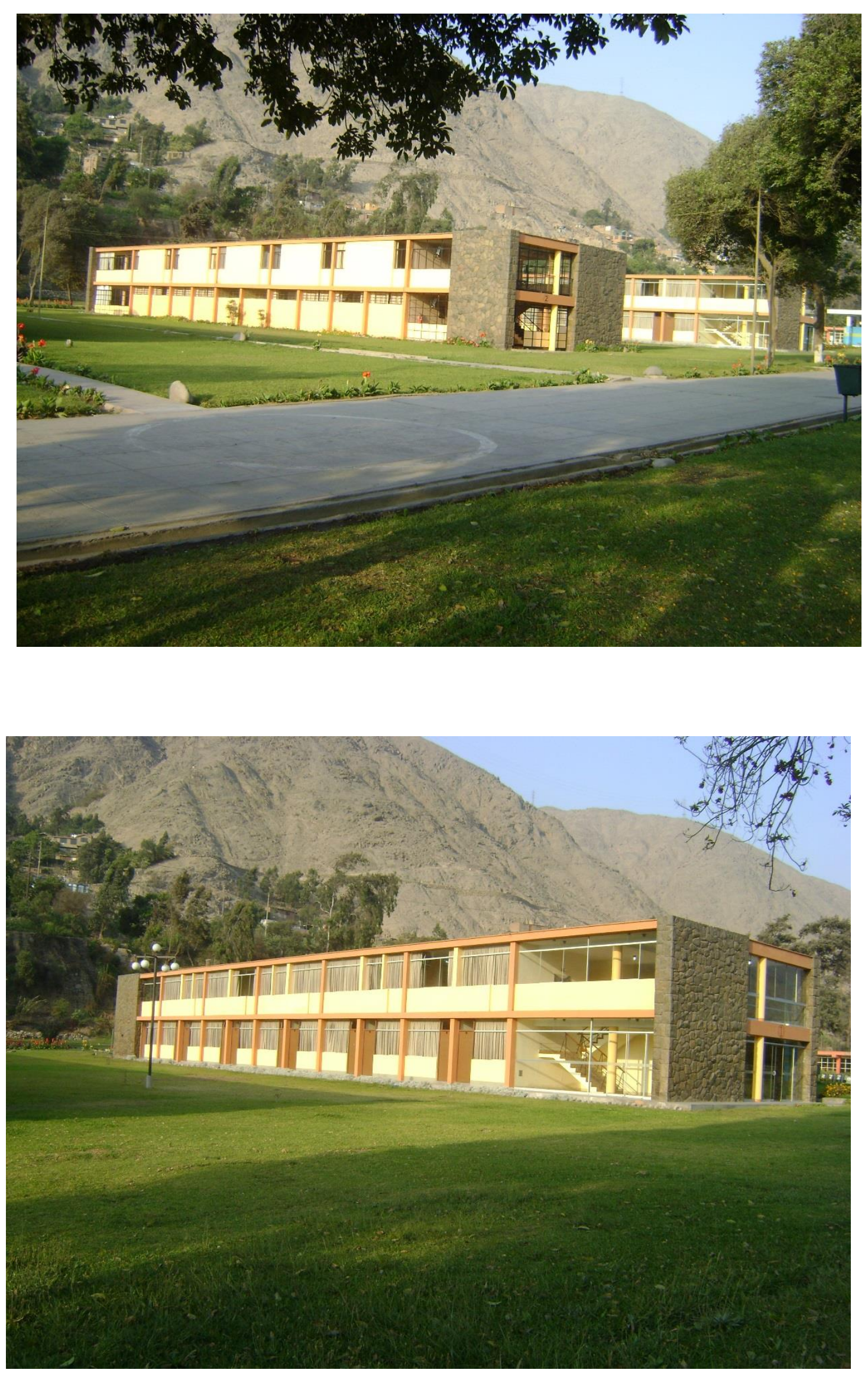

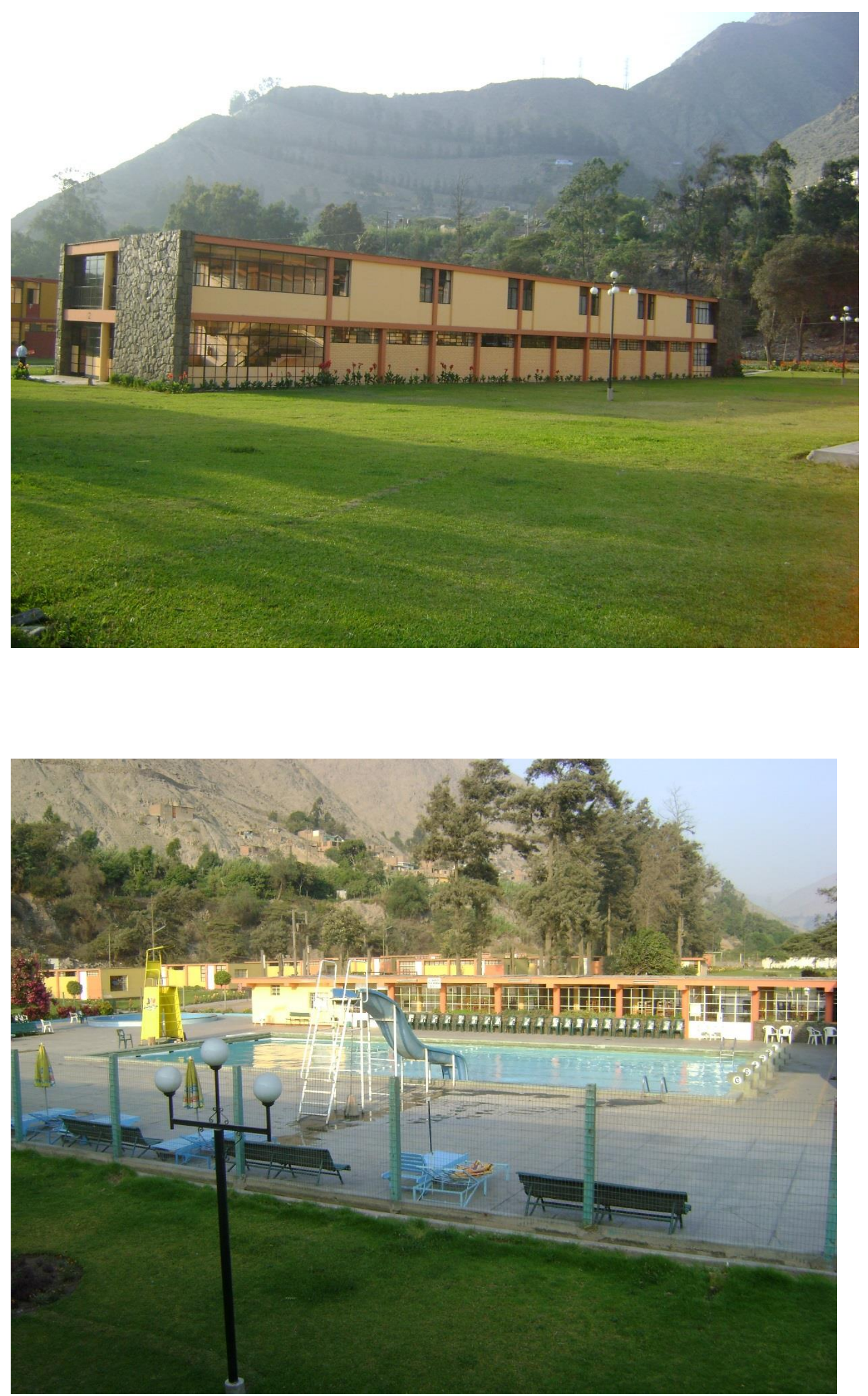

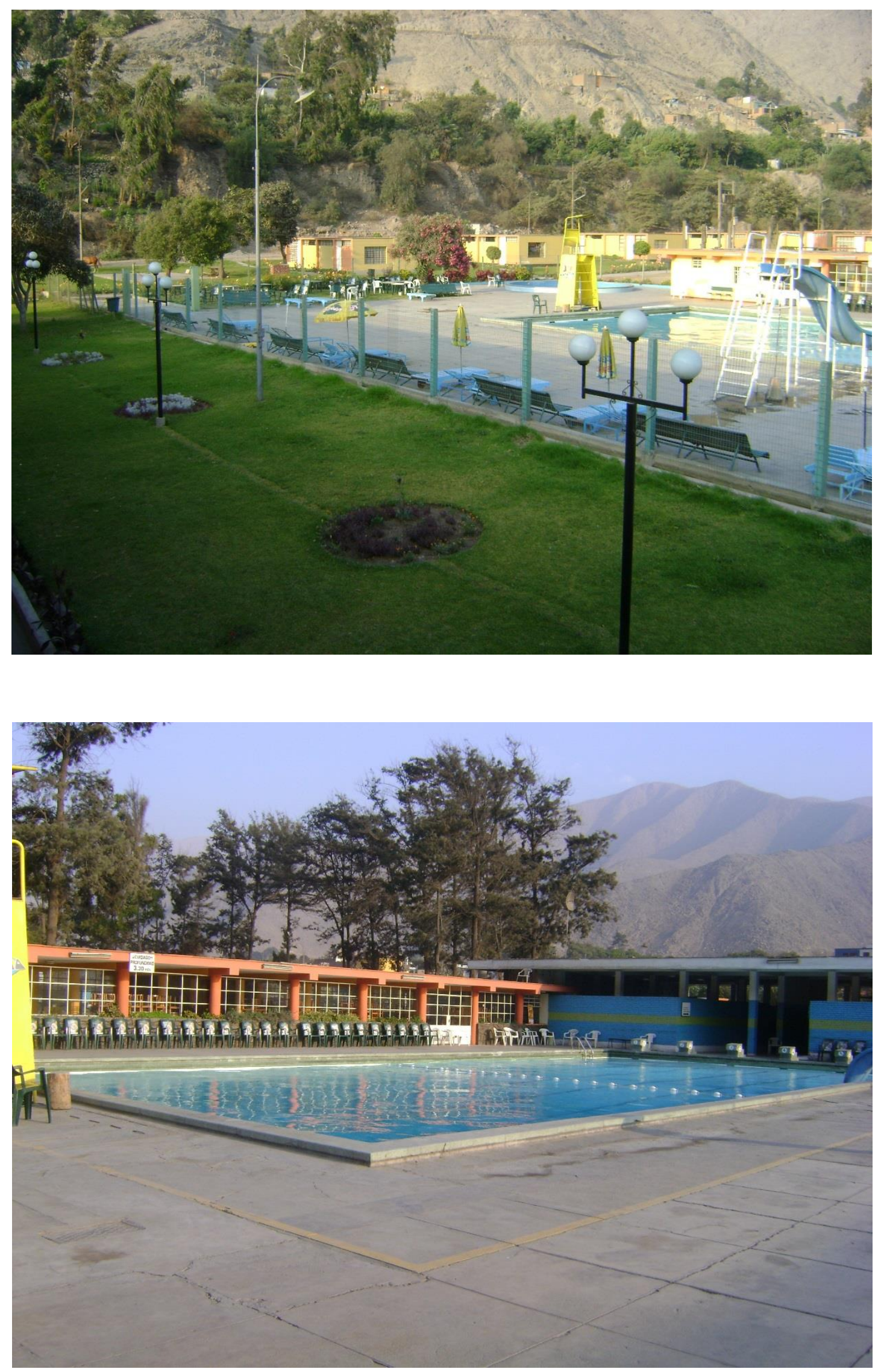


\section{Anexo 5: Proyectos}

\section{- $\quad$ Renovación del Sistema Eléctrico (para ser desarrollado en dos etapas)}

Desde la construcción del CVH el sistema eléctrico no ha tenido ningún mantenimiento. Se ha elaborado el proyecto de mantenimiento del sistema eléctrico del CVH. Se prepararon las bases para efectuar el concurso público y realizar la obra en dos etapas. Se ejecutó el mantenimiento en su primera etapa en el año 2008 y la segunda etapa en el 2009.

Se inició y concluyó la Primera I Etapa del proyecto de Renovación del Sistema Eléctrico Red de media tensión y subestaciones en cabina.

Quedando la segunda II Etapa de la realización de la baja tensión programada a ejecutarse en el periodo 2009.

\section{- $\quad$ Renovación del Sistema de Agua y desagüe}

Las aguas servidas del CVH fluyen al río. Corregir este efecto contaminante significa efectuar primero el estudio del tratamiento de las aguas servidas para luego ejecutar el mantenimiento en el 2009. La coordinación con SEDAPAL para establecer conexión con la red general de desagüe de la zona permitiría reducir costos.

Se ha iniciado ante SEDAPAL el trámite con la presentación del expediente técnico a fin de regularizar la derivación de las aguas servidas del CVH a la troncal de desagüe de SEDAPAL. 
- $\quad$ Ampliación de la infraestructura del CVH.

Para efectos de seguridad de su propiedad como de definición del ámbito del CVH y de evitar invasiones debe efectuarse el estudio del cerco perimétrico para ejecutarlo posiblemente en el 2009.

\section{En el 2008 se han efectuado las siguientes consultorías:}

- $\quad$ Contratación de empresa de servicios para saneamiento físico legal del CVH

- Contratación de un Consultor Especializado en Arquitectura para que se encargue de realizar el inventario físico de la Infraestructura del Centro Vacacional Huampani. 
Anexo 6: Capacidad de convenciones 2014

\begin{tabular}{|c|c|}
\hline AMBIENTES & PAX \\
\hline Auditorio Principal & 250 \\
\hline Salón Auditorio Central & 500 \\
\hline Sala de lectura A y B & 140 \\
\hline Sala Capilla multipropósito A & 35 \\
\hline Sala TV / multipropósito B & 35 \\
\hline Oficina Edificio Múltiple de capacitación $1^{\circ}$ piso & 50 \\
\hline Oficina Edificio Múltiple de capacitación $2^{\circ}$ piso & 50 \\
\hline Edificio Múltiple de capacitación $\mathrm{N}^{\mathrm{o}} 1$ & 40 \\
\hline Aula Edificio Múltiple de capacitación $\mathrm{N}^{\circ} 2$ & 40 \\
\hline Aula Edificio Múltiple de capacitación $\mathrm{N}^{\circ} 3$ & 40 \\
\hline Aula Edificio Múltiple de capacitación $\mathrm{N}^{\circ} 4$ & 40 \\
\hline Aula Edificio Múltiple de capacitación $\mathrm{N}^{\circ} 5$ & 50 \\
\hline Aula Edificio Múltiple de capacitación $\mathrm{N}^{\circ} 6$ & 40 \\
\hline Aula PRE fabricado $\mathrm{N}^{\circ} 7$ & 40 \\
\hline Aula PRE fabricado $\mathrm{N}^{\circ} 8$ & 40 \\
\hline Aulas de capacitación (24 aulas y 48 salitas) & 800 \\
\hline Ambientes de Laboratorios & 400 \\
\hline \multicolumn{2}{|l|}{ Oficina de Apoyo $\mathrm{N}^{\mathrm{o}} 1$} \\
\hline \multicolumn{2}{|l|}{ Oficina de Apoyo $\mathrm{N}^{\circ} 2$} \\
\hline \multicolumn{2}{|l|}{ Oficina de Apoyo $\mathrm{N}^{\circ} 3$} \\
\hline \multicolumn{2}{|l|}{ Oficina de Apoyo $\mathrm{N}^{\circ} 4$} \\
\hline Oficina de Apoyo $\mathrm{N}^{\circ} 5$ & \\
\hline
\end{tabular}

\section{Oficinas de Apoyo}

- $\quad$ Contamos con cinco (05) oficinas de apoyo.

\section{$2004-2007$}

Adquisición de micrófonos de pedestal, pantallas ecram, proyectores multimedia, pizarras acrílicas, mouse, teclados, mouse inalámbricos, reflectores, puntero láser, manteles para mesas de convenciones, cortinas en tela borlón para áreas de convenciones.

- $\quad$ Fabricación de caballetes metálicos. 
- $\quad$ Adquisición de sillas plásticas blancas apilables.

- $\quad$ Adquisición de ventiladores de techo para ambientes de convenciones.

Adquisición de lustradora lavadora de pisos industrial.

Adquisición de cubrecamas, edredones, sábanas y colchones de resorte de una plaza.

Adquisición de un pabellón nacional.

\section{8-2009}

- $\quad$ Adquisición de colchones ortopédicos hoteleros

- $\quad$ Adquisición de cortinas para chalets sextuples

- $\quad$ Adquisición de toallas y sábanas

\section{Recepción}

Ambiente ubicado a la entrada de Edificio principal del CVH, de dos pisos, donde se atiende a los clientes y se lleva el control y registro de alojados, eventos, etc., encargada de supervisar la óptima presentación de las habitaciones y salas de convenciones.

\section{$2004-2009$}

Adquisición de ventiladores de techo para recepción.

Adquisición de uniformes para el personal de Alojamiento y Convenciones.

Capacitación al personal de esa área.

Adquisición de juego de sala de 3,2,1 para recepción

Adquisición de 1 bicicleta para el mensajero.

Adquisición de impresora láser.

Pintado exterior e interior del ambiente. 
ANTES
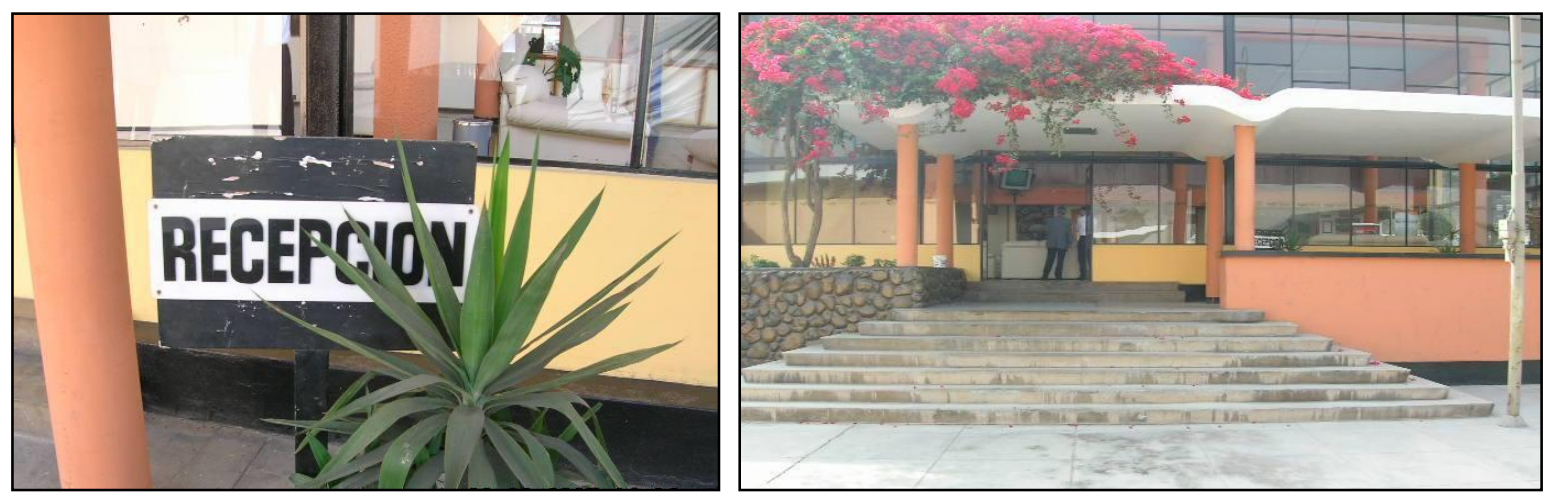

\section{DESPUES}
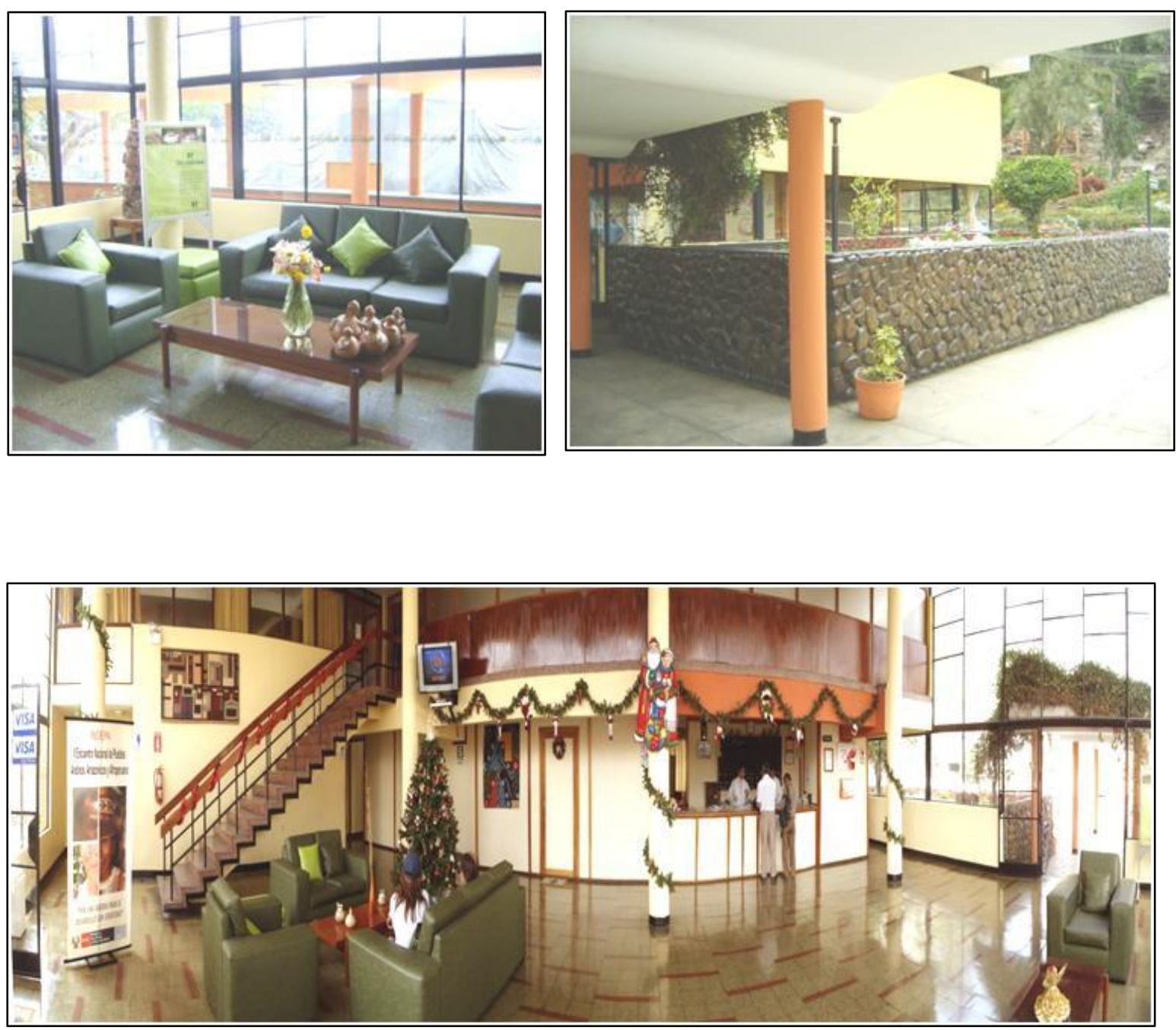


\section{LAVANDERÍA}

Ubicada en el sótano de la cocina; es la encargada de dar el servicio de lavado a las diferentes áreas del CVH. Dado que nuestra venta está dirigida a grupo de convenciones, el objetivo de la lavandería se focaliza en el lavado de lencería de uso de alojamiento, convenciones, alimentos y bebidas, uniformes de los trabajadores y un mínimo de ropa de clientes.

Se encuentra equipada con las siguientes maquinarias: Lavadora industrial, exprimidora centrifuga industrial, secadora de ropa a vapor, planchadora industrial o “calandria”, y un hervidor de jaboncillo. Las máquinas que funcionan a vapor son: la secadora, la calandria y el hervidor.

\section{$2004-2009$}

- $\quad$ Renovación total de 28 metros de tubería de vapor en la lavandería.

- $\quad$ Se tiene programada la instalación de redes de tuberías a vapor y retorno de condensado.

- $\quad$ Mantenimiento de secadora a vapor y de la exprimidora centrífuga. 
MAQUINARIA DE LAVANDERIA (LAVADORAS, CENTRIFUGA,

\section{PLANCHADORES)}
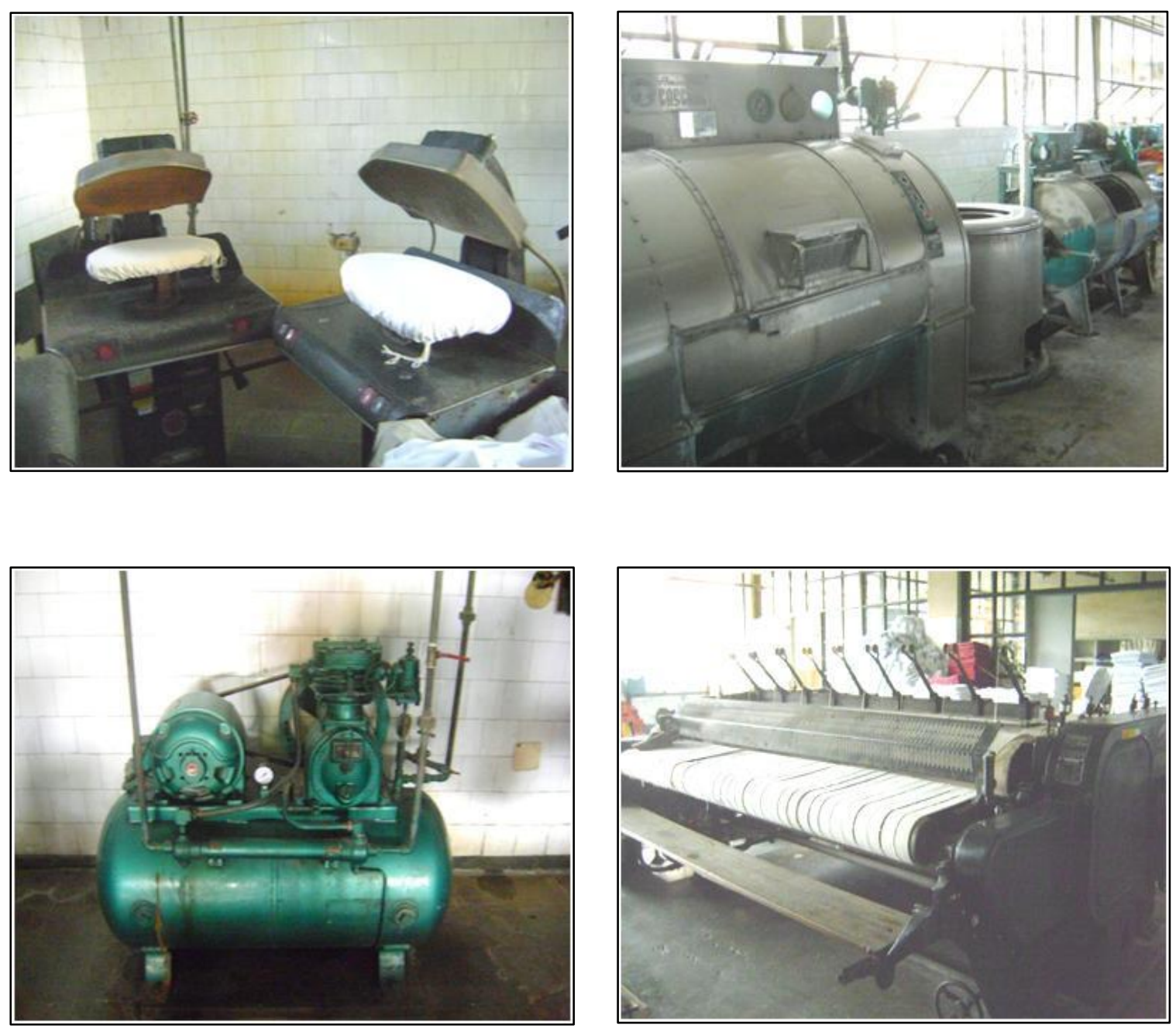

\section{ÁUDITORIO PACHACUTEC (CARPA)}

Ubicado frente a Recepción es una estructura de piedra teniendo por techo un toldo de lona.

En el ejercicio anterior se le dotó de luminarias especiales para auditoriosy tres ventiladores de techo; tiene capacidad para 800 personas. 
$2004-2009$

- $\quad$ Adquisición e instalación de Toldo de lino para carpa.

- $\quad$ Alfombrado del estrado y alfombra roja para centro, iluminación con reflectores y ventiladores para techo.

- $\quad$ Adquisición de Ventiladores extractores de aire.

- $\quad$ Pintado interiores

\section{ANTES}
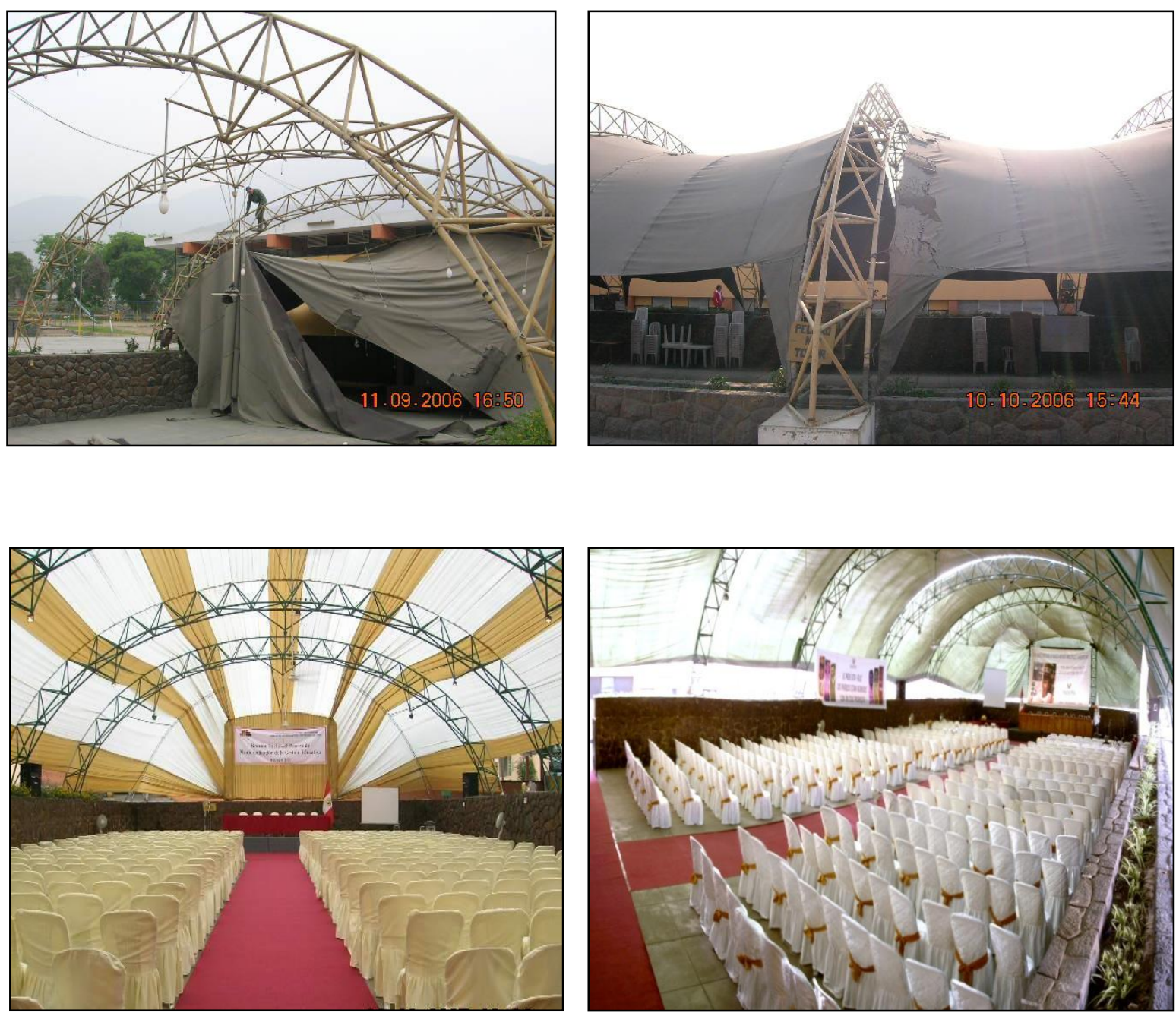


\section{ÁUDITORIO PRINCIPAL}

Ubicado en el primer piso del Restaurante, equipado con 220 butacas aunque se puede adicionar de 60 a 80 sillas más, ambiente utilizado para conferencias y convenciones.

\section{$2004-2009$}

- $\quad$ Adquisición de 4 equipos de aire acondicionado.

- $\quad$ Pintado interior y exterior
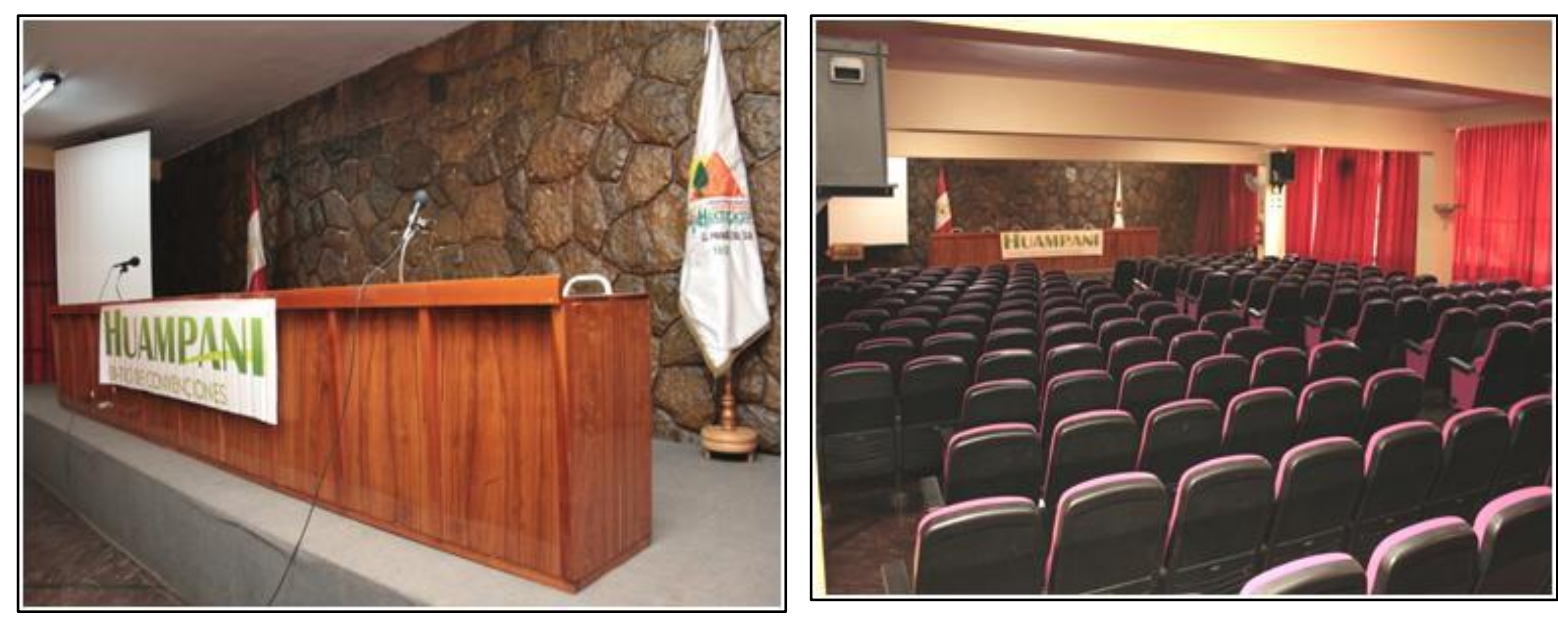

\section{Auditorio 2do piso (terraza comedor principal)}

Ubicado en el segundo piso al lado izquierdo del restaurante, tiene capacidad para 350 personas, se le acondiciona con sillas o mesas a solicitud del cliente. Se ha programado el mantenimiento y adquisición de un estrado para el 2009.
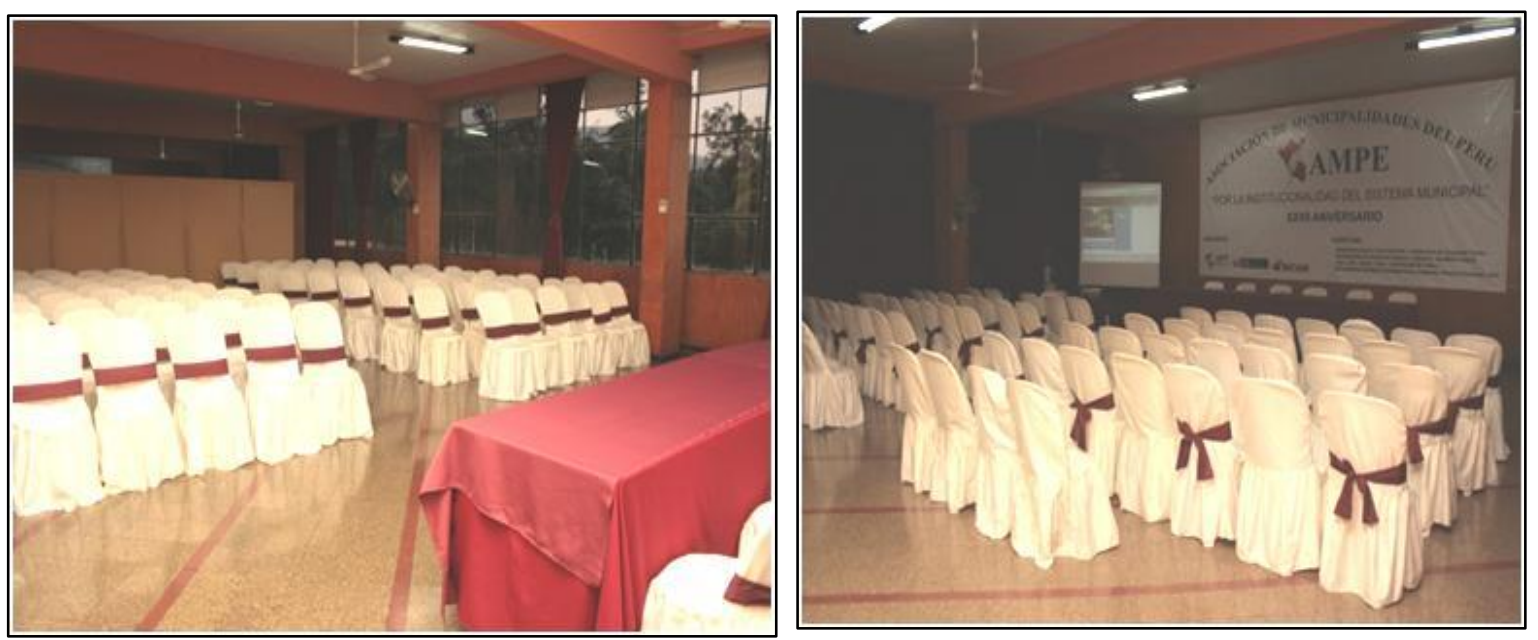


\section{ÁULAS Y OFICINAS DE APOYO}

Son aulas con capacidad entre 40 y 80 personas, equipadas de mesas, sillas, proyector, pizarras acrílicas, punto de Internet a solicitud del cliente, siendo las siguientes:

- $\quad 02$ Salas (1er y 2do. Piso) Edificio Docente.

- $\quad 08$ Aulas 1er. Piso Edificio Docente

- $\quad 02$ salas 2do. Piso de recepción (Grau y Bolognesi)

- $\quad 02$ Salas (al costado de recepción)

- $\quad 04$ Salas en el Edificio El Casino con capacidad entre 60 y 80 personas por aula.

- $\quad 01$ Sala Pachacutec capacidad de 50 a 60 personas.

Se cuenta con 05 oficinas de apoyo 03 ubicados en el primer piso del restaurante, 01 ubicado en el 2 do piso de recepción y 01 al costado de tópico. Estas oficinas están equipadas de mobiliario, puntos de Internet, anexo telefónico.
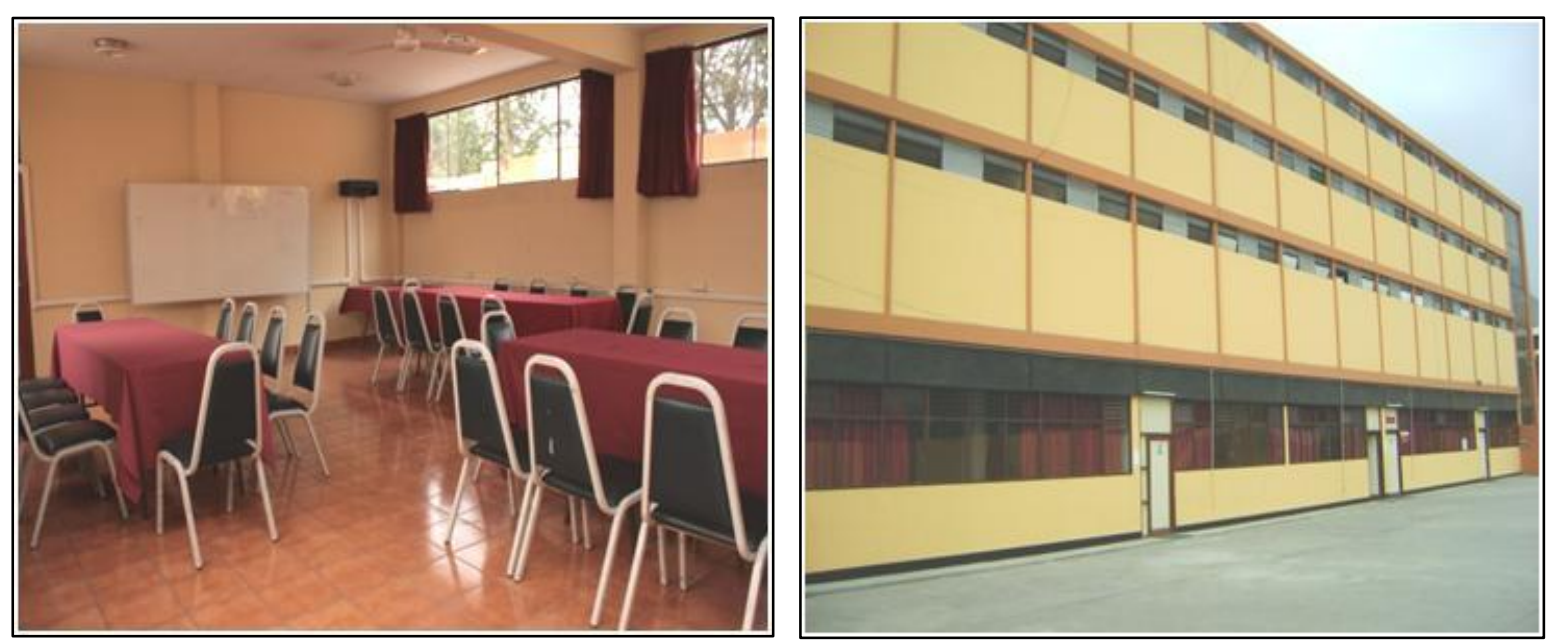


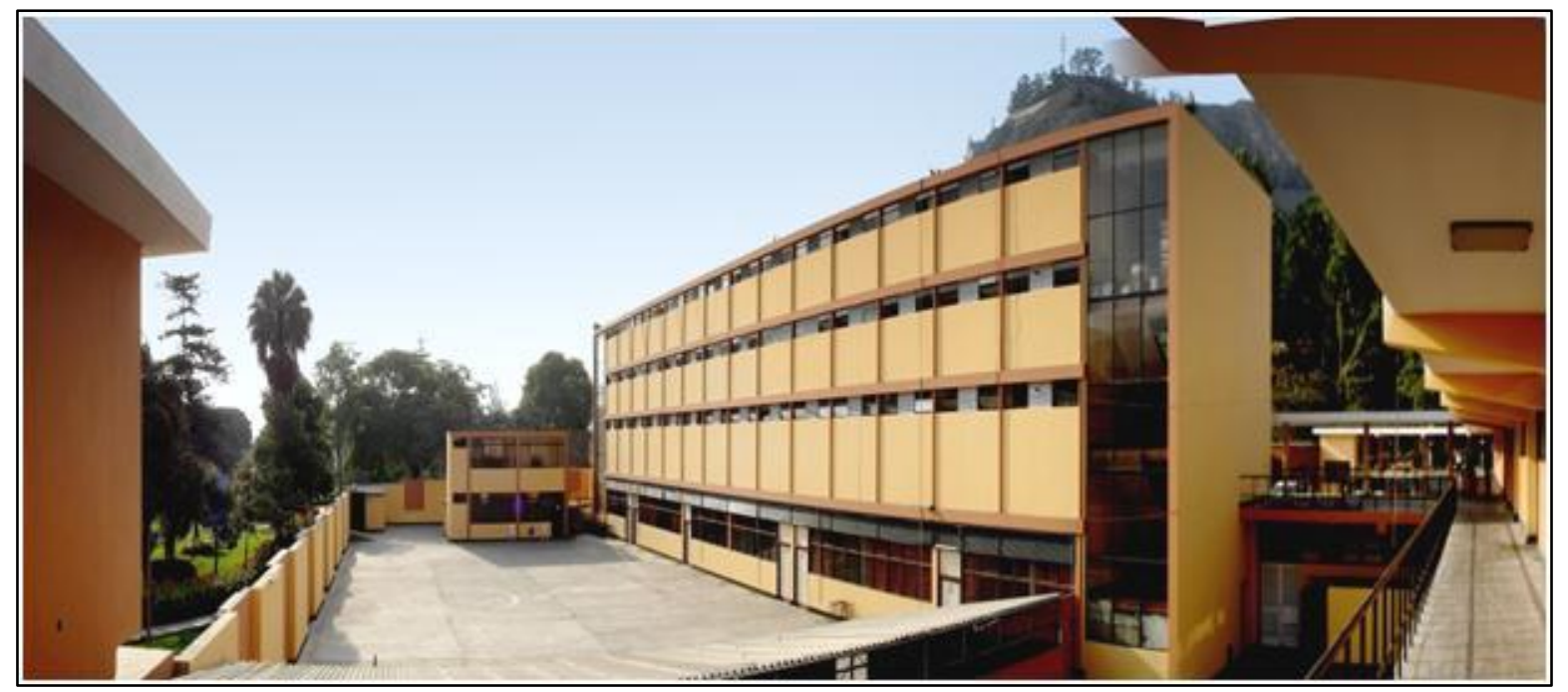

\section{CASINO}

- $\quad$ Pintado externo e interno.

- Mantenimiento de los servicios higiénicos.
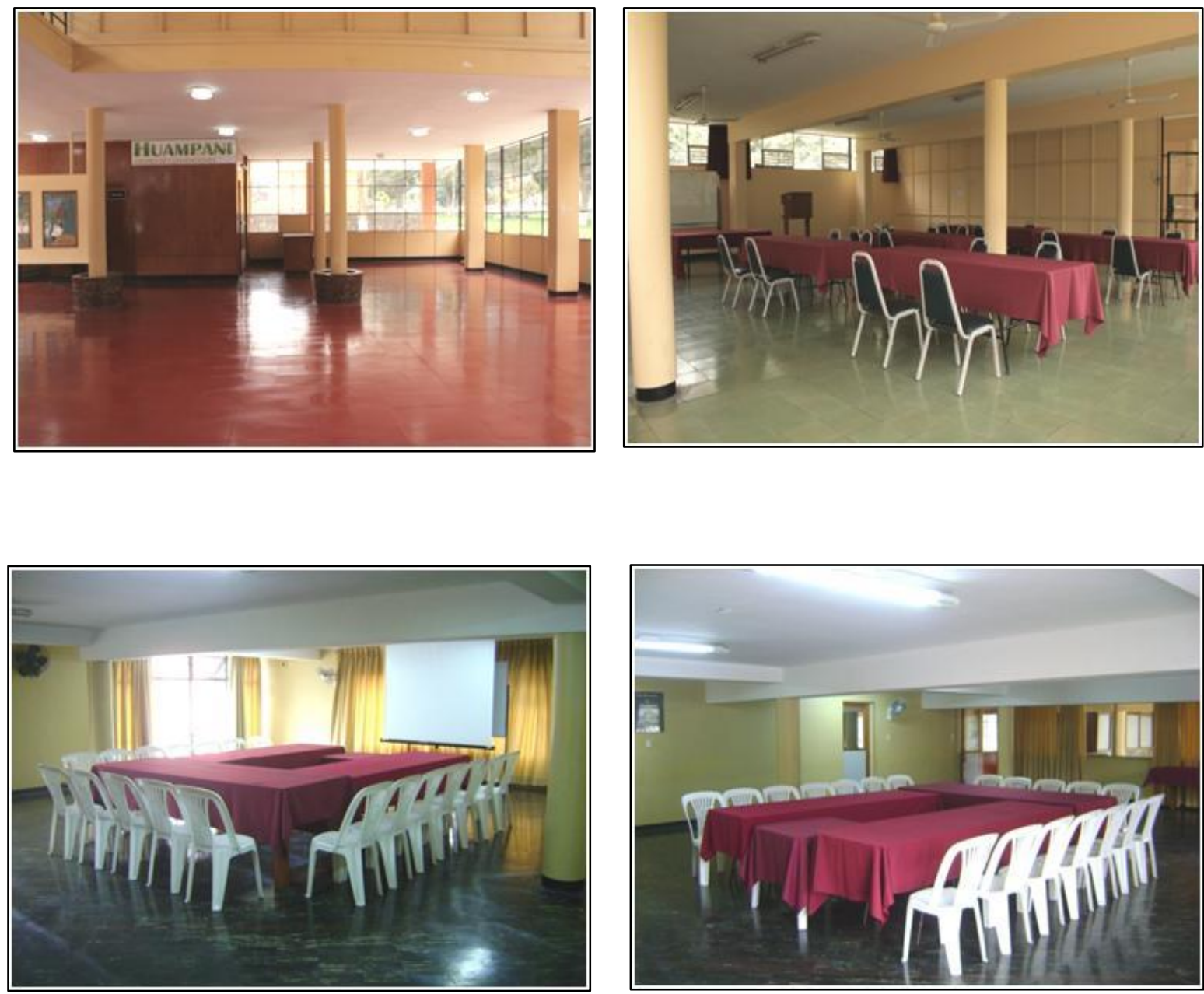


\section{SALÓN DE JUEGOS}

Ubicado en el primer piso del edifico $\mathrm{N}^{\mathrm{o}} 7$ se adaptó y remodelo con mamparas de vidrio y ladrillo caravista, ambiente creado para la distracción del visitante, con juegos de billar, ping pong y ajedrez y otros.

\section{4 - 2009}

- $\quad$ Adquisición de mesas de billar e implementos.

\section{- $\quad$ Pintado interior.}
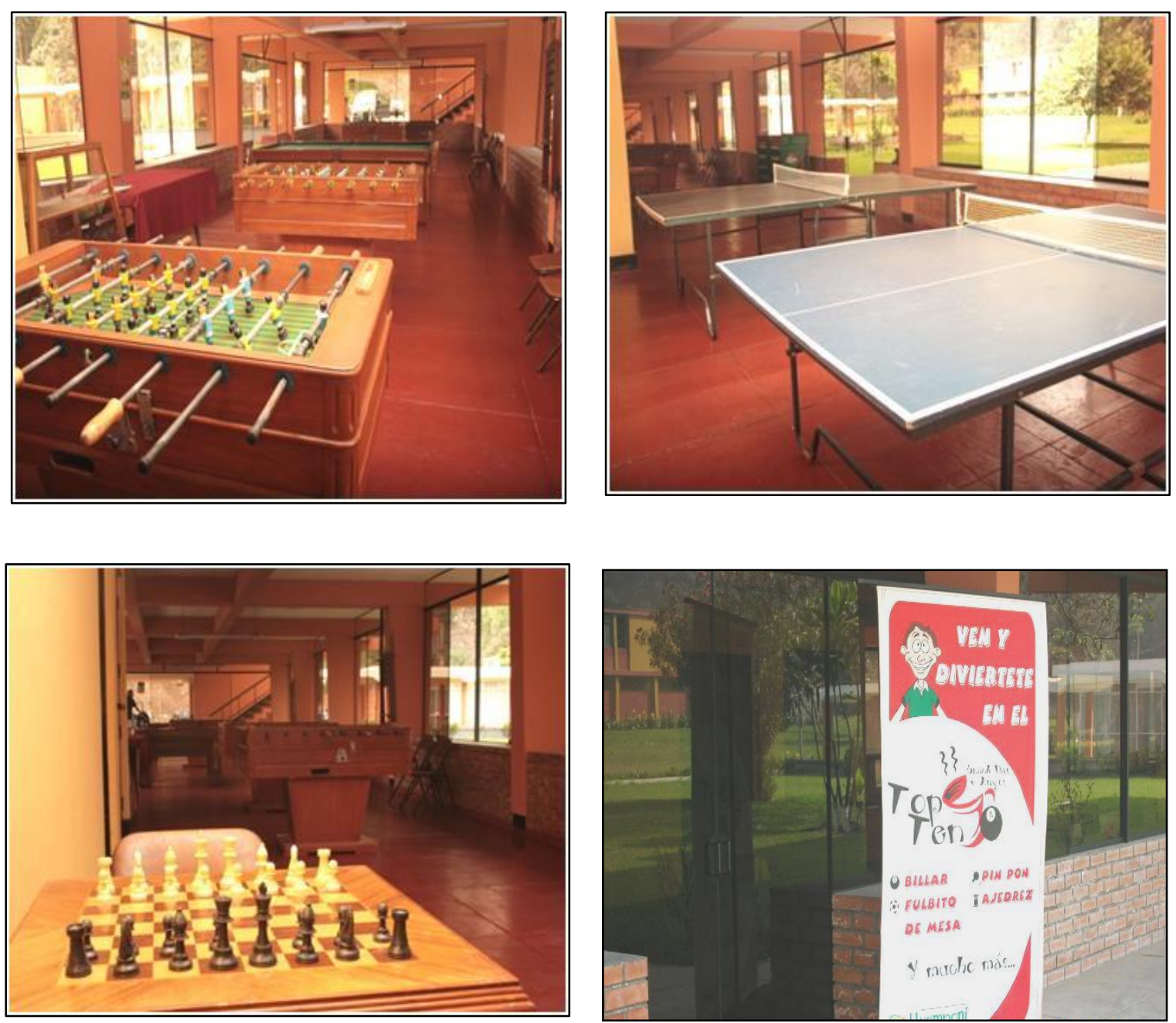


\section{TÓPICO}

Ubicado frente a recepción y atendido por una enfermera, brinda atención de primeros auxilios.

2004 - 2009

- $\quad$ Mantenimiento integral por humedad

- $\quad$ Pintado interior y exterior

- $\quad$ Renovación total de servicios higiénicos

- $\quad$ Adquisición de silla de ruedas

- $\quad$ Adquisición de camilla portátil

- $\quad$ Adquisición de grada portátil

- $\quad$ Adquisición de lámpara de cuello de ganso

- $\quad$ Adquisición de oxígeno
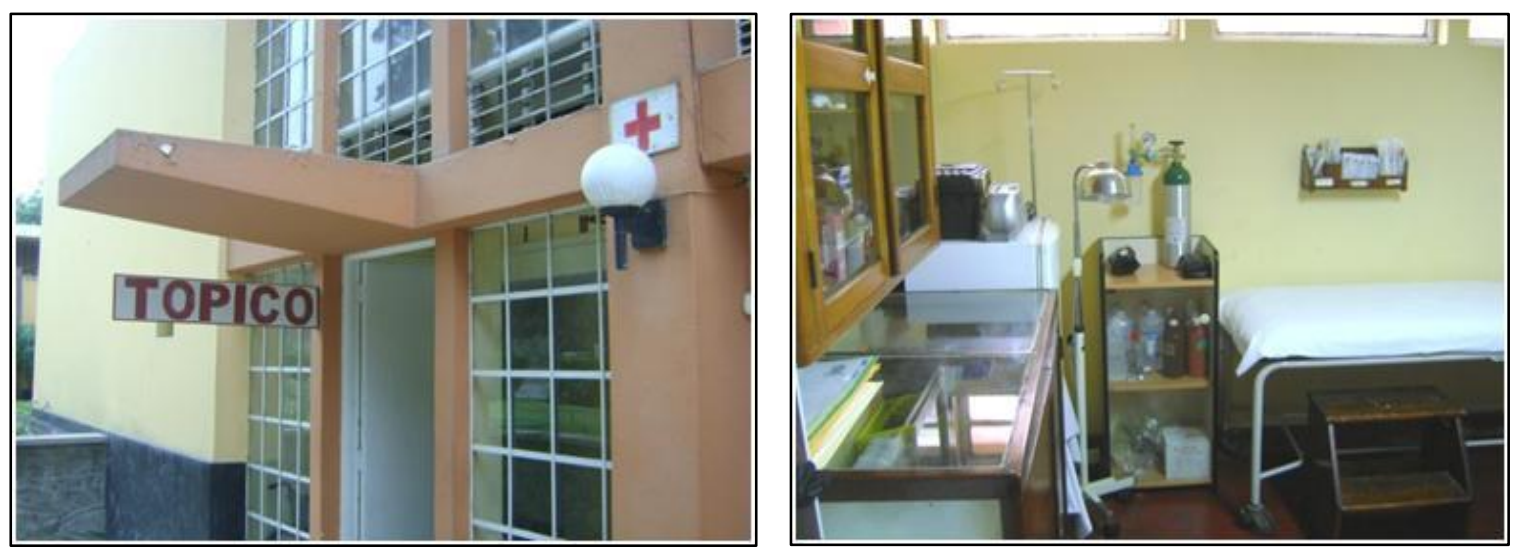
SALA DE ATENCION
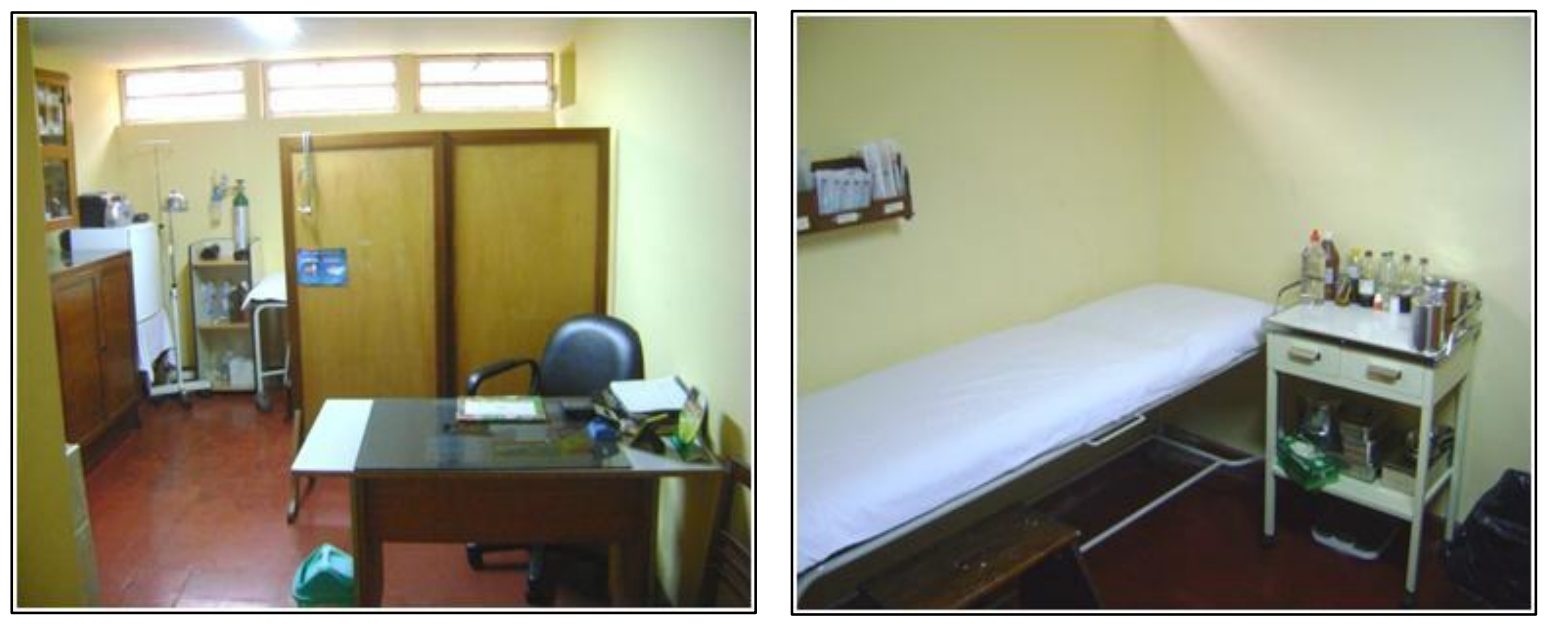

CAMILLA, SILLA DE RUEDAS Y SS.HH REMODELADO
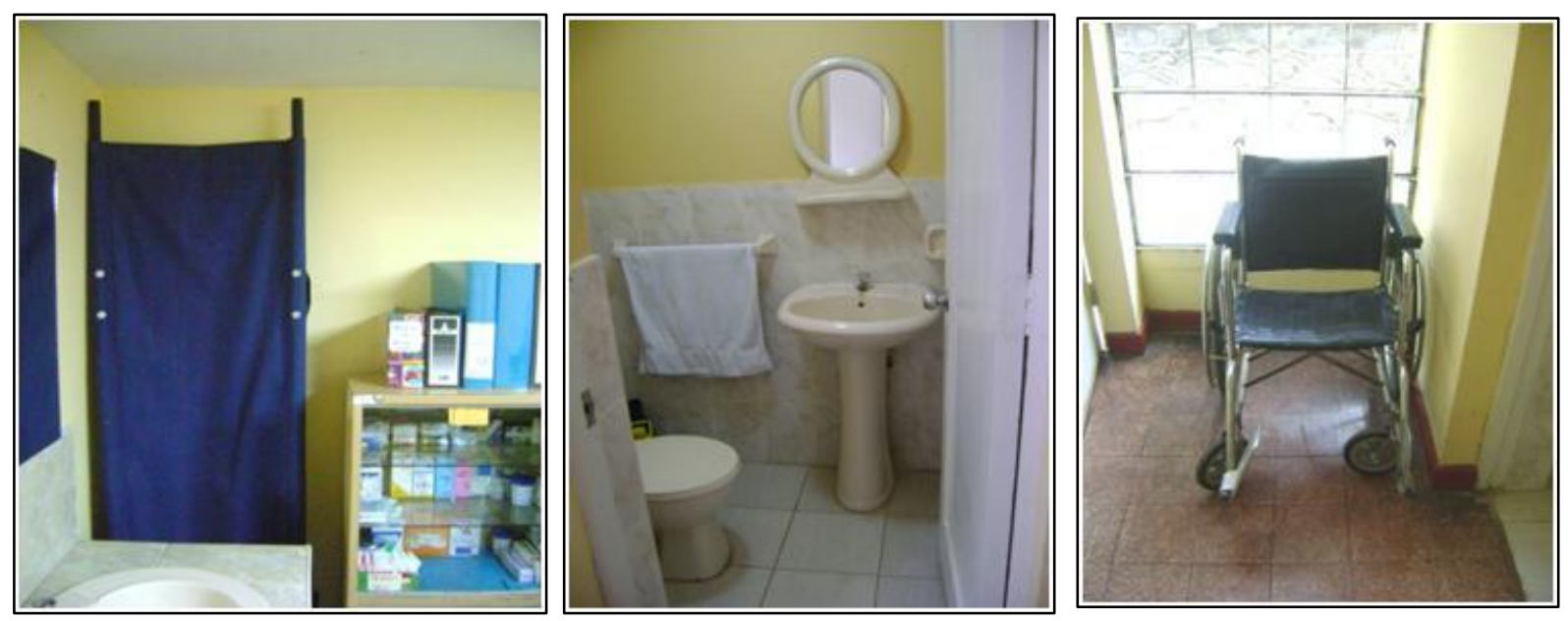


\section{ALIMENTOS Y BEBIDAS}

Esta área es la unidad orgánica de tercer nivel, encargada de planificar, organizar, dirigir, coordinar y supervisar los servicios de los restaurantes, bar, y cocinas para que preste las mejores atenciones de atención al cliente. Está comprendida por los siguientes ambientes:

- Restaurante principal

- Terraza del restaurant

- Cocina Principal

\section{Restaurante principal}

El Restaurante Principal se encuentra ubicado en el segundo piso del Auditorio Principal equipado en total con 50 mesas con 4 sillas con capacidad para 200 personas; al lado derecho el ex Auditorio 2do piso que ahora ha sido ampliado para restaurante, equipado con 30 mesas con 4 sillas con capacidad para 120 personas.

\section{Ampliación del restaurante}

En la terraza al lado del restaurante principal se ha efectuado un mantenimiento de pisos y techo, y se han construido baños para damas y caballeros. Se ha efectuado adquirió 80 mesas Y 320 sillas lo que daría una capacidad de atención adicional de 320 personas por vez. La capacidad total para atención en el restaurante será de 640 personas por vez.

\section{La terraza}

Ubicada al costado del restaurante principal. En la actualidad pueden ubicarse hasta 50 mesas contando con una capacidad de atención de 200 personas por evento. 


\section{Cocina Principal}

La cocina principal es el centro de producción donde se elaboran los alimentos para atención a los clientes y grupos del restaurante.

$2004-2010$

- $\quad$ Mantenimiento de las marmitas.

- $\quad$ Mantenimiento general del caldero.

- $\quad$ Adquisición de Licuadora Industrial.

- $\quad$ Adquisición de Freidora Eléctrica Industrial.

- $\quad$ Adquisición de 2 congeladoras.

- $\quad$ Adquisición de utensilios de cocina ( fuentes, jarras, azucareros, soperas, etc)

- $\quad$ Mantenimiento y reparación de las 6 cámaras de frío.

- $\quad$ Pintado total del interior de la cocina.

- $\quad$ Reparación y mantenimiento de máquina lavadora de platos.

- Mantenimiento de las planchas del fogón.

- $\quad$ Adquisición de cocina industrial.

- Adquisición de Horno Rotativo de 15 bandejas petrolero y coches para hornear.

- $\quad$ Adquisición de divisora de masa.

- $\quad$ Adquisición de amasadora sobadora de acero inoxidable.

- Adquisición de licuadora para bar.

- Uniformes para el personal de cocina. 
COCINA PRINCIPAL Y PASTELERIA
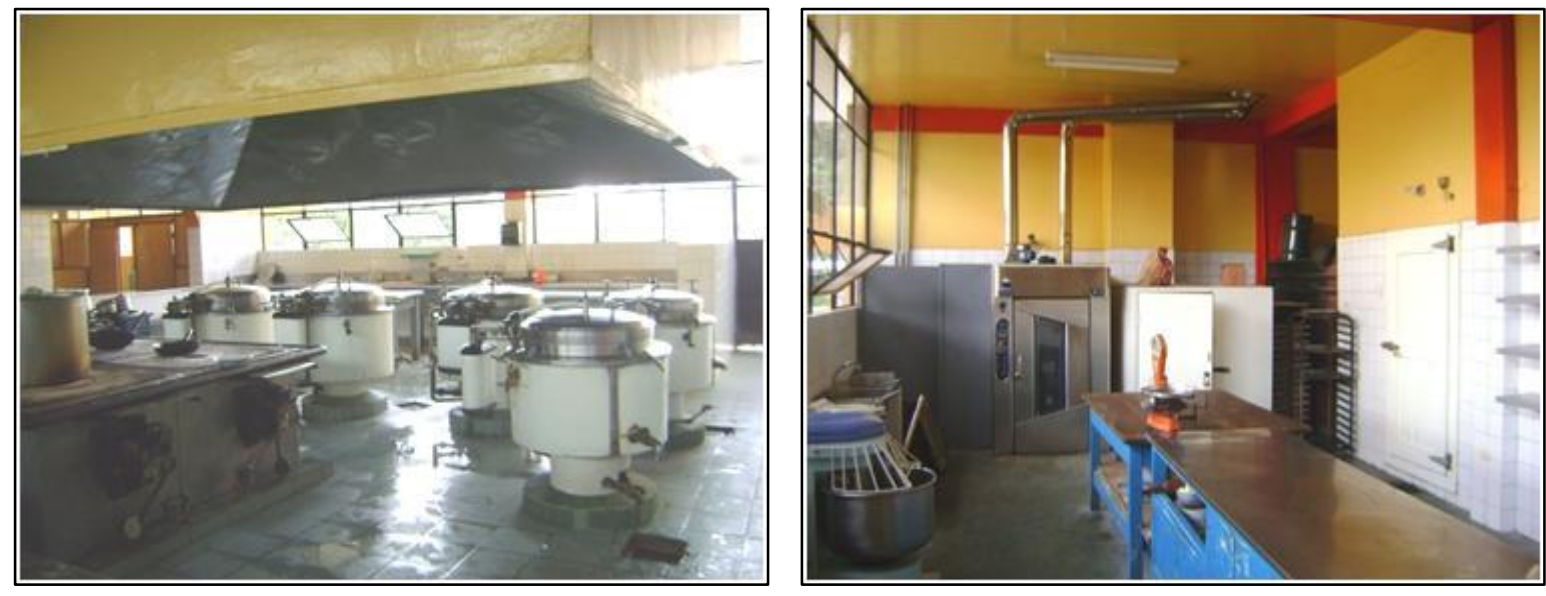

HORNO ROTATIVO, BATIDORA INDUSTRIAL Y FREIDORA ELECTRICA
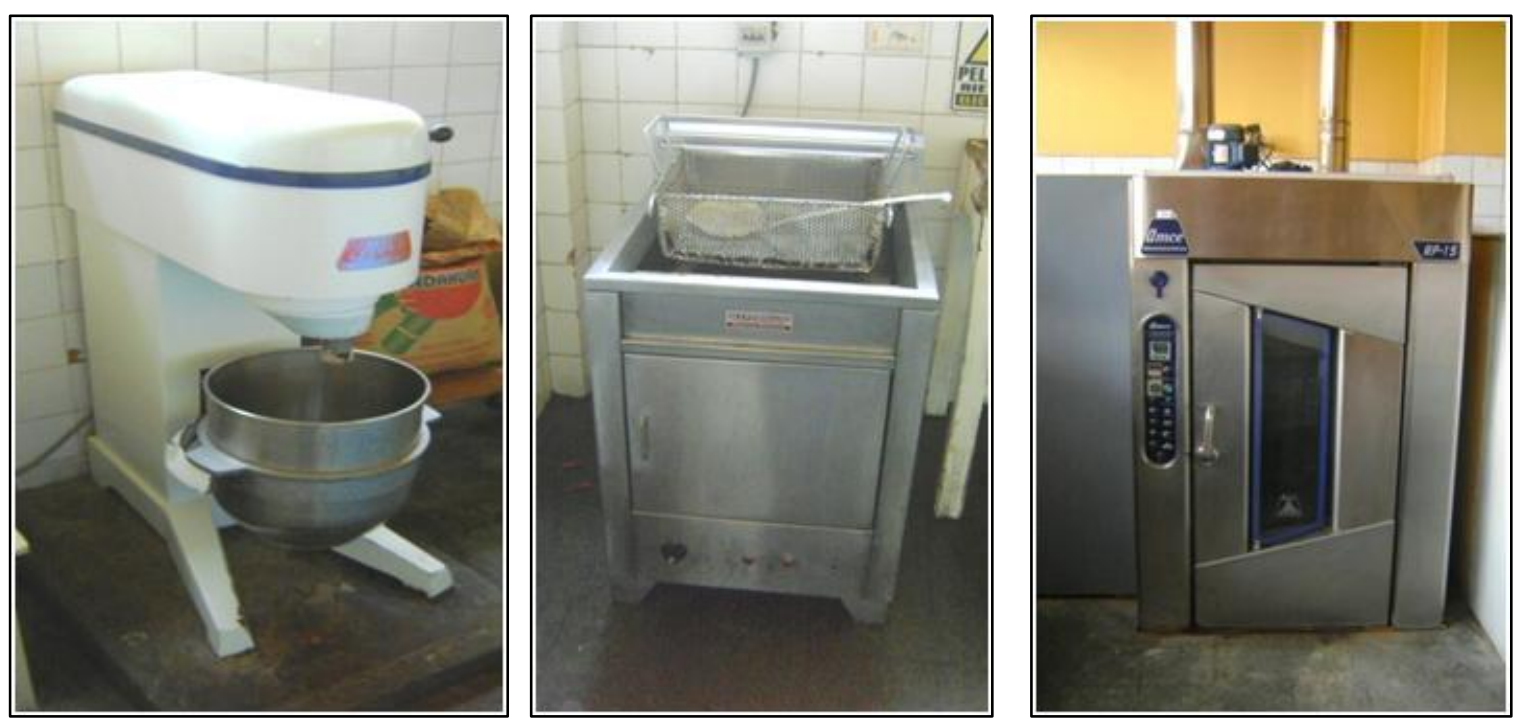

\section{Restaurante Principal "La Sazón del Sol”}

El Restaurante Principal se encuentra ubicado en el segundo piso del Auditorio Principal, al lado derecho del Auditorio 2do piso, equipado con 40 mesas con 4 sillas con capacidad para 160 personas por vez.

- $\quad$ Pintado interior del ambiente.

- $\quad$ Adquisición de manteles y puntas.

- $\quad$ Adquisición de cristalería y menaje. 
- $\quad$ Mantenimiento, lijado y barnizado de sillas.

- $\quad$ Adquisición de manteles para bufetes.

- $\quad$ Adquisición de utensilios para atención de eventos (bufetes, matrimonios, etc)

- $\quad$ Uniformes para el personal de mozos.

- $\quad$ Adquisición de mesas circulares para eventos.

\section{VARIEDAD DE PLATOS A LA CARTA}
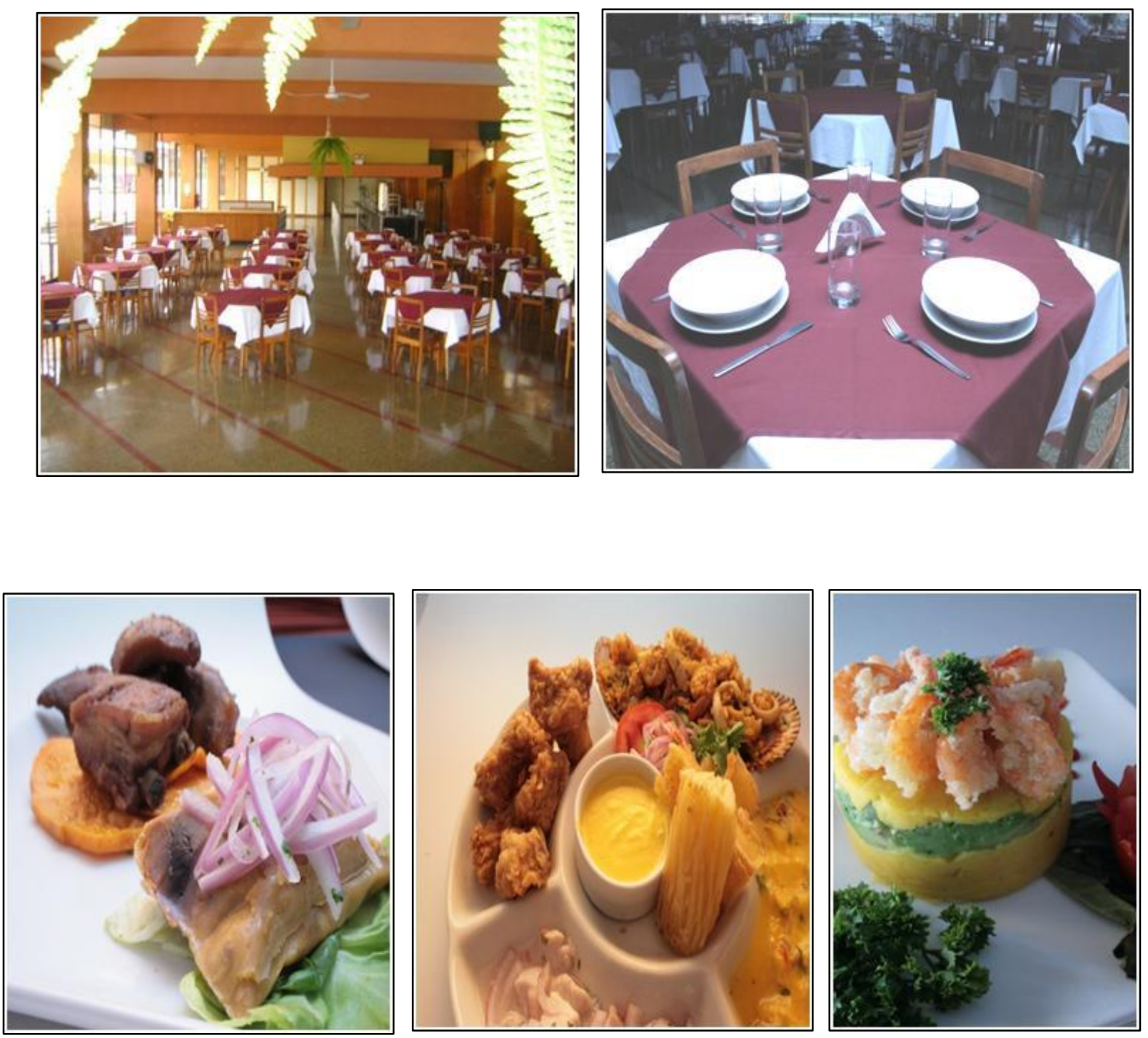


\section{Terraza del Comedor Principal}

Ubicado al costado del Restaurante principal. En la actualidad pueden ubicarse hasta 50 mesas

lo que da una capacidad de atención de 200 personas por vez.

\section{4-2009}

- $\quad$ Adquisición de toldo para comedor

- $\quad$ Adquisición de manteles.

- $\quad$ Adquisición de menaje, vajillas hoteleras, cristalería y muebles auxiliares.
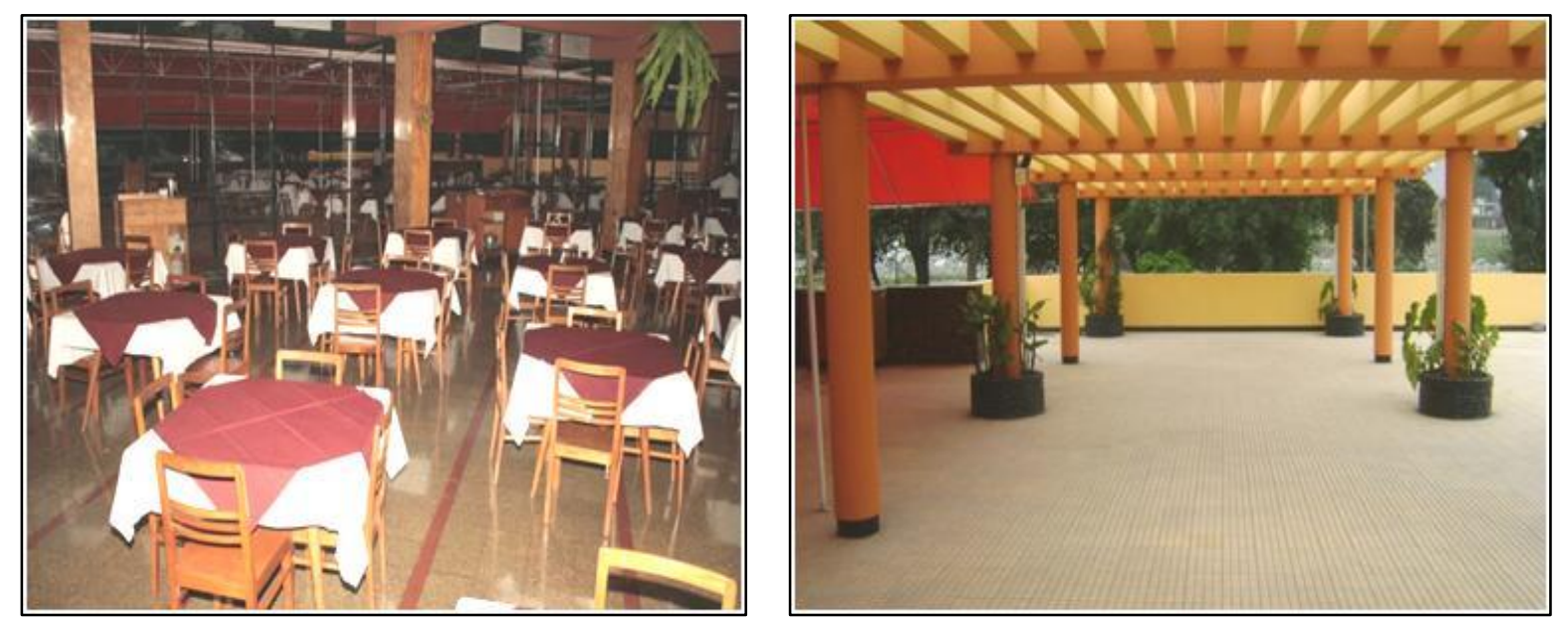

\section{Restaurante y cocina - Pollos a la Brasa "Nautilius"}

Este restaurante se encuentra ubicado al lado de la piscina, tiene capacidad para 20 mesas y atender 80 personas a la vez 


\section{$2004-2010$}

- $\quad$ Pintado inferior y exterior de la cocina y restaurante.

- Se ha programado el mantenimiento integral de los servicios higiénicos.

- $\quad$ Remodelación de cocina Nautilius, construcción de mesas de trabajo y revestimiento de pared y pisos.

- $\quad$ Adquisición de manteles y puntas.

- $\quad$ Renovación de paneles de publicidad.

- $\quad$ Mantenimiento al motor del horno para pollos a la braza.

- $\quad$ Mantenimiento a mesas y sillas, lijado y barnizado.

- $\quad$ Tarrajeo y mejor iluminación de la zona de lavaplatos.

- $\quad$ Transformación de una cocina de kerosene a gas propano.
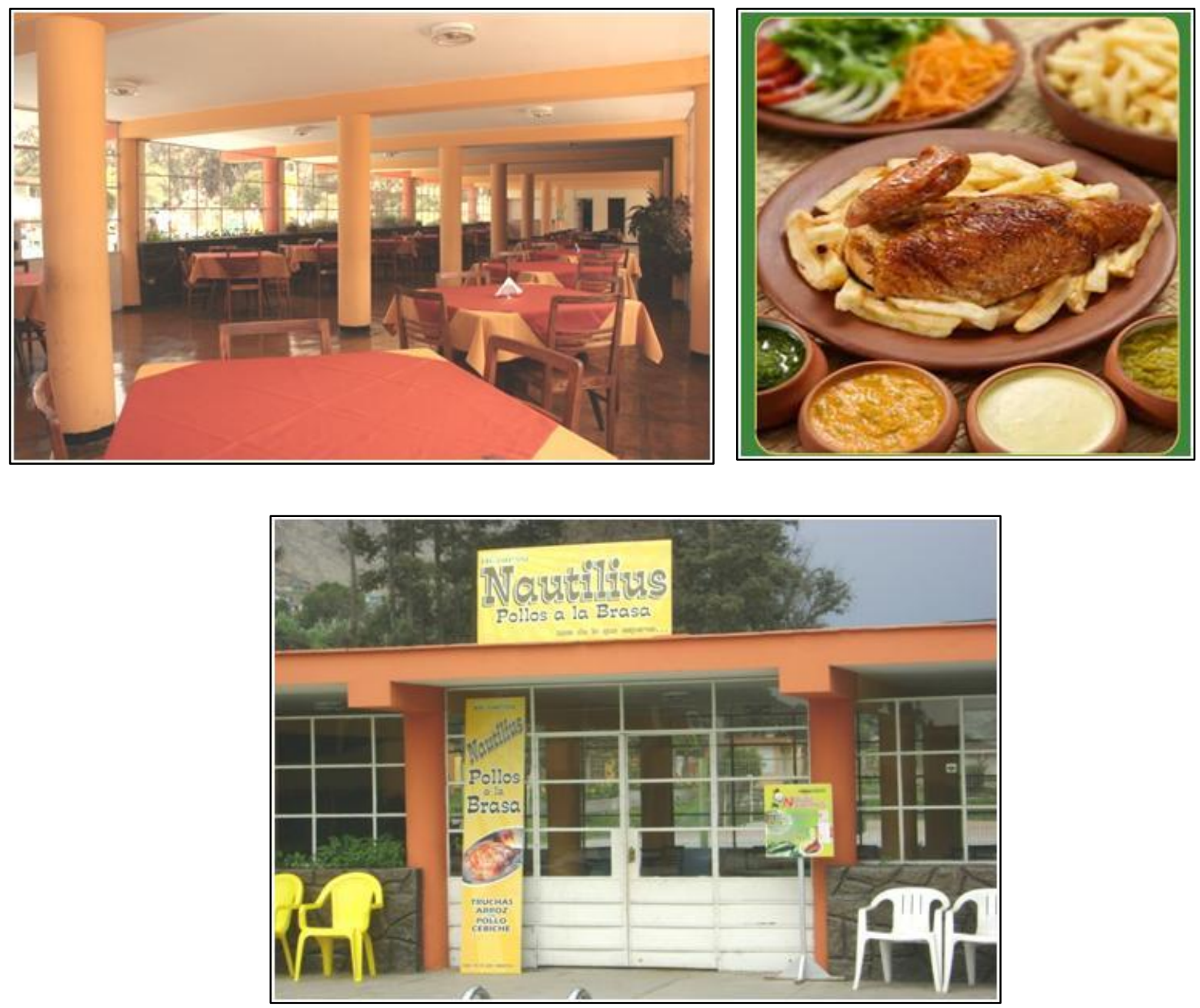


\section{Rotonda Pachamanca}

Ubicado al costado del edificio "El Casino", en este lugar se atiende la venta de pachamanca, parrillas, pollos a la plancha, anticuchos, con la modalidad de autoservicio.

- $\quad$ Renovación integral de los servicios higiénicos damas y caballeros.

- $\quad$ Pintado interior y exterior de los SS.HH.

- $\quad$ Mantenimiento integral del ambiente incluido renovación de pisos.

- $\quad$ Pintado integral del ambiente.

- $\quad$ Adquisición de equipo de sonido.
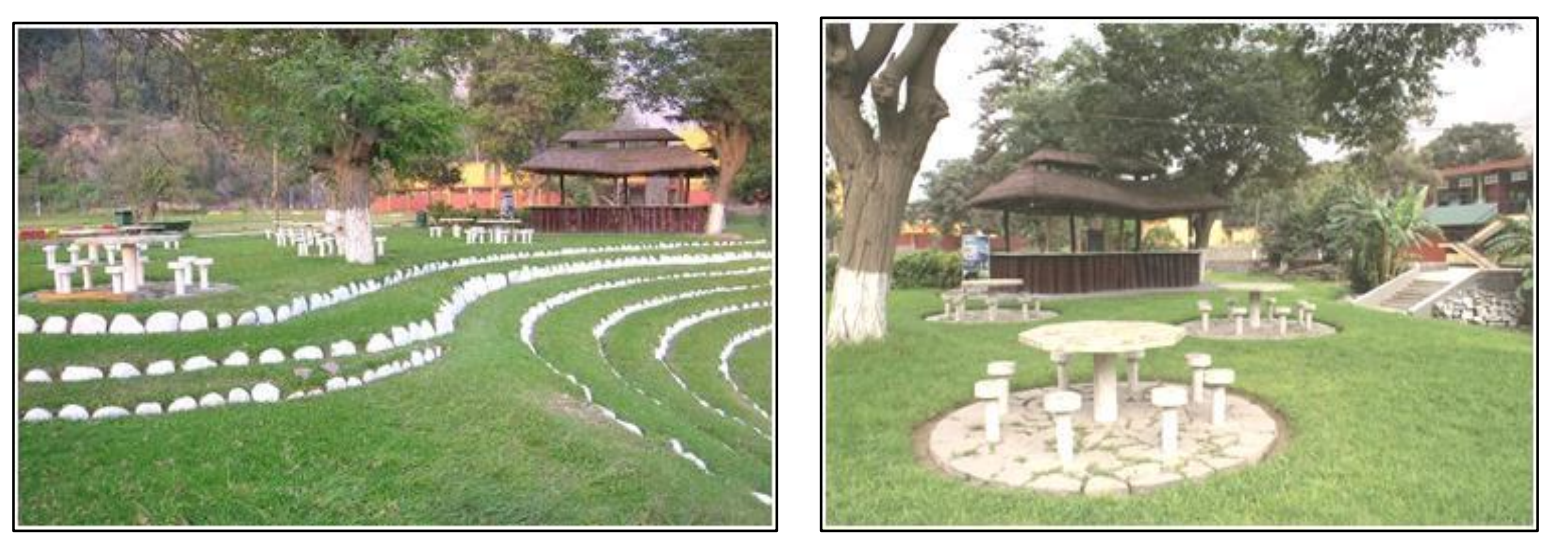

\section{Discoteca "Ganso de Oro"}

Este ambiente está ubicado junto al Edificio 7, destinado a la recreación y esparcimiento de nuestro público alojado y visitante.

- $\quad$ Pintado exterior e interior del área.

- Mantenimiento integral de los servicios.

- $\quad$ Adquisición de máquina de humo, cortado y equipo de luces para discoteca.

- $\quad$ Adquisición de TV 29” pantalla plana con DVD y micrófono.

- $\quad$ Iluminación de terraza.

- $\quad$ Adquisición de modulares, sillas y mesas circulares para discoteca.

- $\quad$ Adquisición de licuadora para tragos. 
Adquisición de cristalería.

Colocación de luces de neón en letreros.

Implementación del kiosco de golosinas (helados, dulces, etc) al lado de la discoteca.

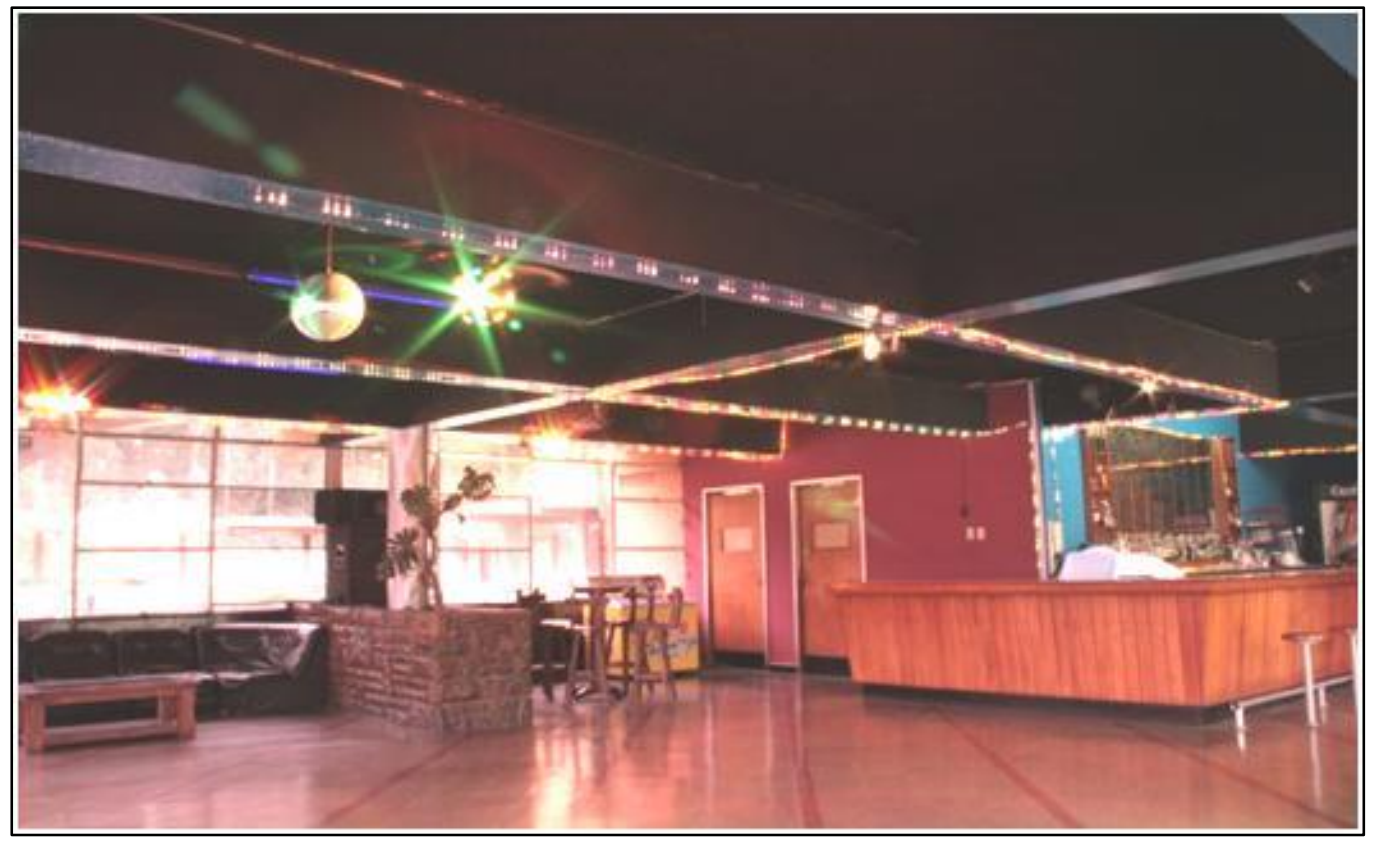




\section{OPERACIONES (ESPARCIMIENTO RECREACIÓN Y JARDINES}

Esta área es la unidad orgánica de tercer nivel encargada de planificar, coordinar, dirigir y controlar los servicios de esparcimiento, recreación y jardines, garantizando el cumplimiento de un adecuado estándar de calidad y confort a través de las siguientes áreas:

1. Mantenimiento

2. Carpintería

3. Jardinería

4. Piscina

\section{Mantenimiento}

Responsable del mantenimiento de las instalaciones maquinaria y equipos

- $\quad$ Mantenimiento y reparación de la bomba de agua.

- $\quad$ Mantenimiento general a la entrada del CVH.

- $\quad$ Fumigaciones mensuales de todas las áreas

- Construcción del cerco perimétrico para protección de linderos.

- $\quad$ Mantenimiento general externo y limpieza química interior del caldero.

- $\quad$ Mantenimiento del ablandador de agua y fabricación del tanque condensado.

- $\quad$ Adquisición de amoladora de gaste para trabajo de cerrajería.

- $\quad$ Servicio de pintado en techos y ambientes en general.

- $\quad$ Mantenimiento en general a las maquinarias y equipos del CVH.

- $\quad$ Pintado de bancas de madera públicas.

- $\quad$ Mantenimiento y pintado de los juegos infantiles.

- Mantenimiento y reparación a las cámaras frigoríficas. 
BAÑOS PÚBLICOS ZONA PACHAMANCA (REMODELACION SERVICIO SS.HH)

\section{ANTES}
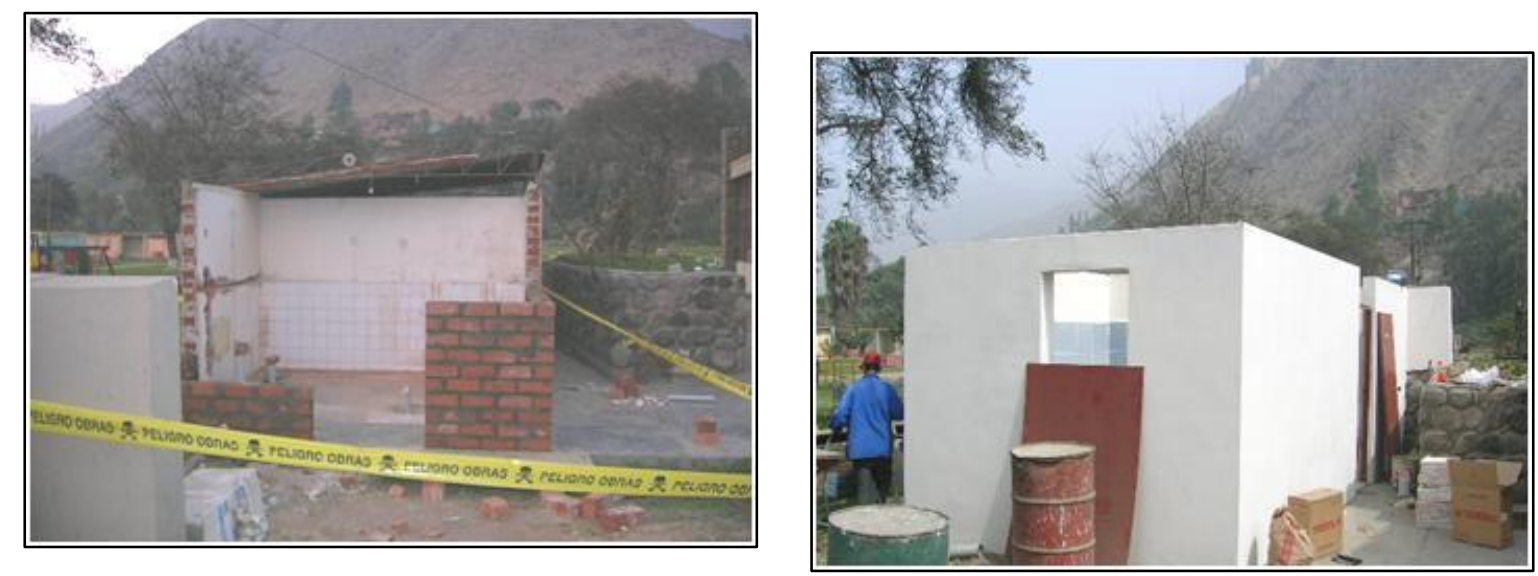

DESPUES
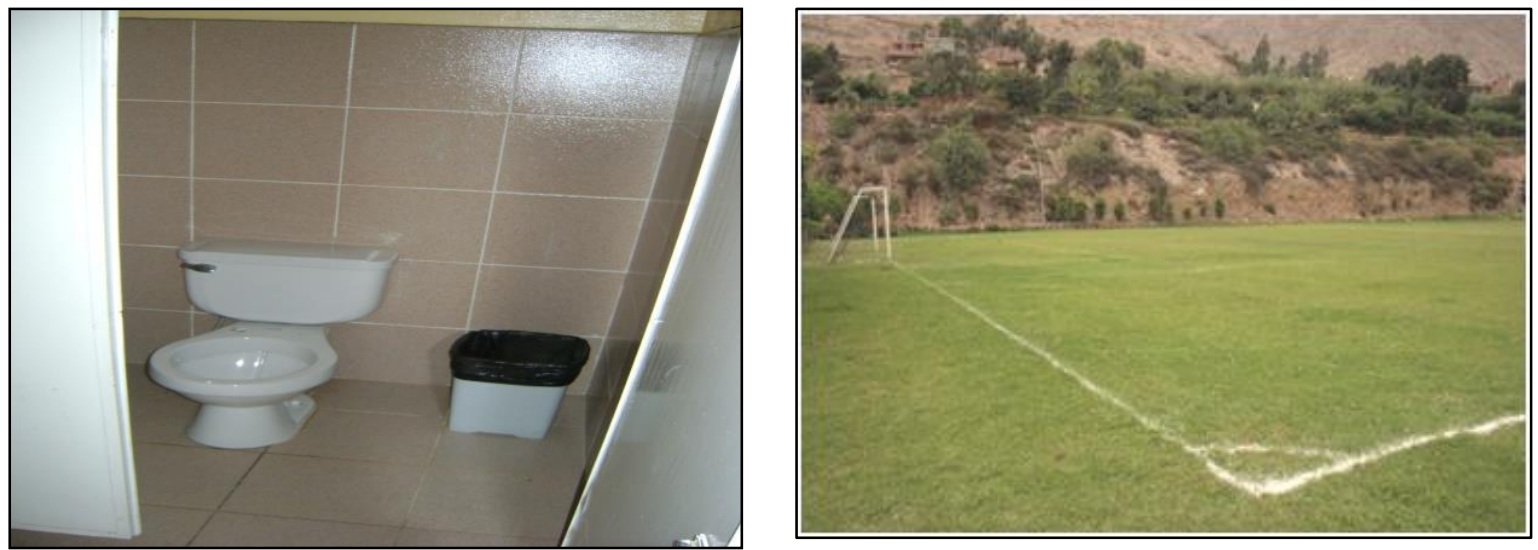


\section{BAÑOS DAMAS Y CABALLEROS EN EL PATIO DE LAS AULAS DEL}

\section{INSTITUTO}
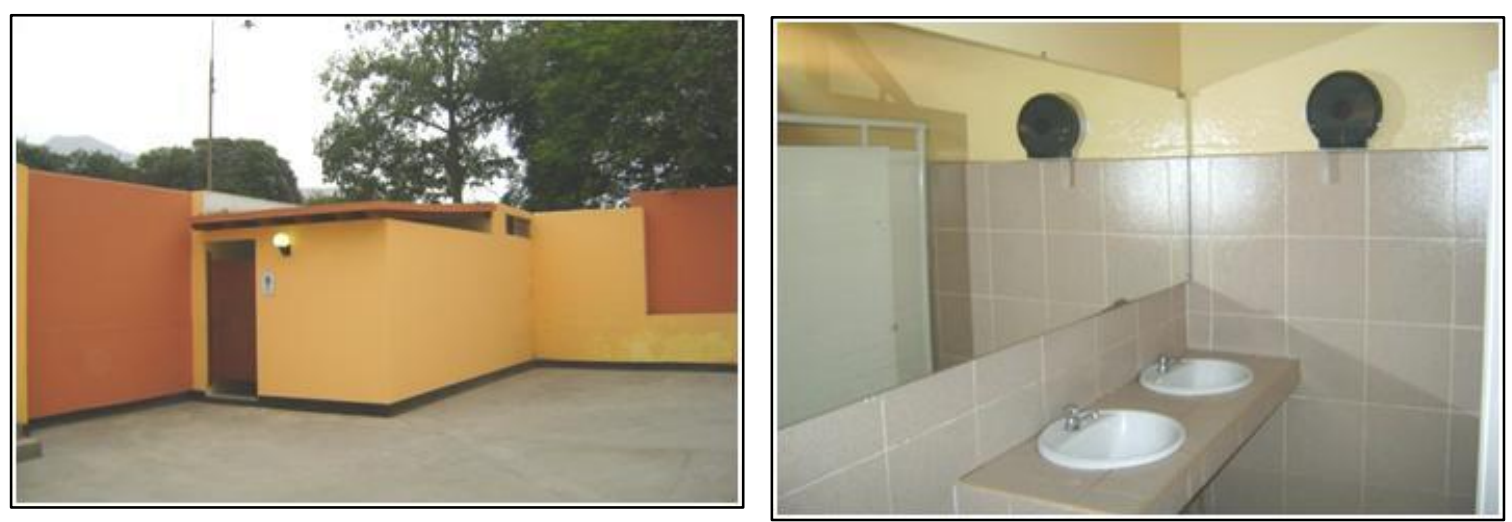

\section{TACHOS NUEVOS DE BASURA}

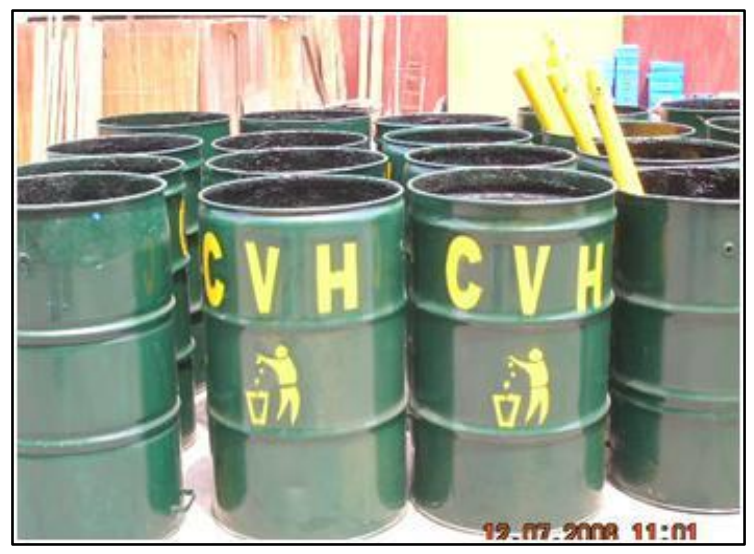

COMEDOR DE OBREROS

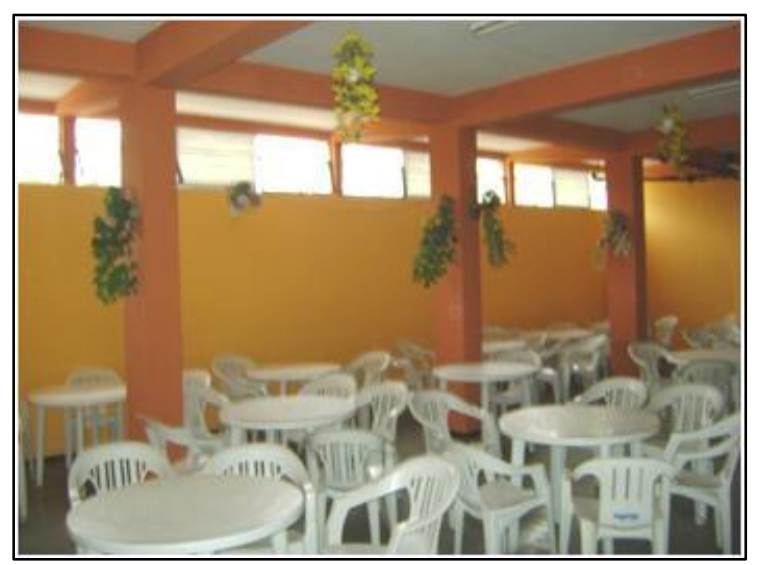

\section{Mantenimiento de vehículos}

- $\quad$ Mantenimiento y reparación general de camioneta RIL 919

- $\quad$ Mantenimiento y reparación general de camioneta station wagon SIK 964

(adquisición de motor petrolero y palieres)

- $\quad$ Mantenimiento y reparación de automóvil BUIC - JG 3342.

- Mantenimiento y reparación de motocard.

- $\quad$ Mantenimiento y reparación Camión WQ 3143 

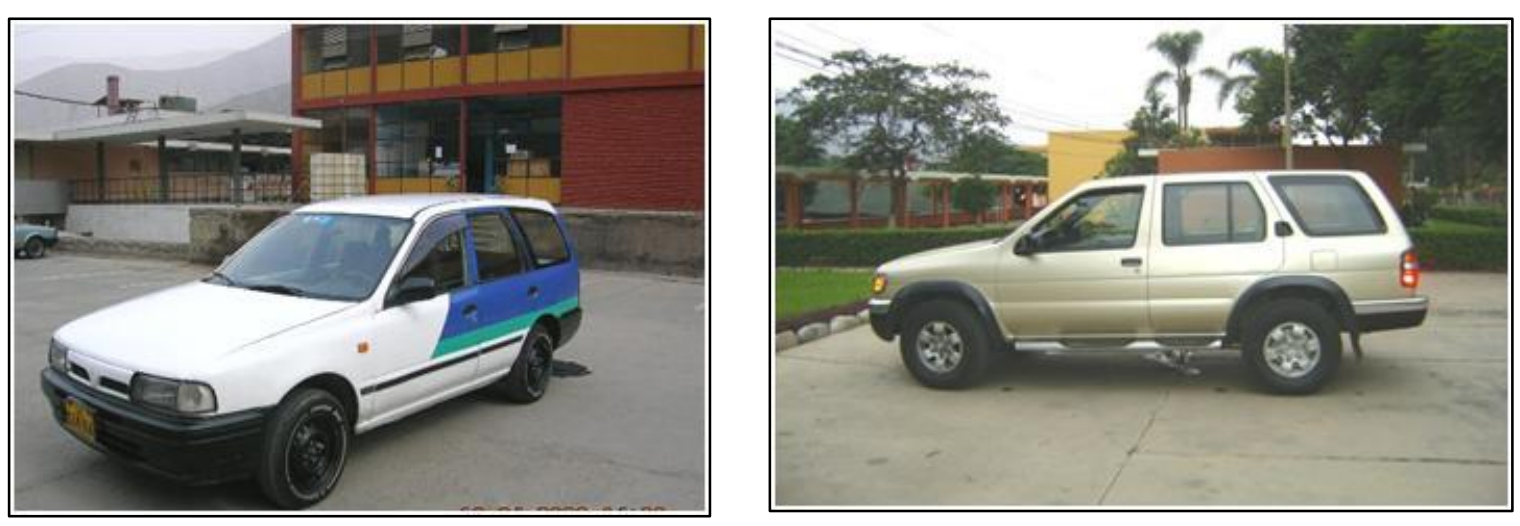

\section{Carpintería}

Es el encargado del constante mantenimiento y reparación del mobiliario de todas las instalaciones como mesas, sillas, camas, cómodas, veladores, fabricación de muebles para oficina y mobiliario.

- Mantenimiento y reparación constante de mesas, sillas, camas, veladores y cómodas (bungalows, chalets, edificios, restaurantes).

- $\quad$ Fabricación de muebles de oficina.

- $\quad$ Adquisición de taladro industrial y motosierra para trabajos rústicos de troncos.

- $\quad$ Adquisición de un a garlopa.

- $\quad$ Adquisición de Ruteadora.

- $\quad$ Adquisición de una máquina de coser industrial.

- $\quad$ Adquisición de una Fresadora.

- $\quad$ Fabricación de sillones para las salitas de habitaciones.

- $\quad$ Mantenimiento de los confortables de edificio 5 y 6. 


\section{SILLONES TAPIZADOS DE SALITAS DE LOS CHALETS}

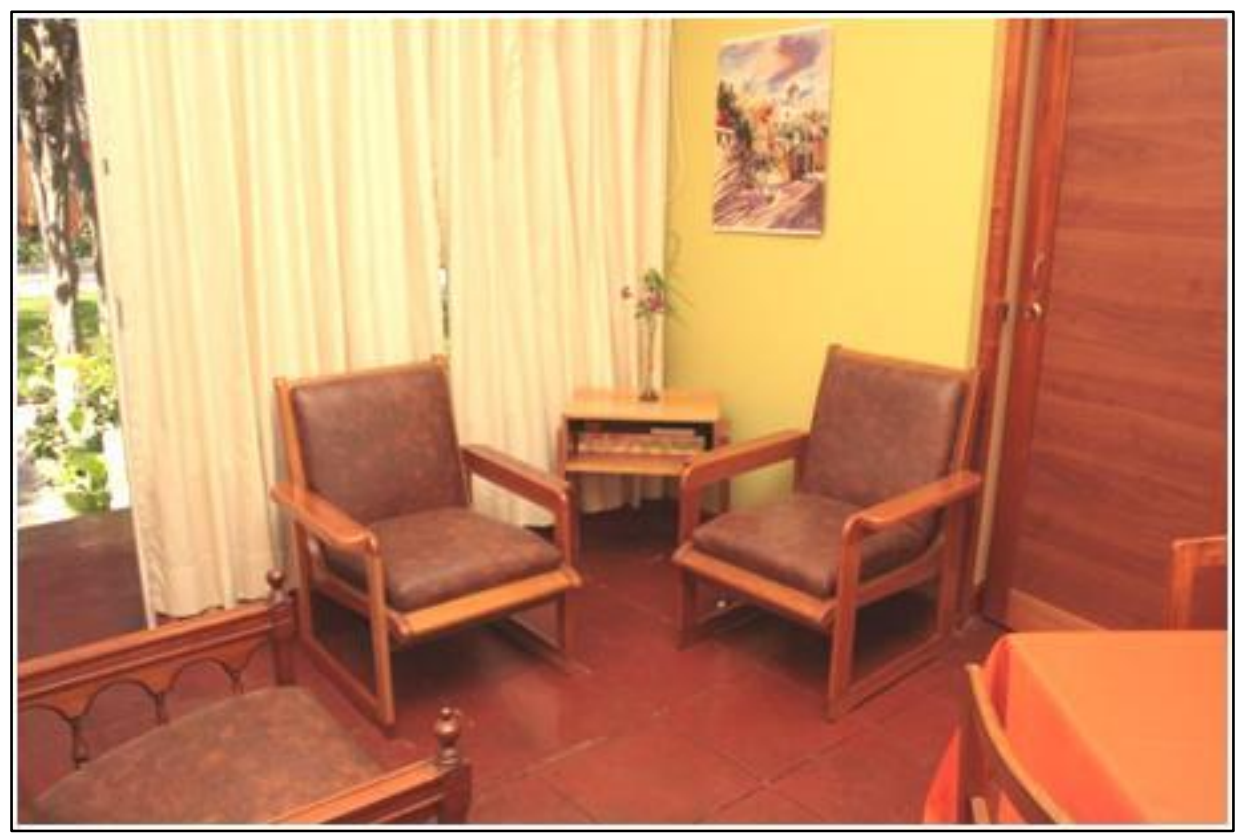

\section{Áreas Verdes - Jardinería}

La Gerencia ha visto por conveniente elaborar un plan de recuperación de estas áreas a fin de ser accesible al público visitante y ampliar las posibilidades atractivas del Centro Vacacional. Las áreas están situadas en su mayoría en zonas accidentadas y se encuentra dispersa la vegetación natural.

- $\quad$ Adquisición de tierra preparada para champas afuera del edificio 1.

- $\quad$ Adquisición y renovación de árboles ornamentales, plantas y flores para los jardines (reforestación).

- $\quad$ Adquisición de moto guadaña, una cortadora de gras de 6 HP, una motosierra con espada de 24 pulgadas y una podadora de altura.

- $\quad$ Limpieza de terreno, quitado de maleza indeseable según plan de restauración.

- $\quad$ Construcción de senderos para acceso a la zona de terreno y cunetas para hacer llegar el agua de regadío. 
- Construcción de muros de piedra para estabilizar el terreno e instalar plantas decorativas.

- $\quad$ Colocación de letreros de señalización indicativas.

- $\quad$ Contratación de un Ingeniero para trabajar la ampliación de áreas verdes.

\section{ANTES}
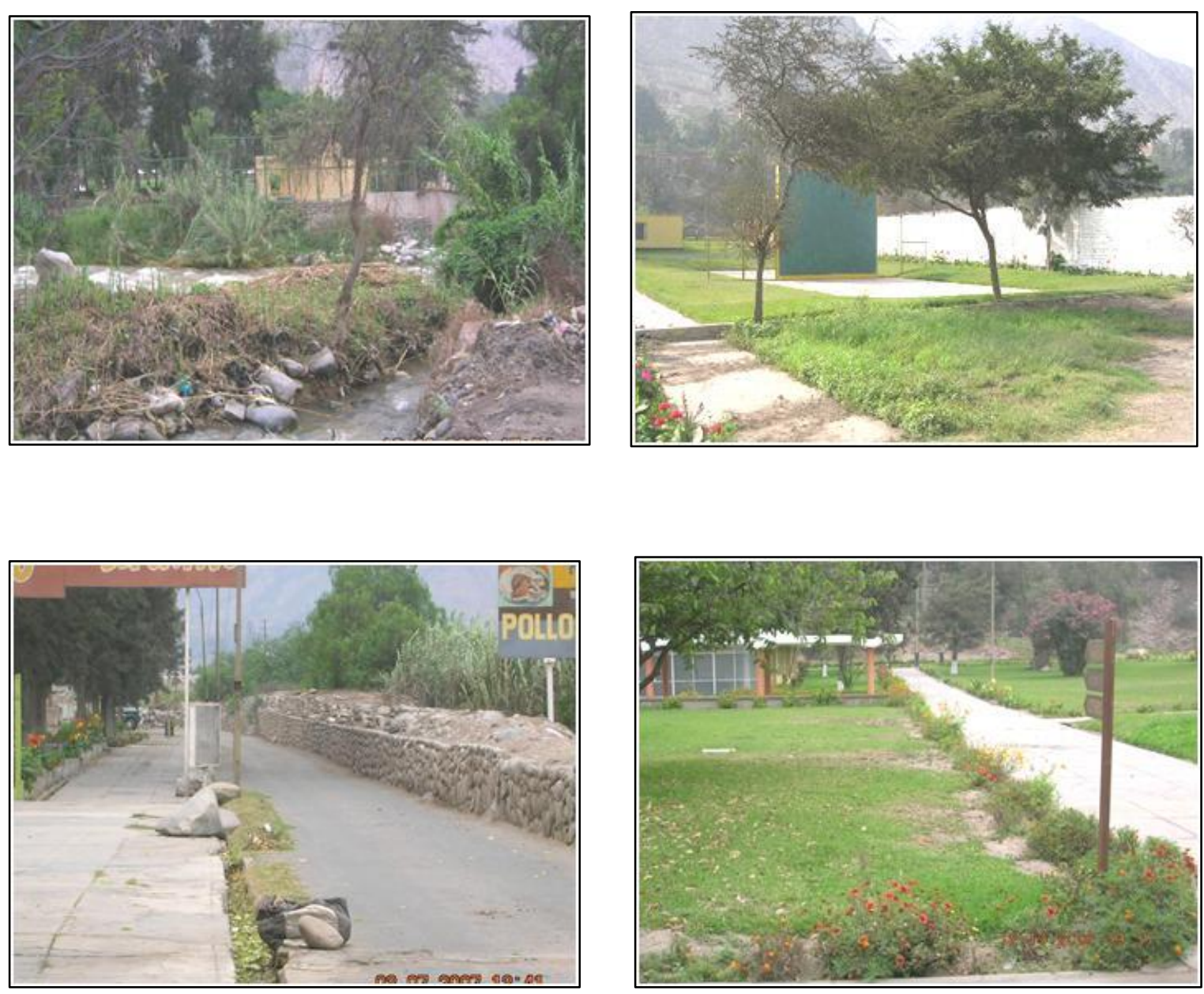

\section{DESPUES}
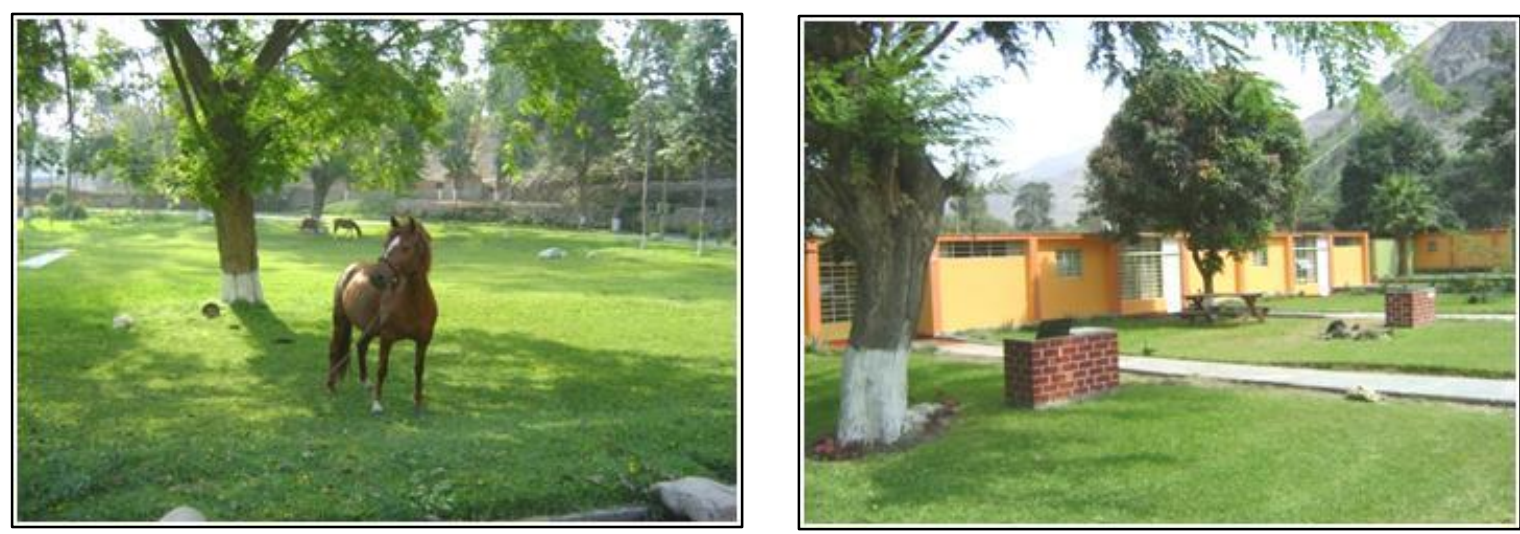

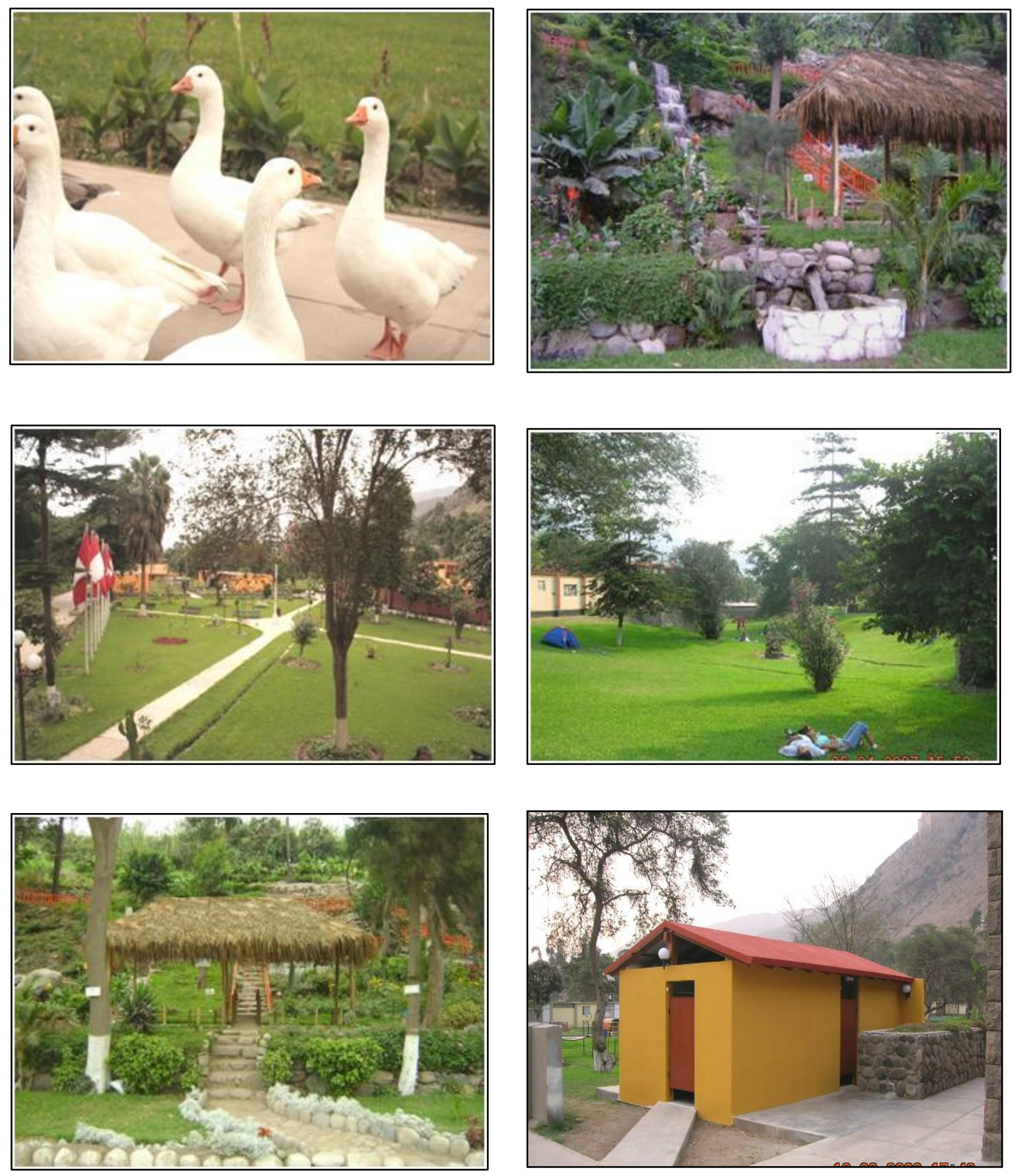


\section{Piscina}

- $\quad$ Adquisición de tobogán.

- $\quad$ Mantenimiento y pintado general de paredes de SS.HH interior y exterior.

- Reconstrucción de servicios higiénicos conexión de la piscina de niños al sistema de filtración de la piscina principal y cambio total de mayólica de piso y pared de piscina de niños.

- $\quad$ Mantenimiento del filtro principal y electro bomba de la piscina de adultos.

\section{ANTES}
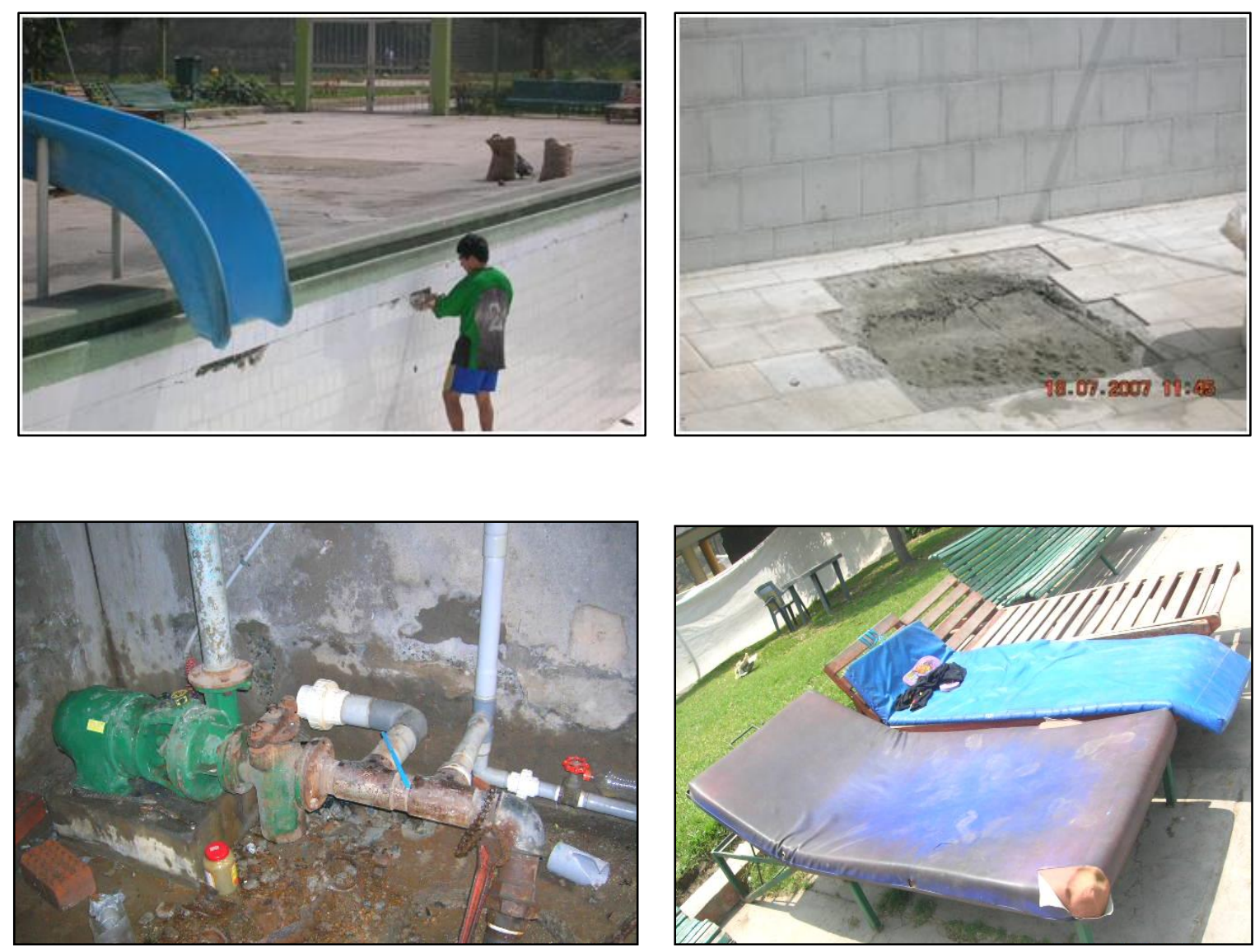
DESPUES

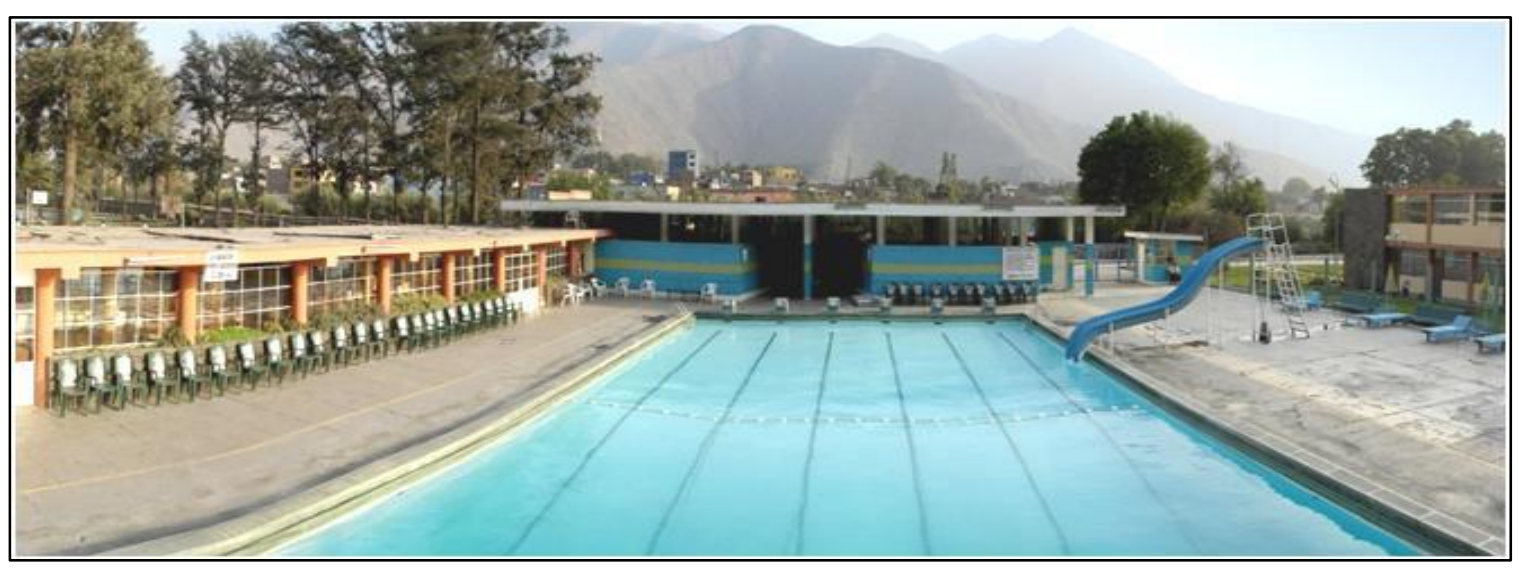




\section{Laguna de Gansos}

- $\quad$ Iluminación de las tres islas de la laguna.

- Mantenimiento de la laguna, instalación de motor recirculación.

- $\quad$ Pintado General de la laguna.

- $\quad$ Adquisición de malla y aspirador.

\section{ANTES}
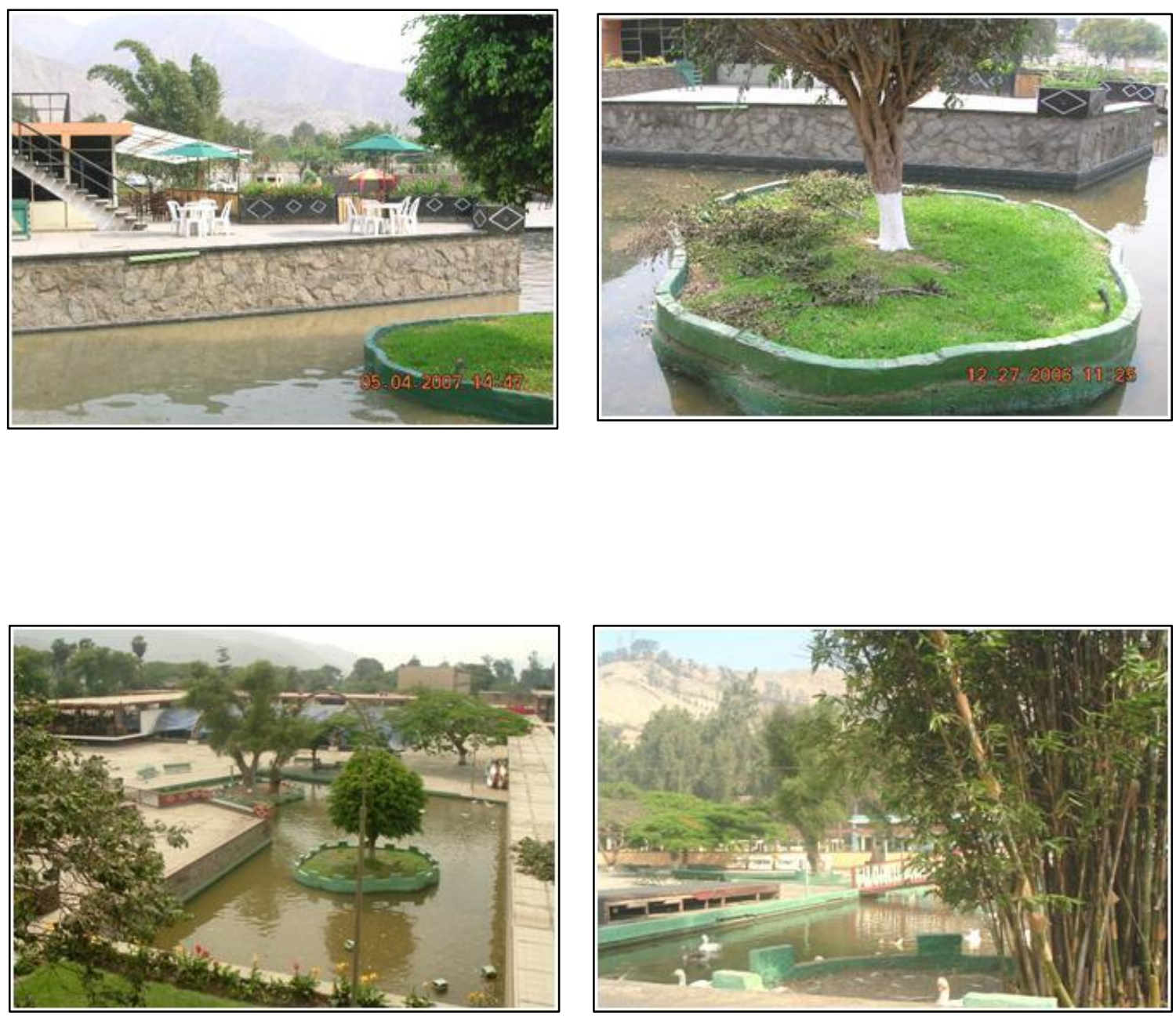
DESPUES
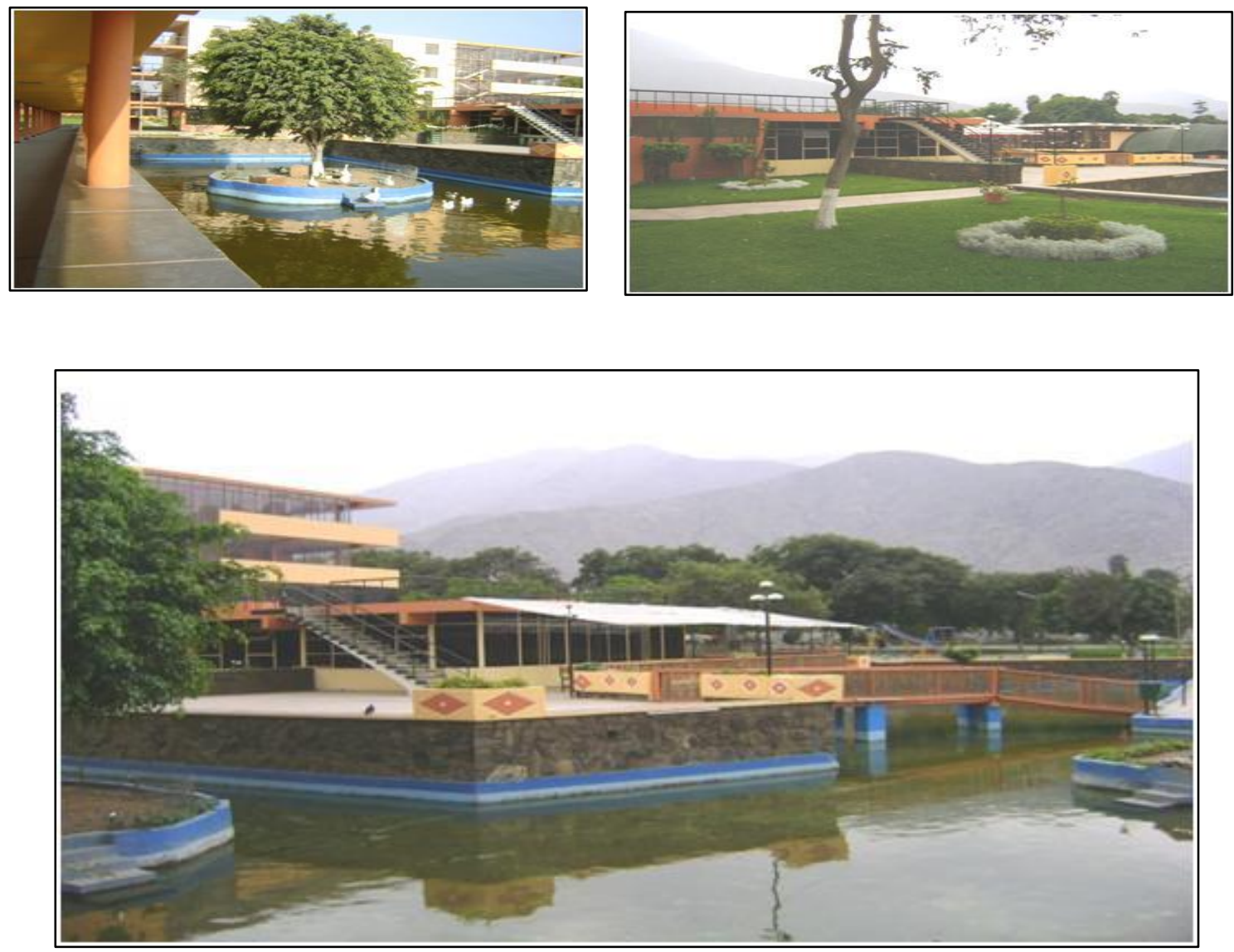

\section{ARCHIVO CENTRAL}

ANTES
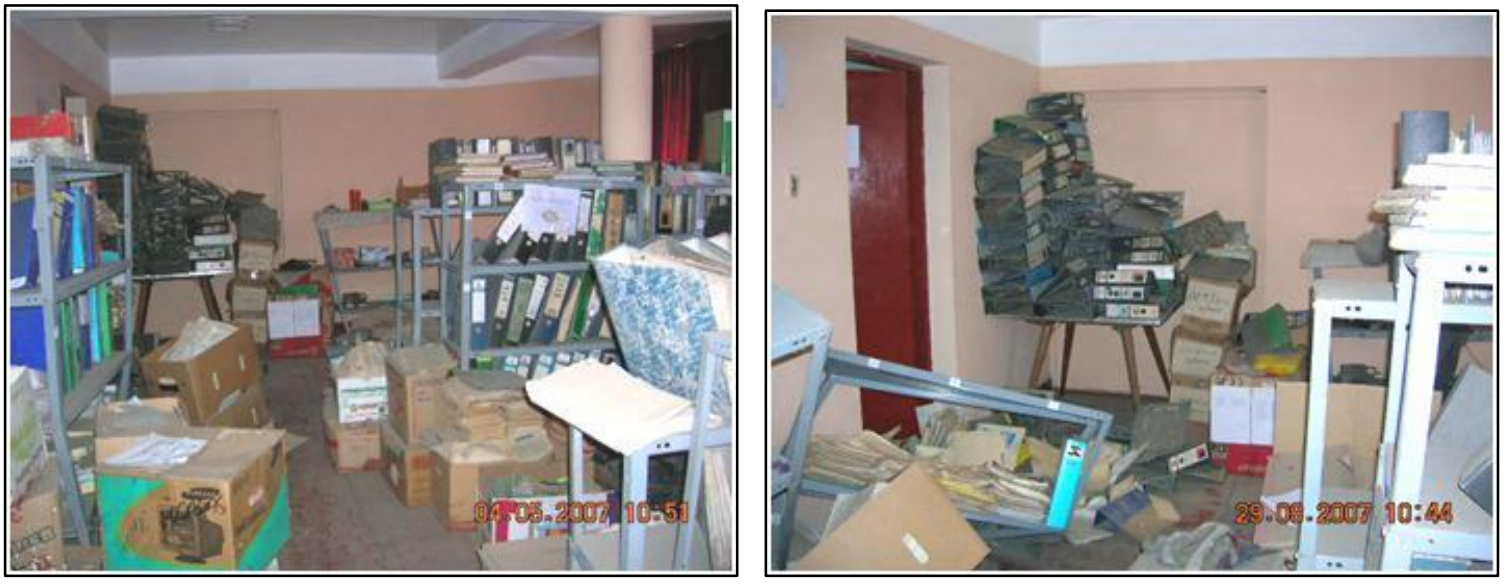


\section{DESPUES}
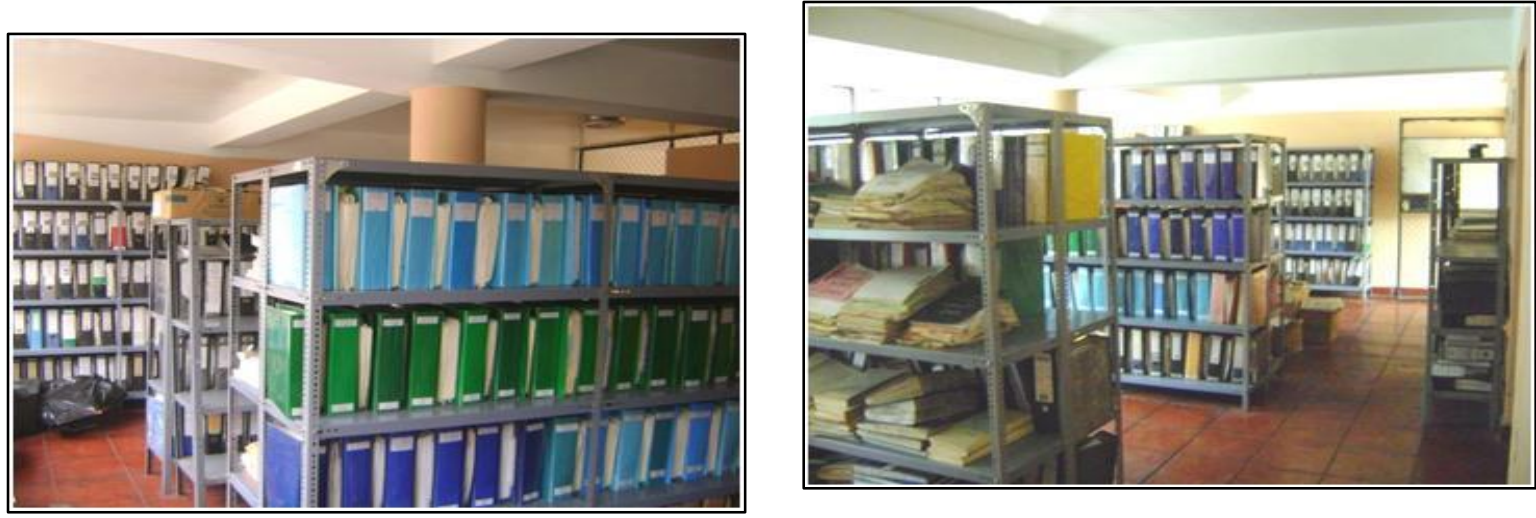

\section{INGRESO PEATONAL Y VEHICULAR}
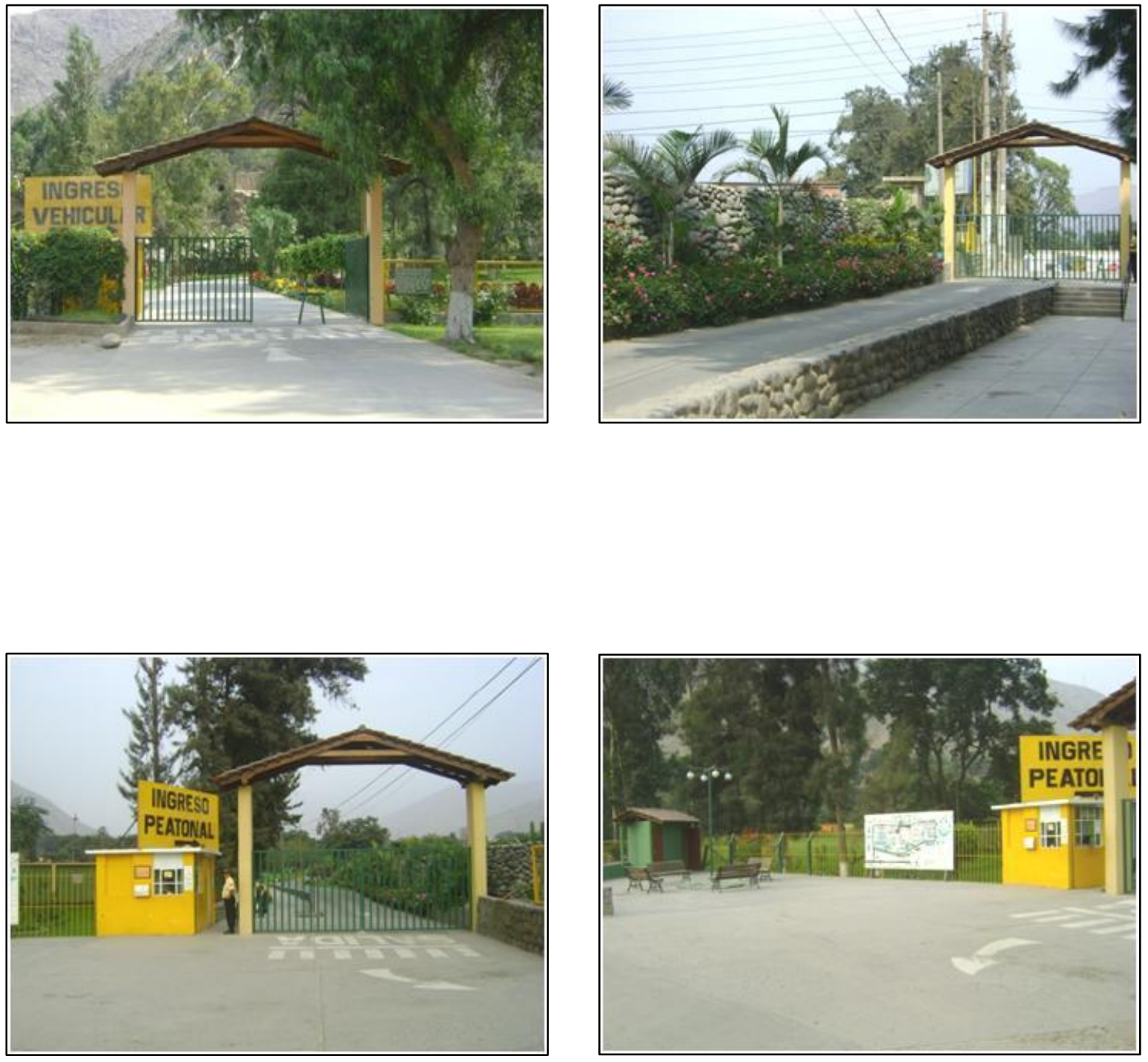
JUEGOS RECREATIVOS
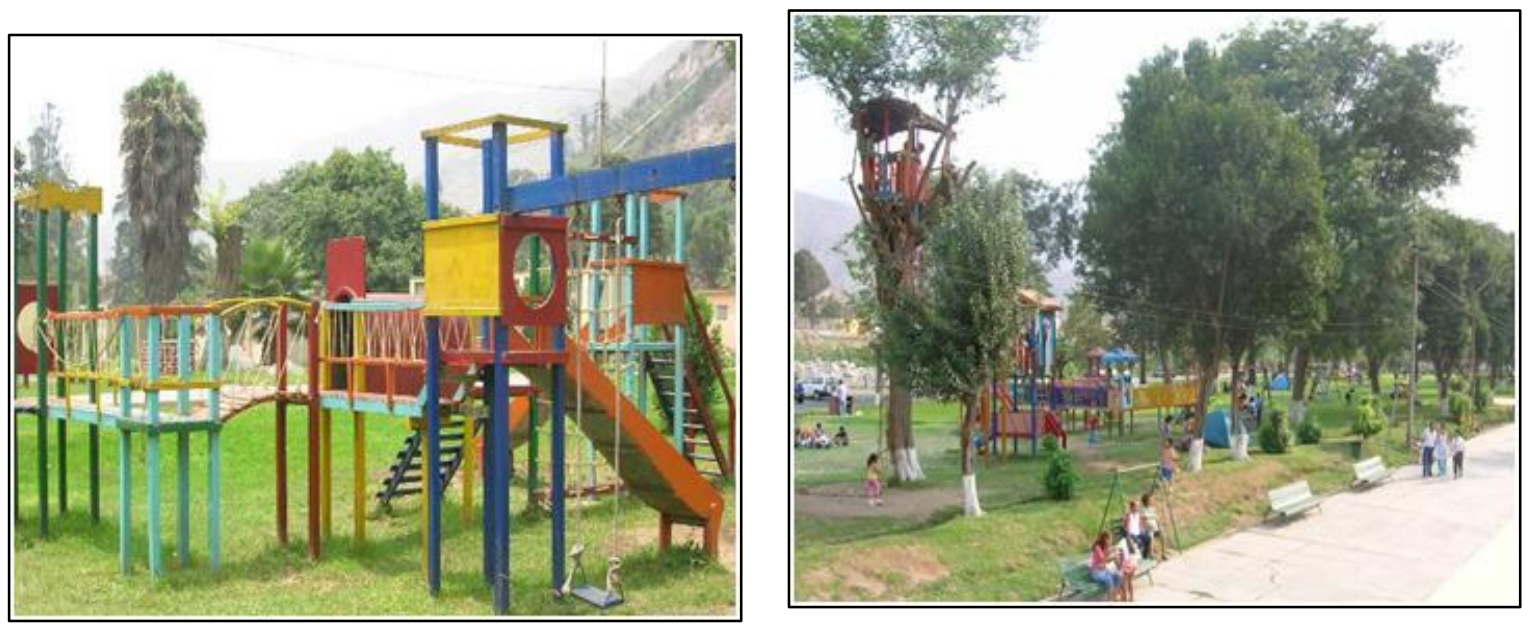

Recuperado de: http://www.huampani.gob.pe/ 
Anexo 7: Cronograma

\begin{tabular}{|c|c|c|c|c|c|c|c|c|c|c|c|c|c|}
\hline \multicolumn{2}{|c|}{ PERSPECTIVA FINANCIERA } & \multicolumn{12}{|c|}{ CRONOGRAMA } \\
\hline INICIATIVAS ESTRATEGICAS & $\begin{array}{c}\text { PRESUPUESTO } \\
\text { S } / .\end{array}$ & MES 1 & MES 2 & MES 3 & MES 4 & MES 5 & MES 6 & MES 7 & MES 8 & MES 9 & $\begin{array}{c}\text { MES } \\
10\end{array}$ & $\begin{array}{c}\text { MES } \\
11\end{array}$ & $\begin{array}{c}\text { MES } \\
12\end{array}$ \\
\hline Control de gastos & $\mathrm{S} / .9,000.00$ & & & & & & & & & & & & \\
\hline Control de endeudamiento & $\mathrm{S} / .2,700.00$ & & & & & & & & & & & & \\
\hline Captación de nuevos clientes & $\mathrm{S} / .5,800.00$ & & & & & & & & & & & & \\
\hline Plan de fidelización y calidad total & $\mathrm{S} / .12,000.00$ & & & & & & & & & & & & \\
\hline $\begin{array}{l}\text { Desarrollo de programas de reducción } \\
\text { de gastos por usuario }\end{array}$ & $\mathrm{S} / .2,700.00$ & & & & & & & & & & & & \\
\hline Tercerización de soporte & $\mathrm{S} / .2,300.00$ & & & & & & & & & & & & \\
\hline
\end{tabular}

Nota. Adaptado de Cuadro de mando integral (p. 161), por R. Kaplan R. y D. Norton, 2000, Barcelona. Copyright 1996 por Ediciones Gestión 2000. Elaboración propia. 


\begin{tabular}{|c|c|c|c|c|c|c|c|c|c|c|c|c|c|}
\hline \multicolumn{2}{|c|}{ PERSPECTIVA CLIENTES } & \multicolumn{12}{|c|}{ CRONOGRAMA } \\
\hline INICIATIVAS & $\begin{array}{c}\text { PRESUPUESTO } \\
\text { S/. }\end{array}$ & MES 1 & MES 2 & MES 3 & MES 4 & MES 5 & MES 6 & MES 7 & MES 8 & MES 9 & $\begin{array}{c}\text { MES } \\
10\end{array}$ & $\begin{array}{c}\text { MES } \\
11\end{array}$ & $\begin{array}{c}\text { MES } \\
12\end{array}$ \\
\hline $\begin{array}{l}\text { Programa de mejora de atención a } \\
\text { clientes }\end{array}$ & $\mathrm{S} / .5,300.00$ & & & & & & & & & & & & \\
\hline $\begin{array}{l}\text { Capacitaciones internas y externas } \\
\text { relacionadas a convenciones }\end{array}$ & $\mathrm{S} / .4,150.00$ & & & & & & & & & & & & \\
\hline Implementar de servicio de post venta & $\mathrm{S} / .4,000.00$ & & & & & & & & & & & & \\
\hline Programa de calidad en el servicio & $\mathrm{S} / .3,000.00$ & & & & & & & & & & & & \\
\hline $\begin{array}{l}\text { Supervisión de proyectos } \\
\text { institucionales }\end{array}$ & $\mathrm{S} / .3,400.00$ & & & & & & & & & & & & \\
\hline Dar a conocer los productos del CVH & $\mathrm{S} / .2,900.00$ & & & & & & & & & & & & \\
\hline Incrementar las políticas de seguridad & $\mathrm{S} / .3,400.00$ & & & & & & & & & & & & \\
\hline $\begin{array}{l}\text { Capacitaciones sobre el uso adecuado } \\
\text { de los insumos }\end{array}$ & $\mathrm{S} / .2,000.00$ & & & & & & & & & & & & \\
\hline $\begin{array}{l}\text { Tener buenas relaciones con los } \\
\text { principales proveedores }\end{array}$ & $\mathrm{S} / .4,500.00$ & & & & & & & & & & & & \\
\hline $\begin{array}{l}\text { Mejorar los procesos de control de } \\
\text { calidad }\end{array}$ & $\mathrm{S} / .5,000.00$ & & & & & & & & & & & & \\
\hline
\end{tabular}

Nota. Adaptado de Cuadro de mando integral (p. 161), por R. Kaplan R. y D. Norton, 2000, Barcelona. Copyright 1996 por Ediciones Gestión 2000. Elaboración propia. 


\begin{tabular}{|c|c|c|c|c|c|c|c|c|c|c|c|c|c|}
\hline \multicolumn{2}{|c|}{ PERSPECTIVA DE PROCESOS INTERNOS } & \multicolumn{12}{|c|}{ CRONOGRAMA } \\
\hline INICIATIVAS & $\begin{array}{c}\text { PRESUPUESTO } \\
\text { S/. }\end{array}$ & $\begin{array}{c}\text { MES } \\
1\end{array}$ & $\underset{2}{\text { MES }}$ & $\underset{3}{\text { MES }}$ & $\underset{4}{\text { MES }}$ & $\begin{array}{c}\text { MES } \\
5\end{array}$ & $\begin{array}{c}\text { MES } \\
6\end{array}$ & $\begin{array}{c}\text { MES } \\
7\end{array}$ & $\begin{array}{c}\text { MES } \\
8\end{array}$ & $\begin{array}{c}\text { MES } \\
9\end{array}$ & $\begin{array}{c}\text { MES } \\
10\end{array}$ & $\begin{array}{c}\text { MES } \\
11\end{array}$ & $\begin{array}{c}\text { MES } \\
12\end{array}$ \\
\hline Programa de manejo de eventos & $\mathrm{S} / .8,300.00$ & & & & & & & & & & & & \\
\hline Programa de coaching voluntario & $\mathrm{S} / .4,100.00$ & & & & & & & & & & & & \\
\hline $\begin{array}{l}\text { Seguimiento de nuevos proyectos } \\
\text { que incentivan la inversión }\end{array}$ & $\mathrm{S} / .2,900.00$ & & & & & & & & & & & & \\
\hline $\begin{array}{l}\text { Establecer estrecha relación con las } \\
\text { empresas institucionales }\end{array}$ & $\mathrm{S} / .4,000.00$ & & & & & & & & & & & & \\
\hline $\begin{array}{l}\text { Implementar programas } \\
\text { relacionados en contar con insumos } \\
\text { mínimos frente a la escasez }\end{array}$ & $\mathrm{S} / .2,200.00$ & & & & & & & & & & & & \\
\hline Mejorar políticas de seguridad & $\mathrm{S} / 2,300.00$ & & & & & & & & & & & & \\
\hline Establecer un planteamiento de & & & & & & & & & & & & & \\
\hline $\begin{array}{l}\text { compras de productos que son de } \\
\text { poca durabilidad }\end{array}$ & $\mathrm{S} / .3,700.00$ & & & & & & & & & & & & \\
\hline $\begin{array}{l}\text { Programa de cumplimiento de los } \\
\text { estándares de seguridad y adquirir } \\
\text { certificaciones }\end{array}$ & $\mathrm{S} / .5,200.00$ & & & & & & & & & & & & \\
\hline
\end{tabular}

Nota. Adaptado de Cuadro de mando integral (p. 161), por R. Kaplan R. y D. Norton, 2000, Barcelona. Copyright 1996 por Ediciones Gestión 2000. Elaboración propia. 


\begin{tabular}{|c|c|c|c|c|c|c|c|c|c|c|c|c|c|}
\hline \multicolumn{2}{|c|}{$\begin{array}{l}\text { PERSPECTIVA DE APRENDIZAJE Y } \\
\text { CRECIMIENTO }\end{array}$} & \multicolumn{12}{|c|}{ CRONOGRAMA } \\
\hline INICIATIVAS & $\begin{array}{c}\text { PRESUPUESTO } \\
\text { S/. }\end{array}$ & MES 1 & MES 2 & MES 3 & MES 4 & MES 5 & MES 6 & MES 7 & MES 8 & MES 9 & $\begin{array}{c}\text { MES } \\
10\end{array}$ & $\begin{array}{c}\text { MES } \\
11\end{array}$ & $\begin{array}{c}\text { MES } \\
12\end{array}$ \\
\hline Programas de capacitaciones & $\mathrm{S} / .12,350.00$ & & & & & & & & & & & & \\
\hline Políticas de promociones & $\mathrm{S} / .1,000.00$ & & & & & & & & & & & & \\
\hline Constantes capacitaciones & $\mathrm{S} / .3,400.00$ & & & & & & & & & & & & \\
\hline $\begin{array}{l}\text { Asignar competencias por áreas y } \\
\text { desarrollo individual }\end{array}$ & $\mathrm{S} / .3,000.00$ & & & & & & & & & & & & \\
\hline Capacitación en sistema & $\mathrm{S} / .5,800.00$ & & & & & & & & & & & & \\
\hline Establecer recursos & S/.0.00 & & & & & & & & & & & & \\
\hline Programa de liderazgo & $\mathrm{S} / .5,500.00$ & & & & & & & & & & & & \\
\hline Coaching & $\mathrm{S} / .5,000.00$ & & & & & & & & & & & & \\
\hline
\end{tabular}

Nota. Adaptado de Cuadro de mando integral (p. 161), por R. Kaplan R. y D. Norton, 2000, Barcelona. Copyright 1996 por Ediciones Gestión 2000. Elaboración propia. 
Anexo 8: Plan Operativo 2016

PLAN OPERATIVO ENERO/ 2016

ENTIDAD: CENTRO VACACIONAL HUAMPANI

RUC: 20155140942

INSTRUMENTO QUE APRUEBA EL PAC:

\begin{tabular}{|c|c|c|c|c|c|c|c|c|c|c|}
\hline $\begin{array}{l}\frac{1}{c} \\
\frac{1}{\alpha} \\
\dot{z}\end{array}$ & 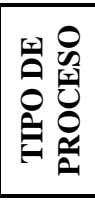 & 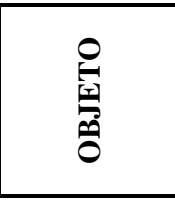 & SÍNTESIS DE ESPECIFICACIONES TÉCNICAS & 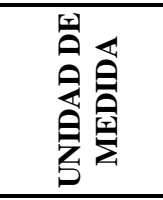 & 㫣 & 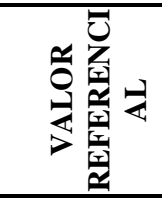 & 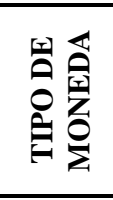 & 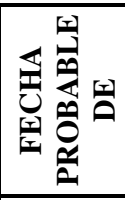 & 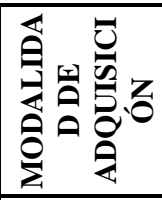 & 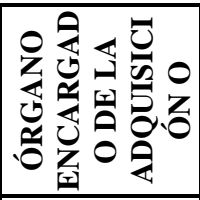 \\
\hline \multicolumn{11}{|c|}{ ÁREA DE OPERACIONES } \\
\hline 1 & $\mathrm{AMC}$ & SERVICIO & Construcción de un pozo artesiano con pared interior de concreto & UNIDAD & 1 & $16,000.00$ & SOLES & ENERO & PROCESO & LOGISTICA \\
\hline 2 & ADP & BIENES & Adquisición de 03 Vehículos por reposición de los existentes & UNIDAD & 3 & $347,700.00$ & SOLES & ENERO & PROCESO & LOGISTICA \\
\hline 3 & $\mathrm{AMC}$ & BIENES & Compra de Bomba Sumergible - Hidrostal de $10 \mathrm{HP}$ & UNIDAD & 2 & $23,000.00$ & SOLES & ENERO & PROCESO & LOGISTICA \\
\hline 4 & AMC & BIENES & Instalación de Red de Gas y Tanque de 500 Galones. & UNIDAD & 1 & $10,800.00$ & SOLES & ENERO & PROCESO & LOGISTICA \\
\hline 5 & - & BIENES & Adquisición de Taladro Industrial de $1 \mathrm{HP}$ & UNIDAD & 1 & $5,000.00$ & SOLES & ENERO & $\mathrm{C} / \mathrm{D}$ & LOGISTICA \\
\hline 6 & - & BIENES & Adquisición de Compresora de 2HP para Pintar & UNIDAD & 2 & $6,000.00$ & SOLES & \begin{tabular}{|l|l} 
ENERO \\
\end{tabular} & $\mathrm{C} / \mathrm{D}$ & LOGISTICA \\
\hline 7 & AMC & BIENES & Instalación de 04 Halls de aluminio y vidrio Edificio $\mathrm{N}^{\circ} 07$ & UNIDAD & 4 & $35,000.00$ & SOLES & ENERO & PROCESO & LOGISTICA \\
\hline 8 & $\mathrm{CP}$ & SERVICIO & $\begin{array}{l}\text { Servicio de Vigilancia y Seguridad en el Centro vacacional } \\
\text { Huampani }\end{array}$ & SERVICIO & 1 & $336,000.00$ & SOLES & ENERO & PROCESO & LOGISTICA \\
\hline 9 & AMC & SERVICIO & Servicio de Fumigación en el Centro Vacacional Huampani & SERVICIO & 1 & $21,000.00$ & SOLES & ENERO & PROCESO & LOGISTICA \\
\hline 10 & - & BIENES & Adquisición de Hidrolavadora de $13 \mathrm{HP}$ & UNIDAD & 1 & $8,500.00$ & SOLES & ENERO & $\mathrm{C} / \mathrm{D}$ & LOGISTICA \\
\hline \multicolumn{11}{|c|}{ ÁREA DE ALOJAMIENTO Y CONVENCIONES } \\
\hline 11 & AMC & BIENES & Adquisición de Ventiladores de Pie & UNIDAD & 40 & $19,200.00$ & SOLES & ENERO & PROCESO & LOGISTICA \\
\hline 12 & $\mathrm{ADS}$ & BIENES & Adquisición de Sábanas de 11/2 Plaza de Polypima & JUEGOS & 1,500 & $45,000.00$ & SOLES & ENERO & PROCESO & LOGISTICA \\
\hline 13 & $\mathrm{ADS}$ & BIENES & Adquisición de Frazadas de 11/2 Plaza & UNIDAD & 1,500 & $52,500.00$ & SOLES & ENERO & PROCESO & LOGISTICA \\
\hline 14 & $\mathrm{AMC}$ & BIENES & Adquisición de confortables para Halls de los Edificios & JUEGOS & 12 & $30,000.00$ & SOLES & ENERO & PROCESO & LOGISTICA \\
\hline 15 & $\mathrm{ADS}$ & BIENES & Adquisición de Cubrecamas 11/2 & UNIDAD & 1,500 & $90,000.00$ & SOLES & ENERO & PROCESO & LOGISTICA \\
\hline 16 & $\mathrm{AMC}$ & BIENES & Adquisición de Toallas & UNIDAD & 1,500 & $20,850.00$ & SOLES & ENERO & PROCESO & LOGISTICA \\
\hline 17 & $\mathrm{AMC}$ & BIENES & Adquisición de Almohadas & UNIDAD & 1,500 & $30,000.00$ & SOLES & \begin{tabular}{|l|l|} 
ENERO \\
\end{tabular} & PROCESO & \begin{tabular}{|l|} 
LOGISTICA \\
\end{tabular} \\
\hline 18 & - & BIENES & Cortinas para duchas de Baños del CVH & UNIDAD & 500 & $8,000.00$ & SOLES & ENERO & $\mathrm{C} / \mathrm{D}$ & LOGISTICA \\
\hline 19 & - & BIENES & Adquisición de 06 Microondas & UNIDAD & 6 & $2,700.00$ & SOLES & ENERO & $\mathrm{C} / \mathrm{D}$ & LOGISTICA \\
\hline 20 & $\mathrm{AMC}$ & BIENES & Adquisición de Televisores Color de 30" - Pantalla Plana & UNIDAD & 20 & $30,000.00$ & SOLES & ENERO & PROCESO & LOGISTICA \\
\hline 21 & - & BIENES & Adquisición de Manteles para el CVH & UNIDAD & 200 & $6,000.00$ & SOLES & ENERO & $\mathrm{C} / \mathrm{D}$ & \begin{tabular}{|l|} 
LOGISTICA \\
\end{tabular} \\
\hline 22 & ADS & BIENES & Adquisición de 01 Lavadora de 100 kg. para la lavandería del CVH & UNIDAD & 1 & $42,450.00$ & SOLES & ENERO & PROCESO & LOGISTICA \\
\hline 23 & $\mathrm{AMC}$ & BIENES & Adquisición de 01 Secadora de 70 kg. para la lavandería del CVH & UNIDAD & 1 & $21,225.00$ & SOLES & ENERO & PROCESO & LOGISTICA \\
\hline 24 & $\mathrm{AMC}$ & BIENES & Adquisición de 174 Cortinas para las aulas y laboratorios del CMSPP & UNIDAD & 174 & $32,150.00$ & SOLES & ENERO & PROCESO & LOGISTICA \\
\hline 25 & ADS & BIENES & Adquisición de 20 Laptop & UNIDAD & 10 & $32,000.00$ & SOLES & ENERO & PROCESO & LOGISTICA \\
\hline 26 & AMC & BIENES & Adquisición de 10 computadores $*$ & UNIDAD & 10 & $25,000.00$ & SOLES & ENERO & PROCESO & LOGISTICA \\
\hline
\end{tabular}




\begin{tabular}{|l|l|l|l|l|}
\hline 27 & AMC & BIENES & Adquisición de 4 Proyectores con Ecram \\
\hline 28 & ADS & BIENES & Adquisición de Closets para los 7 Edificios y 36 Bungalows del CVH \\
\hline 29 & - & BIENES & Adquisición de 01 FAX \\
\hline 30 & AMC & BIENES & Adquisición de Lustradora Industrial Marca Chasqui \\
\hline ÁREA DE ALIMENTOS Y BEBIDAS \\
\hline 31 & ADS & BIENES & Adquisición de maquina lavadora de vajillas \\
\hline 32 & - & BIENES & Adquisición de máquina Procesadora de Alimentos \\
\hline 33 & - & BIENES & Adquisición de máquina peladora de papas \\
\hline 34 & AMC & BIENES & Adquisición de mueble LINEAL de autoservicio \\
\hline 35 & AMC & SERVICIO & Servicio de remodelación y redistribución de las Cámaras de frio \\
\hline 36 & - & BIENES & Adquisición de coches para Traslados de Platos \\
\hline 37 & - & BIENES & Adquisición de SOFTWARE INFOREST \\
\hline 38 & - & BIENES & Adquisición de Estante con ruedas de 5 pisos \\
\hline 39 & AMC & BIENES & Adquisición de menaje de cocina \\
\hline ÁREAS VERDES & \multicolumn{2}{|l}{} \\
\hline 40 & AMC & BIENES & Adquisición de Tractor Podador 15.5 HP \\
\hline ÁREA DE LOGÍSTICA & \multicolumn{2}{|l}{} \\
\hline 41 & ADP & BIENES & Adquisición de Combustible - Petróleo Diesel 2 \\
\hline 42 & LP & BIENES & Adquisición de Carne de Ave - Pollo \\
\hline 43 & ADS & BIENES & Adquisición de Carne de Res \\
\hline 44 & AMC & BIENES & Instalación de Cámara de frio en el Almacén Central \\
\hline 45 & AMC & SERVICIO & $\begin{array}{l}\text { Servicio de Remodelación y Restructuración Integral del Almacén } \\
\text { Central del CVH }\end{array}$ \\
\hline 46 & AMC & BIENES & Adquisición de Útiles de Oficina \\
\hline 47 & - & BIENES & Adquisición de Estantería para el Archivo Central del CVH \\
\hline & & &
\end{tabular}

Nota. Recuperado de
http://www.transparencia.gob.pe/enlaces/pte_transparencia_enlaces.aspx?id_entidad=13099\&id_tema=5\&ver=\#.Wx3In0gvzIU

\begin{tabular}{|c|c|c|c|c|c|c|}
\hline UNIDAD & 4 & $14,000.00$ & SOLES & ENERO & PROCESO & LOGISTICA \\
\hline UNIDAD & & \begin{tabular}{|l|}
$120,000.00$ \\
\end{tabular} & \begin{tabular}{|l|} 
SOLES \\
\end{tabular} & ENERO & PROCESO & \begin{tabular}{|l} 
LOGISTICA \\
\end{tabular} \\
\hline UNIDAD & 1 & 750.00 & SOLES & ENERO & C/D & \begin{tabular}{|l} 
LOGISTICA \\
\end{tabular} \\
\hline UNIDAD & 3 & $15,000.00$ & SOLES & ENERO & PROCESO & \begin{tabular}{|l|} 
LOGISTICA \\
\end{tabular} \\
\hline & & & & & & IOCICTIC \\
\hline $\begin{array}{l}\text { UNIDAD } \\
\text { UNIDAD }\end{array}$ & $\frac{1}{1}$ & $\frac{45,000.40}{6775,40}$ & $\begin{array}{l}\text { SULES } \\
\text { SOLES }\end{array}$ & $\frac{\text { ENEKU }}{\text { FNEPO }}$ & $C / \mathrm{D}$ & \begin{tabular}{|l} 
LOGISTICA \\
\end{tabular} \\
\hline UNIDAD & 1 & $6,701.72$ & SOLES & ENERO & $\mathrm{C} / \mathrm{D}$ & \begin{tabular}{|l} 
LOGISTICA \\
\end{tabular} \\
\hline UNIDAD & 1 & $37,287.17$ & \begin{tabular}{|l|} 
SOLES \\
\end{tabular} & ENERO & PROCESO & \begin{tabular}{|l} 
LOGISTICA \\
\end{tabular} \\
\hline SERVICIO & 1 & $26,000.00$ & \begin{tabular}{|l} 
SOLES \\
\end{tabular} & ENERO & PROCESO & \begin{tabular}{|l} 
LOGISTICA \\
\end{tabular} \\
\hline UNIDAD & 5 & $6,000.00$ & \begin{tabular}{|l|} 
SOLES \\
\end{tabular} & ENERO & C/D & \begin{tabular}{|l} 
LOGISTICA \\
\end{tabular} \\
\hline UNIDAD & 1 & $7,075.00$ & \begin{tabular}{|l|} 
SOLES \\
\end{tabular} & ENERO & $\mathrm{C} / \mathrm{D}$ & \begin{tabular}{|l} 
LOGISTICA \\
\end{tabular} \\
\hline UNIDAD & 1 & $5,000.00$ & SOLES & ENERO & $\mathrm{C} / \mathrm{D}$ & \begin{tabular}{|l} 
LOGISTICA \\
\end{tabular} \\
\hline UNIDAD & 1 & $30,000.00$ & SOLES & ENERO & PROCESO & \begin{tabular}{|l|} 
LOGISTICA \\
\end{tabular} \\
\hline UNIDAD & 2 & $18,564.00$ & SOLES & ENERO & PROCESO & LOGISTICA \\
\hline & & & & & & \\
\hline KG. & $\frac{54,710}{50310}$ & $\frac{20,2000000}{37800000}$ & \begin{tabular}{|l} 
SULES \\
SOLES
\end{tabular} & \begin{tabular}{|l} 
ENEKO \\
ENERO
\end{tabular} & PROCESO & \begin{tabular}{|l} 
LOGISTICA \\
\end{tabular} \\
\hline KG. & 6,281 & $123,000.00$ & SOLES & ENERO & PROCESO & \begin{tabular}{|l} 
LOGISTICA \\
\end{tabular} \\
\hline UNIDAD & 1 & $35,000.00$ & \begin{tabular}{|l} 
SOLES \\
\end{tabular} & ENERO & PROCESO & \begin{tabular}{|l|} 
LOGISTICA \\
\end{tabular} \\
\hline UNIDAD & 1 & $20,000.00$ & SOLES & ENERO & PROCESO & LOGISTICA \\
\hline UNIDAD & & $30,000.00$ & SOLES & ENERO & \begin{tabular}{|l|} 
PROCESO \\
\end{tabular} & \begin{tabular}{|l} 
LOGISTICA \\
\end{tabular} \\
\hline UNIDAD & 1 & $10,000.00$ & SOLES & ENERO & C/D & LOGISTICA \\
\hline
\end{tabular}


PLAN OPERATIVO FEBRERO 2016

ENTIDAD: CENTRO VACACIONAL HUAMPANI

RUC: 20155140942

INSTRUMENTO QUE APRUEBA EL PAC:

\begin{tabular}{|c|c|c|c|c|c|c|c|c|c|c|}
\hline $\begin{array}{l}\text { 空 } \\
\text { 足 } \\
\dot{Z}\end{array}$ & 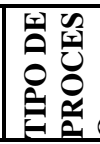 & 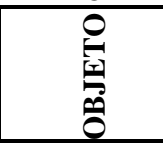 & SÍNTESIS DE ESPECIFICACIONES TÉCNICAS & 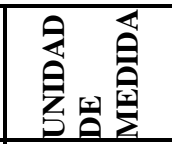 & 穵是 & 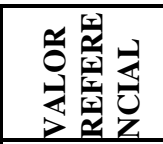 & 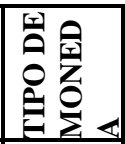 & 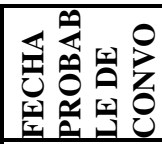 & 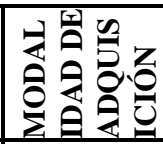 & 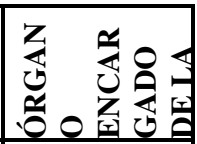 \\
\hline \multicolumn{11}{|c|}{ ÁREA DE OPERACIONES } \\
\hline 1 & ADS & BIENES & Adquisición de un Caldero para las Instalaciones de cocina del CVH & UNIDAD & 1 & $56,600.00$ & SOLES & FEBRERO & PROCESO & LOGISTICA \\
\hline 2 & ADS & SERVICIO & \multirow{2}{*}{\begin{tabular}{|l|} 
Servicio de Conversión de Petróleo Diesel a GLP \\
Adquisición de Bicicletas para el Área de Operaciones y Carpintería \\
\end{tabular}} & UNIDAD & 1 & $25,000.00$ & SOLES & FEBRERO & PROCESO & LOGISTICA \\
\hline 3 & - & BIENES & & UNIDAD & 3 & $1,800.00$ & SOLES & FEBRERO & $\mathrm{C} / \mathrm{D}$ & LOGISTICA \\
\hline 4 & - & BIENES & Adquisición de Motofurgon $125 \mathrm{CC}$ & UNIDAD & 1 & $6,000.00$ & SOLES & FEBRERO & $\mathrm{C} / \mathrm{D}$ & LOGISTICA \\
\hline 5 & $\mathrm{CP}$ & SERVICIO & Servicio de Vigilancia y Seguridad en el Colegio Mayor Presidente del Perú & SERVICIO & 1 & $283,248.00$ & SOLES & FEBRERO & PROCESO & LOGISTICA \\
\hline \multicolumn{11}{|c|}{ ÁREAS VERDES } \\
\hline 6 & - & BIENES & Instalación de Sistema Móvil de riego tecnificado & UNIDAD & 1 & $9,328.41$ & SOLES & FEBRERO & $\mathrm{C} / \mathrm{D}$ & \begin{tabular}{|l|} 
LOGISTICA \\
\end{tabular} \\
\hline 7 & - & BIENES & Adquisición de Microcomputadora + Impresora & UNIDAD & 1 & \begin{tabular}{|l|l|}
$3,500.00$ \\
\end{tabular} & \begin{tabular}{|l|} 
SOLES \\
\end{tabular} & FEBRERO & $\mathrm{C} / \mathrm{D}$ & \begin{tabular}{|l|} 
LOGISTICA \\
\end{tabular} \\
\hline 8 & - & BIENES & Adquisición de Herramientas diversas de jardinería & UNIDAD & 1 & $10,000.00$ & \begin{tabular}{|l|} 
SOLES \\
\end{tabular} & FEBRERO & $\mathrm{C} / \mathrm{D}$ & LOGISTICA \\
\hline 9 & - & BIENES & Adquisición de Sopladora Aspiradora de Hojas & UNIDAD & 1 & $6,000.00$ & SOLES & FEBRERO & $\mathrm{C} / \mathrm{D}$ & LOGISTICA \\
\hline \multicolumn{11}{|c|}{ ÁREA DE RECURSOS HUMANOS } \\
\hline 10 & - & BIENES & Adquisición de Sistema de Control de Asistencia & UNIDAD & 1 & $7,877.80$ & SOLES & FEBRERO & $\mathrm{C} / \mathrm{D}$ & LOGISTICA \\
\hline 11 & - & BIENES & Adquisición de Computadora + Impresora & UNIDAD & 1 & $3,500.00$ & \begin{tabular}{|l|} 
SOLES \\
\end{tabular} & FEBRERO & $\mathrm{C} / \mathrm{D}$ & LOGISTICA \\
\hline 12 & AMC & SERVICIO & Servicio de Capacitación para las Áreas Administrativas & UNIDAD & 1 & $20,000.00$ & \begin{tabular}{|l|} 
SOLES \\
\end{tabular} & FEBRERO & PROCESO & LOGISTICA \\
\hline 13 & AMC & SERVICIO & Servicio de Capacitación para las Áreas Operativas & UNIDAD & 1 & $15,000.00$ & \begin{tabular}{|l|} 
SOLES \\
\end{tabular} & FEBRERO & PROCESO & LOGISTICA \\
\hline 14 & - & BIENES & Adquisición de Software de Planillas para el CVH & UNIDAD & 1 & $5,000.00$ & SOLES & FEBRERO & $\mathrm{C} / \mathrm{D}$ & LOGISTICA \\
\hline 15 & - & BIENES & Adquisición de muebles de oficina & UNIDAD & 1 & $4,300.00$ & \begin{tabular}{|l|} 
SOLES \\
\end{tabular} & FEBRERO & $\mathrm{C} / \mathrm{D}$ & \begin{tabular}{|l|} 
LOGISTICA \\
\end{tabular} \\
\hline \multicolumn{11}{|c|}{ ÁREA DE SISTEMAS } \\
\hline 16 & - & BIENES & Adquisición de Servidor para el CVH & UNIDAD & 1 & $6,000.00$ & SOLES & FEBRERO & $\mathrm{C} / \mathrm{D}$ & LOGISTICA \\
\hline 17 & AMC & BIENES & Adquisición de Licencias de Software - Sistema Operativo y Aplicativos & UNIDAD & 10 & $13,900.00$ & SOLES & FEBRERO & PROCESO & LOGISTICA \\
\hline 18 & AMC & BIENES & Adquisición de Equipos de Computo & UNIDAD & 8 & $28,000.00$ & SOLES & FEBRERO & PROCESO & LOGISTICA \\
\hline 19 & - & BIENES & Adquisición de Fotocopiadora - 100 ppm Digital & UNIDAD & 1 & $5,094.00$ & SOLES & FEBRERO & $\mathrm{C} / \mathrm{D}$ & LOGISTICA \\
\hline 20 & AMC & BIENES & Adquisición de Suministros de Computo & UNIDAD & 1 & $15,000.00$ & SOLES & FEBRERO & PROCESO & LOGISTICA \\
\hline
\end{tabular}

Nota. Recuperado de

http://www.transparencia.gob.pe/enlaces/pte_transparencia_enlaces.aspx?id_entidad=13099\&id_tema=5\&ver=\#.Wx3In0gvzIU 
PLAN OPERATIVO MARZO 2016

ENTIDAD: CENTRO VACACIONAL HUAMPANI

RUC: $\quad 20155140942$

INSTRUMENTO QUE APRUEBA EL PAC:

\begin{tabular}{|c|c|c|c|c|c|c|c|c|c|c|}
\hline$\frac{1}{2}$ & 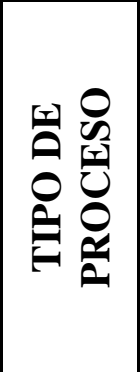 & 号 & $\begin{array}{l}\text { SÍNTESIS DE ESPECIFICACIONES } \\
\text { TÉCNICAS }\end{array}$ & 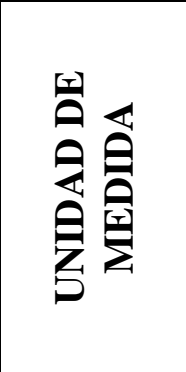 & 是 & 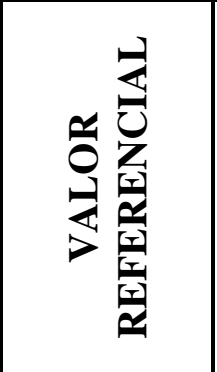 & 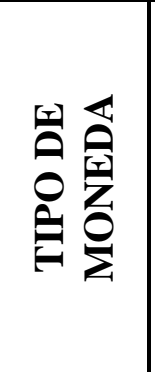 & 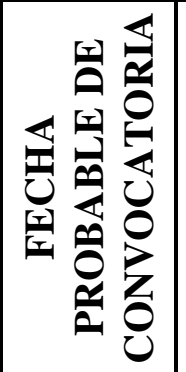 & 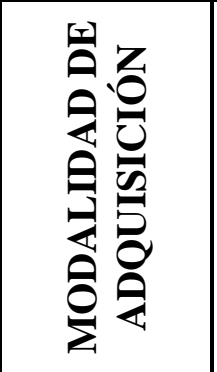 & 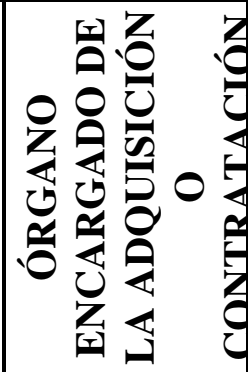 \\
\hline \multicolumn{11}{|c|}{ ÁREA DE OPERACIONES } \\
\hline 1 & ADS & BIENES & Adquisición de Grupo electrógeno & UNIDAD & 1 & $128,000.00$ & SOLES & MARZO & PROCESO & LOGISTICA \\
\hline \multicolumn{11}{|c|}{ ÁREA DE ALOJAMIENTO Y CONVENCIONES } \\
\hline 2 & ADS & BIENES & $\begin{array}{l}\text { Adquisición de Techo para la Carpa Central } \\
\text { del CVH }\end{array}$ & UNIDAD & 1 & $67,920.00$ & SOLES & MARZO & PROCESO & LOGISTICA \\
\hline
\end{tabular}

Nota. Recuperado de

http://www.transparencia.gob.pe/enlaces/pte_transparencia_enlaces.aspx?id_entidad=13099\&id_tema=5\&ver=\#.Wx3In0gvzIU

PLAN OPERATIVO MENSUAL 2016 X ÁREAS

\begin{tabular}{|c|c|c|c|c|c|c|c|c|c|c|}
\hline & $\begin{array}{l}\text { Área de } \\
\text { Operaciones }\end{array}$ & $\begin{array}{l}\text { Área de } \\
\text { Alojamiento } \\
\text { y } \\
\text { Convenciones }\end{array}$ & $\begin{array}{l}\text { Área de } \\
\text { Alimentos } \\
\text { y Bebidas }\end{array}$ & \begin{tabular}{|l|} 
Áreas \\
Verdes
\end{tabular} & $\begin{array}{l}\text { Área de } \\
\text { RRHH }\end{array}$ & $\begin{array}{l}\text { Área de } \\
\text { Sistemas }\end{array}$ & $\begin{array}{l}\text { Área de } \\
\text { Logística }\end{array}$ & $\begin{array}{l}\text { Área de } \\
\text { Operaciones }\end{array}$ & $\begin{array}{l}\text { Área de } \\
\text { Alojamiento y } \\
\text { Convenciones }\end{array}$ & TOTAL \\
\hline Enero & $809,000.00$ & $636,825.00$ & $169,799.30$ & $18,564.00$ & 0.00 & 0.00 & $858,000.00$ & 0.00 & 0.00 & $2,492,188.30$ \\
\hline Febrero & $372,648.00$ & 0 & 0 & $28,828.41$ & $55,677.80$ & $67,994.00$ & 0 & 0 & 0 & $525,148.21$ \\
\hline Marzo & 0 & 0 & 0 & 0 & 0 & 0 & 0 & $128,000.00$ & $67,920.00$ & $195,920.00$ \\
\hline TOTAL & $1,181,648.00$ & $636,825.00$ & $169,799.30$ & $47,392.41$ & $55,677.80$ & $67,994.00$ & $858,000.00$ & $128,000.00$ & $67,920.00$ & $3,213,256.51$ \\
\hline
\end{tabular}

Nota. Recuperado de

http://www.transparencia.gob.pe/enlaces/pte_transparencia_enlaces.aspx?id_entidad=13099\&id_tema=5\&ver=\#.Wx3In0gvzIU 
Anexo 9: Estado de Ganancias y Pérdidas Proyectado

\begin{tabular}{|c|c|c|c|c|c|c|c|c|c|c|c|c|c|}
\hline \multicolumn{14}{|c|}{ CENTRO VACACIONAL HUAMPANÍ } \\
\hline \multicolumn{14}{|c|}{ Estado de Ganancias y Pérdidas } \\
\hline \multicolumn{14}{|c|}{ Al 31 de diciembre de 2007 - 2019} \\
\hline \multirow{2}{*}{\multicolumn{14}{|c|}{ (en nuevos soles) }} \\
\hline & & & & & & & & & & & & & \\
\hline \multicolumn{14}{|l|}{ Ventas Netas } \\
\hline \begin{tabular}{|l|} 
A terceros \\
\end{tabular} & $1,530,564$ & $1,886,634$ & $1,434,854$ & $2,298,471$ & $3,325,225$ & $4,758,398$ & $9,164,831$ & $9,623,073$ & $10,104,227$ & $10,609,438$ & $11,139,910$ & $11,696,905$ & $12,281,750$ \\
\hline \multicolumn{14}{|l|}{\begin{tabular}{|l|} 
A empresas vinculadas \\
\end{tabular}} \\
\hline \multicolumn{14}{|l|}{ Otros ingresos operacionales } \\
\hline \multicolumn{14}{|l|}{ A terceros } \\
\hline TOTAL INGRESOS BRUTOS & $1,530,564$ & $1,886,634$ & $1,434,854$ & $2,298,471$ & $3,325,225$ & $4,758,398$ & $9,164,831$ & $9,623,073$ & $10,104,227$ & $10,609,438$ & $11,139,910$ & $11,696,905$ & $12,281,750$ \\
\hline Costo de ventas & $2,533,181$ & $2,670,270$ & $2,934,519$ & $3,258,415$ & $1,787,474$ & $2,078,199$ & $3,773,321$ & $\begin{array}{ll}-3,961,987 \\
\end{array}$ & $-4,160,086$ & $-4,368,091$ & $-4,586,495$ & $-4,815,820$ & $-5,056,611$ \\
\hline \multicolumn{14}{|l|}{\begin{tabular}{|l|} 
A terceros \\
\end{tabular}} \\
\hline \multicolumn{14}{|l|}{ A empresas vinculadas } \\
\hline UTILIDAD BRUTA & $1,002,617$ & 783,636 & $1,499,665$ & 959,944 & $1,537,751$ & $2,680,199$ & $5,391,510$ & $5,661,086$ & $5,944,140$ & $6,241,347$ & $6,553,415$ & $6,881,085$ & $7,225,140$ \\
\hline Gastos de administración & 927,265 & $1,125,175$ & 955,876 & 842,965 & $2,034,018$ & $1,488,329$ & $1,247,039$ & $-1,309,390$ & $-1,374,860$ & $-1,443,603$ & $-1,515,783$ & $-1,591,572$ & $-1,671,151$ \\
\hline Gastos de ventas & 73,205 & 52,334 & 80,084 & 138,296 & $1,102,409$ & $2,776,059$ & $-3,053,664$ & $-3,206,348$ & $-3,366,665$ & $-3,534,998$ & $-3,711,748$ & $-3,897,336$ & $-4,092,202$ \\
\hline \begin{tabular}{|l|} 
Otros ingresos \\
\end{tabular} & & & 488,251 & 321,239 & & 82,443 & 786,313 & 825,629 & 866,911 & 910,256 & 955,769 & $1,003,557$ & $1,053,735$ \\
\hline Otros Gastos & & & 216,137 & 45,630 & 563,870 & 725,576 & 600,281 & \begin{tabular}{ll|}
$-630,295$ \\
\end{tabular} & $-661,810$ & $-694,900$ & $-729,645$ & $-766,128$ & $-804,434$ \\
\hline UTILIDAD OPERATIVA & $2,003,087$ & $1,961,145$ & $2,263,511$ & $1,665,596$ & $2,162,546$ & $2,227,322$ & $1,276,840$ & $1,340,682$ & $1,407,716$ & $1,478,102$ & $1,552,007$ & $1,629,607$ & $1,711,087$ \\
\hline \begin{tabular}{|l|} 
Ingresos excepcionales \\
\end{tabular} & 364,049 & 208,929 & & & & & & - & - & - & - & - & - \\
\hline \begin{tabular}{|l|} 
Ingresos financieros \\
\end{tabular} & 397 & 1,859 & 1,066 & 106 & & & & - & - & - & - & - & - \\
\hline Cargas Excepcionales & 387,094 & 159,035 & & & 183,229 & 321,116 & 154,606 & $-162,336$ & $-170,453$ & $-178,976$ & $-187,925$ & $-197,321$ & $-207,187$ \\
\hline \begin{tabular}{|l|} 
Cargas Financieras \\
\end{tabular} & 17,441 & 34,898 & 37,290 & 47,496 & 39,624 & 37,331 & 36,258 & $-38,071$ & \begin{tabular}{ll|}
$-39,974$ \\
\end{tabular} & \begin{tabular}{ll|}
$-41,973$ \\
\end{tabular} & $-44,072$ & $-46,275$ & $-48,589$ \\
\hline \begin{tabular}{|l|l|l|l|l|l|} 
REl Ejercicio \\
\end{tabular} & 21,332 & & & & & & & & $-\quad$ & & & $-\cdot$ & \\
\hline RESULTADO ANTES DE PARTIDAS EXTRAORDINARIAS, PART- & $1,799,064$ & $1,767,606$ & $2,299,735$ & $1,712,986$ & $2,078,578$ & $2,585,768$ & $1,085,976$ & $1,140,275$ & $1,197,289$ & $1,257,153$ & $1,320,011$ & $1,386,011$ & 1,455,312 \\
\hline \multicolumn{14}{|l|}{\begin{tabular}{|l|l} 
Participaciones & \\
\end{tabular}} \\
\hline \multicolumn{14}{|l|}{ Impuesto a la renta } \\
\hline RESULTADO ANTES DE PARTIDAS EXTRAORDINARIAS & $1,799,064$ & $1,767,606$ & $2,299,735$ & $1,712,986$ & $2,078,578$ & $2,585,768$ & $1,085,976$ & $1,140,275$ & $1,197,289$ & $1,257,153$ & $1,320,011$ & $1,386,011$ & $1,455,312$ \\
\hline \multicolumn{14}{|l|}{ Ingresos extraordinarios } \\
\hline \multicolumn{14}{|l|}{ Gastos extraordinarios } \\
\hline RESULTADO ANTES DE INTERES MINORITARIO & $1,799,064$ & $1,767,606$ & $2,299,735$ & $1,712,986$ & $2,078,578$ & $2,585,768$ & $1,085,976$ & $1,140,275$ & $1,197,289$ & $1,257,153$ & $1,320,011$ & $1,386,011$ & $1,455,312$ \\
\hline \multicolumn{14}{|l|}{ Interés minuritario } \\
\hline UTILIDAD (PERDIDA) DEL EJERCICIO & $1,799,064$ & $1,767,606$ & $2,299,735$ & $1,712,986$ & $2,078,578$ & $2,585,768$ & $1,085,976$ & $1,140,275$ & $1,197,289$ & $1,257,153$ & $1,320,011$ & $1,386,011$ & $1,455,312$ \\
\hline \begin{tabular}{|l} 
RESULTADO DEL EJERCICIO \\
\end{tabular} & $1,799,064$ & $1,767,606$ & $2,299,735$ & $1,712,986$ & $2,078,578$ & $2,585,768$ & $1,085,976$ & $1,140,275$ & $1,197,289$ & $1,257,153$ & $1,320,011$ & $1,386,011$ & $1,455,312$ \\
\hline
\end{tabular}

Nota. Estado de Ganancias y pérdidas proyectado. Recuperado de

http://www.transparencia.gob.pe/enlaces/pte_transparencia_enlaces.aspx?id_entidad=13099\&id_tema=5\&ver=\#.Wx3In0gvzIU 


\section{Anexo 10: Balance General Proyectado}

\section{CENTRO VACACIONAL HUAMPANÍ}

Balance General Proyectado

Al 31 de diciembre de 2007 - 2019

(en nuevos soles)

\section{ACTIVO}

ACTIVO CORRIENTE

Caja y Bancos

Valores Negociables

Cuentas por cobrar Comerciales

Menos : Provisión Cobranza dudosa

Cuentas por Cobrar a vinculados

Otras cuentas por cobrar

Menos : Provisión Cobranza dudosa

Existencias

\begin{tabular}{|l} 
Menos : Prov. desva. De existencia \\
\hline Gas pagos
\end{tabular}

\begin{tabular}{|l}
\hline Gastos pagados por anticipo \\
\hline TOTAL ACTIVO CORRIENTE
\end{tabular}

\section{ACTIVO NO CORRIENTE}

Cuentas por cobrar a largo plazo

Cuentas por cobrar a vinculadas

a largo plazo

Otras ctas por cobrar a largo plazo

Inversiones permanentes

Menos : Fluctuaciones de valores

y cobranza

Inmuebles, Maquinaria y Equipo

Menos: Depreciación acumulada

Provisión para desval. de los

bienes del activo fijo

Activos intangibles

Menos: Amortización Acumulada

intangible

Impto. a la Renta y Particip. diferidos

activos

\begin{tabular}{|l|}
\hline Otros activos \\
\hline TOTAL ACTIVO NO CORRIENTE \\
\hline
\end{tabular}

TOTAL ACTIVO NO CORRIENT

TOTAL ACTIVO

\begin{tabular}{|c|c|c|c|c|c|c|c|c|c|c|c|c|}
\hline 2007 & 2008 & 2009 & 2010 & 2011 & 2012 & 2013 & 2014 & 2015 & 2016 & 2017 & 2018 & 2019 \\
\hline & & & & & & & & & & & & \\
\hline \multirow[t]{2}{*}{208,310} & 258,194 & 133,840 & 51,624 & 353,253 & 247,109 & 200,303 & 230,348 & 264,900 & 304,635 & 350,330 & 402,880 & 463,312 \\
\hline & & & & & & & - & - & - & - & - & - \\
\hline \multirow{3}{*}{$\begin{array}{l}715,892 \\
-\quad 87,469 \\
\end{array}$} & $1,048,672$ & 826,382 & & & & $1,085,976$ & $1,248,872$ & $1,436,203$ & $1,651,634$ & $1,899,379$ & $2,184,286$ & $2,511,928$ \\
\hline & $\begin{array}{ll}- & 64,155 \\
\end{array}$ & & & & & & - & - & - & - & - & - \\
\hline & 56,184 & 25,420 & $1,207,252$ & 597,770 & $8,672,794$ & $3,567,129$ & $3,388,772$ & $3,219,334$ & $3,058,367$ & $2,905,449$ & $2,760,176$ & $2,622,167$ \\
\hline \multirow{3}{*}{$\begin{array}{ll}97,043 & \\
- & 34,995 \\
99,183 & \\
\end{array}$} & & & 94,270 & 63,605 & 12,576 & $1,188,859$ & $1,129,416$ & $1,072,946$ & $1,019,298$ & 968,333 & 919,917 & 873,921 \\
\hline & - $\quad 13,012$ & & & & & & - & - & - & - & - & - \\
\hline & 98,464 & 83,848 & 127,571 & 121,727 & 111,539 & 137,110 & 157,676 & 181,328 & 208,527 & 239,806 & 275,777 & 317,143 \\
\hline \multirow{3}{*}{$\begin{array}{l} \\
792,475 \\
1,790,439\end{array}$} & & & & & & & - & - & - & - & - & - \\
\hline & 972,791 & 652,343 & 318,327 & 127,947 & 3,275 & - & - & - & - & - & - & - \\
\hline & $2,357,138$ & $1,721,833$ & $1,799,044$ & $1,264,302$ & $9,047,294$ & $6,179,377$ & $6,155,086$ & $6,174,711$ & $6,242,461$ & $6,363,297$ & $6,543,036$ & $6,788,472$ \\
\hline \multirow{5}{*}{ 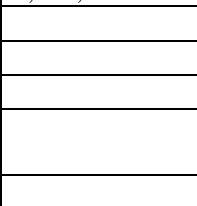 } & & & & & & & - & - & - & - & - & - \\
\hline & & & & & & & - & - & - & - & - & - \\
\hline & & & & & - & - & - & - & - & - & - & - \\
\hline & & & & & - & - & - & - & - & - & - & - \\
\hline & & & & 266,215 & - & - & - & - & - & - & - & - \\
\hline \multirow[t]{2}{*}{39,731} & 39,731 & 39,731 & 39,731 & 39,731 & 39,731 & 39,731 & 45,690 & 52,544 & 60,425 & 69,489 & 79,913 & 91,900 \\
\hline & & & & & $16,057,359$ & $20,411,103$ & $20,615,214$ & $20,821,366$ & $21,029,579$ & $21,239,875$ & $21,452,274$ & $21,666,797$ \\
\hline \multirow{3}{*}{$\begin{array}{l}20,051,299 \\
-\quad 2,415,246 \\
\end{array}$} & $20,705,732$ & \begin{tabular}{|l|}
$20,623,366$ \\
\end{tabular} & $17,165,872$ & $16,755,247$ & 341,104 & 554,344 & 565,431 & 576,740 & 588,275 & 600,040 & $\begin{array}{ll}612,041 \\
\end{array}$ & 624,282 \\
\hline & - $2,969,661$ & $-\quad 3,319,512$ & & & & & - & - & - & - & - & - \\
\hline & & & & & & & - & - & - & - & - & - \\
\hline \multirow[t]{3}{*}{42,467} & 46,351 & 46,351 & & & & & - & - & - & - & - & - \\
\hline & & $\begin{array}{l}-\quad 8,284 \\
\end{array}$ & & & & & - & - & - & - & - & - \\
\hline & & & & & & & - & - & - & - & - & - \\
\hline 335,534 & 500 & 84,941 & 268,664 & 217,139 & 86,641 & 91,670 & 105,421 & 121,234 & 139,419 & 160,332 & 184,382 & 212,039 \\
\hline $18,653,785$ & $17,822,653$ & $17,466,593$ & $17,474,267$ & $17,278,331$ & $16,524,835$ & $21,096,848$ & $21,331,756$ & $21,571,884$ & $21,817,699$ & $22,069,737$ & $22,328,609$ & $22,595,017$ \\
\hline $20,444,224$ & $20,179,791$ & $19,188,426$ & $19,273,311$ & $18,542,633$ & $25,572,129$ & $27,276,225$ & $27,486,842$ & $27,746,594$ & $28,060,160$ & $28,433,034$ & $28,871,645$ & $29,383,490$ \\
\hline & & & & & & & - & - & - & - & - & - \\
\hline & & & & & & & - & - & - & - & - & - \\
\hline & & & & & & & - & - & - & - & - & - \\
\hline & 35,275 & - & & & & & - & & & & & \\
\hline
\end{tabular}

PASIVO Y PATRIMONIO

Sobregiros y Pagarés bancarios 


\begin{tabular}{|c|c|c|c|c|c|c|c|c|c|c|c|c|c|}
\hline Cuentas por cobrar comerciales & 183,412 & - & 111,979 & - & - & - & - & - & - & - & - & - & - \\
\hline Cuentas por pagar a vinculados & & 141,659 & 285,446 & 667,213 & 277,541 & $1,744,798$ & $1,084,713$ & $1,247,420$ & $1,434,533$ & $1,649,713$ & $1,897,170$ & $2,181,745$ & $2,509,007$ \\
\hline Otras cuentas por pagar & 127,571 & 262,634 & 116,863 & 15,878 & 17,104 & 43,019 & 122,772 & 141,188 & 162,366 & 186,721 & 214,729 & 246,938 & 283,979 \\
\hline Parte cte. Deudas a Largo plazo & & & & 98,381 & 27,658 & - & - & - & - & - & - & - & - \\
\hline \multirow[t]{2}{*}{ TOTAL PASIVO CORRIENTE } & 310,983 & 439,568 & 514,288 & 781,472 & 322,303 & $1,787,817$ & $1,207,485$ & $1,388,608$ & $1,596,899$ & $1,836,434$ & $2,111,899$ & $2,428,684$ & $2,792,986$ \\
\hline & & & & & & & & - & - & - & - & - & - \\
\hline PASIVO NO CORRIENTE & & & & & & & & - & - & - & - & - & - \\
\hline Deudas a largo plazo & $1,992,328$ & - & 16,292 & $1,035,273$ & 980,690 & $1,003,800$ & 891,213 & $1,024,894$ & $1,178,629$ & $1,355,423$ & $1,558,736$ & $1,792,547$ & $2,061,429$ \\
\hline Cuentas por pagar a vinculados & & $1,680,855$ & $1,099,353$ & & & 15,646 & 16,832 & 19,357 & 22,260 & 25,599 & 29,439 & 33,855 & 38,934 \\
\hline Ingresos diferidos & & 21,093 & & & & $6,478,319$ & $9,991,947$ & $11,490,739$ & $12,579,048$ & $12,413,082$ & $12,240,480$ & $12,058,079$ & $11,862,360$ \\
\hline Impt a la renta y partic. Diferidos pasivo & & & & & & \begin{tabular}{|l|}
89,915 \\
\end{tabular} & & - & - & - & - & - & - \\
\hline TOTAL PASIVO NO CORRIENTE & $1,992,328$ & $1,701,948$ & $1,115,645$ & $1,035,273$ & 980,690 & $7,587,681$ & $10,899,992$ & $12,534,990$ & $13,779,937$ & $13,794,104$ & $13,828,656$ & $13,884,481$ & $13,962,722$ \\
\hline TOTAL PASIVO & $2,303,311$ & $2,141,516$ & $1,629,933$ & $1,816,745$ & $1,302,993$ & $9,375,498$ & $12,107,477$ & $13,923,598$ & $15,376,836$ & $15,630,538$ & $15,940,554$ & $16,313,165$ & $16,755,709$ \\
\hline \multicolumn{14}{|l|}{ Contingencia } \\
\hline \multicolumn{14}{|l|}{ Interés minoritario } \\
\hline & & & & & & & & & & & & & \\
\hline \multicolumn{14}{|l|}{ PATRIMONIO } \\
\hline Capital & $4,073,990$ & $4,073,990$ & $4,073,990$ & $4,073,990$ & $11,172,469$ & $11,172,469$ & $11,172,469$ & $11,172,469$ & $11,172,469$ & $11,172,469$ & $11,172,469$ & $11,172,469$ & $11,172,469$ \\
\hline Capital Adicional & $7,098,479$ & $7,098,479$ & $7,098,479$ & $7,098,479$ & & & & & & & & & \\
\hline Acciones de inversión & & $3,877,359$ & & & & & & & & & & & \\
\hline Excedente de Revaluación & $3,877,359$ & $2,756,051$ & $3,877,359$ & & & & & & & & & & \\
\hline \multicolumn{14}{|l|}{ Reservas } \\
\hline Resultados acumulados & $3,091,085$ & 232,395 & \begin{tabular}{|l|}
$2,808,396$ \\
\end{tabular} & $6,284,097$ & $6,067,170$ & \begin{tabular}{|l|}
$5,024,162$ \\
\end{tabular} & \begin{tabular}{|l|}
$2,910,302$ \\
\end{tabular} & $1,250,499$ & & & & & \\
\hline Resultado del ejercicio & & & $-\quad 299,735$ & & & & $1,085,976$ & $1,140,275$ & $1,197,289$ & $1,257,153$ & $1,320,011$ & $1,386,011$ & $1,455,312$ \\
\hline TOTAL PATRIMONIO & $18,140,913$ & $18,038,274$ & $17,558,489$ & $17,456,566$ & $17,239,640$ & $16,196,632$ & $15,168,748$ & $13,563,243$ & $12,369,758$ & $12,429,622$ & $12,492,480$ & $12,558,481$ & $12,627,781$ \\
\hline TOTAL PASIVO Y PATRIMONIO & $20,444,224$ & $20,179,790$ & $19,188,422$ & $19,273,311$ & $18,542,633$ & $25,572,129$ & $27,276,225$ & $27,486,841$ & $27,746,594$ & $28,060,161$ & $28,433,035$ & $28,871,645$ & $29,383,490$ \\
\hline
\end{tabular}

Nota. Balance General proyectado. Recuperado de

http://www.transparencia.gob.pe/enlaces/pte_transparencia_enlaces.aspx?id_entidad=13099\&id_tema=5\&ver=\#.Wx3In0gvzIU 
Anexo 11: Flujo de Efectivo Proyectado

CENTRO VACACIONAL HUAMPANí

Estado de Flujo de Efectivo

Al 31 de diciembre de 2007 - 2019

(en nuevos soles)

\begin{tabular}{|c|c|c|c|c|c|c|c|c|c|c|c|c|c|}
\hline & 2007 & 2008 & 2009 & 2010 & 2011 & 2012 & 2013 & 2014 & 2015 & 2016 & 2017 & 2018 & 2019 \\
\hline Ingresos & $1,530,564$ & $1,886,634$ & $1,434,854$ & $2,298,471$ & $3,325,225$ & $4,758,398$ & $9,164,831$ & $9,623,073$ & $10,104,227$ & $10,609,438$ & $11,139,910$ & $11,696,905$ & $12,281,750$ \\
\hline \multicolumn{14}{|l|}{ Gastos } \\
\hline Compras de MP - CV & $2,533,181$ & $2,670,270$ & $2,934,519$ & $3,258,415$ & $1,787,474$ & $2,078,199$ & $3,773,321$ & $3,961,987$ & $4,160,086$ & $4,368,091$ & $4,586,495$ & $4,815,820$ & $5,056,611$ \\
\hline Gastos de Administración & 927,265 & $1,125,175$ & 955,876 & 842,965 & $2,034,018$ & $1,488,329$ & $1,247,039$ & $1,309,390$ & $1,374,860$ & $1,443,603$ & $1,515,783$ & $1,591,572$ & $1,671,151$ \\
\hline Gastos de Ventas & 73,205 & 52,334 & 80,084 & 138,296 & $1,102,409$ & $2,776,059$ & $3,053,664$ & $3,206,348$ & $3,366,665$ & $3,534,998$ & $3,711,748$ & $3,897,336$ & $4,092,202$ \\
\hline Otros Gastos de ventas & & & 216,137 & 45,630 & 563,870 & 725,576 & 600,281 & 630,295 & 661,810 & 694,900 & 729,645 & 766,128 & 804,434 \\
\hline \begin{tabular}{|l|} 
Cargas Financieras \\
\end{tabular} & 17,441 & 34,898 & 37,290 & 47,496 & 39,624 & 37,331 & 36,258 & 38,071 & 39,974 & 41,973 & 44,072 & 46,275 & 48,589 \\
\hline Cargas Excepcionales & 387,094 & 159,035 & & & 183,229 & 321,116 & 154,606 & 162,336 & 170,453 & 178,976 & 187,925 & 197,321 & 207,187 \\
\hline \begin{tabular}{|l|} 
Imprevistos \\
\end{tabular} & 45,917 & 37,733 & 28,697 & 45,969 & 66,505 & 95,168 & 229,121 & 240,577 & 252,606 & 265,236 & 278,498 & 292,423 & 307,044 \\
\hline FLUJO DE CAJA ECONÓMICO & $2,453,539$ & $2,192,811$ & $2,817,749$ & $2,080,300$ & $2,451,904$ & $2,763,380$ & 70,542 & 74,069 & 77,772 & 81,661 & 85,744 & 90,031 & 94,533 \\
\hline Saldo Final de Caja & $2,453,539$ & $2,192,811$ & $2,817,749$ & $2,080,300$ & $2,451,904$ & $2,763,380$ & 70,542 & 74,069 & 77,772 & 81,661 & 85,744 & 90,031 & 94,533 \\
\hline
\end{tabular}

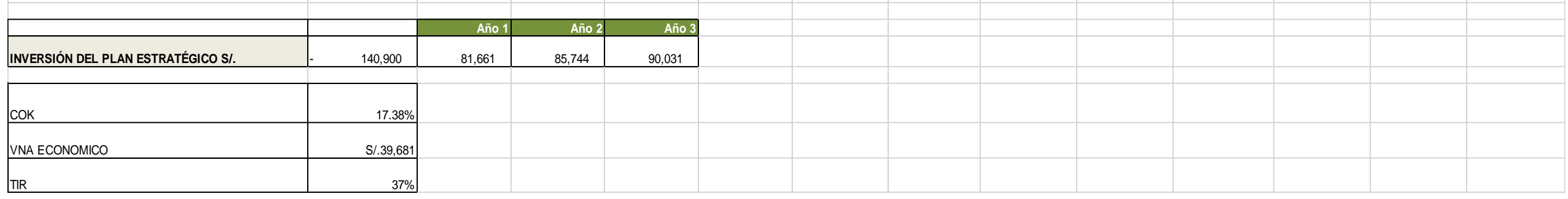

Nota. Flujo de Efectivo proyectado. Recuperado de

http://www.transparencia.gob.pe/enlaces/pte_transparencia_enlaces.aspx?id_entidad=13099\&id_tema=5\&ver=\#.Wx3In0gvzIU 
Anexo 12: Cálculo del COK

Datos del Riesgo:

Empresas del Sector

\begin{tabular}{|c|c|c|c|c|}
\hline $\mathbf{R f}$ & $4.05 \%$ & BE & 2.36 & \multirow{4}{*}{$\begin{array}{l}\text { Damodaran } \\
\text { Ratio Deuda capital/Promedio de } 6 \text { empresas del sector }\end{array}$} \\
\hline \multirow[t]{3}{*}{$\mathbf{R M}$} & 6.00 & $\mathrm{D} / \mathrm{C}$ & 0.78 & \\
\hline & \multicolumn{2}{|c|}{ Tasa Impuestos } & $30.00 \%$ & \\
\hline & & $\mathrm{BOA}$ & 1.53 & \\
\hline
\end{tabular}

COSTO DE CAPITAL Y TASAS DE DESCUENTO

\begin{tabular}{|c|c|c|c|}
\hline $\mathbf{r f}$ & $4.05 \%$ & RM & 6.00 \\
\hline Riesgo País & $1.82 \%$ & & \\
\hline
\end{tabular}

\section{COSTO DE CAPITAL ECONÓMICO (KOA)}

\begin{tabular}{|c|c|c|}
\hline \multicolumn{2}{|c|}{ KE a la Estructura D/C dada } & \multirow{4}{*}{ en Perú $\mathrm{t}=30 \%$} \\
\hline D/C (Empresa) & 0.78 & \\
\hline BE (Beta Patrim. a D/C) & 2.36 & \\
\hline \multicolumn{2}{|l|}{$\mathrm{KE}=\mathrm{rf}+\mathrm{BE}(\mathrm{RM}-\mathrm{rf})$} & \\
\hline KE (COK Acc. a D/C) & 14.12 & $\%$ \\
\hline
\end{tabular}

\begin{tabular}{|c|c|c|}
\hline Beta No Apalancado (On & & \\
\hline Tasa Impuestos & $30.0 \%$ & \\
\hline $\mathrm{Boa}=\mathrm{Be} /[1+(1-\mathrm{T}) \mathrm{D} / \mathrm{C}]$ & & \\
\hline BOA $($ No Apalancado) & 1.53 & \\
\hline $\mathrm{KOA}=\mathrm{rf}+\mathrm{BOA}(\mathrm{RM}-\mathrm{r}$ & & \\
\hline KOA (COK Econ. Puro) & 9.16 & $\%$ \\
\hline & 23.28 & $\mathrm{CO}$ \\
\hline
\end{tabular}




\section{Anexo 13: DAMODARAN}

\begin{tabular}{|c|c|c|c|c|c|c|c|c|c|}
\hline Date updated: & \multicolumn{6}{|l|}{ 05-ene-16 } & & & \\
\hline Created by: & \multicolumn{6}{|c|}{ Aswath Damodaran, adamodar@stern.nyu.edu } & & & \\
\hline What is this data? & \multicolumn{4}{|c|}{ Beta, Unlevered beta and other risk measures } & \multicolumn{2}{|c|}{ US companies } & & & \\
\hline Home Page: & \multicolumn{6}{|c|}{ http://www.damodaran.com } & & & \\
\hline Data website: & \multicolumn{6}{|c|}{ http://www.stern.nyu.edu/ adamodar/New_Home_Page/data.html } & & & \\
\hline Companies in each industry: & \multicolumn{6}{|c|}{ http://www.stern.nyu.edu/ adamodar/pc/datasets/indname.xls } & & & \\
\hline Variable definitions: & \multicolumn{6}{|c|}{ http://www.stern.nyu.edu/ adamodar/New_Home_Page/datafile/variable.htm } & & & \\
\hline Industry Name & $\begin{array}{l}\text { Number of } \\
\text { firms }\end{array}$ & Beta & \begin{tabular}{|l} 
D/E \\
Ratio \\
\end{tabular} & Tax rate & $\begin{array}{l}\text { Unlevered } \\
\text { beta }\end{array}$ & $\begin{array}{l}\text { Cash/Firm } \\
\text { value }\end{array}$ & $\begin{array}{l}\text { Unlevered } \\
\text { beta } \\
\text { corrected } \\
\text { for cash }\end{array}$ & \begin{tabular}{|l} 
HiLo \\
Risk
\end{tabular} & $\begin{array}{l}\text { Standard } \\
\text { deviation } \\
\text { of equity }\end{array}$ \\
\hline Advertising & 44 & 1.08 & $56.26 \%$ & $3.90 \%$ & 0.70 & $5.18 \%$ & 0.74 & 0.6415 & $71.03 \%$ \\
\hline Aerospace/Defense & 92 & 1.33 & $20.50 \%$ & $13.51 \%$ & 1.13 & $5.53 \%$ & 1.20 & 0.4706 & $46.90 \%$ \\
\hline Air Transport & 20 & 1.27 & $69.78 \%$ & $18.34 \%$ & 0.81 & $4.42 \%$ & 0.85 & 0.4583 & $51.95 \%$ \\
\hline Apparel & 63 & 1.06 & $27.86 \%$ & $13.84 \%$ & 0.85 & $3.43 \%$ & 0.88 & 0.5264 & $60.62 \%$ \\
\hline Auto \& Truck & 19 & 0.96 & $128.04 \%$ & $8.01 \%$ & 0.44 & $6.94 \%$ & 0.47 & 0.5315 & $33.71 \%$ \\
\hline Auto Parts & 65 & 1.29 & $32.91 \%$ & $9.64 \%$ & 0.99 & $8.65 \%$ & 1.08 & 0.5060 & $55.06 \%$ \\
\hline Bank (Money Center) & 9 & 1.11 & $216.41 \%$ & $25.82 \%$ & 0.43 & $9.98 \%$ & 0.47 & 0.1576 & $32.77 \%$ \\
\hline Banks (Regional) & 644 & 0.51 & $78.59 \%$ & $24.11 \%$ & 0.32 & $11.86 \%$ & 0.36 & 0.1768 & $28.93 \%$ \\
\hline Beverage (Alcoholic) & 22 & 0.94 & $18.25 \%$ & $11.28 \%$ & 0.81 & $1.29 \%$ & 0.82 & 0.5431 & $58.51 \%$ \\
\hline Beverage (Soft) & 43 & 1.15 & $22.98 \%$ & $5.97 \%$ & 0.95 & $4.20 \%$ & 0.99 & 0.6125 & $54.55 \%$ \\
\hline Broadcasting & 29 & 1.29 & $94.73 \%$ & $21.20 \%$ & 0.74 & $1.90 \%$ & 0.75 & 0.4036 & $47.22 \%$ \\
\hline Brokerage \& Investment Banking & 42 & 1.35 & $285.54 \%$ & $18.15 \%$ & 0.40 & $11.33 \%$ & 0.46 & 0.3991 & $48.05 \%$ \\
\hline Building Materials & 39 & 1.18 & $33.15 \%$ & $22.43 \%$ & 0.94 & $4.47 \%$ & 0.98 & 0.3619 & $44.27 \%$ \\
\hline Business \& Consumer Services & 159 & 1.19 & $35.33 \%$ & $13.76 \%$ & 0.91 & $4.04 \%$ & 0.95 & 0.5041 & $50.13 \%$ \\
\hline Cable TV & 19 & 1.23 & $49.61 \%$ & $17.19 \%$ & 0.87 & $1.41 \%$ & 0.89 & 0.4384 & $41.58 \%$ \\
\hline Chemical (Basic) & 42 & 1.17 & $61.95 \%$ & $8.24 \%$ & 0.74 & $7.73 \%$ & 0.81 & 0.5278 & $54.20 \%$ \\
\hline
\end{tabular}




\begin{tabular}{|c|c|c|c|c|c|c|c|c|c|}
\hline Chemical (Diversified) & 9 & 1.55 & $38.27 \%$ & $18.35 \%$ & 1.18 & $6.35 \%$ & 1.27 & 0.4231 & $40.56 \%$ \\
\hline Chemical (Specialty) & 104 & 1.25 & $31.38 \%$ & $8.45 \%$ & 0.97 & $4.49 \%$ & 1.01 & 0.4718 & $50.43 \%$ \\
\hline Coal \& Related Energy & 38 & 1.49 & $312.08 \%$ & $0.95 \%$ & 0.36 & $6.03 \%$ & 0.39 & 0.7400 & $86.78 \%$ \\
\hline Computer Services & 118 & 1.17 & $28.87 \%$ & $12.84 \%$ & 0.94 & $6.44 \%$ & 1.00 & 0.5040 & $51.74 \%$ \\
\hline Computers/Peripherals & 64 & 1.33 & $18.65 \%$ & $5.48 \%$ & 1.13 & $7.38 \%$ & 1.22 & 0.4964 & $63.91 \%$ \\
\hline Construction Supplies & 52 & 1.65 & $59.08 \%$ & $17.00 \%$ & 1.11 & $6.14 \%$ & 1.18 & 0.4072 & $42.41 \%$ \\
\hline Diversified & 26 & 1.01 & $55.72 \%$ & $15.20 \%$ & 0.68 & $6.92 \%$ & 0.74 & 0.3935 & $27.37 \%$ \\
\hline Drugs (Biotechnology) & 411 & 1.28 & $14.29 \%$ & $1.80 \%$ & 1.12 & $5.92 \%$ & 1.19 & 0.5788 & $88.89 \%$ \\
\hline Drugs (Pharmaceutical) & 157 & 1.02 & $13.01 \%$ & $3.90 \%$ & 0.90 & $3.71 \%$ & 0.94 & 0.5688 & $77.30 \%$ \\
\hline Education & 40 & 1.05 & $46.24 \%$ & $12.05 \%$ & 0.75 & $12.90 \%$ & 0.86 & 0.5333 & $59.62 \%$ \\
\hline Electrical Equipment & 120 & 1.15 & $21.91 \%$ & $6.58 \%$ & 0.95 & $7.40 \%$ & 1.03 & 0.6246 & $71.04 \%$ \\
\hline Electronics (Consumer \& Office) & 25 & 1.23 & $14.81 \%$ & $9.71 \%$ & 1.09 & $6.76 \%$ & 1.16 & 0.5600 & $63.42 \%$ \\
\hline Electronics (General) & 167 & 1.03 & $19.79 \%$ & $9.47 \%$ & 0.87 & $11.28 \%$ & 0.98 & 0.4592 & $59.34 \%$ \\
\hline Engineering/Construction & 51 & 1.32 & $41.91 \%$ & $11.63 \%$ & 0.96 & $9.84 \%$ & 1.07 & 0.5027 & $57.02 \%$ \\
\hline Entertainment & 84 & 1.21 & $29.94 \%$ & $3.25 \%$ & 0.94 & $3.85 \%$ & 0.98 & 0.6763 & $63.16 \%$ \\
\hline Environmental \& Waste Services & 97 & 1.10 & $38.80 \%$ & $7.49 \%$ & 0.81 & $1.09 \%$ & 0.82 & 0.6108 & $65.51 \%$ \\
\hline Farming/Agriculture & 37 & 1.25 & $75.73 \%$ & $9.28 \%$ & 0.74 & $4.30 \%$ & 0.77 & 0.5456 & $48.69 \%$ \\
\hline Financial Svcs. (Non-bank \& Insurance) & 272 & 0.65 & $1338.71 \%$ & $18.75 \%$ & 0.05 & $2.25 \%$ & 0.06 & 0.2686 & $34.97 \%$ \\
\hline Food Processing & 89 & 0.89 & $26.16 \%$ & $14.09 \%$ & $\mathbf{0 . 7 2}$ & $2.46 \%$ & 0.74 & 0.4237 & $38.29 \%$ \\
\hline Food Wholesalers & 14 & 0.73 & $24.97 \%$ & $15.85 \%$ & 0.60 & $1.25 \%$ & 0.61 & 0.4020 & $54.49 \%$ \\
\hline Furn/Home Furnishings & 30 & 1.23 & $30.94 \%$ & $15.53 \%$ & 0.98 & $2.81 \%$ & 1.00 & 0.4213 & $44.49 \%$ \\
\hline Green \& Renewable Energy & 28 & 1.62 & $132.92 \%$ & $0.77 \%$ & 0.70 & $16.85 \%$ & 0.84 & 0.6692 & $62.36 \%$ \\
\hline Healthcare Products & 254 & 1.03 & $19.50 \%$ & $6.42 \%$ & 0.87 & $5.32 \%$ & 0.92 & 0.4977 & $62.16 \%$ \\
\hline Healthcare Support Services & 127 & 1.05 & $28.62 \%$ & $13.84 \%$ & 0.84 & $5.45 \%$ & 0.89 & 0.5328 & $54.32 \%$ \\
\hline Heathcare Information and Technology & 126 & 1.11 & $17.70 \%$ & $6.96 \%$ & 0.95 & $3.45 \%$ & 0.99 & 0.5641 & $60.52 \%$ \\
\hline Homebuilding & 34 & 1.12 & $60.86 \%$ & $21.79 \%$ & 0.76 & $6.20 \%$ & 0.81 & 0.3352 & $41.71 \%$ \\
\hline Hospitals/Healthcare Facilities & 58 & 0.82 & $98.46 \%$ & $10.41 \%$ & 0.44 & $1.35 \%$ & 0.44 & 0.3952 & $36.49 \%$ \\
\hline
\end{tabular}




\begin{tabular}{|c|c|c|c|c|c|c|c|c|c|}
\hline Hotel/Gaming & 73 & 0.97 & $55.41 \%$ & $11.34 \%$ & 0.65 & $4.09 \%$ & 0.68 & 0.4214 & $46.75 \%$ \\
\hline Household Products & 134 & 1.05 & $20.02 \%$ & $8.86 \%$ & 0.89 & $3.21 \%$ & 0.91 & 0.5864 & $62.02 \%$ \\
\hline Information Services & 70 & 1.00 & $15.52 \%$ & $16.46 \%$ & 0.89 & $3.49 \%$ & 0.92 & 0.3596 & $40.74 \%$ \\
\hline Insurance (General) & 20 & 1.04 & $42.76 \%$ & $21.73 \%$ & 0.78 & $4.76 \%$ & 0.82 & 0.2247 & $33.57 \%$ \\
\hline Insurance (Life) & 25 & 1.28 & $79.07 \%$ & $20.29 \%$ & 0.79 & $13.57 \%$ & 0.91 & 0.2733 & $35.59 \%$ \\
\hline Insurance (Prop/Cas.) & 53 & 0.90 & $31.39 \%$ & $21.85 \%$ & 0.72 & $4.55 \%$ & 0.75 & 0.2212 & $32.93 \%$ \\
\hline Investments \& Asset Management & 145 & 1.17 & $76.37 \%$ & $7.90 \%$ & 0.69 & $14.65 \%$ & 0.81 & 0.3926 & $37.84 \%$ \\
\hline Machinery & 130 & 1.44 & $27.57 \%$ & $15.24 \%$ & 1.16 & $5.33 \%$ & 1.23 & 0.4385 & $46.07 \%$ \\
\hline Metals \& Mining & 114 & 1.55 & $85.76 \%$ & $1.42 \%$ & 0.84 & $3.63 \%$ & 0.87 & 0.7487 & $91.02 \%$ \\
\hline Office Equipment \& Services & 24 & 1.82 & $60.56 \%$ & $19.14 \%$ & 1.22 & $5.83 \%$ & 1.29 & 0.3991 & $41.58 \%$ \\
\hline Oil/Gas (Integrated) & 7 & 1.54 & $16.50 \%$ & $8.14 \%$ & 1.33 & $3.11 \%$ & 1.38 & 0.5230 & $50.24 \%$ \\
\hline Oil/Gas (Production and Exploration) & 351 & 1.63 & $82.48 \%$ & $2.91 \%$ & 0.91 & $4.47 \%$ & 0.95 & 0.6976 & $80.22 \%$ \\
\hline Oil/Gas Distribution & 79 & 1.22 & $94.36 \%$ & $5.60 \%$ & 0.65 & $1.00 \%$ & 0.65 & 0.4387 & $47.82 \%$ \\
\hline Oilfield Svcs/Equip. & 143 & 1.74 & $39.08 \%$ & $9.56 \%$ & 1.29 & $8.72 \%$ & 1.41 & 0.5552 & $69.62 \%$ \\
\hline Packaging \& Container & 25 & 1.26 & $54.73 \%$ & $21.41 \%$ & 0.88 & $2.57 \%$ & 0.91 & 0.3542 & $32.10 \%$ \\
\hline Paper/Forest Products & 20 & 1.52 & $89.06 \%$ & $15.88 \%$ & 0.87 & $3.02 \%$ & 0.89 & 0.3852 & $38.53 \%$ \\
\hline Power & 73 & 0.80 & $83.44 \%$ & $23.38 \%$ & 0.49 & $2.51 \%$ & 0.50 & 0.2607 & $29.31 \%$ \\
\hline Precious Metals & 113 & 1.29 & $50.03 \%$ & $1.60 \%$ & 0.87 & $16.27 \%$ & 1.03 & 0.7030 & $93.13 \%$ \\
\hline Publshing \& Newspapers & 39 & 1.45 & $49.57 \%$ & $13.67 \%$ & 1.01 & $5.28 \%$ & 1.07 & 0.4452 & $51.60 \%$ \\
\hline R.E.I.T. & 221 & 0.76 & $89.81 \%$ & $2.17 \%$ & 0.41 & $1.44 \%$ & 0.41 & 0.2171 & $25.71 \%$ \\
\hline Real Estate (Development) & 21 & 1.41 & $62.89 \%$ & $1.06 \%$ & 0.87 & $6.72 \%$ & 0.93 & 0.5535 & $36.15 \%$ \\
\hline Real Estate (General/Diversified) & 12 & 1.22 & $25.47 \%$ & $9.64 \%$ & 0.99 & $3.68 \%$ & 1.03 & 0.3518 & $40.76 \%$ \\
\hline Real Estate (Operations \& Services) & 55 & 1.50 & $64.54 \%$ & $11.19 \%$ & 0.95 & $4.19 \%$ & 0.99 & 0.5382 & $43.44 \%$ \\
\hline Recreation & 65 & 0.91 & $31.61 \%$ & $11.33 \%$ & 0.71 & $4.48 \%$ & 0.75 & 0.4801 & $45.47 \%$ \\
\hline Reinsurance & 3 & 1.03 & $39.48 \%$ & $20.37 \%$ & 0.78 & $12.27 \%$ & 0.89 & 0.1255 & $29.15 \%$ \\
\hline Restaurant/Dining & 83 & 0.76 & $25.85 \%$ & $18.54 \%$ & 0.63 & $2.12 \%$ & 0.64 & 0.4150 & $40.67 \%$ \\
\hline Retail (Automotive) & 26 & 1.06 & $53.16 \%$ & $21.18 \%$ & 0.75 & $1.05 \%$ & 0.76 & 0.3211 & $46.34 \%$ \\
\hline
\end{tabular}




\begin{tabular}{|c|c|c|c|c|c|c|c|c|c|}
\hline Retail (Building Supply) & 5 & 1.47 & $18.73 \%$ & $23.18 \%$ & 1.29 & $1.52 \%$ & 1.31 & 0.3598 & $50.34 \%$ \\
\hline Retail (Distributors) & 83 & 1.22 & $60.34 \%$ & $16.42 \%$ & 0.81 & $1.85 \%$ & 0.83 & 0.5010 & $52.36 \%$ \\
\hline Retail (General) & 19 & 1.16 & $39.49 \%$ & $24.75 \%$ & 0.90 & $3.12 \%$ & 0.92 & 0.2935 & $46.87 \%$ \\
\hline Retail (Grocery and Food) & 17 & 1.04 & $46.89 \%$ & $23.56 \%$ & 0.76 & $1.23 \%$ & 0.77 & 0.3836 & $51.57 \%$ \\
\hline Retail (Online) & 39 & 1.58 & $8.49 \%$ & $11.14 \%$ & 1.46 & $4.03 \%$ & 1.53 & 0.5392 & $50.54 \%$ \\
\hline Retail (Special Lines) & 124 & 1.07 & $46.68 \%$ & $19.95 \%$ & 0.78 & $3.47 \%$ & 0.81 & 0.4567 & $50.69 \%$ \\
\hline Rubber\& Tires & 4 & 1.66 & $65.26 \%$ & $9.60 \%$ & 1.04 & $11.26 \%$ & 1.18 & 0.5027 & $38.00 \%$ \\
\hline Semiconductor & 87 & 1.39 & $12.57 \%$ & $9.51 \%$ & 1.24 & $5.50 \%$ & 1.32 & 0.4118 & $51.24 \%$ \\
\hline Semiconductor Equip & 46 & 1.40 & $37.57 \%$ & $11.25 \%$ & 1.05 & $14.27 \%$ & 1.22 & 0.4048 & $54.21 \%$ \\
\hline Shipbuilding \& Marine & 11 & 1.24 & $56.95 \%$ & $11.82 \%$ & 0.83 & $1.76 \%$ & 0.84 & 0.4948 & $60.89 \%$ \\
\hline Shoe & 11 & 0.82 & $6.79 \%$ & $18.12 \%$ & 0.78 & $3.85 \%$ & 0.81 & 0.4392 & $39.02 \%$ \\
\hline Software (Entertainment) & 17 & 1.42 & $10.23 \%$ & $1.56 \%$ & 1.29 & $12.11 \%$ & 1.46 & 0.5959 & $54.18 \%$ \\
\hline Software (Internet) & 308 & 1.34 & $4.43 \%$ & $3.80 \%$ & 1.28 & $3.29 \%$ & 1.33 & 0.6266 & $64.71 \%$ \\
\hline Software (System \& Application) & 241 & 1.33 & $12.18 \%$ & $6.34 \%$ & 1.19 & $4.43 \%$ & 1.25 & 0.5048 & $59.22 \%$ \\
\hline Steel & 36 & 1.43 & $91.75 \%$ & $11.49 \%$ & 0.79 & $8.70 \%$ & 0.86 & 0.4502 & $51.52 \%$ \\
\hline Telecom (Wireless) & 19 & 1.48 & $150.55 \%$ & $9.38 \%$ & 0.62 & $4.01 \%$ & 0.65 & 0.5072 & $45.11 \%$ \\
\hline Telecom. Equipment & 121 & 1.29 & $20.72 \%$ & $8.86 \%$ & 1.09 & $6.98 \%$ & 1.17 & 0.4771 & $57.78 \%$ \\
\hline Telecom. Services & 65 & 0.95 & $78.10 \%$ & $11.89 \%$ & 0.56 & $1.77 \%$ & 0.57 & 0.4742 & $52.25 \%$ \\
\hline Tobacco & 20 & 1.91 & $19.84 \%$ & $11.64 \%$ & 1.63 & $2.01 \%$ & 1.66 & 0.6963 & $48.90 \%$ \\
\hline Transportation & 21 & 1.41 & $31.12 \%$ & $18.82 \%$ & 1.13 & $5.19 \%$ & 1.19 & 0.3969 & $40.03 \%$ \\
\hline Transportation (Railroads) & 12 & 1.15 & $30.49 \%$ & $15.11 \%$ & 0.92 & $1.31 \%$ & 0.93 & 0.4147 & $31.20 \%$ \\
\hline Trucking & 26 & 1.69 & $101.22 \%$ & $31.25 \%$ & 1.00 & $3.04 \%$ & 1.03 & 0.4031 & $43.08 \%$ \\
\hline Unclassified & 3 & 0.23 & $100.42 \%$ & $0.00 \%$ & 0.11 & $0.35 \%$ & 0.11 & 0.4300 & $24.61 \%$ \\
\hline Utility (General) & 20 & 0.55 & $70.51 \%$ & $26.58 \%$ & 0.36 & $0.65 \%$ & 0.36 & 0.1581 & $25.03 \%$ \\
\hline Utility (Water) & 18 & 0.47 & $49.00 \%$ & $14.60 \%$ & 0.33 & $0.70 \%$ & 0.33 & 0.3123 & $36.78 \%$ \\
\hline Total Market & 7480 & 1.13 & $71.49 \%$ & $10.95 \%$ & 0.69 & $4.81 \%$ & 0.73 & 0.4681 & $51.65 \%$ \\
\hline
\end{tabular}

Nota: DAMODARAN, Aswath. Betas by setor (en línea). US, 2016. (Citado 15 de Junio 2016). Excel. Recuperado de:

http://www.stern.nyu.edu/ adamodar/pc/datasets/histretSP.xls. 
Anexo 14: RIESGO DE MERCADO

\begin{tabular}{|l|l|l|}
\hline Date updated: & 31-dic-11 \\
\hline Created by: & Aswath Damodaran, adamodar@stern.nyu.edu & \multicolumn{2}{l|}{$\begin{array}{l}\text { Historical returns: Stocks, T.Bonds \& T.Bills } \\
\text { with premiums }\end{array}$} & US companies \\
\hline What is this data? & $\underline{\text { http://www.damodaran.com }}$ \\
\hline Home Page: & $\underline{\text { http://www.stern.nyu.edu/ adamodar/New_Home_Page/data.html }}$ \\
\hline Data website: & $\underline{\text { http://www.stern.nyu.edu/ adamodar/pc/datasets/indname.xls }}$ \\
\hline $\begin{array}{l}\text { Companies in each } \\
\text { industry: }\end{array}$ & $\underline{\text { http://www.stern.nyu.edu/ adamodar/New_Home_Page/datafile/variable.h }}$ \\
\hline Variable definitions: & \\
\hline
\end{tabular}

Customized Geometric risk premium estimator

What is your riskfree rate?

Enter your starting year

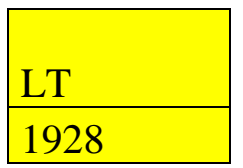

Value of stocks in starting

year:

Value of T.Bills in starting

year:

Value of T.bonds in starting

year:

Estimate of risk premium based on your

inputs:
Estimates of risk premiums from 1928, over the last 50 years and over the last 10 years

are provided at the bottom of this table.

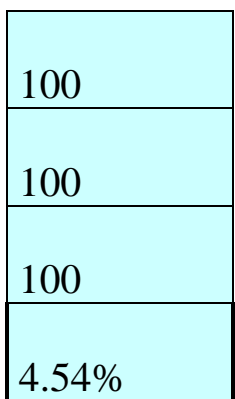

INVESTING, Rentabilidad-Bono de EEUU a 10 años. (en línea). US, 2016. (citado 15 de Junio 2016). Recuperado en: httlles.investing.com/rates-bonds/us.-10-year-bond-yield-historical-data 


\begin{tabular}{|c|c|c|c|c|c|c|c|c|c|}
\hline \multirow[b]{2}{*}{ Year } & \multicolumn{3}{|c|}{ Annual Returns on Investments in } & \multicolumn{3}{|c|}{ Compounded Value of $\$ 100$} & \multirow[b]{2}{*}{$\begin{array}{l}\text { Stocks - } \\
\text { Bills }\end{array}$} & \multirow[b]{2}{*}{ Stocks - Bonds } & \multirow[b]{2}{*}{\begin{tabular}{|l} 
Historical \\
risk \\
premium
\end{tabular}} \\
\hline & $S \& P 500$ & $\begin{array}{l}\text { 3-month } \\
\text { T.Bill }\end{array}$ & 10-year T. Bond & Stocks & T.Bills & T.Bonds & & & \\
\hline 1928 & $43.81 \%$ & $3.08 \%$ & $0.84 \%$ & $\$ 143.81$ & $\$ \quad 103.08$ & $\$ \quad 100.84$ & $40.73 \%$ & $42.98 \%$ & \\
\hline 1929 & $-8.30 \%$ & $3.16 \%$ & $4.20 \%$ & $\$ \quad 131.88$ & $\$ 106.34$ & $\$ 105.07$ & $-11.46 \%$ & $-12.50 \%$ & \\
\hline 1930 & $-25.12 \%$ & $4.55 \%$ & $4.54 \%$ & $\$ 98.75$ & $\$ 111.18$ & $\$ 109.85$ & $-29.67 \%$ & $-29.66 \%$ & \\
\hline 1931 & $-43.84 \%$ & $2.31 \%$ & $-2.56 \%$ & $\$ 55.46$ & $\$ 113.74$ & $\$ 107.03$ & $-46.15 \%$ & $-41.28 \%$ & \\
\hline 1932 & $-8.64 \%$ & $1.07 \%$ & $8.79 \%$ & $\$ 50.66$ & $\$ 114.96$ & $\$ 116.44$ & $-9.71 \%$ & $-17.43 \%$ & \\
\hline 1933 & $49.98 \%$ & $0.96 \%$ & $1.86 \%$ & $\$ 75.99$ & $\$ 116.06$ & $\$ 118.60$ & $49.02 \%$ & $48.13 \%$ & \\
\hline 1934 & $-1.19 \%$ & $0.32 \%$ & $7.96 \%$ & $\$ 75.09$ & $\$ 116.44$ & $\$ 128.05$ & $-1.51 \%$ & $-9.15 \%$ & \\
\hline 1935 & $46.74 \%$ & $0.18 \%$ & $4.47 \%$ & $\$ 110.18$ & $\$ 116.64$ & $\$ 133.78$ & $46.57 \%$ & $42.27 \%$ & \\
\hline 1936 & $31.94 \%$ & $0.17 \%$ & $5.02 \%$ & $\$ 145.38$ & $\$ 116.84$ & $\$ 140.49$ & $31.77 \%$ & $26.93 \%$ & \\
\hline 1937 & $-35.34 \%$ & $0.30 \%$ & $1.38 \%$ & $\$ 94.00$ & $\$ 117.19$ & $\$ 142.43$ & $-35.64 \%$ & $-36.72 \%$ & \\
\hline 1938 & $29.28 \%$ & $0.08 \%$ & $4.21 \%$ & $\$ 121.53$ & $\$ 117.29$ & $\$ 148.43$ & $29.21 \%$ & $25.07 \%$ & \\
\hline 1939 & $-1.10 \%$ & $0.04 \%$ & $4.41 \%$ & $\$ 120.20$ & $\$ 117.33$ & $\$ 154.98$ & $-1.14 \%$ & $-5.51 \%$ & \\
\hline 1940 & $-10.67 \%$ & $0.03 \%$ & $5.40 \%$ & $\$ 107.37$ & $\$ 117.36$ & $\$ 163.35$ & $-10.70 \%$ & $-16.08 \%$ & \\
\hline 1941 & $-12.77 \%$ & $0.08 \%$ & $-2.02 \%$ & $\$ 93.66$ & $\$ 117.46$ & $\$ 160.04$ & $-12.85 \%$ & $-10.75 \%$ & \\
\hline 1942 & $19.17 \%$ & $0.34 \%$ & $2.29 \%$ & $\$ 111.61$ & $\$ 117.85$ & $\$ 163.72$ & $18.84 \%$ & $16.88 \%$ & \\
\hline 1943 & $25.06 \%$ & $0.38 \%$ & $2.49 \%$ & $\$ 139.59$ & $\$ 118.30$ & $\$ 167.79$ & $24.68 \%$ & $22.57 \%$ & \\
\hline 1944 & $19.03 \%$ & $0.38 \%$ & $2.58 \%$ & $\$ 166.15$ & $\$ 118.75$ & $\$ 172.12$ & $18.65 \%$ & $16.45 \%$ & \\
\hline 1945 & $35.82 \%$ & $0.38 \%$ & $3.80 \%$ & $\$ 225.67$ & $\$ 119.20$ & $\$ 178.67$ & $35.44 \%$ & $32.02 \%$ & \\
\hline 1946 & $-8.43 \%$ & $0.38 \%$ & $3.13 \%$ & $\$ 206.65$ & $\$ 119.65$ & $\$ 184.26$ & $-8.81 \%$ & $-11.56 \%$ & \\
\hline 1947 & $5.20 \%$ & $0.57 \%$ & $0.92 \%$ & $\$ 217.39$ & $\$ 120.33$ & $\$ 185.95$ & $4.63 \%$ & $4.28 \%$ & \\
\hline 1948 & $5.70 \%$ & $1.02 \%$ & $1.95 \%$ & $\$ 229.79$ & $\$ 121.56$ & $\$ 189.58$ & $4.68 \%$ & $3.75 \%$ & \\
\hline 1949 & $18.30 \%$ & $1.10 \%$ & $4.66 \%$ & $\$ 271.85$ & $\$ 122.90$ & $\$ 198.42$ & $17.20 \%$ & $13.64 \%$ & \\
\hline 1950 & $30.81 \%$ & $1.17 \%$ & $0.43 \%$ & $\$ 355.60$ & $\$ 124.34$ & $\$ 199.27$ & $29.63 \%$ & $30.38 \%$ & \\
\hline 1951 & $23.68 \%$ & $1.48 \%$ & $-0.30 \%$ & $\$ 439.80$ & $\$ 126.18$ & $\$ 198.68$ & $22.20 \%$ & $23.97 \%$ & \\
\hline
\end{tabular}




\begin{tabular}{|c|c|c|c|c|c|c|c|c|c|}
\hline 1952 & $18.15 \%$ & $1.67 \%$ & $2.27 \%$ & $\$ 519.62$ & $\$ 128.29$ & $\$ 203.19$ & $16.48 \%$ & $15.88 \%$ & \\
\hline 1953 & $-1.21 \%$ & $1.89 \%$ & $4.14 \%$ & $\$ 513.35$ & $\$ 130.72$ & $\$ 211.61$ & $-3.10 \%$ & $-5.35 \%$ & \\
\hline 1954 & $52.56 \%$ & $0.96 \%$ & $3.29 \%$ & $\$ 783.18$ & $\$ 131.98$ & $\$ 218.57$ & $51.60 \%$ & $49.27 \%$ & \\
\hline 1955 & $32.60 \%$ & $1.66 \%$ & $-1.34 \%$ & $\$ 1,038.47$ & $\$ 134.17$ & $\$ 215.65$ & $30.94 \%$ & $33.93 \%$ & \\
\hline 1956 & $7.44 \%$ & $2.56 \%$ & $-2.26 \%$ & $\$ 1,115.73$ & $\$ 137.60$ & $\$ 210.79$ & $4.88 \%$ & $9.70 \%$ & \\
\hline 1957 & $-10.46 \%$ & $3.23 \%$ & $6.80 \%$ & $\$ 999.05$ & $\$ 142.04$ & $\$ 225.11$ & $-13.69 \%$ & $-17.25 \%$ & \\
\hline 1958 & $43.72 \%$ & $1.78 \%$ & $-2.10 \%$ & $\$ 1,435.84$ & $\$ 144.57$ & $\$ 220.39$ & $41.94 \%$ & $45.82 \%$ & \\
\hline 1959 & $12.06 \%$ & $3.26 \%$ & $-2.65 \%$ & $\$ 1,608.95$ & $\$ 149.27$ & $\$ 214.56$ & $8.80 \%$ & $14.70 \%$ & \\
\hline 1960 & $0.34 \%$ & $3.05 \%$ & $11.64 \%$ & $\$ 1,614.37$ & $\$ 153.82$ & $\$ 239.53$ & $-2.71 \%$ & $-11.30 \%$ & $6.11 \%$ \\
\hline 1961 & $26.64 \%$ & $2.27 \%$ & $2.06 \%$ & $\$ 2,044.40$ & $\$ 157.30$ & $\$ 244.46$ & $24.37 \%$ & $24.58 \%$ & $6.62 \%$ \\
\hline 1962 & $-8.81 \%$ & $2.78 \%$ & $5.69 \%$ & $\$ 1,864.26$ & $\$ 161.67$ & $\$ 258.38$ & $-11.59 \%$ & $-14.51 \%$ & $5.97 \%$ \\
\hline 1963 & $22.61 \%$ & $3.11 \%$ & $1.68 \%$ & $\$ 2,285.80$ & $\$ 166.70$ & $\$ 262.74$ & $19.50 \%$ & $20.93 \%$ & $6.36 \%$ \\
\hline 1964 & $16.42 \%$ & $3.51 \%$ & $3.73 \%$ & $\$ 2,661.02$ & $\$ 172.54$ & $\$ 272.53$ & $12.91 \%$ & $12.69 \%$ & $6.53 \%$ \\
\hline 1965 & $12.40 \%$ & $3.90 \%$ & $0.72 \%$ & $\$ 2,990.97$ & $\$ 179.28$ & $\$ 274.49$ & $8.50 \%$ & $11.68 \%$ & $6.66 \%$ \\
\hline 1966 & $-9.97 \%$ & $4.84 \%$ & $2.91 \%$ & $\$ 2,692.74$ & $\$ 187.95$ & $\$ 282.47$ & $-14.81 \%$ & $-12.88 \%$ & $6.11 \%$ \\
\hline 1967 & $23.80 \%$ & $4.33 \%$ & $-1.58 \%$ & $\$ 3,333.69$ & $\$ 196.10$ & $\$ 278.01$ & $19.47 \%$ & $25.38 \%$ & $6.57 \%$ \\
\hline 1968 & $10.81 \%$ & $5.26 \%$ & $3.27 \%$ & $\$ 3,694.23$ & $\$ 206.41$ & $\$ 287.11$ & $5.55 \%$ & $7.54 \%$ & $6.60 \%$ \\
\hline 1969 & $-8.24 \%$ & $6.56 \%$ & $-5.01 \%$ & $\$ 3,389.77$ & $\$ 219.96$ & $\$ 272.71$ & $-14.80 \%$ & $-3.23 \%$ & $6.33 \%$ \\
\hline 1970 & $3.56 \%$ & $6.69 \%$ & $16.75 \%$ & $\$ 3,510.49$ & $\$ 234.66$ & $\$ 318.41$ & $-3.12 \%$ & $-13.19 \%$ & $5.90 \%$ \\
\hline 1971 & $14.22 \%$ & $4.54 \%$ & $9.79 \%$ & $\$ 4,009.72$ & $\$ 245.32$ & $\$ 349.57$ & $9.68 \%$ & $4.43 \%$ & $5.87 \%$ \\
\hline 1972 & $18.76 \%$ & $3.95 \%$ & $2.82 \%$ & $\$ 4,761.76$ & $\$ 255.01$ & $\$ 359.42$ & $14.80 \%$ & $15.94 \%$ & $6.08 \%$ \\
\hline 1973 & $-14.31 \%$ & $6.73 \%$ & $3.66 \%$ & $\$ 4,080.44$ & $\$ 272.16$ & $\$ 372.57$ & $-21.03 \%$ & $-17.97 \%$ & $5.50 \%$ \\
\hline 1974 & $-25.90 \%$ & $7.78 \%$ & $1.99 \%$ & $\$ 3,023.54$ & $\$ 293.33$ & $\$ 379.98$ & $-33.68 \%$ & $-27.89 \%$ & $4.64 \%$ \\
\hline 1975 & $37.00 \%$ & $5.99 \%$ & $3.61 \%$ & $\$ 4,142.10$ & $\$ 310.90$ & $\$ 393.68$ & $31.01 \%$ & $33.39 \%$ & $5.17 \%$ \\
\hline 1976 & $23.83 \%$ & $4.97 \%$ & $15.98 \%$ & $\$ 5,129.20$ & $\$ 326.35$ & $\$ 456.61$ & $18.86 \%$ & $7.85 \%$ & $5.22 \%$ \\
\hline 1977 & $-6.98 \%$ & $5.13 \%$ & $1.29 \%$ & $\$ 4,771.20$ & $\$ 343.09$ & $\$ 462.50$ & $-12.11 \%$ & $-8.27 \%$ & $4.93 \%$ \\
\hline 1978 & $6.51 \%$ & $6.93 \%$ & $-0.78 \%$ & $\$ 5,081.77$ & $\$ 366.87$ & $\$ 458.90$ & $-0.42 \%$ & $7.29 \%$ & $4.97 \%$ \\
\hline
\end{tabular}




\begin{tabular}{|c|c|c|c|c|c|c|c|c|c|}
\hline 1979 & $18.52 \%$ & $9.94 \%$ & $0.67 \%$ & $\$ 6,022.89$ & $\$ 403.33$ & $\$ 461.98$ & $8.58 \%$ & $17.85 \%$ & $5.21 \%$ \\
\hline 1980 & $31.74 \%$ & $11.22 \%$ & $-2.99 \%$ & $\$ 7,934.26$ & $\$ 448.58$ & $\$ 448.17$ & $20.52 \%$ & $34.72 \%$ & $5.73 \%$ \\
\hline 1981 & $-4.70 \%$ & $14.30 \%$ & $8.20 \%$ & $\$ 7,561.16$ & $\$ 512.73$ & $\$ 484.91$ & $-19.00 \%$ & $-12.90 \%$ & $5.37 \%$ \\
\hline 1982 & $20.42 \%$ & $11.01 \%$ & $32.81 \%$ & $\$ 9,105.08$ & $\$ 569.18$ & $\$ 644.04$ & $9.41 \%$ & $-12.40 \%$ & $5.10 \%$ \\
\hline 1983 & $22.34 \%$ & $8.45 \%$ & $3.20 \%$ & $\$ 11,138.90$ & $\$ 617.26$ & $\$ 664.65$ & $13.89 \%$ & $19.14 \%$ & $5.34 \%$ \\
\hline 1984 & $6.15 \%$ & $9.61 \%$ & $13.73 \%$ & $\$ 11,823.51$ & $\$ 676.60$ & $\$ 755.92$ & $-3.47 \%$ & $-7.59 \%$ & $5.12 \%$ \\
\hline 1985 & $31.24 \%$ & $7.49 \%$ & $25.71 \%$ & $\$ 15,516.60$ & $\$ 727.26$ & $\$ \quad 950.29$ & $23.75 \%$ & $5.52 \%$ & $5.13 \%$ \\
\hline 1986 & $18.49 \%$ & $6.04 \%$ & $24.28 \%$ & $\$ 18,386.33$ & $\$ 771.15$ & $\$ 1,181.06$ & $12.46 \%$ & $-5.79 \%$ & $4.97 \%$ \\
\hline 1987 & $5.81 \%$ & $5.72 \%$ & $-4.96 \%$ & $\$ 19,455.08$ & $\$ 815.27$ & $\$ 1,122.47$ & $0.09 \%$ & $10.77 \%$ & $5.07 \%$ \\
\hline 1988 & $16.54 \%$ & $6.45 \%$ & $8.22 \%$ & $\$ 22,672.40$ & $\$ 867.86$ & $\$ 1,214.78$ & $10.09 \%$ & $8.31 \%$ & $5.12 \%$ \\
\hline 1989 & $31.48 \%$ & $8.11 \%$ & $17.69 \%$ & $\$ 29,808.58$ & $\$ 938.24$ & $\$ 1,429.72$ & $23.37 \%$ & $13.78 \%$ & $5.24 \%$ \\
\hline 1990 & $-3.06 \%$ & $7.55 \%$ & $6.24 \%$ & $\$ 28,895.11$ & $\$ 1,009.08$ & $\$ 1,518.87$ & $-10.61 \%$ & $-9.30 \%$ & $5.00 \%$ \\
\hline 1991 & $30.23 \%$ & $5.61 \%$ & $15.00 \%$ & $\$ 37,631.51$ & $\$ 1,065.69$ & $\$ 1,746.77$ & $24.62 \%$ & $15.23 \%$ & $5.14 \%$ \\
\hline 1992 & $7.49 \%$ & $3.41 \%$ & $9.36 \%$ & $\$ 40,451.51$ & $\$ 1,101.98$ & $\$ 1,910.30$ & $4.09 \%$ & $-1.87 \%$ & $5.03 \%$ \\
\hline 1993 & $9.97 \%$ & $2.98 \%$ & $14.21 \%$ & $\$ 44,483.33$ & $\$ 1,134.84$ & $\$ 2,181.77$ & $6.98 \%$ & $-4.24 \%$ & $4.90 \%$ \\
\hline 1994 & $1.33 \%$ & $3.99 \%$ & $-8.04 \%$ & $\$ 45,073.14$ & $\$ 1,180.07$ & $\$ 2,006.43$ & $-2.66 \%$ & $9.36 \%$ & $4.97 \%$ \\
\hline 1995 & $37.20 \%$ & $5.52 \%$ & $23.48 \%$ & $\$ 61,838.19$ & $\$ 1,245.15$ & $\$ 2,477.55$ & $31.68 \%$ & $13.71 \%$ & $5.08 \%$ \\
\hline 1996 & $22.68 \%$ & $5.02 \%$ & $1.43 \%$ & $\$ 75,863.69$ & $\$ 1,307.68$ & $\$ 2,512.94$ & $17.66 \%$ & $21.25 \%$ & $5.30 \%$ \\
\hline 1997 & $33.10 \%$ & $5.05 \%$ & $9.94 \%$ & $\$ 100,977.34$ & $\$ 1,373.76$ & $\$ 2,762.71$ & $28.05 \%$ & $23.16 \%$ & $5.53 \%$ \\
\hline 1998 & $28.34 \%$ & $4.73 \%$ & $14.92 \%$ & $\$ 129,592.25$ & $\$ 1,438.70$ & $\$ 3,174.95$ & $23.61 \%$ & $13.42 \%$ & $5.63 \%$ \\
\hline 1999 & $20.89 \%$ & $4.51 \%$ & $-8.25 \%$ & $\$ 156,658.05$ & $\$ 1,503.58$ & $\$ 2,912.88$ & $16.38 \%$ & $29.14 \%$ & $5.96 \%$ \\
\hline 2000 & $-9.03 \%$ & $5.76 \%$ & $16.66 \%$ & $\$ 142,508.98$ & $\$ 1,590.23$ & $\$ 3,398.03$ & $-14.79 \%$ & $-25.69 \%$ & $5.51 \%$ \\
\hline 2001 & $-11.85 \%$ & $3.67 \%$ & $5.57 \%$ & $\$ 125,622.01$ & $\$ 1,648.63$ & $\$ 3,587.37$ & $-15.52 \%$ & $-17.42 \%$ & $5.17 \%$ \\
\hline 2002 & $-21.97 \%$ & $1.66 \%$ & $15.12 \%$ & $\$ 98,027.82$ & $\$ 1,675.96$ & $\$ 4,129.65$ & $-23.62 \%$ & $-37.08 \%$ & $4.53 \%$ \\
\hline 2003 & $28.36 \%$ & $1.03 \%$ & $0.38 \%$ & $\$ 125,824.39$ & $\$ 1,693.22$ & $\$ 4,145.15$ & $27.33 \%$ & $27.98 \%$ & $4.82 \%$ \\
\hline 2004 & $10.74 \%$ & $1.23 \%$ & $4.49 \%$ & $\$ 139,341.42$ & $\$ 1,714.00$ & $\$ 4,331.30$ & $9.52 \%$ & $6.25 \%$ & $4.84 \%$ \\
\hline 2005 & $4.83 \%$ & $3.01 \%$ & $2.87 \%$ & $\$ 146,077.85$ & $\$ 1,765.59$ & $\$ 4,455.50$ & $1.82 \%$ & $1.97 \%$ & $4.80 \%$ \\
\hline
\end{tabular}




\begin{tabular}{|c|c|c|c|c|c|c|c|c|c|}
\hline 2006 & $15.61 \%$ & $4.68 \%$ & $1.96 \%$ & $\$ 168,884.34$ & $\$ 1,848.18$ & $\$ 4,542.87$ & $10.94 \%$ & $13.65 \%$ & $4.91 \%$ \\
\hline 2007 & $5.48 \%$ & $4.64 \%$ & $10.21 \%$ & $\$ 178,147.20$ & $\$ 1,933.98$ & $\$ 5,006.69$ & $0.84 \%$ & $-4.73 \%$ & $4.79 \%$ \\
\hline 2008 & $-36.55 \%$ & $1.59 \%$ & $20.10 \%$ & $\$ 113,030.22$ & $\$ 1,964.64$ & $\$ 6,013.10$ & $-38.14 \%$ & $-56.65 \%$ & $3.88 \%$ \\
\hline 2009 & $25.94 \%$ & $0.14 \%$ & $-11.12 \%$ & $\$ 142,344.87$ & $\$ 1,967.29$ & $\$ 5,344.65$ & $25.80 \%$ & $37.05 \%$ & $4.29 \%$ \\
\hline 2010 & $14.82 \%$ & $0.13 \%$ & $8.46 \%$ & $\$ 163,441.94$ & $\$ 1,969.84$ & $\$ 5,796.96$ & $14.69 \%$ & $6.36 \%$ & $4.31 \%$ \\
\hline 2011 & $2.10 \%$ & $0.03 \%$ & $16.04 \%$ & $\$ 166,871.56$ & $\$ 1,970.44$ & $\$ 6,726.52$ & $2.07 \%$ & $-13.94 \%$ & $4.10 \%$ \\
\hline 2012 & $15.89 \%$ & $0.05 \%$ & $2.97 \%$ & $\$ 193,388.43$ & $\$ 1,971.42$ & $\$ 6,926.40$ & $15.84 \%$ & $12.92 \%$ & $4.20 \%$ \\
\hline 2013 & $32.15 \%$ & $0.07 \%$ & $-9.10 \%$ & $\$ 255,553.31$ & $\$ 1,972.72$ & $\$ 6,295.79$ & $32.08 \%$ & $41.25 \%$ & $4.62 \%$ \\
\hline 2014 & $13.52 \%$ & $0.05 \%$ & $10.75 \%$ & $\$ 290,115.42$ & $\$ 1,973.77$ & $\$ 6,972.34$ & $13.47 \%$ & $2.78 \%$ & $4.60 \%$ \\
\hline 2015 & $1.36 \%$ & $0.21 \%$ & $1.28 \%$ & $\$ 294,060.84$ & $\$ 1,977.91$ & $\$ 7,061.89$ & $1.15 \%$ & $0.08 \%$ & $4.54 \%$ \\
\hline \multirow{2}{*}{\multicolumn{4}{|c|}{ Arithmetic Average }} & \multicolumn{3}{|c|}{ Risk Premium } & \multicolumn{2}{|l|}{ Standard Error } & \\
\hline & & & & & Stocks - T.Bills & Stocks - T.Bonds & Stocks - T.Bills & Stocks - T.Bonds & \\
\hline $1928-2015$ & $11.41 \%$ & $3.49 \%$ & $5.23 \%$ & & $7.92 \%$ & $6.18 \%$ & $2.15 \%$ & $2.29 \%$ & \\
\hline $1966-2015$ & $11.01 \%$ & $4.97 \%$ & $7.12 \%$ & & $6.05 \%$ & $3.89 \%$ & $2.42 \%$ & $2.74 \%$ & \\
\hline 2006-2015 & $9.03 \%$ & $1.16 \%$ & $5.16 \%$ & & $7.87 \%$ & $3.88 \%$ & $6.06 \%$ & $8.66 \%$ & \\
\hline \multirow{2}{*}{\multicolumn{4}{|c|}{ Geometric Average }} & & \multicolumn{2}{|l|}{ Risk Premium } & & & \\
\hline & & & & & Stocks - T.Bills & Stocks - T.Bonds & & & \\
\hline $1928-2015$ & $9.50 \%$ & $3.45 \%$ & $4.96 \%$ & & $6.05 \%$ & $4.54 \%$ & & & \\
\hline $1966-2015$ & $9.61 \%$ & $4.92 \%$ & $6.71 \%$ & & $4.69 \%$ & $2.90 \%$ & & & \\
\hline 2006-2015 & $7.25 \%$ & $1.14 \%$ & $4.71 \%$ & & $6.11 \%$ & $2.53 \%$ & & & \\
\hline
\end{tabular}

INVESTING, S\&P 500 (SPX). (en línea). US, 2016. (citado 15 de Junio 2016). Recuperado en: httplles.investing.com/indices/us-spx500historical-data 


\section{Anexo 15.}

\section{Principales hoteles de Lima}

Esta información es relevante ya que para realizar un planteamiento de hotel 5 estrellas competitivo es necesario conocer la oferta establecida en esta categoría, en el caso de este estudio con la concentración en la ciudad de Lima.

\section{- $\quad$ Swissôtel Lima}

Este establecimiento fue inaugurado en 1966 con el nombre de Hotel El Oro Verde y posteriormente se vendió y fue renombrado como Swissotel.

"Swissôtel Lima está ubicado en el distrito de San Isidro, corazón cultural y financiero de la ciudad, brindando acceso a tiendas exclusivas y a los mejores establecimientos de vida nocturna. El hotel cuenta con 244 lujosas habitaciones distribuidas en 16 pisos, que van desde una Suite Presidencial, Executive Suites, Junior Suites hasta habitaciones Premier. Todas las habitaciones están elegantemente decoradas y alfombradas. Las habitaciones Ejecutivas, incluyendo Junior y Executive Suites, tienen el privilegio de contar con el acceso al Executive Lounge, así como a una sala de reunión privada, y laptops a disposición del huésped” (Hoteles Luxury, Los Mejores Hoteles del Perú, Cenfotur, 2015, pág. 10).

"Swissôtel Lima brinda la mejor infraestructura, comodidad y excelente servicio, que lo posicionan como uno de los mejores hoteles de Lima" (Hoteles Luxury, Los Mejores Hoteles del Perú, Cenfotur, 2015, pág. 10). 
Actualmente Swissôtel Lima pasó de tener 244 a 345 lujosas habitaciones al terminar su programa de expansión en Setiembre del 2015 cuando culminó la construcción de su segunda torre de habitaciones de 18 pisos, con una inversión de 40 millones de dólares. “Además la segunda torre cuenta con salones de eventos con capacidad para 1000 personas en total, la misma capacidad de la primera torre. La nueva infraestructura también cuenta con sótanos para 500 estacionamientos y un moderno spa y cancha de tenis.

\section{- JW Marriott International}

El JW Marriott Hotel Lima, fue inaugurado el mes de Julio del año 2000, pertenece a la cadena norteamericana Marriott Hoteles, ubicado en el distrito de Miraflores, ocupa una manzana y forma parte de un complejo compuesto además por una torre de oficinas y una galería comercial Tiene 24 pisos y todas sus habitaciones tienen una vista privilegiada del mar que baña la costa de Miraflores.

“Marriott International es una corporación líder en la industria hotelera mundial, cuenta con más de 3,200 hoteles alrededor del planeta y más de 150,000 empleados. En nuestro país, JW MARRIOTT HOTEL LIMA se encuentra en el céntrico distrito de Miraflores, en Lima. Es un lugar que ofrece una nueva perspectiva de lujo y un nuevo estándar de servicio. Entre sus características más importantes destaca el exclusivo e impecable servicio, inigualable vista al mar y una privilegiada ubicación" (Hoteles Luxury Peru). (Hoteles Luxury, Los Mejores Hoteles del Perú, Cenfotur, 2015, pág. 12).

"Sus 300 habitaciones finamente decoradas, incluyendo doce suites, disponen de todas las comodidades que un viajero de negocios o placer pueda requerir. Desde ellas, se podrá divisar la belleza del Océano Pacífico y disfrutar de todo en un ambiente grato y elegante. 
Las instalaciones del hotel cuentan con áreas para no fumadores y dispone de pisos ejecutivos con una sala donde el viajero disfrutará de un tranquilo ambiente para conversar o leer”. (Hoteles Luxury, Los Mejores Hoteles del Perú, Cenfotur, 2015, pág. 12).

"Para los que gusten del deporte, el JW Marriott Hotel Lima brinda una piscina al aire libre y el Health Club - Spa, que cuenta con las más modernas máquinas cardiovasculares, aeróbicos y últimos tratamientos corporales. Asimismo, el hotel tiene amplios salones de conferencias equipados con la tecnología más sofisticada, salones para congresos y eventos sociales, salones de directorio y un equipo de trabajo dedicado exclusivamente a preparar los detalles de estos sucesos que se llevan a cabo en sus instalaciones" (Hoteles Luxury, Los Mejores Hoteles del Perú, Cenfotur, 2015, pág. 12).

“Además, el Centro Ejecutivo brinda servicio de computadora, fotocopiadora, faxes y asesoramiento personal para asistir cualquier tipo de consulta. Entre lo más distinguido del Hotel se encuentra la gran variedad de ofertas culinarias, como el restaurante La Vista, con el mejor servicio de buffet y platos a la carta, dispuesto a atender al viajero las 24 horas del día y ofrecerle lo mejor de su cocina. Asimismo, cuenta con el JW Sushi Ceviche Lounge, donde también podrá disfrutar de la más variada selección de piqueos, fusión, música de primera clase en vivo y de una excelente e inolvidable. (Hoteles Luxury, Los Mejores Hoteles del Perú, Cenfotur, 2015, pág. 12).

Con motivo de atender la demanda de alojamiento en los eventos internacionales que se realizan en Lima, desde Octubre 2014 hasta inicios del 2016, el Hotel JW Marriott asumió "una remodelación total de las habitaciones y los pasillos dándoles una tonalidad distinta, pasando de un concepto JW clásico hacia uno más contemporáneo, ya que nuestros 
clientes tienen en promedio de 35 a 50 años y les gusta una elegancia más sofisticada", con una inversión de 7 millones de dólares. (Tnews 09.10.2014)

\section{- $\quad$ Westin Lima Hotel \& Convention Center}

El Westin Lima Hotel \& Convention Center fue inaugurado el 27 de mayo del 2011, siendo el primer hotel Westin en Sudamérica y “el edificio más alto del país, con una altura de 118metros y 30 pisos". El hotel, está dirigido al segmento corporativo, "cuenta con un área de 72,000 m2, 311 habitaciones y un Centro de Convenciones de 7,900 m2 con una capacidad para 2,000 personas", dos restaurantes, 727 plazas de parqueo, diferentes bares, y un spa de lujo de 1815 m². (Hoteles Luxury, Los Mejores Hoteles del Perú, Cenfotur, 2015, pág. 14).

“El Westin Lima Hotel \& Convention Center, cuenta con una ubicación privilegiada en el distrito financiero y comercial de San Isidro, que permite que el huésped cuente con numerosos restaurantes, embajadas, galerías de arte, sedes de empresas, y centros comerciales a pocos minutos del hotel” (Hoteles Luxury, Los Mejores Hoteles del Perú, Cenfotur, 2015, pág. 14).

“Todas las suites cuentan con ambientes separados de la habitación y para aquellos huéspedes que buscan hacer ejercicio en la privacidad de su habitación, el hotel ofrece la Westin Workout y la Suite Presidencial, que incluyen un mini gimnasio con la mejor vista de la ciudad" (Hoteles Luxury, Los Mejores Hoteles del Perú, Cenfotur, 2015, pág. 14).

"Las habitaciones cuentan con la famosa Heavenly Bed ${ }^{\circledR}$ y Heavenly Bath ${ }^{\circledR}$, un dormitorio y baño perfectos para la comodidad y lujo de los más exigentes viajeros. También cuentan con acceso a internet WiFi, televisores LCD con programación de cable, además de 
minibar, walk-in closet, caja de seguridad, entre otras características” (Hoteles Luxury, Los Mejores Hoteles del Perú, Cenfotur, 2015, pág. 14).

“El Heavenly Spa by Westin®, por su parte es el spa urbano más grande de la región, y está diseñado para el relax y la renovación. Cuenta con un menú de más de 100 tratamientos en base a productos naturales. El hotel cuenta con dos excelentes restaurantes. El Market 770, que presenta una propuesta innovadora de cocina de mercado existente, basada en los productos propios de cada temporada. El comensal puede optar por platos caseros o más sofisticados” (Hoteles Luxury, Los Mejores Hoteles del Perú, Cenfotur, 2015, pág. 14).

“El Maras Restaurante, por su parte, es un punto de encuentro que ofrece una cocina peruana moderna, que rescata sus sabores típicos y crea nuevas sensaciones en el paladar de sus comensales. El hotel, cuenta también con el Westin Executive Club, un espacio con atención personalizada para los huéspedes de las suites y pisos ejecutivos. El Lobby Lounge, que es el ambiente perfecto para que nuestros viajeros tengan reuniones de trabajo y citas de negocios con toda comodidad. El In Situ Bar presenta una propuesta conservadora en donde podrá disfrutar de los mejores cócteles internacionales en un ambiente sofisticado y lleno de estilo” (Hoteles Luxury, Los Mejores Hoteles del Perú, Cenfotur, 2015, pág. 14).

\section{- $\quad$ Belmond Miraflores Park Hotel}

Su apertura se realizó en el año 1999 con el nombre Miraflores Park. Belmond Miraflores Park Hotel celebró su renovación y reapertura el 05 de Junio del 2014, luego de una remodelación que tuvo un costo de más de 13 millones de dólares, de esta manera se presentó oficialmente la marca Belmond, que como se sabe, reemplaza a Orient Express que operaba el hotel desde el 2001 con el nombre de Miraflores Park Hotel. (Tnews 06.06.2014) 
“El Miraflores Park Hotel está situado en una de las zonas más céntricas de Lima, el distrito de Miraflores. Conocido por su ubicación cerca al Océano Pacífico, goza de vistas espectaculares hacia el mar. Como todos los hoteles de la cadena Orient-Express, éste combina un servicio personalizado, restaurantes excepcionales e instalaciones de lujo. Cuenta con las mejores opciones para que el huésped se pueda relajar. El Zest Spa, está ubicado en el piso once, con una vista privilegiada. El viajero también puede refrescarse nadando en la piscina temperada, mientras disfruta de la impresionante vista de la ciudad y del mar, porque ha sido diseñada para crear el efecto maravilloso de ver el infinito, pues el agua parece desaparecer a la distancia y mezclarse con el paisaje" (Hoteles Luxury, Los Mejores Hoteles del Perú, Cenfotur, 2015, pág. 16).

“Las suites del Miraflores Park Hotel son espaciosas y elegantes. Todas cuentan con espectaculares vistas a la costa y una gama de accesorios en la habitación. Cada detalle de las mismas ha sido diseñado con el máximo cuidado para que los huéspedes queden satisfechos y complacidos” (Hoteles Luxury, Los Mejores Hoteles del Perú, Cenfotur, 2015, pág. 16).

“El Hotel ofrece diferentes tipos de suites, entre ellas están las: Ejecutiva, Junior, y Presidencial. Entre las Suites Ejecutivas hay 15 que tienen vista panorámica a la ciudad, 48 suites con vista al mar y otras 3 con una terraza con vistas al jardín de la suite. Las 12 Suites Junior en el Hotel, ofrecen maravillosos panoramas y características de lujo. El Miraflores Park Hotel cuenta con un piso de Suites Presidenciales, el cual ofrece 4 suites, con una perfecta combinación de estilo clásico y moderno. Cada suite ofrece un dormitorio privado, una sala de estar con comedor, jacuzzi, sauna en el cuarto de baño. Tres de ellas ofrecen una 
terraza exterior y una piscina privada, entre otras características" (Hoteles Luxury, Los Mejores Hoteles del Perú, Cenfotur, 2015, pág. 16).

\section{- Delfines Hotel \& Casino}

“Abrió sus puertas en julio de 1997, para convertirse en el lugar preferido por los viajeros de negocios, brindándoles el ambiente ideal para descansar y las facilidades que necesitan para el éxito de su trabajo. El hotel está ubicado en el distrito de San Isidro, la zona más exclusiva de Lima, cuenta con una vista privilegiada a una de las mayores áreas verdes de la capital: El Lima Golf Club. Desde el ingreso al hotel, podrá sentir su aroma característico a: apple jack, además, la iluminación ambiental lo ayudará a relajarse en un ambiente confortable. Cuenta con 206 exclusivas y acogedoras habitaciones:

\section{Habitaciones Superiores}

27 Habitaciones Ejecutivas

7 Junior Suites

12 Senior Suites

4 Deluxe Suites

1 Suite Olimpo

El salón Mediterráneo con capacidad para 1200 personas, es perfecto para congresos, ferias, eventos empresariales, entre otros" (Hoteles Luxury, Los Mejores Hoteles del Perú, Cenfotur, 2015, pág. 18).

\section{- $\quad$ Fiesta Hotel \& Casino}


“Fiesta Hotel \& Casino está ubicado en el distrito de Miraflores, zona céntrica por sus lugares turísticos, restaurantes y tiendas que se encuentran a pocos minutos del centro de la ciudad. Posee cómodas habitaciones dúplex estilo loft y modernas instalaciones que albergan los servicios más completos. El Hotel está especialmente diseñado para viajeros de turismo o negocios que planean una larga estadía” (Hoteles Luxury, Los Mejores Hoteles del Perú, Cenfotur, 2015, pág. 20).

“Las 66 habitaciones dúplex (Junior Suite Queen y Executive Suite King) ofrecen una estadía totalmente placentera. Todas las habitaciones cuentan con aire acondicionado, televisores LCD con cable, mini bar, caja de seguridad digital, internet inalámbrico, servicio de lavandería, entre otras comodidades. Todas las comodidades de un hotel cinco estrellas" (Hoteles Luxury, Los Mejores Hoteles del Perú, Cenfotur, 2015, pág. 20).

“En los tres primeros pisos del edificio, se encuentra las instalaciones del "Fiesta Casino" único en el Perú al mismo estilo de los casinos de Las Vegas. Son $5.500 \mathrm{~m}^{2}$ de pura emoción con máquinas tragamonedas de última generación, salas de póker VIP y otros interesantes juegos de mesa. El huésped podrá disfrutar del mejor entretenimiento y espectaculares shows en vivo sin tener que salir del hotel" (Hoteles Luxury, Los Mejores Hoteles del Perú, Cenfotur, 2015, pág. 20).

“En el interior del Casino, los huéspedes tienen acceso al restaurante Salsa’s Bar \& Grill, que además de ofrecerle una excelente variedad de platillos y bebidas, tiene más de 140 televisores y una exclusiva pantalla gigante HD de 60m x 60m (la más grande de Lima), en donde podrán disfrutar de los más importantes eventos deportivos del mundo y los mejores programas de televisión. En el Salsa’s Bar \& Grill también pueden realizar divertidas 
apuestas de una amplia variedad de eventos deportivos" (Hoteles Luxury, Los Mejores Hoteles del Perú, Cenfotur, 2015, pág. 20).

“En Fiesta Hotel \& Casino usted puede vivir la máxima experiencia de bienestar y relajación, además de vivir una fiesta inolvidable, el único complejo en donde encontrará todo el entretenimiento en un solo lugar" (Hoteles Luxury, Los Mejores Hoteles del Perú, Cenfotur, 2015, pág. 20).

\section{- Hotel Plaza del Bosque}

“El Hotel Plaza del Bosque está ubicado en el área empresarial - residencial del distrito de San Isidro, en la ciudad de Lima. Está rodeado de hermosos parques y jardines, teniendo en su periferia muchos locales comerciales, centros financieros, culturales, turísticos y de entretenimiento, excelentes opciones para que el viajero pueda disfrutar de su estadía" (Hoteles Luxury, Los Mejores Hoteles del Perú, Cenfotur, 2015, pág. 22).

"El hotel cuenta con 95 amplias suites totalmente equipadas, todas sus categorías satisfacen las distintas necesidades del viajero. Entre los diferentes tipos de habitaciones están la Suite Junior, Suite Ejecutiva, Suite Master, Suite El Bosque y la Suite Plaza o Presidencial, las cuales han sido diseñadas pensando en la comodidad y confort del viajero" (Hoteles Luxury, Los Mejores Hoteles del Perú, Cenfotur, 2015, pág. 22).

"El Hotel posee tres salones totalmente equipados para satisfacer cualquier exigencia en negocios y conferencias. El salón Paz Soldán tiene una capacidad para 300 personas, puede ser dividido en tres ambientes, donde se puede apreciar la maravillosa vista de la ciudad. Los otros dos salones como el Bosque y el Plaza son más pequeños, todos están 
implementados con tecnología de punta para la completa satisfacción de sus necesidades. El Business Center provee todos los servicios requeridos por los ejecutivos. Y para los momentos de relax, el Hotel Plaza del Bosque cuenta con un gimnasio completamente equipado. Además, la piscina está ubicada en el noveno piso, desde la cual se tiene una fantástica vista” (Hoteles Luxury, Los Mejores Hoteles del Perú, Cenfotur, 2015, pág. 22).

\section{- $\quad$ Sonesta Hotel El Olivar}

“Sonesta Hotel El Olivar está ubicado en el corazón de San Isidro, reconocido distrito de Lima, por sus tradicionales residencias, casonas, parques, finos restaurantes, tiendas y muy cerca a los principales centros empresariales de la ciudad. Este exclusivo hotel de 134 habitaciones, totalmente remodeladas, ofrece tanto al turista como al pasajero de negocio, el confort, la tecnología y el excelente servicio personalizado que caracteriza a Sonesta. Posee además una fabulosa vista del Bosque El Olivar, reconocido patrimonio cultural de la ciudad, cuyos árboles de olivo tienen más de 450 años de antigüedad y cuya belleza es motivo de orgullo para el distrito" (Hoteles Luxury, Los Mejores Hoteles del Perú, Cenfotur, 2015, pág. 24).

"Las Suites son bastante amplias e ideales para relajarse. Cada una cuenta con jacuzzi y sauna. Asimismo la Suite Presidencial, inspirada en art deco, le da ese toque de elegancia y buen estilo. En el sexto piso y con una inmejorable vista se encuentran la piscina y el gimnasio, este último con las mejores máquinas y de uso exclusivo para los huéspedes. También cuenta con peluquería y barbería, donde los clientes son engreídos con los tratamientos más exclusivos". (Hoteles Luxury, Los Mejores Hoteles del Perú, Cenfotur, 2015, pág. 24). 
"El huésped tiene a su disposición todos los servicios propios de un hotel de primer nivel, como centro de negocios con acceso a internet, servicio de taxi, estacionamiento privado, guest service las 24 horas, asistencia al turista, asistencia médica y mucho más. 12 nuevos salones para eventos fueron inaugurados recientemente. El hotel puede acomodar ahora grupos de hasta 350 personas. Las salas varían desde los Pancho Fierro (3 salas de conferencia independientes capaces de integrarse en un gran salón), pasando por la espectacular Plaza Olivar, perfecta para banquetes, reuniones sociales y exposiciones, hasta las Pérgolas I y II, las cuales ofrecen una vista panorámica de la ciudad de Lima y del histórico bosque El Olivar, del cual el hotel toma su nombre” (Hoteles Luxury, Los Mejores Hoteles del Perú, Cenfotur, 2015, pág. 24).

"El Olivar Restaurant Bar se encuentra dentro de las lujosas instalaciones del hotel el cual cuenta con una variada selección de especialidades que destacan por la audaz fusión de los mejores productos regionales con estupendas recetas de otras partes del mundo. Asimismo, clásicos de la cocina nacional preparados con un estilo singular y toques innovadores. Arte e inspiración que sorprenden por su combinación de sabores, texturas y aromas”. (Hoteles Luxury, Los Mejores Hoteles del Perú, Cenfotur, 2015, pág. 24).

“Además de un fino servicio y agradable ambiente. Para los que desean probar otras delicias el hotel presenta como alternativa el Restaurant Gourmet Japonés Ichi Ban, donde podrá disfrutar deliciosas especialidades, en uno de los mejores restaurantes de comida japonesa en Lima" (Hoteles Luxury, Los Mejores Hoteles del Perú, Cenfotur, 2015, pág. 23).

\section{- Business Tower Hotel}

El establecimiento original fue operado inicialmente con el nombre de Hotel Prince, después de varios años cuando la zona de San Isidro pasó a ser un importante centro 
financiero y empresarial, el hotel se remodeló totalmente y fue reinaugurado con el nombre de Business Tower Hotel o BTH.

“El BTH cuenta con 129 habitaciones. Este año se estrenó el espectacular piso LOFT, área que contiene 12 dormitorios al mismo estilo vanguardista y minimalista de los hoteles de Nueva York. Dos de estas habitaciones pertenecen a la categoría dúplex, caracterizadas por sus techos altos, ambientes adecuados, una moderna decoración y un sofisticado concepto de iluminación. También destaca el salón Naciones, con capacidad para 250 personas. El hotel brinda servicios personalizados las 24 horas del día” (Hoteles Luxury, Los Mejores Hoteles del Perú, Cenfotur, 2015, pág. 28).

"Los servicios incluyen lo mejor en comodidades, como el servicio de movilidad para el pasajero desde el aeropuerto, en el nuevo modelo Mercedes Benz de color blanco, alerta médica, conexión inalámbrica a internet en todas las áreas e incluso una fragancia única para los diferentes ambientes. Además, el huésped puede hacer uso de una moderna pantalla táctil para revisar sus cuentas. El hotel brinda soporte técnico, impresiones, asistencia secretarial, sistema de iluminación a control remoto, ambientes cómodos para trabajar y descansar. Igualmente ofrece 6 salones más un directorio” (Hoteles Luxury, Los Mejores Hoteles del Perú, Cenfotur, 2015, pág. 28).

“En cuanto a opciones gastronómicas, el grupo ha inaugurado recientemente el espectacular restaurante Quimera, el cual es la opción perfecta para el comensal que busca experimentar sensaciones nuevas. Se caracteriza por combinar de manera acertada lo tradicional con lo moderno y por utilizar lo último en tecnología de cocina. Además, cuenta con un bar que ofrece los más exquisitos cocktails, donde destacan sus insuperables Chilcanos. Cada servicio mantiene un alto estándar de calidad y enfoque a las necesidades del cliente” (Hoteles Luxury, Los Mejores Hoteles del Perú, Cenfotur, 2015, pág. 28). 


\section{ANEXO 16}

\section{SERVICIOS OFRECIDOS POR LOS COMPETIDORES DIRECTOS DEL CVH}

Las particularidades de los establecimientos categorizados como Hotel 5 estrellas en la ciudad de Lima se han detallado en el ítem II.4 de esta investigación. En las Tablas siguientes 22 a24 se muestra un análisis comparativo sobre la oferta de servicios al huésped EN Hoteles 5 estrellas, podemos resaltar los siguientes cinco hoteles han sido seleccionados por ser considerados altamente competitivos para un nuevo hotel:

Tabla 1. Oferta hoteles 5 estrellas

\begin{tabular}{|c|c|c|c|c|c|}
\hline Características & JW MARRIOTT & $\begin{array}{c}\text { WESTIN HOTEL } \\
\& \\
\text { CONVENTION } \\
\text { CENTER }\end{array}$ & $\begin{array}{l}\text { BELMOND } \\
\text { MIRAFLORES } \\
\text { PARK }\end{array}$ & SWISSOTEL & $\begin{array}{l}\text { CASA ANDINA } \\
\text { PRIVATE } \\
\text { COLLECTION }\end{array}$ \\
\hline Ubicación & $\begin{array}{l}\text { Miraflores, con } \\
\text { frente a parque } \\
\text { y vista al mar }\end{array}$ & $\begin{array}{l}\text { San Isidro } \\
\text { Centro } \\
\text { financiero }\end{array}$ & $\begin{array}{l}\text { Miraflores, con } \\
\text { frente a parque } \\
\text { y vista al mar }\end{array}$ & $\begin{array}{c}\text { San Isidro } \\
\text { Centro } \\
\text { empresarial }\end{array}$ & $\begin{array}{c}\text { Miraflores } \\
\text { Centro comercial }\end{array}$ \\
\hline $\begin{array}{c}\text { Servicios y } \\
\text { comodidades }\end{array}$ & $\begin{array}{l}-25 \text { pisos } \\
\cdot 300 \\
\text { habitaciones } \\
\text {-Cuidado de } \\
\text { niños, } \\
\text { - mostrador de } \\
\text { reserva de } \\
\text { aerolíneas, } \\
\text {-tienda de } \\
\text { regalos } \\
\text {-Parqueo en el } \\
\text { sótano con } \\
\text { capacidad para } \\
420 \text { vehículos }\end{array}$ & $\begin{array}{l}\text {-30 pisos } \\
\text { •301 } \\
\text { habitaciones } \\
\text { •Hospedaje } \\
\text { para niños } \\
\text { hasta } 12 \text { años } \\
\text { es de cortesía } \\
\text { - servicio de } \\
\text { guardería } \\
\text {-3 tiendas de } \\
\text { regalos } \\
\text {-Parqueo en } \\
\text { sótanos con } \\
\text { capacidad para } \\
727 \text { vehículos }\end{array}$ & $\begin{array}{l}-11 \text { pisos } \\
\text {-81suites } \\
\text { - Se considera } \\
\text { un hotel de lujo } \\
\text {-Parqueo en } \\
\text { terreno ubicado } \\
\text { a } 60 \text { metros del } \\
\text { hotel }\end{array}$ & $\begin{array}{l}\cdot 18 \text { pisos } \\
\cdot 345 \\
\text { habitaciones } \\
\cdot 2 \text { torres } \\
\text {-Parqueo en } \\
\text { sótanos con } \\
\text { capacidad para } \\
500 \text { vehículos }\end{array}$ & $\begin{array}{l}\text {-18 pisos } \\
\text {-148 } \\
\text { habitaciones } \\
\text {-Parqueo en } \\
\text { sótanos con } \\
\text { capacidad para } \\
\text { vehículos }\end{array}$ \\
\hline $\begin{array}{l}\text { Alimentos y } \\
\text { bebidas }\end{array}$ & $\begin{array}{l}\text { - Restaurante La } \\
\text { Vista, servicios } \\
\text { de buffet en } \\
\text { desayuno, } \\
\text { almuerzo y tea } \\
\text { time } \\
\text { - JW Sushi \& } \\
\text { ceviche Lounge } \\
\text { - Lobby bar }\end{array}$ & $\begin{array}{l}\text { - Restaurante } \\
\text { Maras } \\
\text {-Market 770, } \\
\text { servicios de } \\
\text { buffet en } \\
\text { desayuno, } \\
\text { almuerzo y tea } \\
\text { time } \\
\text { - Lobby Lounge } \\
\text { - Insitu Bar } \\
\text { - Oh bar } \\
\text { - Bar de la } \\
\text { Terraza del } \\
\text { Maras }\end{array}$ & $\begin{array}{l}\text {-Restaurante } \\
\text { Tragaluz } \\
\text { - Restaurante } \\
\text { The } \\
\text { Observatory, } \\
\text { servicios de } \\
\text { buffet en } \\
\text { desayuno, } \\
\text { - Belo Bar }\end{array}$ & $\begin{array}{l}\text {-Restaurante La } \\
\text { Locanda; } \\
\text { - Restaurante Le } \\
\text { Café; } \\
\text { - Restaurante La } \\
\text { Fondue } \\
\text { - Restaurante } \\
\text { Sushi Cage } \\
\text {-Pastelería } \\
\text { europea Gourmet } \\
\text { Deli } \\
\text { - Lobby Bar }\end{array}$ & $\begin{array}{l}\text { - Restaurante } \\
\text { Alma Cocina Viva } \\
\text { - Café Sama } \\
\text { - Lobby Bar }\end{array}$ \\
\hline
\end{tabular}




\begin{tabular}{|c|c|c|c|c|c|}
\hline \multirow[b]{2}{*}{ Características } & \multicolumn{5}{|c|}{ Tabla 28 Oferta hoteles 5 estrellas } \\
\hline & JW MARRIOTT & $\begin{array}{c}\text { WESTIN HOTEL } \\
\& \\
\text { CONVENTION } \\
\text { CENTER } \\
\end{array}$ & $\begin{array}{l}\text { BELMOND } \\
\text { MIRAFLORES } \\
\text { PARK }\end{array}$ & SWISSOTEL & $\begin{array}{l}\text { CASA ANDINA } \\
\text { PRIVATE } \\
\text { COLLECTION }\end{array}$ \\
\hline Habitaciones & $\begin{array}{l}\text {-4 tipos de } \\
\text { habitaciones de } \\
33 \mathrm{~m} 2 \text { a } 84 \mathrm{~m} 2 \\
\text { y una suite } \\
\text { presidencial } \\
\text {-cama King o } \\
\text { dos camas } \\
\text { dobles } \\
\text { - Mesa y silla } \\
\text { Ejecutiva } \\
\text {-TV Led } 37 \\
\text { pulgadas } \\
\text {-Minibar, } \\
\text { servicio de café } \\
\text { y té } \\
\text { - Reloj } \\
\text { despertador } \\
\text { - Control de } \\
\text { temperatura } \\
\text { individual } \\
\text {-Caja de } \\
\text { seguridad en la } \\
\text { habitación } \\
\text {-Éste es un } \\
\text { hotel de no } \\
\text { fumar } \\
\text { •Clóset } \\
\text { - Habitación con } \\
\text { aire } \\
\text { acondicionado }\end{array}$ & 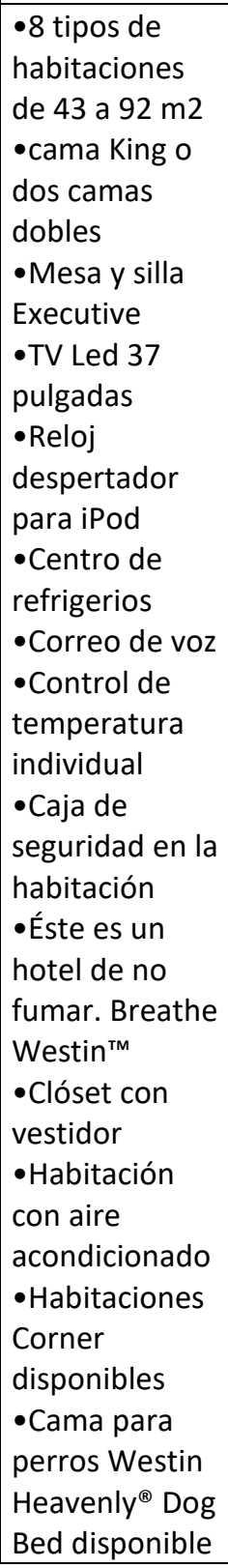 & $\begin{array}{l}\text {-5 tipos de } \\
\text { habitaciones de } \\
45 \text { a } 60 \text { m2 y } 2 \\
\text { suites } \\
\text { presidenciales } \\
\text { con piscina } \\
\text { privada } \\
\text { temperada } \\
\text { - Cama tamaño } \\
\text { king o dos camas } \\
\text { dobles } \\
\text {-Estación de } \\
\text { café } \\
\text {-Zona de } \\
\text { descanso con } \\
\text { sillones y } \\
\text { escritorio } \\
\text { - Las suites } \\
\text { deluxe y } \\
\text { presidenciales } \\
\text { pueden abrir sus } \\
\text { ventanas con } \\
\text { control remoto } \\
\text { - Dos líneas } \\
\text { telefónicas } \\
\text {-Internet } \\
\text { inalámbrico } \\
\text { - Televisor LCD } \\
\text { de pantalla } \\
\text { panorámica y } \\
\text { reproductor de } \\
\text { DVD } \\
\text {-Minibar } \\
\text { completamente } \\
\text { abastecido }\end{array}$ & $\begin{array}{l}\text {-5 tipos de } \\
\text { habitaciones de } \\
91 \mathrm{~m} 2 \text { a } 60 \mathrm{~m} 2 \text { y } 1 \\
\text { suite presidencial } \\
\text { - Una cama King } \\
\text { size o dos camas } \\
\text { full size. } \\
\text { •TV LED } 26 " \text { con } \\
\text { cable high } \\
\text { definition; suites } \\
\text { con TV Led de } 42 \\
\text { pulgadas } \\
\text {-Wi-Fi } \\
\text { - Suministro de } \\
\text { corriente } 110 / 220 \\
\text { voltios } \\
\text { - Máquina de café } \\
\text { expreso e } \\
\text { infusiones } \\
\text {-1 botella con } \\
\text { agua de cortesía } \\
\text { por persona } \\
\text { - plancha con } \\
\text { planchador, }\end{array}$ & $\begin{array}{l}\text {-5 tipos de } \\
\text { habitaciones } \\
\text {-1 cama Queen, } \\
\text { King ó } 2 \text { camas } \\
\text { Full-size } \\
\text {-TV LCD } \\
\text { - Mini bar } \\
\text { - Coffee Kit } \\
\text { - Caja de } \\
\text { Seguridad Digital } \\
\text { - Radio / Reloj } \\
\text { Despertador } \\
\text { - Escritorio / Mesa } \\
\text { de Desayuno } \\
\text {-Aire } \\
\text { Acondicionado / } \\
\text { Calefacción }\end{array}$ \\
\hline
\end{tabular}




\begin{tabular}{|c|c|c|c|c|c|}
\hline $\begin{array}{c}\text { Baño de } \\
\text { habitaciones }\end{array}$ & $\begin{array}{l}\text {-Bañera y } \\
\text { ducha } \\
\text { independientes } \\
\text {-Secador de } \\
\text { cabello } \\
\text {-Artículos de } \\
\text { tocador } \\
\text { Neutrógena } \\
\text {-Batas de baño } \\
\text { y zapatillas de } \\
\text { cama }\end{array}$ & $\begin{array}{l}\text {-Bañera y } \\
\text { ducha } \\
\text { independientes } \\
\text { •Ducha } \\
\text { Heavenly }^{\circledR} \\
\text { Shower } \\
\text {-Secador de } \\
\text { cabello } \\
\text {-Artículos de } \\
\text { tocador White } \\
\text { Tea by } \\
\text { Westin } \\
\text { - Batas de baño } \\
\text { y zapatillas de } \\
\text { cama }\end{array}$ & $\begin{array}{l}\text {-Baños de } \\
\text { mármol, } \\
\text {-suministros de } \\
\text { corriente } \\
110 / 220 \text { voltios, } \\
\text {-bata, pantuflas, } \\
\text { - secadora de } \\
\text { cabello, } \\
\text {-balanza }\end{array}$ & $\begin{array}{l}\text {-Baños de } \\
\text { mármol, } \\
\text { - suministros de } \\
\text { corriente } 110 / 220 \\
\text { voltios, } \\
\text { - bata, pantuflas, } \\
\text { - secadora de } \\
\text { cabello, } \\
\text { - balanza }\end{array}$ & $\begin{array}{l}\text { - suministros de } \\
\text { corriente } 110 / 220 \\
\text { voltios, } \\
\text { - bata, pantuflas, } \\
\text { - secadora de } \\
\text { cabello, }\end{array}$ \\
\hline
\end{tabular}

\begin{tabular}{|c|c|c|c|c|c|}
\hline \multirow[b]{2}{*}{ Características } & \multicolumn{5}{|c|}{ Tabla 29. Oferta hoteles 5 estrellas } \\
\hline & JW MARRIOTT & $\begin{array}{c}\text { WESTIN HOTEL \& } \\
\text { CONVENTION } \\
\text { CENTER }\end{array}$ & \begin{tabular}{|c|} 
BELMOND \\
MIRAFLORES \\
PARK \\
\end{tabular} & SWISSOTEL & $\begin{array}{l}\text { CASA ANDINA } \\
\text { PRIVATE } \\
\text { COLLECTION }\end{array}$ \\
\hline $\begin{array}{l}\text { Salas de } \\
\text { reuniones }\end{array}$ & \begin{tabular}{|l} 
•15 Salas de \\
Reuniones, \\
$\bullet$ más de 1,200 \\
mt2 de espacio \\
de reuniones \\
en total. \\
•El Salón San \\
Martín con un \\
espacio de 550 \\
mt2 y tiene \\
una máxima \\
capacidad de \\
600 personas, \\
se puede \\
dividir hasta \\
en 6 salas. \\
•Internet \\
inalámbrico.
\end{tabular} & \begin{tabular}{|l}
$\bullet 17$ salas de \\
reuniones del \\
hotel \\
$\bullet 2.529$ metros \\
cuadrados de \\
espacio funcional \\
• salas desde 10 \\
invitados hasta \\
2.000 \\
$\bullet$ El salón \\
Limatambo con \\
$1.627,01$ m2 tiene \\
capacidad hasta \\
2,000 personas es \\
el más grande en \\
un hotel en Lima, \\
puede dividirse \\
hasta en 5 salas
\end{tabular} & $\begin{array}{l}-8 \text { espaciosas } \\
\text { salas de } \\
\text { reuniones y } \\
\text { eventos con } \\
\text { capacidad } \\
\text { máxima de } 400 \\
\text { personas }\end{array}$ & $\begin{array}{l}\text {-salones de } \\
\text { eventos con } \\
\text { capacidad total } \\
\text { hasta de } 2000 \\
\text { personas entre } \\
\text { todos ellos }\end{array}$ & $\begin{array}{l}\bullet 6 \text { salas de } \\
\text { eventos. Se } \\
\text { pueden unir } \\
\text { hasta dos de } \\
\text { ellas }\end{array}$ \\
\hline $\begin{array}{l}\text { Servicios } \\
\text { ejecutivos }\end{array}$ & $\begin{array}{l}\text {-Centro de } \\
\text { negocios en las } \\
\text { instalaciones } \\
\text { con personal } \\
\text { especializado } \\
\text {-Vip lounge }\end{array}$ & $\begin{array}{l}\text { - Centro de } \\
\text { negocios en las } \\
\text { instalaciones con } \\
\text { personal } \\
\text { especializado } \\
\text { - Westin Executive } \\
\text { Club Lounge }\end{array}$ & \begin{tabular}{|l}
-Centro de \\
negocios \\
- Club Lounge, \\
acceso libre \\
sólo para los \\
pasajeros \\
ubicados desde \\
el piso 8 al 10
\end{tabular} & $\begin{array}{l}\text {-Piso ejecutivo } \\
\text { con acceso al } \\
\text { Executive Club } \\
\text { Lounge }\end{array}$ & $\begin{array}{l}\text { - Centro de } \\
\text { internet } \\
\text {-Cajero } \\
\text { automático }\end{array}$ \\
\hline
\end{tabular}




\begin{tabular}{|c|c|c|c|c|c|}
\hline Entretenimiento & $\begin{array}{l}\text { - Gimnasio } \\
\text { - Sauna, } \\
\text { - Piscina al } \\
\text { aire libre no } \\
\text { temperada } \\
\text { - Cancha de } \\
\text { tenis }\end{array}$ & $\begin{array}{l}\text {-Piscina interior } \\
\text { con temperatura } \\
\text { regulada } \\
\text { - Heavenly Spa by } \\
\text { Westin }^{\text {TM }} \text { con } \\
2,000 m 2 \text { de área } \\
\text { techada y } \\
\text { tratamientos de } \\
\text { hidroterapia en } \\
\text { piscinas del } \\
\text { circuito termal, } \\
\text { salas de } \\
\text { tratamiento } \\
\text { individual } \\
\text { - Gimnasio } \\
\text { WestinWORKOUT } \\
\text { Fitness Studio } \\
\text {-Peluquería y } \\
\text { salón de belleza }\end{array}$ & $\begin{array}{l}\text {-Gimnasio, } \\
\text {-Spa, } \\
\text { - Piscina al aire } \\
\text { libre } \\
\text { temperada }\end{array}$ & $\begin{array}{l}\text { - Gimnasio, } \\
\text { - Spa con } 13 \\
\text { salas de } \\
\text { tratamiento } \\
\text { - Piscina } \\
\text { techada } \\
\text { temperada }\end{array}$ & $\begin{array}{l}\text {-Gimnasio, } \\
\text {-Sauna, } \\
\text {-Piscina techada } \\
\text { temperada } \\
\text {-Peluquería y } \\
\text { salón de belleza }\end{array}$ \\
\hline
\end{tabular}

\section{Definición de los servicios a ofrecer en el establecimiento.}

A la vista del análisis mostrado anteriormente en los acápites VI.4 Conclusiones del estudio de mercado al VI.7 Servicios ofrecido por los competidores directos, se puede proponer un nuevo establecimiento con la clasificación de Hotel y la categoría de 5 estrellas, seleccionando el destino Lima, ubicación en el Malecón de la Reserva del distrito de Miraflores, por tener la zonificación RDMA compatible con el uso de hotel 5 estrellas, y considerando que la demanda potencial será de turistas corporativos y vacacionistas de alto poder adquisitivo, con las siguientes particularidades.

\begin{tabular}{|c|c|}
\hline Ubicación & $\begin{array}{l}\text { Miraflores, con frente a parque y vista al mar } \\
3,045 \mathrm{~m} 2) \\
\end{array}$ \\
\hline $\begin{array}{l}\text { Servicios y } \\
\text { comodidades }\end{array}$ & $\begin{array}{l}\text {-31 pisos } \\
\text {-310 habitaciones } \\
\text { - Hospedaje para niños hasta } 12 \text { años de cortesía } \\
\text { - tiendio de guardería } \\
\text { - Parqueo en regalos: alpaca y platería } \\
\text { Panos con capacidad para } 700 \text { vehículos }\end{array}$ \\
\hline $\begin{array}{l}\text { Alimentos y } \\
\text { bebidas }\end{array}$ & $\begin{array}{l}\text { - Restaurante de comida peruana e internacional a la carta "cocina de autor" } \\
\text { - Restaurante-cafetería servicios de buffet al desayuno, almuerzo y tea time } \\
\text { - Lobby Lounge con presentaciones en vivo de } 7.00 \text { a } 9.00 \mathrm{pm} \\
\text { - Cóctel-Bar apropiado para un after office }\end{array}$ \\
\hline
\end{tabular}




\begin{tabular}{|c|c|}
\hline Habitaciones & $\begin{array}{l}\text { - } 5 \text { tipos de habitaciones de } 45 \text { a65 m2 } \\
\text { - cama King o dos camas queen } \\
\text { - Mesa y silla ergonómica } \\
\text { - TV Led } 42 \text { pulgadas } \\
\text { - Reloj despertador para iPod } \\
\text { - Centro de refrigerios: minibar, cafetera, kit de servicio } \\
\text { - Correo de voz } \\
\text { - Control de temperatura individual } \\
\text { - Caja de seguridad en la habitación } \\
\text { - Clóset con vestidor } \\
\text { - Habitación con aire acondicionado } \\
\text { - Se admitirá perros mascota hasta de } 15 \text { kilos }\end{array}$ \\
\hline $\begin{array}{c}\text { Baño de } \\
\text { habitaciones }\end{array}$ & $\begin{array}{l}\text { - Bañera y ducha independientes } \\
\text { - Espejo de aumento para maquillaje } \\
\text { - Secador de cabello de gran potencia } \\
\text { - Artículos de tocador de productos naturales en empaques reciclables } \\
\text { - Batas de baño y zapatillas de cama }\end{array}$ \\
\hline $\begin{array}{l}\text { Salas de } \\
\text { reuniones }\end{array}$ & $\begin{array}{l}\text {-15 Salas de Reuniones, } \\
\cdot 2,000 \mathrm{mt} 2 \text { de espacio de reuniones en total con una máxima capacidad de } 2000 \\
\text { personas, que se pueda dividir hasta en } 6 \text { salas. } \\
\text {-Internet inalámbrico de alta velocidad. }\end{array}$ \\
\hline $\begin{array}{l}\text { Servicios } \\
\text { ejecutivos }\end{array}$ & $\begin{array}{l}\text { - Centro de negocios con personal especializado } \\
\text { - Lounge ejecutivo con servicios gratuitos para los huéspedes de suites y } \\
\text { habitaciones de pisos altos }\end{array}$ \\
\hline Entretenimiento & $\begin{array}{l}\text { - Piscina techada temperada } \\
\text { - Spa con tratamientos en diferentes salas incluyendo productos nativos } \\
\text { - Gimnasio con sala de Pilates } \\
\text {-Peluquería y salón de belleza } \\
\text {-El hotel buscará un acuerdo con un club que permita a los huéspedes disfrutar } \\
\text { de las instalaciones deportivas }\end{array}$ \\
\hline
\end{tabular}

Adicionalmente para ser altamente competitivos habrá que tener otras consideraciones, recomendando el Análisis FODA.- Como ejemplo:

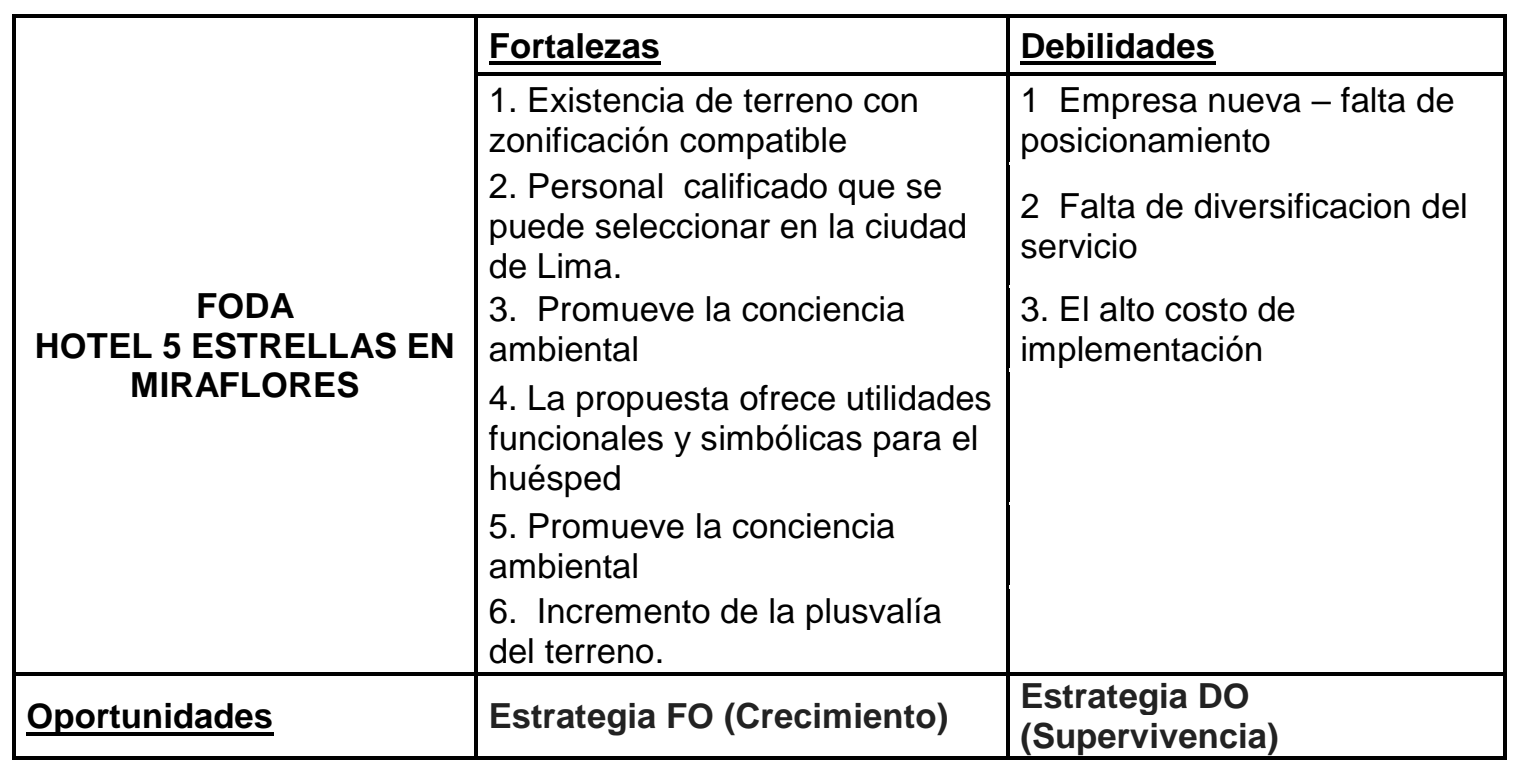




\begin{tabular}{|c|c|c|}
\hline $\begin{array}{l}\text { 1. Cremiciento del Turismo } \\
\text { Internacional y nacional } \\
\text { 2. Cremiento económico en } \\
\text { Lima y en el Perú } \\
\text { 3. El Mincetur está } \\
\text { incentivando nuevas } \\
\text { inversiones hoteleras } \\
\text { 4. Muchas marcas } \\
\text { internacionales de } \\
\text { reconocido prestigio } \\
\text { hotelero están en busca de } \\
\text { posiciones en Lima }\end{array}$ & $\begin{array}{l}\text { Penetración de Mercado } \\
\text { (F4+O4+O5): Impulsar las } \\
\text { ventas a traves de publicidad } \\
\text { web para promover los } \\
\text { beneficios de la y a su vez } \\
\text { promover la conciencia } \\
\text { ambiental } \\
\\
\text { (F1+O1+O2) Liderar en la oferta } \\
\text { del servicio integral a partir de la } \\
\text { calidad del mismo }\end{array}$ & $\begin{array}{l}\text { (D1+O4) Desarrollar } \\
\text { promociones e impulso de } \\
\text { ventas resaltandas a la } \\
\text { calidad del producto }\end{array}$ \\
\hline Amenazas & Estrategia FA (Supervivencia) & Estrategia DA (Defensiva) \\
\hline $\begin{array}{l}\text { 1. Cadenas extranjeras } \\
\text { están interesadas en invertir } \\
\text { en el Perú }\end{array}$ & $\begin{array}{l}\text { Segmentar el mercado (nichos) : } \\
\text { (F6+F7+ A3) especialización } \\
\text { para maximizar las ventas } \\
\text { Buscar fórmulas asociativas: } \\
\text { asociarse con otras empresas } \\
\text { (marcas o franquicias)que } \\
\text { posean lo que nos falta: } \\
\text { (F1+F6+A3) } \\
\text { Gestionar abastecimientos con } \\
\text { costos más económicos por } \\
\text { volumen conseguir nuevos } \\
\text { clientes en el exterior ( } F 1+ \\
\text { A2+A3) }\end{array}$ & $\begin{array}{l}\text { Desarrollar promociones e } \\
\text { impulsar las ventas resaltando } \\
\text { la calidad y la diferenciación } \\
\text { (D1+A3) } \\
\text { La estrategia de riesgo } \\
\text { compartido (join venture) } \\
\text { D3+A2 +A3 minimiza costos } \\
\text { de implementación con } \\
\text { accionistas y socios } \\
\text { estratégicos } \\
\text { Diversificar los segmentos de } \\
\text { mercado para atención los } \\
\text { fines de semana (D2+A3) } \\
\\
\text { Desarrollar buenas relaciones } \\
\text { comerciales y de segumiento } \\
\text { con los clientes. (D1+A2) } \\
\text { Ampliar la divesificación de } \\
\text { los servicios e implementar } \\
\text { capacitación al personal para } \\
\text { la atención al cliente con cero } \\
\text { errores y creando una } \\
\text { experiencia memorable. } \\
\text { (D2+A4) }\end{array}$ \\
\hline
\end{tabular}

Fuente:

\section{Consideraciones adicionales}

a) Número de pisos.- Por la zonificación se puede alcanzar gran altura y para ser llamado el edificio más alto del Perú (slogan que hizo conocido en su momento al Hotel Westin) se propone alcanzar 31 pisos.

b) Distribución de cada nivel o piso.- Es importante considerar que las áreas sociales se distribuyan en los primeros niveles, se recomienda pensar en un doble núcleo de circulación vertical, uno para los servicios derivados que se ofrecen tanto al huésped 
alojados como al cliente externo: locales de alimentos y bebidas, salas de eventos y otro exclusivo para la torre de alojamiento.

c) Número y tipo de habitaciones, tarifa por habitación.- Se ha pensado en la instalación de aproximadamente 310 habitaciones o más, que es el número posible de desarrollar en el número de pisos planteado y de acuerdo al área del terreno. Las tipos de habitaciones tendrán que ser de luxe (estándar), ejecutivas, ejecutivas de esquina, suites, suites de esquina, y además una o dos como suite presidencial

d) Materiales y acabados.- Es necesario que los materiales de acabados y revestimientos así como el mobiliario y equipos que represente el status (utilidad simbólica) que busca el turista corporativo y el vacacionista de lujo.

e) Gestión ambiental.- Para que la edificación hotelera sea compatible con la responsabilidad ambiental podrá obtener una certificación o sello verde como LEED (Leadership in Energy \& Environmental Design), deberá cumplir con los créditos de certificación:

- Sitio sustentable.- de acuerdo al emplazamiento sugerido y la zonificación que ostenta el terreno en el Malecón de la Reserva este crédito se cumpliría por que actualmente se encuentra subutilizado y es conveniente un edificio de mayor altura.

- Eficiencia en el uso del agua.- Es trascendental en estos tiempos pensar en el reciclaje de agua, para lo cual se sugiere considerar una planta de tratamiento de agua y recirculación en el sótano del edificio.

- Energía y atmósfera.- En cuanto a la iluminación, al proponer un hotel que promueve conciencia ambiental será necesario considerar el uso de lámparas led que ahorran el 80\% del consumo de energía eléctrica, son más eficientes y tienen una larga vida útil

- Materiales y recursos.- Considerando la ubicación del hotel es necesario pensar en una arquitectura bioclimática., por ejemplo si se usa el muro cortina (fachada de vidrio) recibirá el sol en diferentes horas en los frentes del terreno, por ello habrá que buscar el 
color y laminado del vidrio que absorben los rayos UV y que al mismo tiempo puedan actuar como aislante térmico. (vidrio insulado)

- Calidad del ambiente interior.- De acuerdo a los requerimientos de la clase y categoría de Hotel 5 estrellas el edificio deberá contar con aire acondicionado o climatización correspondiente que otorgue una adecuada ventilación, confort térmico y acústico, además del control de contaminantes al ambiente. Esto se verá facilitado con menor gasto de energía en climatización al usar vidrios que son aislantes térmicos y también la adecuada distribución de ambientes y selección de materiales de revestimiento para paredes y pisos aseguran el confort acústico.

- Innovación en el diseño también le otorga algunos puntos

f) Seguridad.- Para el diseño de accesos y salidas de emergencia, pasajes de circulación de personas, escaleras, sistema contra incendios, etc se debe tomar en cuenta la Norma A130 Requisitos de Seguridad. De acuerdo a las investigaciones realizadas para el estudio las condiciones de seguridad de la edificación son apreciadas por los huéspedes ya que tienen el recuerdo cercano del último terremoto en Pisco y otros eventos como incendio en hoteles de otros países. Adicionalmente es recomendable sugerir que también es importante pensar en la seguridad de la manipulación de equipos eléctricos y a gas que son de uso intensivo en los hoteles por lo que los gerentes consultados recomiendan tener planes de mantenimiento contratados con las empresas proveedoras de los mismos equipos.

g) Acceso a personas con discapacidad.- La Norma A-030 Hospedaje del Reglamento Nacional de Edificaciones establece en el artículo $5^{\circ}$ que las edificaciones de hospedaje deben cumplir los requerimientos exigidos por la norma A-120 Accesibilidad para personas con discapacidad y de las personas adultas mayores. Estas normas están referidas a las rampas de acceso, rutas accesibles, y el número de habitaciones, baños y estacionamientos accesibles en la edificación hotelera 
h) Responsabilidad social. Si bien una de las formas de Responsabilidad Social Empresarial es la Gestión Ambiental a la cual ya se ha referido el presente estudio, también es imprescindible que una empresa hotelera tenga un programa de Responsabilidad Social con sus huéspedes, cumpliendo lo ofrecido; con sus colaboradores y con la comunidad.

\section{ANEXO 17}

\begin{tabular}{|c|c|c|}
\hline \multicolumn{3}{|c|}{ POBLACION ECONOMICAMENTE ACTIVA - PERU } \\
\hline AÑO & $\mathbf{N}^{\circ}$ PERSONAS & \% DE CRECIMIENTO \\
\hline 2001 & $3,779,400.00$ & \\
\hline 2002 & $3,831,500.00$ & 1.379 \\
\hline 2003 & $4,062,900.00$ & 6.039 \\
\hline 2004 & $4,110,000.00$ & 1.159 \\
\hline 2005 & $4,019,700.00$ & -2.197 \\
\hline 2006 & $4,301,800.00$ & 7.018 \\
\hline 2007 & $4,588,200.00$ & 6.658 \\
\hline 2008 & $4,722,500.00$ & 2.927 \\
\hline 2009 & $4,785,100.00$ & 1.326 \\
\hline 2010 & $4,942,400.00$ & 3.287 \\
\hline 2011 & $5,030,100.00$ & 1.774 \\
\hline 2012 & $5,144,100.00$ & 2.266 \\
\hline
\end{tabular}

Adaptado del "Instituto Nacional de Estadística e Informática". Elaboración propia.

\begin{tabular}{|c|c|c|}
\hline \multicolumn{3}{|c|}{ POBLACION ESTIMADA Y PROYECTADA - PERU } \\
\hline AÑO & N'HABITANTES & $\begin{array}{c}\text { \% DE } \\
\text { CRECIMIENTO }\end{array}$ \\
\hline 2012 & $30,135,875$ & \\
\hline 2013 & $30,475,144$ & 1.126 \\
\hline 2014 & $30,814,175$ & 1.112 \\
\hline 2015 & $31,151,643$ & 1.095 \\
\hline 2016 & $31,488,625$ & 1.082 \\
\hline 2017 & $31,826,018$ & 1.071 \\
\hline 2018 & $32,162,184$ & 1.056 \\
\hline 2019 & $32,495,510$ & 1.036 \\
\hline 2020 & $32,824,358$ & 1.012 \\
\hline 2021 & $33,149,016$ & 0.989 \\
\hline
\end{tabular}

Adaptado del "Instituto Nacional de Estadística e Informática". Elaboración propia. 


\begin{tabular}{|c|c|}
\hline MOTIVO DE VISITA AL PERU & $\%$ \\
\hline Vacaciones, recreacion u ocio & 65 \\
\hline Negocios & 14 \\
\hline Visitar a familiares o amigos & 14 \\
\hline Salud (tratamiento médico) & 3 \\
\hline Asistir a seminarios, conferencias, convenciones o congresos & 2 \\
\hline Misiones / Trabajo religioso / voluntariado & 1 \\
\hline Educación (realizar estudios, investigaciones por grado, etc.) & 1 \\
\hline
\end{tabular}

Adaptado de "PromPeru". Elaboración propia.

\begin{tabular}{|c|c|c|}
\hline \multicolumn{3}{|c|}{ INGRESO DE TURISTAS INTERNACIONALES } \\
\hline AÑO & $\mathbf{N}^{\circ}$ TURISTAS & \% DE CRECIMIENTO \\
\hline 2001 & 939,947 & \\
\hline 2002 & $1,113,800$ & 18.496 \\
\hline 2003 & $1,301,868$ & 16.885 \\
\hline 2004 & $1,450,357$ & 11.406 \\
\hline 2005 & $1,685,722$ & 16.228 \\
\hline 2006 & $2,047,610$ & 21.468 \\
\hline 2007 & $2,221,725$ & 8.503 \\
\hline 2008 & $2,451,436$ & 10.339 \\
\hline 2009 & $2,547,496$ & 3.919 \\
\hline 2010 & $2,787,577$ & 9.424 \\
\hline 2011 & $3,222,927$ & 15.618 \\
\hline 2012 & $3,487,346$ & 8.204 \\
\hline
\end{tabular}

Adaptado del "Instituto Nacional de Estadística e Informática". Elaboración propia. 


\begin{tabular}{|c|c|c|}
\hline \multicolumn{3}{|c|}{ INGRESO DE DIVISAS POR FLUJO TURISTICO } \\
\hline AÑO & INGRESOS (MILLONES DE \$) & \% DE CRECIMIENTO \\
\hline 2001 & 733.12 & \\
\hline 2002 & 787.42 & 7.407 \\
\hline 2003 & 963.11 & 22.312 \\
\hline 2004 & 1141.98 & 18.572 \\
\hline 2005 & 1308.29 & 14.563 \\
\hline 2006 & 1570.25 & 20.023 \\
\hline 2007 & 1722.81 & 9.716 \\
\hline 2008 & 1991.02 & 15.568 \\
\hline 2009 & 2013.98 & 1.153 \\
\hline 2010 & 2008.13 & -0.290 \\
\hline 2011 & 2359.74 & 17.509 \\
\hline 2012 & 2657.23 & 12.607 \\
\hline
\end{tabular}

Adaptado del "Instituto Nacional de Estadística e Informática". Elaboración propia. 